University of South Florida

DIGITAL COMMONS

Digital Commons @ University of

@ UNIVERSITY OF SOUTH FLORIDA

South Florida

Research Reports

National Center for Transit Research (NCTR)

Archive (2000-2020)

2-1-2016

\title{
Methodology for Linking Greenways and Trails with Public Transportation in Florida
}

CUTR

Follow this and additional works at: https://digitalcommons.usf.edu/cutr_nctr

\section{Recommended Citation}

"Methodology for Linking Greenways and Trails with Public Transportation in Florida," National Center for Transit Research (NCTR) Report No. CUTR-NCTR-RR-2016-13, Center for Urban Transportation Research, University of South Florida, 2016.

DOI: https://doi.org/10.5038/CUTR-NCTR-RR-2016-13

Available at: https://scholarcommons.usf.edu/cutr_nctr/65

This Technical Report is brought to you for free and open access by the National Center for Transit Research (NCTR) Archive (2000-2020) at Digital Commons @ University of South Florida. It has been accepted for inclusion in Research Reports by an authorized administrator of Digital Commons @ University of South Florida. For more information, please contact digitalcommons@usf.edu. 


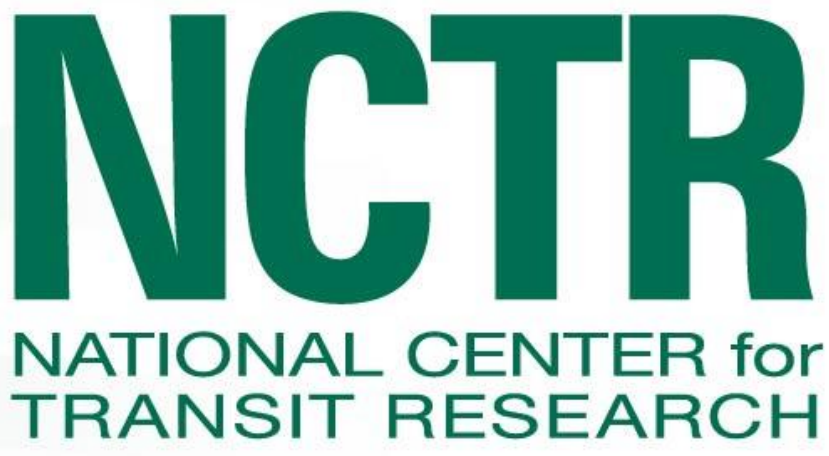

\section{Methodology for Linking Greenways and Trails with Public Transportation in Florida}

\section{Final Report February 2016}

FDOT PROJECT NO.

BDV26-977-03

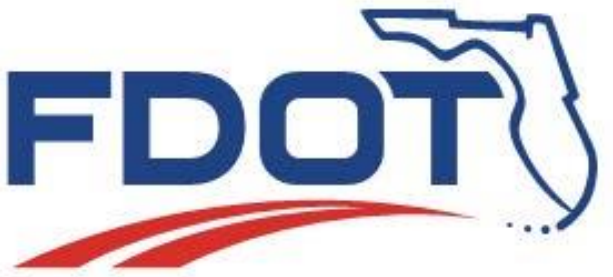




\section{Disclaimer}

The contents of this report reflect the views of the authors, who are responsible for the facts and the accuracy of the information presented herein. This document is disseminated under the sponsorship of the Department of Transportation University Transportation Centers Program and the Florida Department of Transportation, in the interest of information exchange. The U.S. Government and the Florida Department of Transportation assume no liability for the contents or use thereof.

The opinions, findings, and conclusions expressed in this publication are those of the authors and not necessarily those of the State of Florida Department of Transportation. 
Metric Conversion

\begin{tabular}{|c|c|c|c|c|}
\hline SYMBOL & WHEN YOU KNOW & $\begin{array}{c}\text { MULTIPLY } \\
\text { BY }\end{array}$ & TO FIND & SYMBOL \\
\hline \multicolumn{5}{|c|}{ LENGTH } \\
\hline in & inches & 25.4 & millimeters & $\mathrm{mm}$ \\
\hline ft. & feet & 0.305 & meters & $\mathrm{m}$ \\
\hline yd. & yards & 0.914 & meters & $\mathrm{m}$ \\
\hline mi & miles & 1.61 & kilometers & $\mathrm{km}$ \\
\hline \multicolumn{5}{|c|}{ VOLUME } \\
\hline fl. oz. & fluid ounces & 29.57 & milliliters & $\mathrm{mL}$ \\
\hline gal & gallons & 3.785 & liters & $\mathrm{L}$ \\
\hline $\mathbf{f t}^{3}$ & cubic feet & 0.028 & cubic meters & $\mathrm{m}^{3}$ \\
\hline $\mathbf{y d}^{3}$ & cubic yards & 0.765 & cubic meters & $\mathrm{m}^{3}$ \\
\hline \multicolumn{5}{|c|}{ NOTE: volumes greater than $1000 \mathrm{~L}$ shall be shown in $\mathrm{m}^{3}$} \\
\hline \multicolumn{5}{|c|}{ MASS } \\
\hline oz. & ounces & 28.35 & grams & $g$ \\
\hline lb. & pounds & 0.454 & kilograms & $\mathrm{kg}$ \\
\hline $\mathbf{T}$ & $\begin{array}{l}\text { Short tons ( } 2000 \\
\text { lb.) }\end{array}$ & 0.907 & $\begin{array}{l}\text { megagrams } \\
\text { (or "metric } \\
\text { ton") }\end{array}$ & $\mathrm{Mg}(\mathrm{or}$ "t") \\
\hline \multicolumn{5}{|c|}{ TEMPERATURE (exact degrees) } \\
\hline${ }^{\circ} \mathbf{F}$ & Fahrenheit & $\begin{array}{c}5(F-32) / 9 \\
\text { or }(F-32) / 1.8\end{array}$ & Celsius & ${ }^{\circ} \mathrm{C}$ \\
\hline
\end{tabular}




\section{Technical Report Documentation}

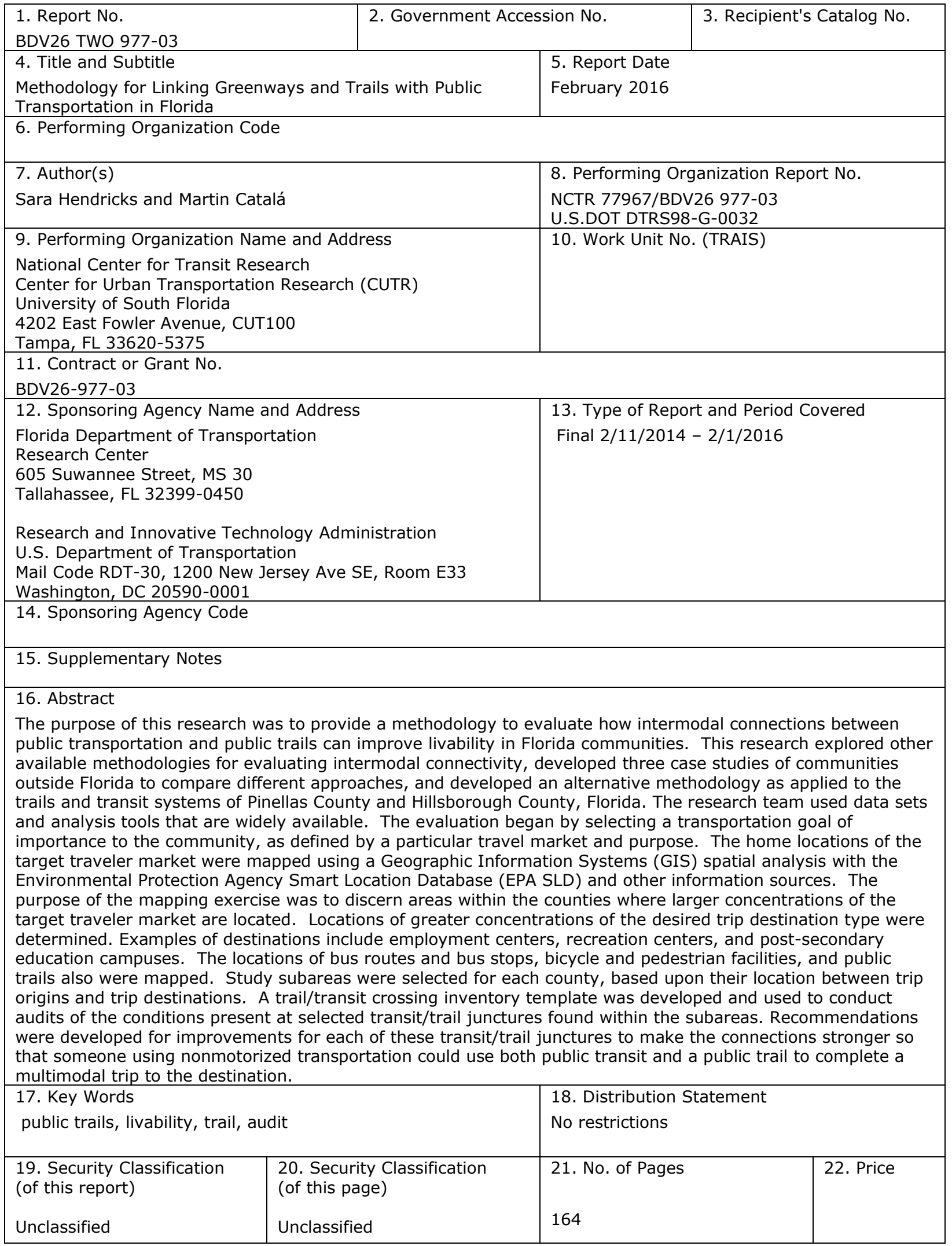




\section{Table of Contents}

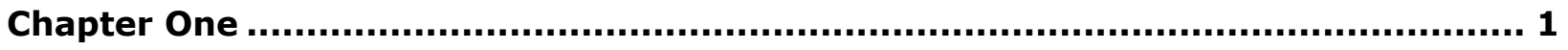

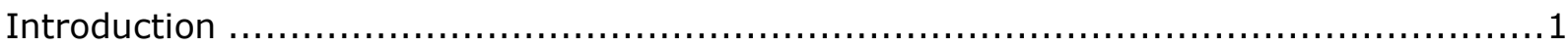

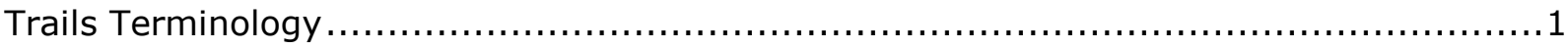

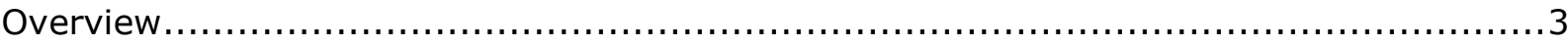

Chapter Two .................................................................................................................. 8

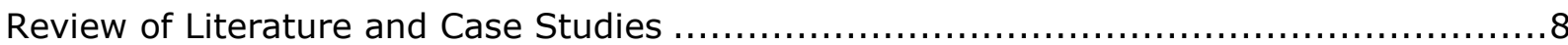

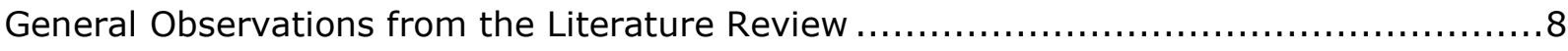

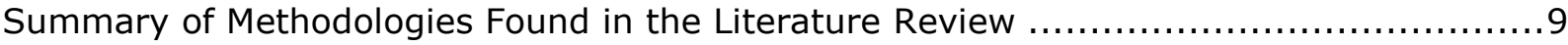

Summary of Methodologies of Case Studies ................................................ 11

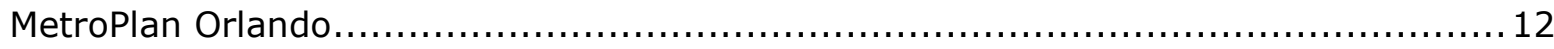

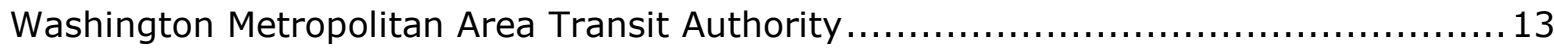

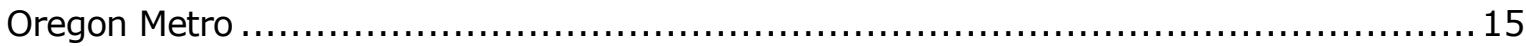

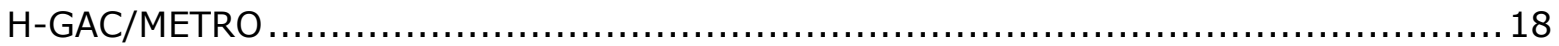

Comparative Elements Used in the Development of a Methodology ...................... 19

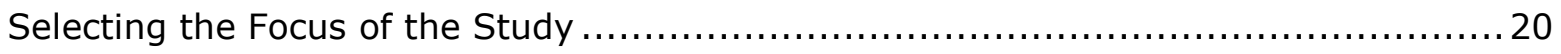

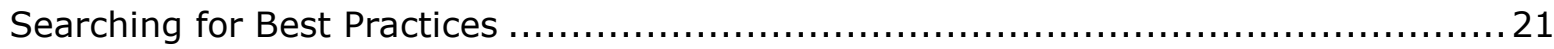

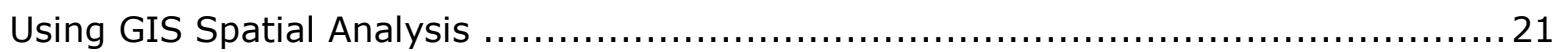

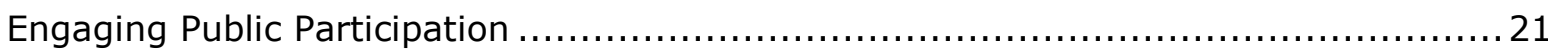

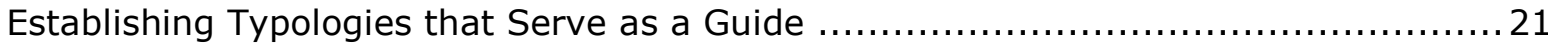

Narrowing the Focus to a Manageable Number for Representation or

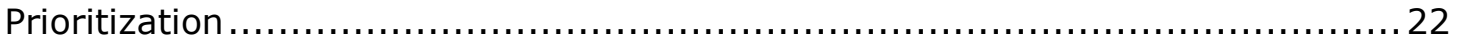

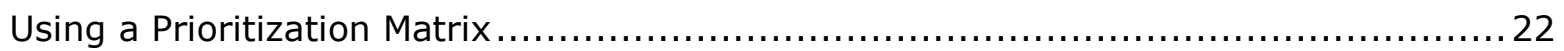

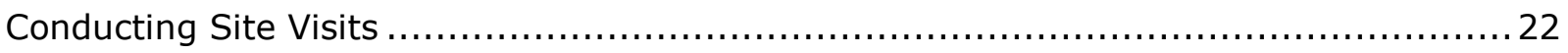

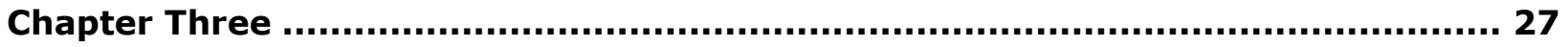

Specification and Characterization of Study Areas in Hillsborough and Pinellas

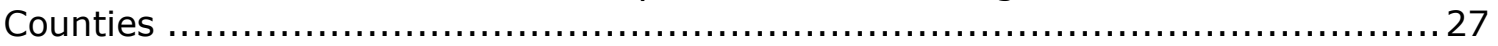

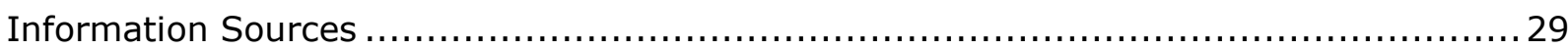

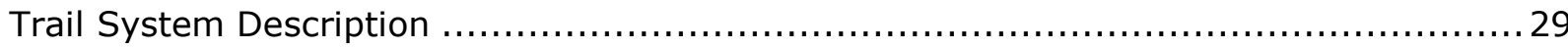

Trail Planning in Pinellas and Hillsborough Counties ...................................... 30

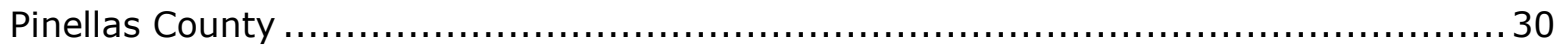

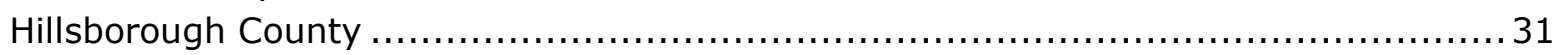

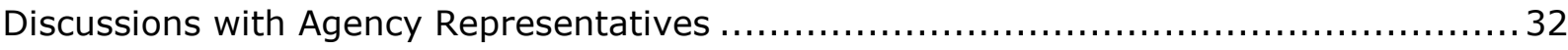

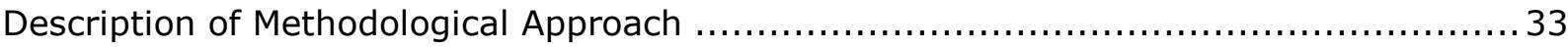

Chapter Four ............................................................................................ 75

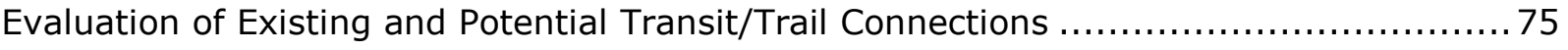

Hillsborough County, Upper Tampa Bay Trail ............................................. 75 
Scenario 1: Trail and Public Transit Connect: Sheldon Road........................... 75

Scenario 2: Trail and Public Transit Intersect but do not Connect: Linebaugh

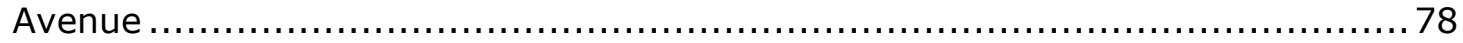

Scenario 3: Trail and Public Transit do not Intersect: Waters Avenue $\ldots \ldots \ldots \ldots \ldots \ldots \ldots . \ldots 2$

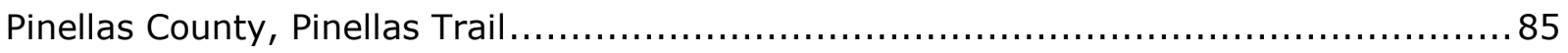

Scenario 1: Trail and Public Transit Connect: 8 th Avenue SW ........................ 85

Scenario 2: Trail and Public Transit Intersect but do not Connect: Gooden

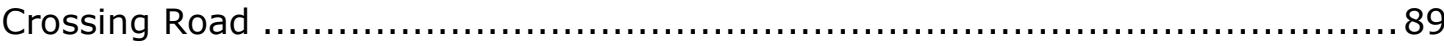

Scenario 3: Trail and Public Transit do not Intersect: $96^{\text {th }}$ Place $N \ldots \ldots \ldots \ldots \ldots \ldots \ldots . . . \ldots 3$

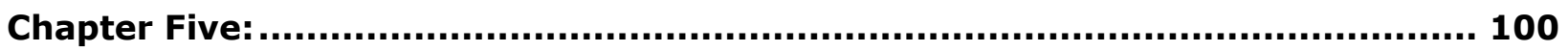

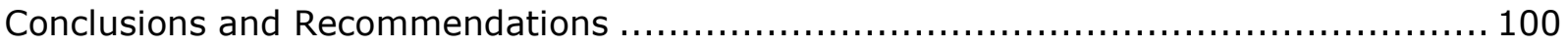

Trail Locations may not be Optimal for Transportation .................................. 100

Gains in Comfort when Bicycling and Using Public Transportation May Encourage

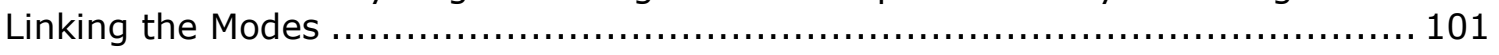

Transit/Trail Connections Can Serve a Variety of Goals .............................. 101

Transit/Trail Linkages Should be Considered at the Transportation Planning Stage ...... 101

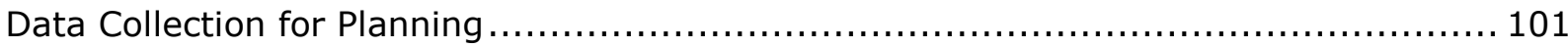

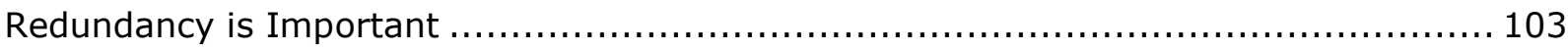

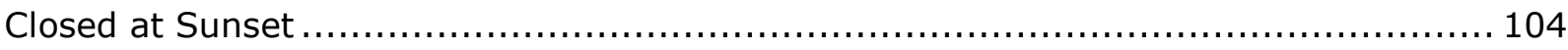

On-Street Roadway Improvements Link Trails to Transit ............................. 104

Signs, Maps, Brochures, Websites, and Mobile Phone Apps Should Cross-Promote

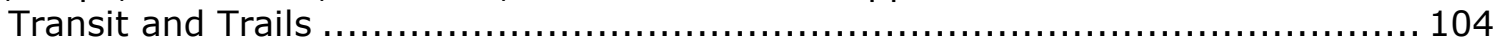

Adopt Policies for Planning and Promotion ........................................... 105

Develop and Promote a Multimodal Route Finding System ............................ 105

Use Crowd Sourcing for Continual Transit and Trail User Feedback ...................... 106

Use Local Knowledge to Identify Needed Amenities ................................... 106

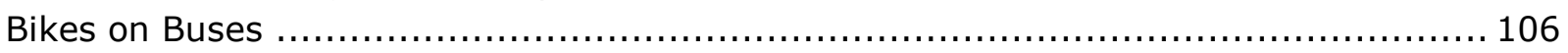

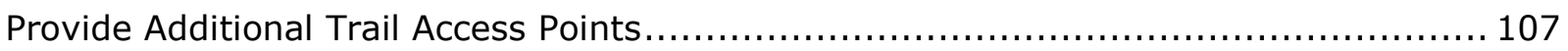

Economic Activity at Trail/Transit Crossings ............................................. 107

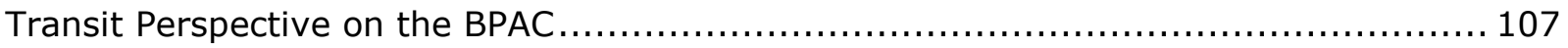

References ..................................................................................................... 109

Appendix A: Inventories of Six Selected Transit/Trail Crossings...................... 114

Appendix B: Transit/Trail Crossing Inventory Template ............................. 144 


\section{List of Figures}

Figure 1: Census tracts in Hillsborough County with the highest ranking of bicycle commuters are overlaid with the trails in red and transit routes in green. .............. 6

Figure 2: Census tracts in Hillsborough County with the highest numbers of public transit

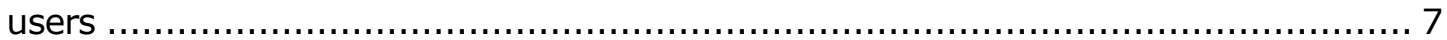

Figure 3: The study area includes Hillsborough and Pinellas Counties, Florida.................... 28

Figure 4: Steps in the method for linking greenways and trails with public transportation ........ 35

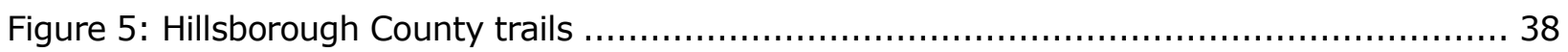

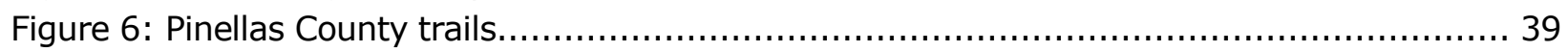

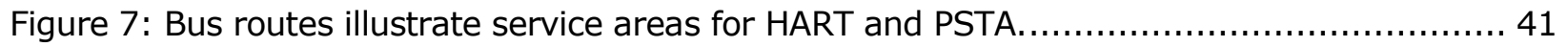

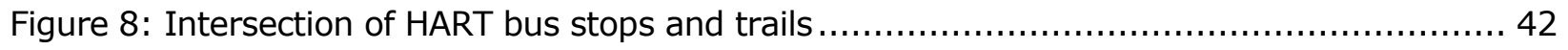

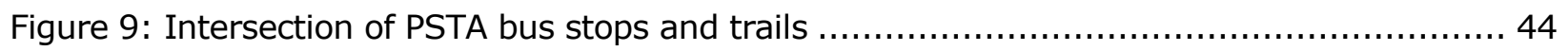

Figure 10: Low wage worker home location concentration with blue having the highest

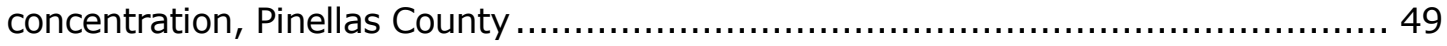

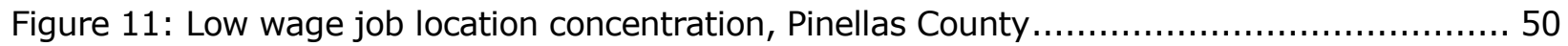

Figure 12: Low wage worker home location concentration with blue having the highest concentration, Hillsborough County .................................................... 51

Figure 13: Low wage job location concentration, Hillsborough County.......................... 52

Figure 14: 80th percentile of low wage jobs and low wage workers in Hillsborough County ...... 53

Figure 15: 80th percentile of low wage jobs and low wage workers in Pinellas County ............ 54

Figure 16: Locations of school age population in Hillsborough County attending postsecondary education.......................................................................... 56

Figure 17: Locations of school age population in Pinellas County attending post-secondary

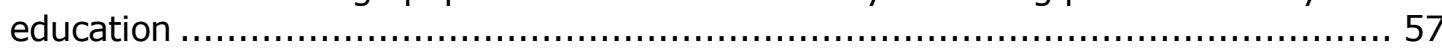

Figure 18: Locations in Hillsborough County having the highest concentrations of school

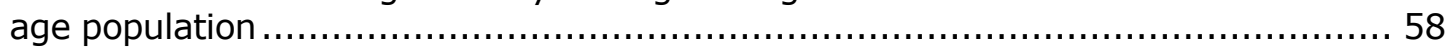

Figure 19: Locations in Pinellas County having the highest concentrations of post-

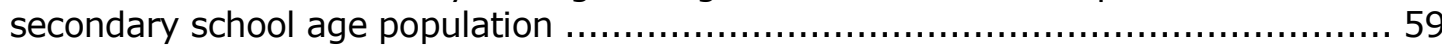

Figure 20: Jobs and lower income workers in southern Hillsborough County ..................... 61

Figure 21: Jobs and lower income workers in northern Hillsborough County ..................... 62

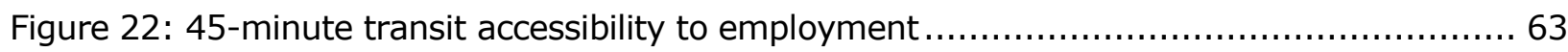

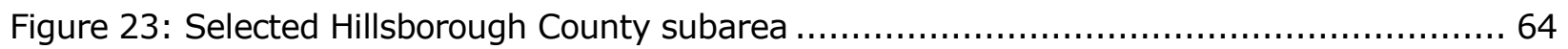

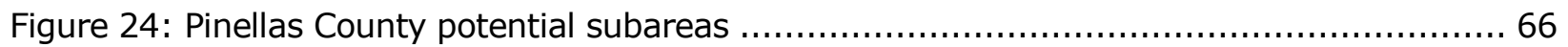

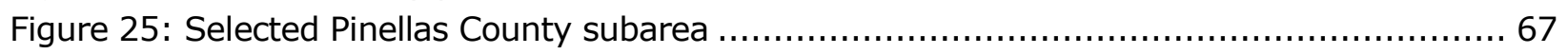

Figure 26: Location of relative numbers of Hillsborough County seniors by census block group and the locations of recreational opportunities ..................................... 68

Figure 27: Location of relative numbers of Pinellas County seniors by ensus block group

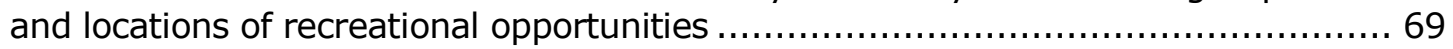

Figure 28: Hillsborough County subarea with three selected crossing locations .................... 72

Figure 29: Pinellas County subarea with three selected crossing locations ....................... 73

Figure 30: Hillsborough Scenario 1, HART Route 39 and Upper Tampa Bay Trail at

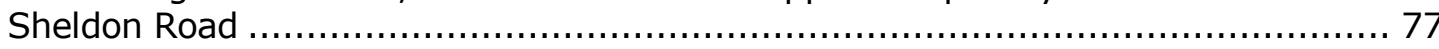

Figure 31: Hillsborough Scenario 1, Sheldon Road looking southbound at intersection with Upper Tampa Bay Trail 
Figure 32: Hillsborough Scenario 2, HARTFlex Town 'N Country and Upper Tampa Bay Trail at Linebaugh Avenue.....

Figure 33: Hillsborough Scenario 2, sidewalk leading from Linebaugh Avenue to the Upper Tampa Bay Trail

Figure 34: Hillsborough Scenario 2, Upper Tampa Bay Trail underpass at Linebaugh Avenue, after heavy rain.

Figure 35: Hillsborough Scenario 3: HART Northwest Transfer Center and Upper Tampa Bay Trail at W. Waters Avenue Bridge...

Figure 36: Hillsborough Scenario 3, W. Waters Avenue Bridge over Flood Control Channel A.

Figure 37: Pinellas Scenario 1, PSTA Route 66 and Pinellas Trail at 8th Avenue SW in Largo

Figure 38: Pinellas Scenario 1, PSTA Route 66 looking eastbound on 8th Avenue SW at the Pinellas Trail.

Figure 39: Pinellas Scenario 2, PSTA Routes 61 and Pinellas Trail at Gooden Crossing Road, and PSTA Route 59 at the Ulmerton Road bridge over Pinellas Trail in Largo

Figure 40: Pinellas Scenario 2, PSTA Route 61, looking northbound along Railroad Avenue at Gooden Crossing with Pinellas Trail

Figure 41: Pinellas Scenario 2, looking southbound along Railroad Avenue toward Ulmerton Road.

Figure 42: Pinellas Scenario 2, looking eastbound, where PSTA Route 59 passes under the Pinellas Trail bridge at Ulmerton Road.

Figure 43: Pinellas Scenario 3, Pinellas Trail at 96th Place North is proximate to but does not intersect with the closest PSTA Route 58.

Figure 44: Pinellas Scenario 3, 96th Place N., looking westbound toward its intersection with the Pinellas Trail....

Figure 45: Pinellas Scenario 3, $113^{\text {th }}$ Street N. at St. Petersburg College where there are no bike lanes or sidewalk facilities

Figure 46: Pinellas Scenario 3, intersection of $102^{\text {nd }}$ Avenue N with 113th St. N

Figure 47: Pinellas Scenario 3, PSTA Route 58 bus stop is located within the St. Petersburg College, Seminole Campus. 


\section{List of Tables}

Table 1: Methodologies at a Glance: Case Study Comparisons for Evaluating Transit/Trail Connections for Identifying Improvements............................................. 23

Table 2: Hillsborough Trail Locations within 2000 Feet of HART Bus Stops......................... 43

Table 3: Pinellas Trail Locations within 2000 Feet of PSTA Bus Stops ............................ 45

Table 4: Examples of Alternative Data Sources................................................... 46

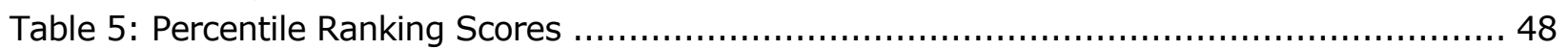

Table 6: Location of Proposed Trail/Transit Connection Scenarios in Hillsborough and

Pinellas Counties ........................................................................ 71 


\section{Acknowledgments}

Study authors would like to thank the staff of the Hillsborough County Metropolitan Planning Organization, the Pinellas County Metropolitan Planning Organization, the Hillsborough County Department of Parks and Recreation, the Pinellas County Parks \& Conservation Resources Department, Pinellas Suncoast Transit Authority, Hillsborough Area Regional Transit Authority, and the members of the Bicycle Pedestrian Advisory Committees of Hillsborough MPO and Pinellas MPO for their time and thoughtful input during the research for this report. 


\section{Executive Summary}

The goal of this research study is to improve community livability by enhancing access and connectivity through the improvement of connections between public transportation service and public trails. Such connections could extend the transit service area outward and enable pedestrians and bicyclists to access areas to which they might not otherwise travel due to traffic congestion, physical barriers, or safety concerns. The purpose of this research was to develop a methodology to evaluate how to provide better intermodal connections between public transportation and trails. This report offers a description of an approach that uses readily available data and Geographic Information Systems (GIS) spatial analysis to identify transit-using populations that could be readily and easily served by transit in conjunction with trails and greenways.

Hillsborough County and Pinellas County in Florida were used as illustrative locations for methodology development. Hillsborough Area Regional Transit Authority (HART) and Pinellas Suncoast Transit Authority (PSTA) serve these counties. The public trails systems in Hillsborough and Pinellas Counties are in a stage of planning and development. The trails will ultimately connect to the larger regional and statewide system, giving trail users nonmotorized access to the Tampa Bay area and beyond. This study began with a literature review to determine what other methodologies may have been used by other areas in Florida and nationwide. The review found that among planning efforts for non-motorized transportation by local governments and metropolitan planning organizations, the emphasis has been upon evaluation of the street system to develop complete networks of sidewalks and bicycle facilities. While the goal of intermodalism is articulated in long-range planning, pedestrian and bicycle access to public transit tends to focus upon the street system. Trail planning tends to focus upon the development of the trail network with connections to on-street bicycle and pedestrian facilities rather than public transit.

This study also completed the development of three case studies of urban areas that conducted evaluations involving transit connectivity for bicyclists and pedestrians. In comparison with a prioritization methodology used by MetroPlan Orlando, Florida, the three case studies included those for the Washington Metropolitan Area Transit Authority, Oregon Metro, and the Houston-Galveston Area Council with METRO in Texas. Each case study featured a different planning goal. Although trails were included in the evaluations of all the case studies, trails were not the main focus of any of them. The evaluation methodology for each case study location was considered to see what elements of these methodologies might be useful to borrow for an evaluation of trails connectivity with public transit.

Recommendations for a methodology to evaluate trails connectivity with transit were developed and demonstrated. Discussions with representatives of planning, parks, and transit agencies for Hillsborough and Pinellas Counties provided useful information and direction for locating available data sources. It is proposed to begin the evaluation by selecting a transportation goal of importance to the community as defined by a particular travel market and purpose. Such a goal can be found in the community's comprehensive plan transportation element or other planning documents, or articulated through a public participation process. For 
purposes of demonstrating the methodology, three target travel markets and three trip purposes were selected. These are low-income workers seeking access to employment opportunities, senior citizens seeking access to recreational opportunities, and adult students seeking access to school campuses. The home locations of these target markets were mapped using a Geographic Information Systems (GIS) spatial analysis with the Environmental Protection Agency Smart Location Database (EPA SLD) and other information sources. The purpose of the mapping exercise was to discern areas within the counties where larger concentrations of the target traveler markets are located. Likewise, locations of greater employment intensities were mapped, in addition to the locations of recreation centers and post-secondary education campuses. The locations of bus routes and bus stops, bicycle and pedestrian facilities, and public trails also were mapped.

These trails included the Fred Marquis Pinellas Trail in Pinellas County and the Upper Tampa Bay Trail in Hillsborough County. Study subareas were selected for each county, based upon their location between trip origins and trip destinations. For example, if the location of higher concentrations of adult students and the locations of post-secondary educational opportunities are known, then the general travel desire line connecting these two areas constitutes a subarea within which a student must travel to access the school. Within the subarea, trail crossings at streets with bus service were identified as those transit/trail junctures of interest. For a student to access the school location, there are trails that connect with transit, which the student can use to complete a multimodal trip to school. These junctures were categorized using a typology that distinguishes the junctures based upon the level of investment needed to improve the juncture. These three categories included those trails that directly connect with public transit where only minor improvements might be made, secondly, those trails that intersect with a transit route but do not connect well with transit due to some physical barrier, and thirdly, those trail locations that come close to transit service but do not intersect. These locations might require the most investment in developing a safe and convenient transit/trail connection.

Through site visits, one example of each of these three categories was identified for both Pinellas and Hillsborough Counties for further review. A trail/transit crossing inventory template was developed and used to conduct audits of the conditions present at these locations. Recommendations were developed for improvements for each of these transit/trail junctures to make the connection stronger so that someone using nonmotorized transportation could use both public transit and a public trail to complete a multimodal trip to the destination.

Conclusions and recommendations also were developed after applying this suggested methodology. Community planners should first consider what they want to accomplish, and then tailor their methodology to support accomplishment of the goal. The methodology described and demonstrated in this report will have consistent, predictable, and repeatable results when applied to other communities, using data sets and analysis tools that are widely available. If there are opportunities to find more planning resources, then it is recommended that local governments invest in a program of data collection that better characterizes nonmotorized travel in their communities. Such information about the unique travel characteristics of their populations will enhance decision making about prioritizing transit/trail connections for improvements and what types of improvements should be provided. 
Conclusions and recommendations also were developed after applying this suggested methodology. Community planners should first consider what they want to accomplish, and then tailor their methodology to support accomplishment of the goal. The methodology described and demonstrated in this report will have consistent, predictable, and repeatable results when applied to other communities, using data sets and analysis tools that are widely available. If there are opportunities to find more planning resources, then it is recommended that local governments invest in a program of data collection that better characterizes nonmotorized travel in their communities. Such information about the unique travel characteristics of their populations will enhance decision making about prioritizing transit/trail connections for improvements and what types of improvements should be provided.

It was observed that redundancy is important in the transportation system that serves pedestrians, bicyclists, and transit riders. Especially where there are trail overpasses or underpasses provided at multilane highways, these locations also should be considered for on-street improvements under circumstances when the trail overpass or underpass cannot be used. Finally, public transit and public trails agencies should cross-promote the opportunity to complete a journey by using both trails and transit in the same trip. 


$\begin{array}{ll}\text { Abbreviations/Acronyms } \\ \text { AASHTO } & \begin{array}{l}\text { American Association of State Highway and Transportation } \\ \text { Officials }\end{array} \\ \text { ADA } & \text { Americans with Disabilities Act } \\ \text { APA } & \text { American Planning Association } \\ \text { API } & \text { Application Programming Interface } \\ \text { APTA } & \text { American Public Transportation Association } \\ \text { ATP } & \text { Active Transportation Plan } \\ \text { BART } & \text { (San Francisco) Bay Area Rapid Transit } \\ \text { BBG } & \text { Bayshore Boulevard Greenway } \\ \text { BPAC } & \text { Bicycle and Pedestrian Advisory Committee } \\ \text { CNT } & \text { Center for Neighborhood Technology } \\ \text { EPA } & \text { Environmental Protection Agency } \\ \text { FDEP } & \text { Florida Department of Environmental Protection } \\ \text { FDOT } & \text { Florida Department of Transportation } \\ \text { FGTS } & \text { Florida Greenways \& Trails System } \\ \text { FHWA } & \text { Federal Highway Administration } \\ \text { FTA } & \text { Federal Transit Administration } \\ \text { FTP } & \text { File transfer protocol } \\ \text { GIS } & \text { Geographic Information Systems } \\ \text { GPS } & \text { National Trails Training Partnership } \\ \text { GTFS } & \text { Global Positioning System } \\ \text { HART } & \text { General Transit Feed Specification } \\ \text { H-GAC/METRO } & \text { Hillsborough Area Regional Transit Authority } \\ \text { ITE } & \text { Houston-Galveston Area Council with METRO } \\ \text { LEHD } & \text { Lenstitute of Transportation Engineers } \\ \text { LOS } & \text { Metropolitan Transit Authority of Harris County, Texas } \\ \text { METRO } & \text { Netropolitan Planning Organization } \\ \text { MPO } & \text { NCTR } \\ \text { NTTP } & \text { OGT }\end{array}$


$\mathrm{PICH} \quad$ Partnerships in Community Health

PSE Policy, Systems, and Environmental (improvements, federal Healthy People 2020 Vision)

PSTA Pinellas Suncoast Transit Authority

RRFB Rectangular Rapid Flash Beacons

RTP Regional Transportation Plan

SLD Smart Location Database

SOS State of the System

TBARTA Tampa Bay Area Regional Transportation Authority

TCQSM Transit Capacity and Quality of Service Manual

TCRP Transit Cooperative Research Program

TRID

Transport Research International Documentation

TriMet

Tri-County Metropolitan Transportation District of Oregon

WMATA

Washington Metropolitan Area Transit Authority 


\section{Chapter One}

\section{Introduction}

The goal of this research project is to improve livability in Florida communities by developing a methodology to evaluate how to provide better intermodal connections between public transportation and trails. Such connections could extend the transit service area outward and enable pedestrians and bicyclists to access areas to which they might not otherwise travel due to traffic congestion, physical barriers, or safety concerns. These connections will contribute to a community's goal to help complete the integration of a multimodal system where travelers can use a combination of trails, greenways, and public transportation in a single trip to reach their destinations. Hillsborough and Pinellas Counties in Florida were used as illustrative locations for methodology development. Hillsborough Area Regional Transit (HART) and Pinellas Suncoast Transit Authority (PSTA) serve these counties.

\section{Trails Terminology}

Before defining "trails" as used in this study, it is useful to consider various terminology. From the standpoint of trails and greenways organizations that approach the topic from a perspective of greenspace preservation and enjoyment, there are no standardized definitions for trails and greenways that have been adopted by all major public and private entities involved in their development and management. The terms "trail" and "greenway" often are used interchangeably, or one term might be described as a subset of the other. For example, as described in the website of the East Coast Greenway Alliance, "The East Coast Greenway is a developing trail system, linking many of the major cities of the Eastern Seaboard between Canada and Key West. Nearly 30 percent of the route is already on trafficfree greenways, creating safe, accessible routes for people of all ages and abilities."(East Coast Greenway Alliance 2015)

Charles E. Little is considered to be one of the contemporary leaders of the greenway movement in the United States. He described greenways as "A linear open space established along either a natural corridor, such as a riverfront, stream valley, or ridgeline, or overland along a railroad right-of-way converted to recreational use, a canal, a scenic road, or other route...Any natural or landscaped course for pedestrian or bicycle passage...An open-space connector linking parks, nature reserves, cultural features, or historic sites with each other and with populated areas...Locally, certain strip or linear parks designated as a parkway or greenbelt." (Little 1990, 1)

Greenways and trails development in Florida does allude to travel purposes. For example, the basic criteria for designation of a trail to be included in the Florida 
Greenways and Trails System is that the land (or waterways), which can be publicly or privately owned, must:

- Protect and/or enhance natural, recreational, cultural or historic resources; and

- Provide linear open space or a hub or a site; or

- Promote connectivity between or among conservation lands, communities, parks, other recreational facilities, cultural sites, or historic sites.

The mission of the Florida Greenways and Trails System is "...to create a network of greenways and trails throughout Florida, connecting one end of the state to the other..."(FDEP 2015)

From the standpoint of providing trails as transportation facilities, the term shared use path is used. The AASHTO Guide for the Development of Bicycle Facilities distinguishes the differences between shared use paths and on-road bicycle facilities, including shared roadways, signed shared roadways, and bicycle lanes.

Generally, shared use paths should be used to serve corridors not served by streets and highways or where wide utility or former railroad right-of-way exists, permitting such facilities to be constructed away from the influence of parallel streets. Shared use paths should offer opportunities not provided by the road system. They can provide a recreational opportunity or, in some instances, can serve as direct commute routes if cross flow by motor vehicles and pedestrians is minimized. The most common applications are along rivers, ocean fronts, canals, utility rights-of-way, former or active railroad rights-of-way, within college campuses, or within and between parks. There may also be situations where such facilities can be provided as part of planned developments. Another common application of shared use paths is to close gaps in bicycle travel caused by construction of cul-de-sacs, railroads, and freeways or to circumvent natural barriers (rivers, mountains, etc.). While shared use paths should be designed with the bicyclist's safety in mind, other users such as pedestrians, joggers, dog walkers, people pushing baby carriages, persons in wheelchairs, skate boarders, in-line skaters and others are also likely to use such paths.(AASHTO 1999, 8)

Much of the most recent national discussion about the differences among the facilities is for purposes of designing for ADA (Americans with Disabilities Act) accessibility. The Federal Highway Administration (FHWA) also considers that trails designed to provide a transportation function while supporting multiple users are called shared use paths.

The Florida Department of Transportation (FDOT) Plans Preparation Manual, Chapter 8, Pedestrian, Bicycle, and Public Transit Facilities, includes a section on shared use paths. The Manual describes shared use paths thus.

Shared use paths are paved facilities physically separated from motorized vehicular traffic by an open space or barrier and either within the highway right-of-way or an independent right-of-way. Shared use paths are used by bicyclists, pedestrians, skaters, runners, and others. The bicycle's operating characteristics will govern the design of shared use paths, as well as the 
requirements of the 2006 ADA Standards for Transportation Facilities. (FDOT 2015)

Within the context of this study, trails of interest include shared use paths and other public facilities that are linear, such as greenways, so that someone on foot or on bicycle can potentially use the trail for a transportation purpose to travel from some origin to a destination. As opposed to a shared use path, recreational trails are often loops that remain within the confines of a park property, in which someone following the trail will end up where he or she started, where both origin and destination may be located at the same point. In some cases, a portion of a loop trail may serve a transportation purpose where connections exist to other facilities.

Regional trails in Florida often are referred to as greenways. Community trails typically are owned and/or managed by municipal governments. In some instances where a transportation purpose can be served, public trails of interest to this study might include unpaved trails but trails that are intended for intensive use by the public, particularly for those using street bicycles, are paved. Unpaved trails are more likely to be single-track (where one must stop and step aside to allow another going in the opposite direction to pass by), and used for recreation and nature observation. In this study that focuses upon trail/transit connectivity, greater distances can be traveled by bicycle. For purposes of analyzing the utility of a trail/transit connection, researchers used the bicyclist as the focus; however, greenways and shared use paths also are designed for other nonmotorized users. The analysis focus upon the bicyclist in this study was not meant to imply that pedestrians and others will not consider using a trail/transit connection for transportation, although the shorter distances that can be traveled may somewhat limit the use of connection options.

\section{Overview}

There are several possible ways to approach the question of how best to improve public trail connectivity to public transit. Under ideal hypothetical circumstances, a community would have unlimited resources and could develop an interconnected network of public transit routes with public trails, which maximizes connections. To accomplish this, community planners would realign bus routes and public trails to make these connections. Oregon Metro's Council Creek Regional Trail Master Plan is an example of this, where alternative trail alignments have been considered in conjunction with transit availability (Parametrix 2015). However, it is an infrequent opportunity at best for a community to start from scratch. Public trails usually are aligned where there are existing rights-of-way, utility easements, or natural formations, such as parallel to a river. The alignments of bus routes represent a carefully considered balance of multiple community priorities, including making service accessible to more patrons, providing service to communities that rely more heavily upon public transit, and serving major destinations. Serving community priorities must be balanced with covering the costs to provide the service by maximizing revenues and cost efficiencies. Any consideration to change an existing bus route must be weighed against multiple potential impacts to existing riders, impacts to fare box revenue, and impacts to schedules and the timing of transfers. In recognition of these conditions, this research study used a conservative 
approach, prioritizing opportunities to improve connections of public trails to public transit without the need to move a public trail or bus route. This study focuses on areas of a community where public transit already exists or is within reach via use of a public trail.

It was found in the analysis that there are 365 HART bus stops within 2000 feet (approximately an 11-minute walk) of 18 existing or programmed trail locations in Hillsborough County and there are over 1,400 PSTA bus stops within 2000 feet of trail locations in Pinellas County. These are large numbers of potential transit/trail connections from which to choose for making connectivity improvements. The question then becomes which of these trail/transit connection areas should be prioritized for improvements, given limited public resources. This research has resulted in recommendations for an approach to prioritize those connections that advance goals that are important to the community.

There can be several potential prioritization approaches, some of it determined by the type of information that is already available to planners. For example, one approach takes advantage of opportunities where redevelopment funds or highway improvement funds are already planned to be used, as a means to select trail/transit connection locations for further improvement. The Pinellas County Enterprise Geographic Information Systems (GIS) provides a new public GIS applications portal for accessing several types of specific information, including the location of parks and recreation centers, a pavement preservation program, MPO construction projects, MPO trails, and Pinellas County greenways. There also are datasets relating to the locations of Community Redevelopment Areas, Brownfield Areas, Urban Job Tax Credit Areas, Reduced Transportation Impact Fee Areas, and Municipal Planning Areas. Overlays of various data may enable planners to identify, for example, where trails and greenways exist relative to land redevelopment proposals or funded highway reconstruction or repaving projects. This is an opportunistic approach for making improvements to trail crossings at these locations, especially where there also is bus service, to be included as part of ongoing proposals or plans.

An example of a second potential approach could be to select the bus routes with the highest current ridership and prioritize locations along those bus routes where public trails cross streets served by public transit or that run in close proximity to a street crossing. Conversely, planners could start with identifying locations along public trails where count data indicate higher levels of walking and bicycling relative to other trail locations. Trail segments with highest usage near points of access where bus routes cross could provide a means of prioritization. This approach focuses on transit/trail connections at the locations of greatest existing activity, offering service to the greatest number of people who are already either trail users or transit riders.

A third approach could be to focus upon travel markets instead of locations of transit and trail activity. For example, planners could focus upon bicyclists by identifying the home location of larger concentrations of persons who already bicycle for transportation. This potential market may more likely use trails that are near the home location. For example, Figure 1 below illustrates the home location, by Census tract in Hillsborough County, with higher numbers of bicyclists relative to 
other Census tracts. These areas were ranked based on their relative percentage ranking and assigned a score of $1-10$, with 10 being the highest, and the number corresponding to the percentile rank. The map below illustrates the Census tracts ranked in the top $80^{\text {th }}$ percentile overlaid with the bicycle trails and bus routes. Locations with higher numbers of bicyclists living close to bike trails offer a potential market to connect these users with trails. Additionally, the Census tracts with higher rankings of the home locations of commuters who use public transit also can be mapped and overlaid with the trails and transit routes, as shown below in Figure 2.

The advantage of this approach is to target existing bus riders and bicyclists as "low hanging fruit." Those who already use public transit or bicycle for transportation may be a ready market for pairing public transit and bicycling to complete a trip. This could potentially increase trip frequency by the combination of bicycling and public transit by those who already use those modes. However, this approach may be less useful if the goal is to attract new people to use public transit and trails, who might not have done so otherwise. It also does not take into consideration how public transit and trails can be combined to complete a trip for determining a 
prioritization approach for identifying trail/transit locations for connection improvements.

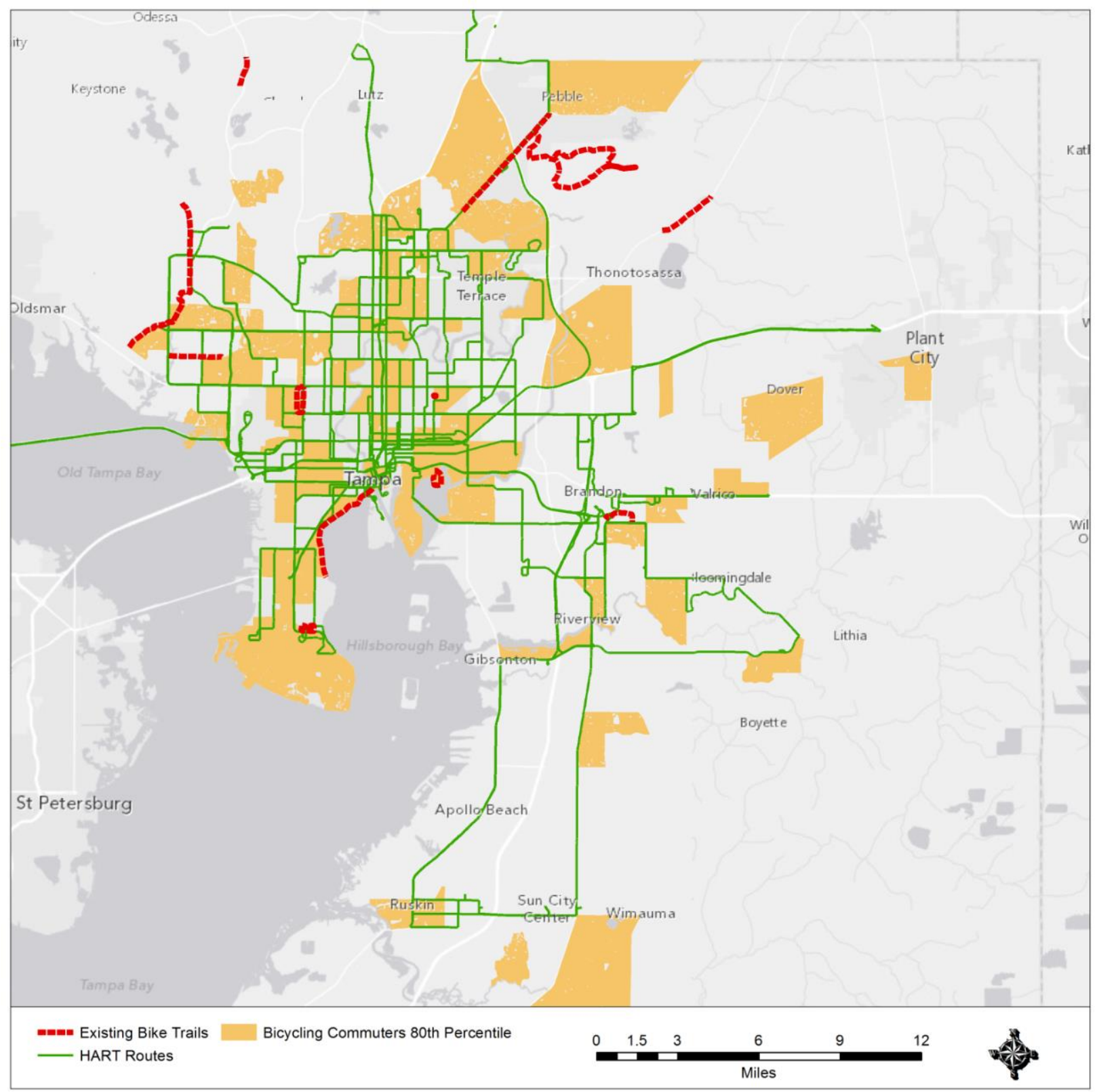

Figure 1: Census tracts in Hillsborough County with the highest ranking of bicycle commuters are overlaid with the trails in red and transit routes in green. 


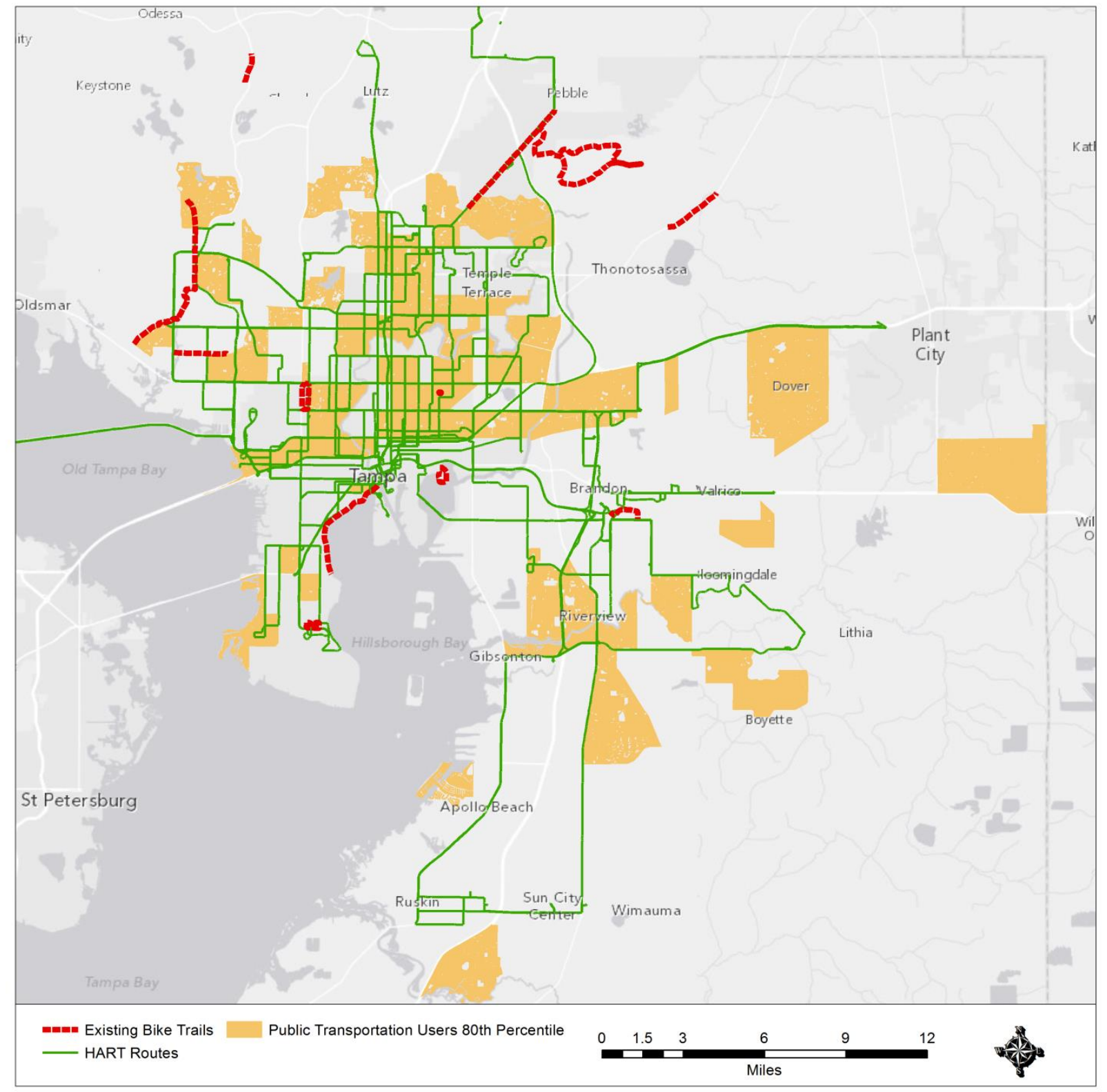

Figure 2: Census tracts in Hillsborough County with the highest numbers of public transit users 


\section{Chapter Two}

\section{Review of Literature and Case Studies}

To identify other existing evaluation methodologies, a literature search was conducted for reference manuals, studies, and plans that relate to the topic of public transit connectivity to public trails and greenways. From this starting point, additional searches were made on the websites of the National Trails Training Partnership (NTTP), hosted by American Trails, and the Rails-to-Trails Conservancy. Searches on various keywords were made using Transport Research International Documentation (TRID). Searches also were made for relevant documents from the Transit Cooperative Research Program (TCRP), the Resource Library of the American Public Transportation Association (APTA), the Transportation Research Board of The National Academies, Institute of Transportation Engineers (ITE), and American Planning Association (APA). A search was conducted on the Web pages for the Federal Highway Administration's (FHWA) Manuals and Guides for Trail Design, Construction, Maintenance, and Operation, and for Signs. General searches using Google and Google Scholar also were conducted, including searches for examples of local government and regional bicycle and pedestrian planning that included intermodal connections with public transit.

\section{General Observations from the Literature Review}

Presently, there is very little discussion among trails organizations regarding connecting public trails and greenways with public transit. Even in organizations that focus upon urban trails, the public transit/trails connection tends not to enter the discussion.

Among planning efforts for non-motorized transportation by local governments, the emphasis tends to be upon use of the street system to develop complete networks of sidewalks and bicycle facilities, such as wide curb lanes and bicycle lanes. Methodologies are available for prioritizing bicycle and pedestrian improvements for investments, based upon criteria that reflect community-identified values. The more commonly articulated goal in urban trails planning is to connect urban trails to the larger and growing urban bicycle lane, bicycle route and sidewalk network of the roadway. Even so, the plans reviewed also showed variation in the degree to which public trails were integrated with non-motorized transportation planning for on-street bicycle and pedestrian facilities. A greater focus in discussions about public trails planning tends to be from the perspective of public health benefits of active transportation and in the conduct of health impact assessments.

There may be some hesitancy on the part of bicycle advocates to place much emphasis upon public trails for transportation purposes due to the concern that the presence of trails could be used as an excuse not to invest further public funds into street improvements for bicyclists and pedestrians. In addition, experienced bicyclists who are trails planning advocates might prefer to make the entire trip on bicycle, if possible, rather than having to switch modes to public transit. This makes sense for longer distance recreational bicyclists, but others may prefer to make a shorter bike trip with the remainder of the journey by public transit. This could be for a variety of reasons, including physical ability, especially for utilitarian bicycling where carrying items might make bicycling more difficult. Others may 
fear venturing into a more urbanized area on bicycle due to safety concerns riding in traffic, or traveling with children who may not be able to bicycle longer distances. Depending on climate, others might simply desire a heated or air conditioned bus for part of the journey. Local governments that place an emphasis upon transportation equity and serving lower income populations are more likely to see the potential benefits for multimodal travel for utilitarian purposes.

As discussed earlier under Trails Terminology, advocacy groups and local governments tend to use their own vocabulary and definitions for terms relating to trails that serve a transportation function. This may suggest that the national discussion about trails serving a transportation function is still in the early stages.

The current emphases in research about bicycle facilities include increasing bicycling activity, increasing bicycling safety on-street, measurement of usage, evaluation, and greenway planning. In the literature on public transit planning, station access is a large concern and many studies and reports are available that focus on pedestrian and bicycle access to transit from the street system but little discussion was found relating to public transit's perspective on connectivity with public trails and greenway systems.

\section{Summary of Methodologies Found in the Literature Review}

A brief summary of methodological approaches that relate in some way to planning public transit connectivity with public trails is provided below. Most of these findings do not explicitly address methods for evaluating transit/trail connectivity but do offer analysis approaches that potentially could be used as part of a methodology. A more detailed discussion of each of these approaches with associated references is contained in the literature review in the Task 1 Technical Memorandum.

- The Transit Capacity and Quality of Service Manual (TCQSM) provides a method for calculating the transit service coverage area, based on walking distance assumptions. (FTA 2013, 5.79-88)

- The TCQSM also provides a method for comparing the existing transit service coverage area with the transit-supportive area, based on assumptions about minimum necessary residential density and employment intensity to support transit.

- The regional transportation planning agency, Oregon Metro, conducted a Geographic Information Systems (GIS) analysis of the pedestrian network to estimate impact on walking activity resulting from closing gaps. (Alta Planning + Design 2013) The Oregon Metro Active Transportation Plan (ATP) calls for filling in gaps in sidewalks and trails within a mile of stops and stations and filling in gaps in bicycle facilities within three miles of stops and stations. (Oregon Metro 2014b)

- The City of Maple Valley, WA, used public participation to prioritize evaluation criteria (safety, ease of connection to destinations, proximity to destinations, and multimodal access) that were then applied to prioritize routes for improvements. (City of Maple Valley 2013, 6-7)

- The Metropolitan Transit-Metropolitan Council of the Twin Cities region in Minnesota used a method to compile a list of on-street pedestrian and bicycle roadway improvements to better connect to public transit at bus stops. They 
conducted a survey of community representatives to identify most desired improvements. They conducted a bus stop analysis using GIS, and assigned a greater ranking for improvements to bus stops along priority bus routes and gave greatest priority to ADA compliance. They evaluated level of bicycle comfort at the bus stops, based upon average daily traffic, posted speed limit, number of travel lanes, presence of parallel parking, percentage bus and truck traffic, presence of curb, and level of activity relating to vehicles leaving and entering properties along the bus route. Specific improvements were then identified, with priority given to the higher-ranking bus stops. (H. R. Green Company 2009)

- A multimodal route-finding system called Cyclopath was developed at the University of Minnesota for the Twin Cities Metro Transit bus network and roadway and bicycle trail network. It enables users to plan trips pairing bicycling with a bus ride. After deployment of this product in summer 2011, approximately 15 percent of route requests were observed to be for multimodal routes. Similar activity in the San Francisco Bay area was noted in the development of Web sites and mobile phone apps to enable recreational users to access trails via public transit. While these efforts involve trip planning, not system planning, such applications can support the use of developed transit/trail connections. (Terveen 2013)

- The Street Smart Walk Score $\AA$, originally developed at the University of British Columbia in 2007, is a tool that helps evaluate walkability of a neighborhood or community by quantifying the number of amenities and their proximity to a location of interest. The Walk Score $®$ Travel Time Application Programming Interface (API) can be used to show travel times by walking, bicycling, and transit. (Walk Score $®$ )

- The Housing and Transportation Affordability Index, developed by the Center for Neighborhood Technology (CNT), calculates affordability using American Community Survey characteristics for households and transportation usage by Census block group. The tool uses indicators such as frequency of transit service within a given neighborhood, transit access from any block group within a 30-minute walk, and average block size and intersection density. (CNT)

- Robert Cervero of the University of California, Berkeley, measured an increase in the bike-and-ride mode share after investments of bicycle infrastructure were made near transit stops of the San Francisco Bay Area Rapid Transit (BART) system. (Cervero, Caldwell, and Cuellar 2013, 83-105)

- The Miami-Dade County Trail Design Guidelines and Standards as applied to the Ludlam Trail Case Study is a detailed treatment of concepts found in the Great Greenways, Trails, and Water Trails of the Open Space System Master Plan of the Miami-Dade County Parks and Recreation Department. It provides general guidelines for the design of non-motorized urban shareduse trails and paths in Miami-Dade County, based upon the specific guidance for Ludlam Trail. (AECOM 2011)

The Ludlam Trail case study is an informative example because there are 17 street crossings within the 6.2-mile trail corridor for which individual evaluations were conducted. The trail corridor has significant multi-modal transportation value because it connects with four schools, three parks, several neighborhoods, and is 
bounded on the south end by the Dadeland Mall. It passes over three canals (overcoming physical barriers) and has the opportunity to connect with regional transit service at the Dadeland North Metrorail station. This case study resulted in best practice principles for accessible street crossings for those that are above grade as well as those for at-grade local, connector, and arterial streets. These streets are the primary access opportunities from the trail to public bus service. The Ludlam Trail Case Study recommends that trail access should be primarily through the use of sidewalk connections in addition to access from private property. Unlike other trail plans reviewed, it offers transit connection recommendations:

Several bus stops exist within $250^{\prime}$ of the corridor and should be encouraged to be relocated within or immediately adjacent to the corridor to best serve trail users. Existing transit facilities such as SW $8^{\text {th }}$ St., Tamiami Trail, should be improved to include a covered bus shelter and seating. (AECOM 2011, 17)

The Ludlam Trail Case Study generally addresses the relationship of the trail to public transit.

It is desirable to provide seamless connections between various modes of travel including bikes, buses, transit and automobiles. Transit information and directional signs should be placed at all trailheads, including bus/transit schedules if possible. Directional signs throughout the Ludlam Trail corridor should identify the locations of the nearest bus/transit stops; and signs at the transit stops should inform riders regarding how to access the trail. Amenities should be provided to encourage multi-modal use. Bicycle parking should be provided at transit stops, along with transit shelters and benches. (AECOM 2011,37)

\section{Summary of Methodologies of Case Studies}

In addition to describing a method used by MetroPlan Orlando in central Florida, three case study examples from outside Florida were developed that summarize the methodologies used by localities to implement transit/trail connection planning. It is important to note that while all of the case studies included consideration of trails, none of the case studies had a primary trail-to-transit focus. These included case studies for the Washington Metropolitan Area Transit Authority (WMATA, also known at Metro), Oregon Metro, and the Houston-Galveston Area Council with METRO (H-GAC/METRO). The Task 2 Technical Memorandum for this study provided a detailed discussion of each case study. These include the location and general description of the transit system and the trail system, the entity that initiated the plan or study and their goal or motivation for doing so, a description of 
the methodology, and observations about the methodologies based upon several criteria.

The criteria include the following:

- Ability to tailor the method to a particular community

- Labor intensiveness/ease of implementation

- Level of expertise required to analyze results

- Amount of data required and level of ease collecting the data

- Special equipment or software needed

From these four examples, two represent MPOs incorporating public transit and public trails connectivity as multimodal transportation system development within a long range transportation plan. A third example represents a public transit-initiated study, and the fourth example was a joint effort on the part of an MPO and a public transit agency to improve bicycle-to-transit connections. Each case study community had a different goal that influenced the contents of their methodologies. No examples from other cities were found that shared the same goal as this study, but some elements of the methodologies of each case study were useful for further consideration. A brief summary of each of the methodologies is included below.

\section{MetroPlan Orlando}

One of the goals of MetroPlan Orlando's bicycle and pedestrian portion of their 2040 Long Range Transportation Plan was to prioritize bicycle and pedestrian projects that will shift travelers away from single occupant vehicle travel. (MetroPlan Orlando 2015) Evaluation criteria included expanding the bicycle/pedestrian network to provide connectivity to transit with particular attention to additional connectivity provided to SunRail and other transit emphasis corridors. MetroPlan Orlando began with a slate of already programmed projects. Unlike the case studies from outside Florida, the purpose of MetroPlan's analysis was to prioritize proposed bicycle and pedestrian projects from a pool of applications submitted annually by local governments. The resulting list included the top sidewalk and bicycle projects for each of the three counties in their metropolitan planning area and the top trail connection projects. Projects also were analyzed separately according to order of magnitude of cost. Projects estimated to cost more than $\$ 300,000$ per phase were limited to one phase per year per jurisdiction. Selected bicycle, pedestrian and trails projects were added to the back of the programmed projects list. These projects move up the list as prioritized projects are completed and as funds become available.

MetroPlan Orlando used a prioritization matrix that identifies criteria of importance to the community and assigned weights to the criteria. This is an element of their methodology that was also used by H-GAC/METRO, summarized below. For trails projects, there was a separate application form from that used for bicycle and pedestrian projects. Unlike the analysis for on-street bicycle lanes and sidewalks that included a transit emphasis multiplier, the trails criteria were different. These included the regional importance of the trail, the existence of a local match, trail surface type and project readiness, economic development potential, and lastly, intermodal connectivity. Similar to the Oregon Metro plan, summarized below, the development of a regional trail system is important to MetroPlan Orlando. Regional 
importance is weighted the highest at 50 percent and includes more points for longer trails that connect to other trails, that cross jurisdictional boundaries, serve significant destinations, and that serve an underserved area. Intermodal connectivity was weighted at 5 percent. Its criteria included the number of bus stops or rail stations directly served, connection to other facilities that connect directly to transit, and headways of bus and rail service that can be accessed by the trail. These also included the maximum number of buses or trains served by a single stop or station per day, which also are served directly or indirectly by the trail projects. A Bicycle and Pedestrian Advisory Committee (BPAC) subcommittee evaluated the projects by assigning scores for each criterion, using their judgment, and then submitted the result of their evaluation to the BPAC.

\section{Washington Metropolitan Area Transit Authority}

Unlike MetroPlan Orlando that is a metropolitan planning organization, the Washington Metropolitan Area Transit Authority (WMATA) operates 91 rail stations serving communities in Maryland, Virginia, and Washington, D.C. This region enjoys an extensive network of public trails, some of which have been in existence for decades. WMATA conducted a transit study that applied a methodology to improving rail station connectivity to bicycle and pedestrian facilities. (Parsons Brinckerhoff and Toole Design Group 2010) WMATA's study was motivated by projections of growing ridership while not having the capacity to accommodate future ridership at stations with space and access limitations, particularly for car parking. Their solution was to make access to the Metrorail stations by walking and bicycling as convenient and safe as possible so that more WMATA patrons choose to leave their cars at home. The study identifies strategies to enhance pedestrian and bicycle access and connectivity in and around Metrorail Stations, concentrating on recommendations for physical infrastructure improvements, and policies and programs to encourage multimodal trips. The study was not specific to public trails but included them.

The methodology included a bike shed analysis with a three-mile area radius and the development of a station area typology to categorize similar stations and organize recommendations around those similarities. With input from WMATA staff, a consultant developed a typology of nine Metrorail station types based upon the needs of bicyclists and pedestrians, which may differ according to the land use arrangement and transportation characteristics surrounding the station. The nine types represented the range of conditions that bicyclists and pedestrians experience based upon land use patterns. A representative station was selected for each of the nine Metrorail station types, and was developed as a case study. The case study development was augmented by on-site observations. Recommendations for each of the nine case study stations were developed to improve bicycle and pedestrian access at that station. These recommendations were to be used as a starting point to guide the investigation of needed improvements at the other stations that were categorized in that same type.

The examples excerpted and bulleted below provide a flavor of the kinds of specific recommendations regarding trail access that resulted from the bike shed analysis 
for two station assessments characterized as suburban residential areas. (Parsons Brinckerhoff and Toole Design Group 2010, Appendix B)

- Install a short access path, crosswalk, striped (or curbed) median refuge, safety signage and pedestrian actuated signal; provide signage indicating Metro access from the trail.

- Install a short access path, crosswalk, striped median refuge and full signal and add direction signage for trail users.

- Install bike lanes on Belle Haven Road; and bike lanes or shared lane markings on Belle View Blvd.

- Improve the crossing at Tulane Drive.

- Stock the station kiosk with Anacostia Tributary Trail brochure/maps.

- Repair all trail bridge entries within one mile of the station.

- Improve trail access for adjacent neighborhoods with stairs, curb ramps, trail pavement realignments, and removal of gates.

- Extend trail lighting systems.

- Complete the Prince George's Connector Trail.

- Create direct stairway linkages between the Prince George's Connector Trail and the Avondale neighborhood by widening and upgrading the trail surfaces and relocating bridges.

- Expand trail lighting to the northwest along the Sligo Trail and north along the NW Branch Trail.

Most Florida urban areas do not yet have an extensive network of urban trails on a scale that can be found in the Washington, D.C. region. Florida's transit oriented development is in earlier stages of formation. Planners refer to transit ready development where public transit may serve in the future. However, the WMATA approach could be useful to Florida urban areas that provide rail service and the approach to a station area assessment is adaptable to any transit access point that needs pedestrian and bicycle improvements.

The detailed recommendations for station-area planning and programming, especially using a three-mile bike shed radius, would likely require a level of resources not available to most Florida transit agencies. However, developing the station area typology to group together similar stations that likely demonstrate comparable pedestrian and bicycle safety and access issues is a useful way to approach a large number of study locations, while enabling consideration of the small scale fine-grain street characteristics that influence the travel experience of bicyclists and pedestrians. Planners relied on site observations and stakeholder input in the development of recommendations. Ongoing local stakeholder groups specific to each station area were recommended. This would require continuous public outreach efforts but could reap a long-term benefit in customer relations.

WMATA was the only case study that recommended the analysis should include establishing bicycle and pedestrian performance indicators for volume, safety, security, maintenance, and customer satisfaction. These would be applied to establish a baseline, and again after improvements were put in place, to evaluate the effectiveness of the improvements. It was recommended to determine the frequency with which the assessments should be made and by which partner agency. It was recommended that improvements in performance could be 
correlated with specific actions undertaken. This is a particularly insightful approach to include an evaluation component. This also would require large staff resources in the short run but potentially more success and saved effort in the long term.

\section{Oregon Metro}

Oregon Metro ${ }^{1}$, the metropolitan planning organization for the Portland-Salem Metropolitan Area, adopted the 2014 Regional Transportation Plan. It contains policies that support bicycle and pedestrian access to transit, including the following.

- Improve pedestrian and bicycle access to transit.

- Build an interconnected regional network of bicycle routes and districts integrated with transit and nature that prioritizes seamless, safe, convenient and comfortable access to urban centers and essential daily needs, including schools and jobs for all ages and abilities.

- Improve bicycle-transit connections.

- Build a well-connected network of pedestrian routes, including safe street crossings, integrated with transit and nature that prioritizes seamless, safe, convenient, and comfortable access to urban centers and essential daily needs, including schools and jobs, for all ages and abilities.

- Improve pedestrian access to transit. (Oregon Metro 2014a, Chapter 2-57, $68,70,79,81)$

The Regional Active Transportation Plan (ATP) that includes bicycle and pedestrian modes is a part of the 2014 Regional Transportation Plan (RTP) for Multnomah, Clackamas, and Washington Counties in Oregon and 25 cities, including Portland (Oregon Metro 2014b). As part of the ATP, a regional bicycle network evaluation was undertaken and a separate regional pedestrian network evaluation was done. Oregon Metro's motivation for its evaluation was to develop bicycle and pedestrian networks that increase physical activity, access, safety, and equity. The goal was to develop these networks that could actually function independently by mode. For example, the purpose of the analysis was to determine what kind of network structure would best serve bicycle trips. If a traveler wanted to bicycle from one side of the region to another, the bicycle network would enable the bicyclist to do so (Oregon Metro 2013). Public transit was integrated with the Plan's Regional Bicycle Network Functional Classifications (Oregon Metro 2014c).

Most recently, Oregon Metro developed the Council Creek Regional Trail Master Plan. It considered proximity to transit as part of its evaluation of trail alignment options (Parametrix 2015).

The methodology for the regional network evaluation of the ATP included a GIS analysis, the application of a bicycle travel demand model, and the use of a functional class system for bicycle facilities and pedestrian facilities. For example,

\footnotetext{
1 Oregon Metro is known as either "Oregon Metro" or simply "Metro". For purposes of this report, the name "Oregon Metro" is used to distinguish it from the other two case studies, in which WMATA also is known as Metro and the public transit agency in Houston is known as METRO.
} 
the regional bicycle network concept would connect bicycle facilities of different functional classes, including bicycle parkways (the spine of the network), regional bikeways, community bikeways, regional trails, and bike-transit facilities (primarily bike parking). These functional class designations help inform decision making on where and how to prioritize investments. These various types of bicycle facilities run through and connect 74 bicycle districts in the region. According to Oregon Metro, a bicycle district is an area with a concentration of transit, commercial, cultural, educational, institutional, and recreational destinations where bicycling is intended to be safe, attractive and comfortable. Bicycle districts are in locations of regional and town centers as well as transit station communities.

Bicycle travel demand modeling may provide insight into the greatest bicycle travel desire lines. Which origin-destination pairs generate the most bicyclists? Given that information, what is the quality of the bicycle routes connecting the two? As a part of the ATP, a bicycle travel modeling tool was used to evaluate different concepts for a regional bicycle network, based upon each network's ability to accomplish the criteria of increased access, safety, equity and physical activity. The bicycle travel model then tested three additional bicycle network design alternatives against the baseline 2035 bicycle traffic scenario to see which concept encouraged the most bicycling. These scenarios included the "spider web", the grid network, and a mobility corridors parkway concept. (Oregon Metro 2013) Oregon Metro also used the results of a study by Portland State University that engaged 164 volunteer utilitarian bicyclists to carry Global Positioning System (GPS) devices to determine revealed preference for route type. (Broach, Dill, and Gliebe 2012) The bicycle model captures both commute and non-commute trips and the network uses all streets and trails in the transportation network. The bicycle model network was integrated with the automobile and transit networks. The model estimates the favorability of bicycling as a mode of choice compared to the other modes, based upon household attributes and route experience. However, it does not model bicycle to transit trips.

Increased density and connectivity of the bicycle network, which includes trails, allow for increased access to regional destinations. Bus stops with high volumes of riders, as identified by TriMet, were designated as a type of regional destination. There is a Regional Destinations map in Appendix 10 of the ATP, identifying them as major attractors and trip generators. The map "Shows overlap of regional destinations with regional pedestrian, bicycle and frequent transit routes, city and town centers and station communities." (Oregon Metro 2013,40) Significant bus stops were defined as high ridership bus stops identified by TriMet. Model results indicated that increasing bike network density increases bicycle activity, and that bike mode share increases the most for commuting trips, suggesting the importance of connecting to jobs. The model outputs showed particularly strong bicycle travel in areas that offer many destinations, and along diagonal bicycle routes and on bridges that overcome barriers. In addition to a regional bicycle network, there also is a corresponding regional pedestrian network and public trails network that is recognized to serve a transportation function and is considered an important element of the bicycle and pedestrian networks. These facilities are intended to support the regional transit network. (Oregon Metro 2012, 71-72) Pedestrian trips are part of the regional model but a routable pedestrian network 
was not developed. Instead, the purpose of the pedestrian analysis was to map walking conditions to help identify opportunities where improvements are needed.

Like the bicycle network, there are also pedestrian facilities of different functional classes. These include pedestrian parkways, regional pedestrian corridors, and pedestrian districts. There are different design guidelines for different functional classes of pedestrian facilities. Similarly, to a bicycle district, a pedestrian district is an area with a concentration of transit, commercial, cultural, educational, institutional and recreational destinations where pedestrians want to go. A high amount of walking activity either exists and/or is planned within pedestrian districts. All transit station communities are pedestrian districts and so bus stops with high ridership may be designated as pedestrian districts in the future. There also is a functional classification for trails, including regional, community, and local or neighborhood trails.

A total of 82 pedestrian corridors were analyzed. They are planned to have a safe convenient walking environment, easy access to transit, and high density mixed use land development. Additionally, a total of 74 pedestrian districts and transit station communities were analyzed. For each of the 74 pedestrian districts and 82 pedestrian corridors, several factors were measured along a scale of one to five, in which one represents the least supportive environment and a five the most supportive. The factors measured were auto speed, auto volume, number of auto lanes, pedestrian and bicycle crashes, percentage sidewalk completion, percentage tree canopy, signalized crossings, and a measure of residential and employment density using a $1 / 4$-mile buffer around the pedestrian corridors. The results of the analysis can be used to identify pedestrian corridors and pedestrian districts that score particularly low, showing the reasons for the low scores and pointing to countermeasures and improvements to address those deficiencies.

Compared to the other case studies, this study made the greatest attempt to understand bicycle travel behavior and to use that insight to evaluate the bicycle network concepts. Oregon Metro's methodology provides a detailed description of bicycling conditions in cycle analysis zones based upon a rich database of information that other municipalities or regions might not have. Oregon Metro's approach is data intensive. Many municipalities do not have the data that were used in the evaluation process. Access to these data sets is necessary to replicate the evaluation process used by Metro Oregon. The development of model outputs creates a different data challenge. If any of the data needs to be collected, this approach may be time and resource prohibitive.

In addition to Oregon Metro's evaluation of the pedestrian districts and pedestrian corridors, the regional transit agency, TriMet had conducted its own pedestrian network analysis to identify barriers to pedestrian access to transit and opportunities for improvements at transit stops. (TriMet 2011) TriMet analyzed almost all of their transit stops (close to 7,000) using a GIS analysis and a scoring system that assigned points to each transit stop. A base analysis for each transit stop measured the level of passenger activity through developing a profile that included population and employment density, land use mix, street connectivity, ridership at the transit stop, transfer opportunities, and the locations of desired destinations close to the transit stop. An overlay for each transit stop was 
developed that identified deficiencies in the environment, such as missing sidewalks, as well as opportunities, such as urban renewal projects. The scores of the base analysis and overlay analysis were combined for each transit stop to result in a composite score. Clusters of high scoring transit stops were compared to Census tract maps showing areas with higher prevalence of low-income households and minority households to further identify areas where people are most transit dependent. A total of 621 transit stops were then shared with staff of local jurisdictions and criteria were established for the selection of the top ten transit stops upon which to focus. A transit advisory committee composed of stakeholders provided input to help select the top ten and to develop stakeholder support. ${ }^{2}$

For each of the top ten transit stops, a profile was developed addressing the following.

- Mapped conditions within 0.5 mile of the transit stop

- Places to access locally on foot

- Places to access regionally by transit

- 15-minute walking radius

- 15-minute radius covered by transit service

- Top five intersections near where riders board and alight transit

- Site visit observations

- Five key actions to improve the pedestrian environment

\section{H-GAC/METRO}

An example of a methodology for linking bicycling with public transportation comes from a joint study of the Houston-Galveston Area Council (H-GAC) in Houston, Texas, and the Metropolitan Transit Authority of Harris County (METRO) that serves a four-county region. The study, "Bike \& Ride Access \& Implementation Plan" considered both on-street bicycle facilities and trails. (Asakura Robinson Company LLC, Traffic Engineers, Inc., and Nancy R. Edmonson Transportation Consulting 2014) H-GAC is an association of local governments and elected officials in a 13county area known as the Gulf Coast Planning Region.

METRO found that while their overall ridership was decreasing, bike boardings on buses were increasing. Recognizing the potential for bicycle/transit connections to increase METRO ridership, the study was done to develop recommendations for improving those connections. This is a starting point that is almost opposite to WMATA's concern about a lack of station capacity due to increased ridership. The $\mathrm{H}-\mathrm{GAC} / \mathrm{METRO}$ study was focused upon transit patrons who access the station by bicycle and who prefer to take their bicycle with them on transit. While the development of improved bicycle facilities surrounding the major METRO transit nodes is outside METRO's control, the study identified several actions that the transit agency could take within transit property, including infrastructure enhancements, bike parking, on-vehicle provisions for bicycles, wayfinding, marketing and planning. The study also provided recommendations for interagency

\footnotetext{
2 For a more complete discussion about the Pedestrian Network Analysis Project, go to the TriMet Web page, "Better Walking Access to Transit." Accessed December 21, 2015. http://trimet.org/projects/pednetwork/index.htm\# report.
} 
coordination to advance connectivity improvements to the streets and trails that are near the transit nodes.

The H-GAC/METRO study sought to identify trends in the existing system, to receive input from system users, and learn from other transit agency best practices for integrating bicycling and transit. The methodology that was used to develop recommendations consisted of five main components.

AGIS spatial analysis was applied to look region wide at demographic characteristics that influence mode choice. A regression analysis was used to identify what factors are associated with more trips made by bicycles connecting to transit. Like Oregon Metro, $\mathrm{H}-\mathrm{GAC} / \mathrm{METRO}$ was interested in traveler behavior and preferences. They employed public engagement of both existing bicyclists and transit users, and those considering these modes. It was accomplished through a combination of an online survey, focus groups, an on-board bus survey, and public meetings. Like WMATA, case studies also were conducted of other public transit systems in the U.S. for transferable best practices in the areas of bikes on trains, bikes on buses, bike parking facilities, marketing, planning and evaluation.

Site visits were undertaken at selected transit nodes to develop recommendations for specific connectivity improvements. H-GAC/METRO used a similar strategy to WMATA by selecting representative transit stations to examine. WMATA created a typology of nine transit station types according to the anticipated needs of bicyclists and pedestrians that may vary by the type of rail station environment.

Alternatively, H-GAC/METRO selected 31 "transit nodes" which were a sampling of high service bus hubs, rail stations and park and ride lots that were geographically dispersed so that, for example, some transit nodes were in the downtown while others were in a suburban setting. To place priority on improving access by bicycle to METRO facilities that offer the highest potential for providing service, a matrix was developed to rate the 31 representative transit nodes according to two main reasons why bicyclists would want to connect to them. The first reason is that a transit node provides a high level of transportation service, and second, that a transit node provides connections to a destination of interest, accessible by bicycle. Criteria for each reason were developed for a scoring system. Points were added and the transit nodes scoring the most points were ranked as those that provide the most potential to improve connectivity for bicyclists. Recommendations for each transit node were described according to project description, timeframe of implementation, ease of implementation, estimated cost, and an identification of partners needed for coordination.

\section{Comparative Elements Used in the Development of a Methodology}

The discussion below is a synthesis of findings from the literature review and case studies in selecting those comparative elements for use in a methodology to apply to Hillsborough and Pinellas Counties. Table 1 below summarizes these characteristics.

It was demonstrated from the Cervero study (Cervero, Caldwell, and Cuellar 2013) that evidence exists that by providing bicycle infrastructure near rail stations, the bicycle-to-rail mode share increases. Making intermodal improvements makes a difference. It also was demonstrated by Cyclopath that the availability of 
multimodal bicycle/transit route-finding systems indicates a desire for multimodal routes. Since its deployment in the summer of 2011 approximately 15 percent of route requests were for multimodal routes. (Terveen 2013)

All of the methods used by the case studies are labor intensive. Part of the labor intensity of a methodology may be linked to its comprehensiveness. The question is how comprehensive must it be to determine the most useful result. If it can be known which socio economic factors best predict bicycling and walking activity or best represent areas that need the facilities the most, it might be favorable to keep the analysis simple by looking at fewer indicators. Such an approach might reduce the need for special equipment, reduce the types of data needed, and reduce the need for special expertise.

Oregon Metro's analysis found more bicycle trips near major destination areas and more bicycle trips where there are facilities that overcome barriers (i.e., bridges). H-GAC/METRO's analysis found that the shorter the bus service headway along the bus route, the more bike boardings per revenue mile. They also found that the higher the population density within the buffer area along the bus route, the more bike boardings per revenue mile. They found that the characteristics of the bus routes with high numbers of bicyclists boarding were those providing high frequency service, the presence of express service that carries bicyclists beyond barriers like freeways, and the longer length of the bus route. In short, more bicyclists are found accessing premium transit service, areas of high population density and major destinations, and on facilities that overcome a barrier, such as a bridge. These also tend to describe higher ridership routes.

\section{Selecting the Focus of the Study}

Each of the case studies had a different goal and used different combinations of methods. While all of the case studies included consideration of trails, none of the case studies had a primary trail-to-transit focus. The Houston-Galveston Area Council (H-GAC) was interested in providing bicycle access improvements to "transit nodes" that provide a high level of service. These are rail stations, transit transfer centers, and park-and-ride lots. The Washington Metropolitan Area Transit Authority (WMATA) and MetroPlan Orlando also were interested in prioritizing improvements to provide better access to rail stations. TriMet, the transit agency in Oregon Metro's planning area, also conducted bus stop assessments to identify and prioritize locations for needed access improvements. What these case studies have in common is the element that is stationary. Rail stops, and to a lesser degree, bus stops, remain in one location. Therefore, it is the area surrounding these locations that must provide for pedestrian and bicycle access to the transit stops. Likewise, in this study about connecting public trails to public transit, the locations of the public trails and the streets over which the trails cross will remain stationary. Those cross streets that provide transit service are the locations to consider and the focus 
of this study because the cross streets provide the intersections of the trail and the transit service.

\section{Searching for Best Practices}

Two of the case studies looked at best practices from elsewhere. This study also took advantage of reviewing methodologies from other transit agencies outside Florida.

\section{Using GIS Spatial Analysis}

All of the case studies used GIS spatial analysis and associated mapping to highlight attributes of the demographics of travelers, land use patterns, and transportation network. This study also used a GIS spatial analysis. Each case study from Task 2 utilized similar datasets to identify areas for locating and enhancing bike and transit connections. In general, all the case studies used transit service characteristics, demographic conditions and built environment characteristics. All the case studies in Task 2 utilized proximity to transit services as a measure for evaluation. Simple distance and proximity evaluations, frequency of service (MetroPlan Orlando, Oregon Metro), and activity levels at the stops (WMATA) were used. The case studies utilized these data in different ways, but the value and importance of existing transit service data is evident. For all the case studies, the local transit agency provided the bus stop data including ridership, service characteristics, and location information.

\section{Engaging Public Participation}

All of the case studies incorporated public participation to help guide the prioritization of locations and associated improvements. Public participation included collecting feedback from Web sites devoted to utilitarian and commuter bicyclists, bicycle and pedestrian advisory committees, transportation agencies, and other stakeholder groups, such as neighboring property owners and law enforcement, volunteer bicyclists participating in travel behavior studies, and surveys and meetings with bicycle and pedestrian organizations, the transit advisory committee, transit users, and the general public. This study sought input from the Hillsborough and Pinellas MPO BPACs and government agency staff.

\section{Establishing Typologies that Serve as a Guide}

WMATA has a strong rail system infrastructure with ridership approaching capacity and an extensive network of public trails that are aligned near many rail stations. Pinellas and Hillsborough Counties are still in the early stages of developing their transit systems and public trail networks. Each of the WMATA rail station areas are either located within high-density transit-oriented development districts or are stations that have large parking areas. The particular WMATA station area typologies poorly fit the characteristics of the bus route/trail connections in Hillsborough County and Pinellas County. Nonetheless, the WMATA rail station area typology is a concept that might be suited to other locations in Florida that have light rail systems, such as Orlando, Jacksonville, and the municipalities in Southeast Florida. In addition, the use of a typology was a way to generalize the operating conditions and attributes of the areas as they affect bicyclists and pedestrians, with general improvement concepts developed for each of the station types as a point of departure for developing specific recommendations from on-site observations. This 
is a concept that can be borrowed from the WMATA case study. It can be applied to the trail locations in Hillsborough County and Pinellas County by developing a typology suited to these transit/trail locations.

\section{Narrowing the Focus to a Manageable Number for Representation or Prioritization}

TriMet from the Oregon Metro planning area, H-GAC/METRO, and WMATA all used methods that narrowed the number of candidate transit stop locations to be evaluated. By applying a scoring system that focused upon high activity, high deficiencies, and high prevalence of low-income population, the focus upon the entire TriMet system of over 7,000 bus stops was reduced down to 621 stops, then finally the top ten locations. H-GAC/METRO's system wide study of all its transit stops reduced the focus to 31 high service transit nodes. WMATA narrowed its focus down from 86 rail stations to nine representative examples for the development of a means to evaluate them. In this study, a method to narrow the focus of intersections for further consideration was also used.

\section{Using a Prioritization Matrix}

The trail corridor constitutes all the potential locations for transit connections. Similarly with WMATA, their focus also was on a corridor. Years from now, when the proposed trail networks of Hillsborough and Pinellas Counties grow denser and the bus systems will have geographically expanded, there will be much more than two major trail spines. There will be denser networks of transit/trail intersections, requiring a more system wide approach that enables comparison of disparate locations and projects. The prioritization matrix and a scoring system was used for this purpose, like those used by MetroPlan Orlando, TriMet and H-GAC/METRO. A scoring system can include several criteria that are identified by the community and weighted to match their relative importance. At that future stage, it may be better for Hillsborough and Pinellas Counties to consider prioritizing improvements to transit/trail connections with greater emphasis upon the characteristics of the bus routes, such as those with higher ridership. A scoring system can also reflect policy decisions, such as whether to prioritize the completion of gaps in a trail-to-transit route, whether to prioritize serving areas with greater travel activity, or whether to prioritize improvements in underserved areas of the community that have few transit services and trail facilities.

\section{Conducting Site Visits}

Finally, all the case studies conducted on-site visits and observations of the selected locations. This study also conducted on-site visits. 
Table 1: Methodologies at a Glance: Case Study Comparisons for Evaluating Transit/Trail Connections for Identifying Improvements 


\begin{tabular}{|c|c|c|c|c|}
\hline $\begin{array}{l}\text { STUDY } \\
\text { ELEMENTS }\end{array}$ & $\begin{array}{l}\text { METROPLAN ORLANDO } \\
(\text { MPO) }\end{array}$ & WMATA (TRANSIT AGENCY) & $\begin{array}{l}\text { OREGON METRO (MPO } \\
\text { WITH RESULTS FROM } \\
\text { TRANSIT STUDY) }\end{array}$ & $\begin{array}{l}\text { H-GAC/METRO (MPO-LED WITH } \\
\text { TRANSIT AGENCY PARTNER) }\end{array}$ \\
\hline \multirow[t]{2}{*}{ Study goal } & Reduce SOV mode share. & $\begin{array}{l}\text { Change mode of travel to rail stations from } \\
\text { motor vehicle to non-motorized. }\end{array}$ & $\begin{array}{l}\text { Increase physical activity, } \\
\text { access, safety, and equity. }\end{array}$ & $\begin{array}{l}\text { Increase METRO ridership by } \\
\text { improving bicycle to transit } \\
\text { connections. }\end{array}$ \\
\hline & $\begin{array}{l}\text { Close system gaps by selecting } \\
\text { municipal bike/pedestrian } \\
\text { project applications with priority } \\
\text { on supporting transit emphasis } \\
\text { corridors; select municipal trail } \\
\text { project applications that improve } \\
\text { regional network and improve } \\
\text { intermodal connections as a } \\
\text { minor consideration. }\end{array}$ & $\begin{array}{l}\text { Identify physical and programmatic } \\
\text { improvements to encourage walking and } \\
\text { bicycling to the station. }\end{array}$ & $\begin{array}{l}\text { Long range plan to develop a } \\
\text { complete regional bicycle } \\
\text { network and a complete } \\
\text { pedestrian network so that } \\
\text { modes can function } \\
\text { independently. } \\
\text { Identify and prioritize gaps to } \\
\text { be filled, with consideration } \\
\text { given to intermodal } \\
\text { connections with transit. }\end{array}$ & $\begin{array}{l}\text { Provide infrastructure enhancements, } \\
\text { bike parking, on-vehicle provisions for } \\
\text { bicycles, wayfinding, marketing and } \\
\text { planning. Partner with host } \\
\text { municipalities to advance connectivity } \\
\text { improvements to the streets and } \\
\text { trails. }\end{array}$ \\
\hline $\begin{array}{l}\text { Methodological } \\
\text { Elements }\end{array}$ & $\begin{array}{l}\text { GIS analysis. } \\
\text { Prioritization matrix of weighted } \\
\text { criteria. } \\
\text { Criteria included regional } \\
\text { importance of the trail (longer } \\
\text { trails that connect to other trails, } \\
\text { cross jurisdictional boundaries, } \\
\text { serve significant destinations, } \\
\text { serve an underserved area), the } \\
\text { existence of a local match, trail } \\
\text { surface type, project readiness, } \\
\text { economic development potential, } \\
\text { intermodal connectivity. } \\
\text { Number of bus stops or rail } \\
\text { stations directly served, } \\
\text { connection to other facilities that } \\
\text { connect directly to transit, } \\
\text { headways of bus and rail service } \\
\text { that can be accessed by the } \\
\text { trail, and maximum number of } \\
\text { buses or trains served by a } \\
\text { single stop or station per day } \\
\text { served directly or indirectly by } \\
\text { the trail projects. }\end{array}$ & $\begin{array}{l}\text { GIS analysis. } \\
\text { Bike shed analysis of 3-mile radius of rail } \\
\text { stations for near term, mid-term and long term } \\
\text { improvement recommendations. } \\
\text { Station area typology representing range of } \\
\text { conditions encountered by bicyclists and } \\
\text { pedestrians. }\end{array}$ & $\begin{array}{l}\text { Region wide GIS analysis. } \\
\text { Application of a bicycle travel } \\
\text { demand model (does not } \\
\text { model bicycle to transit trips). } \\
\text { Use of a hierarchical functional } \\
\text { class system for pedestrian } \\
\text { facilities and bicycle facilities } \\
\text { that includes regional trails, } \\
\text { and design guidelines for each. } \\
\text { Transit stop assessment using } \\
\text { prioritization scoring system. }\end{array}$ & $\begin{array}{l}\text { Region wide GIS analysis to look at } \\
\text { what influences mode choice. } \\
\text { Regression analysis to identify factors } \\
\text { associated with more trips made by } \\
\text { bicycles connecting to transit. } \\
\text { Conduct of case studies of other } \\
\text { public transit systems in the U.S. } \\
\text { looking for transferable best practices. } \\
\text { Site visits at } 31 \text { representative transit } \\
\text { nodes to develop recommendations } \\
\text { for specific connectivity } \\
\text { improvements. }\end{array}$ \\
\hline
\end{tabular}




\begin{tabular}{|c|c|c|c|c|}
\hline $\begin{array}{l}\text { STUDY } \\
\text { ELEMENTS }\end{array}$ & $\begin{array}{l}\text { METROPLAN ORLANDO } \\
(\text { MPO) }\end{array}$ & WMATA (TRANSIT AGENCY) & $\begin{array}{l}\text { OREGON METRO (MPO } \\
\text { WITH RESULTS FROM } \\
\text { TRANSIT STUDY) }\end{array}$ & $\begin{array}{l}\text { H-GAC/METRO (MPO-LED WITH } \\
\text { TRANSIT AGENCY PARTNER) }\end{array}$ \\
\hline $\begin{array}{l}\text { Public } \\
\text { participation }\end{array}$ & $\begin{array}{l}\text { Web site devoted to utilitarian } \\
\text { and commuter bicyclists. } \\
\text { Bicycle and pedestrian advisory } \\
\text { committee. }\end{array}$ & $\begin{array}{l}\text { Meetings with stakeholder groups. } \\
\text { Interviews with other transit agencies for best } \\
\text { practices. }\end{array}$ & $\begin{array}{l}\text { Observational studies using } \\
\text { volunteer bicyclists. } \\
\text { Support from The Intertwine } \\
\text { Initiative Transit advisory } \\
\text { committee. }\end{array}$ & $\begin{array}{l}\text { Public engagement of both existing } \\
\text { bicyclists and transit users, and those } \\
\text { considering these modes, } \\
\text { accomplished through a combination } \\
\text { of an online survey, focus groups, an } \\
\text { on-board bus survey, and public } \\
\text { meetings. }\end{array}$ \\
\hline $\begin{array}{l}\text { Study } \\
\text { Elements }\end{array}$ & $\begin{array}{l}\text { MetroPlan Orlando } \\
\text { (MPO) }\end{array}$ & $\begin{array}{l}\text { WMATA } \\
\text { (transit agency) }\end{array}$ & $\begin{array}{l}\text { Oregon Metro } \\
\text { (MPO with results from } \\
\text { TrANSIT study) }\end{array}$ & $\begin{array}{l}\text { H-GAC/METRO } \\
\text { (MPO-led with transit agency partner) }\end{array}$ \\
\hline $\begin{array}{l}\text { Site } \\
\text { observation }\end{array}$ & none & yes & yes & Yes \\
\hline $\begin{array}{l}\text { Adaptability to } \\
\text { Florida } \\
\text { communities }\end{array}$ & $\begin{array}{l}\text { Adaptable in that a community } \\
\text { can identify its own criteria of } \\
\text { value and assign weights. }\end{array}$ & $\begin{array}{l}\text { Directly adaptable for communities with rail } \\
\text { systems. Also, can substitute a trail spine for a } \\
\text { rail line and develop a trail crossing typology. }\end{array}$ & $\begin{array}{l}\text { Would require extensive data } \\
\text { collection and analysis. }\end{array}$ & $\begin{array}{l}\text { With sufficient resources, all elements } \\
\text { of the methodology could be } \\
\text { borrowed and tailored to another } \\
\text { community's characteristics and } \\
\text { priorities. }\end{array}$ \\
\hline $\begin{array}{l}\text { Labor } \\
\text { intensiveness }\end{array}$ & $\begin{array}{l}\text { Applicants for funding do much } \\
\text { of the field work, while } \\
\text { MetroPlan evaluates the } \\
\text { applications. }\end{array}$ & $\begin{array}{l}\text { Labor intensive with regard to site observations } \\
\text { but periodic assessments can build off the initial } \\
\text { base line data gathering. }\end{array}$ & $\begin{array}{l}\text { Labor intensive to do } \\
\text { observational studies on travel } \\
\text { behavior and development of } \\
\text { bicycle travel model. }\end{array}$ & $\begin{array}{l}\text { Labor intensive to design, administer } \\
\text { and analyze multiple survey } \\
\text { instruments. } \\
\text { Labor intensive with regard to site } \\
\text { observations but periodic assessments } \\
\text { can build off the initial base line data } \\
\text { gathering. }\end{array}$ \\
\hline $\begin{array}{l}\text { Expertise } \\
\text { required }\end{array}$ & $\begin{array}{l}\text { GIS analysis capabilities, use of } \\
\text { data from travel demand model, } \\
\text { familiarity with spreadsheets. } \\
\text { Assignment of scores } \\
\text { qualitatively determined by } \\
\text { BPAC subcommittee. }\end{array}$ & $\begin{array}{l}\text { Experiential knowledge and expertise in } \\
\text { commuter bicycling, pedestrian safety, trail and } \\
\text { roadway design and traffic control. } \\
\text { GIS analysis capabilities. }\end{array}$ & $\begin{array}{l}\text { Travel demand modeling and } \\
\text { GIS analysis capabilities. }\end{array}$ & $\begin{array}{l}\text { Knowledge of survey design and } \\
\text { regression analysis. }\end{array}$ \\
\hline
\end{tabular}




\begin{tabular}{|c|c|c|c|c|}
\hline $\begin{array}{l}\text { STUDY } \\
\text { ELEMENTS }\end{array}$ & $\begin{array}{l}\text { METROPLAN ORLANDO } \\
(\text { MPO) }\end{array}$ & WMATA (TRANSIT AGENCY) & $\begin{array}{l}\text { OREGON METRO (MPO } \\
\text { WITH RESULTS FROM } \\
\text { TRANSIT STUDY) }\end{array}$ & $\begin{array}{l}\text { H-GAC/METRO (MPO-LED WITH } \\
\text { TRANSIT AGENCY PARTNER) }\end{array}$ \\
\hline Data intensity & $\begin{array}{l}\text { Population density and } \\
\text { employment intensity. } \\
\text { Magnitude of trip making activity } \\
\text { by Traffic Analysis Zone. } \\
\text { Complete facilities inventories. } \\
\text { Bicycle suitability data for } \\
\text { Bicycle LOS Model. } \\
\text { Public transit stops and routes } \\
\text { data. }\end{array}$ & $\begin{array}{l}\text { Examination of all available routes to the } \\
\text { station. } \\
\text { Traffic volumes, motor vehicle speed, slope, side } \\
\text { street linkages. } \\
\text { Population density and employment intensity } \\
\text { surrounding the station. } \\
\text { Average daily ridership, mode split, volumes of } \\
\text { different modes accessing the station. } \\
\text { Station size, orientation, layout. } \\
\text { Surrounding transportation network layout. } \\
\text { Number and type of destinations accessible } \\
\text { within walking distance } \\
\text { Bicycle counts, bike parking supply, usage. } \\
\text { Station parking counts. }\end{array}$ & $\begin{array}{l}\text { Auto speed, auto volume, } \\
\text { number of auto lanes, } \\
\text { pedestrian and bicycle crashes, } \\
\text { percentage sidewalk } \\
\text { completion, percentage tree } \\
\text { canopy, signalized crossings, } \\
\text { and a measure of residential } \\
\text { and employment density using } \\
\text { a } 1 / 4 \text {-mile buffer around the } \\
\text { pedestrian corridors. } \\
\text { Bicycle facility and trail } \\
\text { inventory. } \\
\text { Network density, connectivity, } \\
\text { household attributes. } \\
\text { Bicycle and pedestrian count } \\
\text { data. } \\
\text { Observational studies. }\end{array}$ & $\begin{array}{l}\text { Motor vehicle traffic count data, } \\
\text { intersection density, major } \\
\text { destinations, street and off-road } \\
\text { bicycle facilities, wayfinding signage, } \\
\text { bicycle crash locations, population } \\
\text { density and employment intensity, } \\
\text { characteristics of transit nodes, } \\
\text { including multiple bus routes, access } \\
\text { to express service, headways, long } \\
\text { distance routes, bicycle parking, bike } \\
\text { boardings by transit route, self- } \\
\text { reported travel behavior, self-reported } \\
\text { travel preferences. }\end{array}$ \\
\hline $\begin{array}{l}\text { Special } \\
\text { equipment } \\
\text { needed }\end{array}$ & $\begin{array}{l}\text { GIS software, spreadsheet } \\
\text { software. }\end{array}$ & GIS software, roadway survey tools. & $\begin{array}{l}\text { Travel modelling software, GIS } \\
\text { software, GPS devices. }\end{array}$ & $\begin{array}{l}\text { GIS software, statistical software, } \\
\text { spreadsheet software. }\end{array}$ \\
\hline
\end{tabular}




\section{Chapter Three}

Specification and Characterization of Study Areas in Hillsborough and Pinellas Counties

As the subject of methodology development for addressing connectivity between trails and public transit service, the Florida Department of Transportation selected Hillsborough County and Pinellas County as the study locations for illustrative purposes. Pinellas County, Florida, is located along the Gulf Coast, in the west 
central part of the state. Hillsborough County is adjacent to and directly east of Pinellas County. This area is shown in Figure 3.

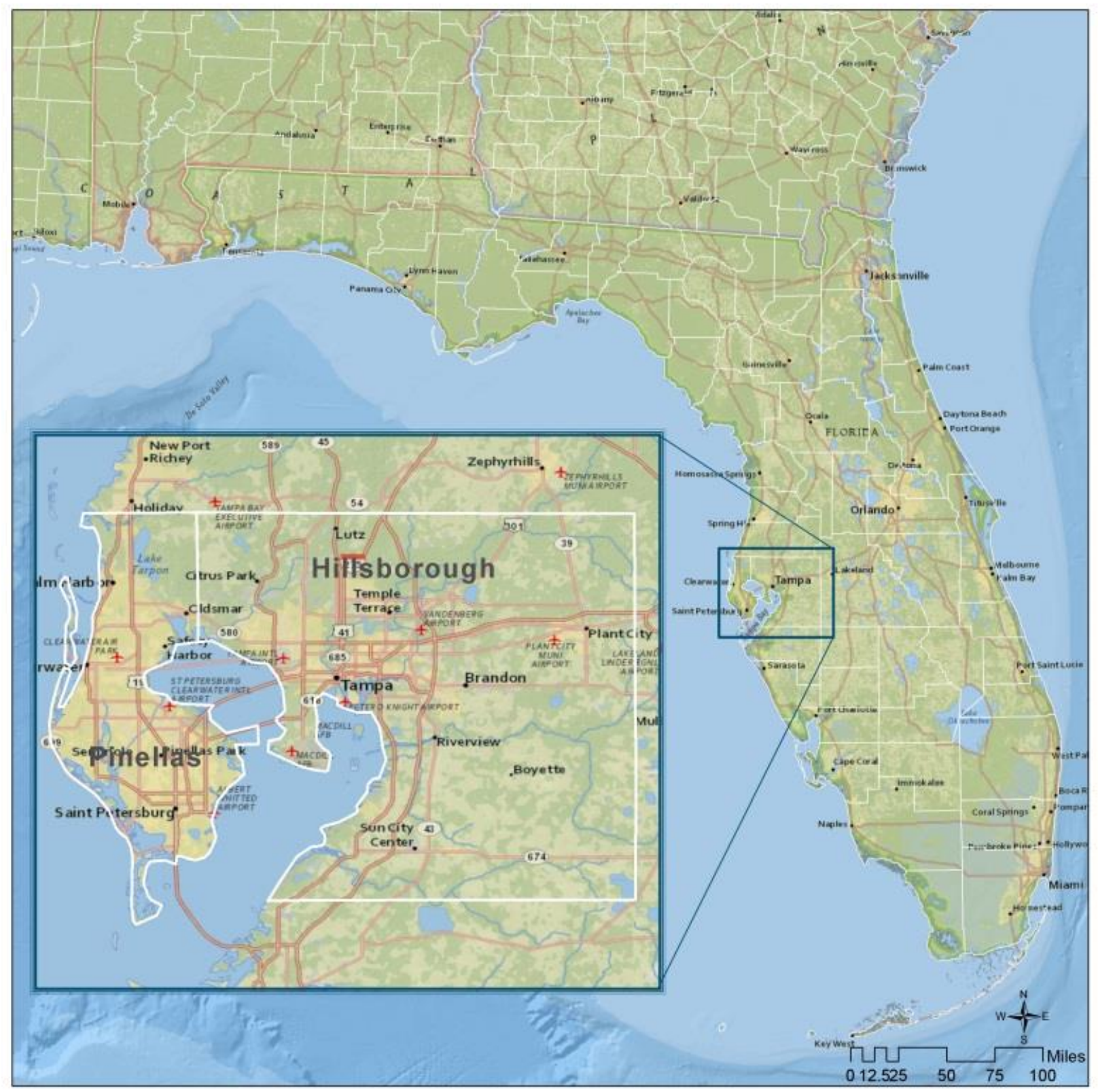

Figure 3: The study area includes Hillsborough and Pinellas Counties, Florida.

The Task 3 Memorandum included a summary from a detailed review of planning documents describing existing, planned and programmed public trails and greenways, sidewalks and on-street bicycle facilities in the study area. There was a description of the existing trail networks and transit systems. For both counties, maps were created illustrating the existence of official public trails, and greenways, overlaid with fixed route public transportation service. Maps also were developed to illustrate demographic characteristics of existing and potential travelers. Portions of the Task 3 memorandum that describe the methodology are included below. 


\section{Information Sources}

Information sources used for both Hillsborough and Pinellas Counties included the local government comprehensive plan, the transit development plan, and community master plans. The Metropolitan Planning Organizations (MPO) for both Hillsborough and Pinellas Counties were the primary data sources for the investigation. These included the MPO long-range transportation plans and associated transportation improvement programs. Greenways and public trails, particularly those that lend not only recreational but also transportation value, often cross jurisdictions and MPOs maintain regional data. Federal grants allocated through the metropolitan transportation planning process also are a large source of funding for public transit, public trails and greenways, and bicycle and pedestrian facilities.

Information sources also included planning documents and maps of parks and conservation departments, government departmental Web pages, newsletters of MPO committees, such as Livable Roadways and the Bicycle and Pedestrian Advisory Committees (BPAC), and BPAC meeting minutes. Input was received from the MPO BPAC technical support staff and BPAC committee members, transit agency planners, and parks and conservation staff. Data sources were identified for the identification of existing, proposed, and programmed trail facilities and public transit service. Data sources also were identified and considered for characterizing the demographics of existing and potential travelers. The selection and use of data is discussed below.

\section{Trail System Description}

Both Hillsborough and Pinellas Counties have a history of public trail planning. For example, the Fred Marquis Pinellas Trail, a 47-mile multi-use path that runs north/south along the western side of Pinellas County, celebrated its $25^{\text {th }}$ anniversary in December 2015. In 1989, the Penny for Pinellas sales tax allocated three percent of its raised revenue toward sidewalk and trail improvements, including the Pinellas Trail. In 1995, the Pinellas Board of County Commissioners adopted Comprehensive Plan policies to include striped four-foot bicycle lanes as part of roadway construction projects, where possible. (Pinellas County 2012, 4-2) The Penny Extension in 1997 allocated six percent toward sidewalk and trail improvements. The Penny for Pinellas was extended a second time in 2007 that will cover projects to 2020. Since then, The Pinellas County MPO has considered the application of a consistent approach to trail crossings with roadways, based upon a design handbook commissioned by the Florida Department of Transportation. (University of North Carolina Highway Safety Research Center 1999) Additionally, a Crossing Treatments Methodology was developed for assigning priority and traffic control at the intersection of shared use paths and roadways. (Petritsch and Fellerhoff 2014)

In Hillsborough County, the Hillsborough Greenways Master Plan was developed in 1995 to articulate a vision for a county-wide system of greenways (Hillsborough County Planning and Development Management Department 1995). While conceived primarily as recreation and nature corridors, the planning process did consider the potential of greenways to provide alternative transportation. Today the Upper Tampa Bay Trail that was one of five originally identified recreation 
corridors in the 1995 Plan now provides 7.3 miles of continuous trail with another 4.35 miles now under construction. ${ }^{3}$

The trail systems of both counties are planned to connect to the wider regional and statewide public trail system in Florida. This system is guided by the Florida Greenways \& Trails System (FGTS) Plan. (Florida Office of Greenways and Trails 2013) The Opportunity Maps that correspond to the FGTS Plan are currently being updated. In the FGTS Plan, transportation is recognized as one of the functions for the statewide system. This statewide paved multi-use (non-motorized) trail system is envisioned to allow someone to walk or bicycle along both coasts of Florida and connect to several east-to-west trail corridors. The "FGTS Plan Opportunity Map" (2012) shows the Pinellas Trail potentially connecting to the south to the Skyway Connector Corridor and beyond to the Southwest Coast Connector. To the north, the Pinellas Trail is proposed to connect to the Coast to Coast Connector that would cross Florida and connect to the East Coast Greenway that runs the length of the Atlantic coast of Florida. Likewise, the planned greenways in Hillsborough County could reach beyond county lines in all four directions. (Florida Office of Greenways and Trails 2012, 9)

\section{Trail Planning in Pinellas and Hillsborough Counties Pinellas County}

The Pinellas MPO Bicycle Pedestrian Master Plan (2013a) is intended to facilitate the development of a network of bicycle and pedestrian facilities that maximizes opportunities for people to get around the County by foot and bicycle. The proposed facilities contained in the Plan were selected based upon their location on rights-of-way on the major road network, made up of principal and minor arterials and collector roads. Pinellas County is divided into 14 planning sectors. A map for each sector illustrates proposed sidewalks, bike lanes and trails. Trail facilities include community trails that are maintained by the municipalities, the Pinellas Trail, and the Pinellas Trail Loop. The Pinellas Trail is considered to be the core of the County trail network. The community trails are meant to serve as connectors to the Pinellas Trail Loop. Locations for facilities were evaluated by the Pinellas MPO based upon right-of-way, pavement widths, speed limits and traffic volumes. Proposed trail facilities include those from the Pinellas Trailways Plan of the Pinellas MPO 2035 Long Range Transportation Plan (2013b, Figure 26) and other facilities that were recommended to improve connectivity within the network and to important destination points such as beaches, employment centers, shopping malls and schools. These included locations along right-of-way corridors not occupied by a paved road, which provide connections to existing or planned bike lanes or trails. Maps for each planning sector illustrating the proposed facilities show "Transit Station/Terminal" as one of 14 trip destination types listed in the map legend (Pinellas MPO 2013a).

The "2014 Pinellas State of the System (SOS) Report" provided an overall count of the number of trail users. The most recent tally was 618,188 Pinellas Trail users in 2013. (Pinellas MPO 2015a, 54) Recently, Pinellas County purchased five

3 "Upper Tampa Bay Trail." Hillsborough Parks, Recreation and Conservation Department website, description of current Upper Tampa Bay Trail Phase IV Section C construction. Accessed December 21, 2015. http://www.hillsboroughcounty.org/index.aspx?NID=3497. 
monitoring devices for the Pinellas Trail to count the number of runners, bikers and walkers who use the trail. These are infrared monitors that can differentiate direction of travel and whether the individual was walking or bicycling. Three sensors are permanently mounted in the north, central, and south locations of the trail, and two monitors are portable.

The Pinellas MPO recently applied for and was awarded a grant from The National Centers for Disease Control. This is a program to award grants for the development of Partnerships in Community Health (PICH), a competitively awarded grant opportunity for urban areas, rural areas, and Native American tribal organizations. The purpose of the 3-year initiative is to improve health and reduce the burden of chronic diseases through the work of multi-sector community service coalitions. PICH supports population-based strategies to expand the reach and health impact of the policy, systems, and environmental (PSE) improvements. The program is to advance the federal Healthy People 2020 Vision. Awardees develop Community Health Improvement Plans (or Community Action Plans) that incorporate Risk Factor Related Population-Based Strategies. These Strategies include improved access to healthy food and beverage options, improved access to physical activity options, and improved clinical and community linkages. The Pinellas MPO applied for and was awarded one of these grants in the spring, 2015, administered through the FL Department of Health, to identify improvements that will increase access to physical activity. The scope of work identifies, evaluates, and prioritizes projects to improve access to Pinellas County parks and the Pinellas Trail. Projects will include completing gaps in sidewalk network, installing bike lanes, and improving signage and wayfinding. (Pinellas MPO 2015b)

\section{Hillsborough County}

The "Hillsborough County Bicycle \& Pedestrian Counts, 2000 \& 2005" report (Tindale Oliver and Associates, Inc. 2005), conducted for the Hillsborough County MPO, contains collected nonmotorized travel count data for both years at selected intersections. Four of these intersections were in the general vicinity of the study area. These included Ehrlich Road at Gunn Highway, West Waters Avenue at Hanley Road, West Linebaugh Avenue at Anderson Road, and Montague Street at Waters Avenue. These counts for both years were conducted on a weekday in spring. The data showed increases in observed bicycle and pedestrian activity. Most of the bicycle and pedestrian activity was observed between 9 a.m. and 4 p.m., the Ehrlich Road and Waters Avenue locations being in the top four intersections that indicated the largest increases in bicycle and pedestrian activity. The report cites the completion of a four-mile portion of the Upper Tampa Bay Trail as a possible major reason for the increases. A larger number of nonmotorized users at the Ehrlich Road at Gunn Highway intersection was observed to be seniors during the latter part of the day.

The Hillsborough County MPO 2025 Comprehensive Pedestrian Plan, Final Report (Hillsborough County MPO 2004) calls for the promotion of better access to public transportation. The assessment of pedestrian demand did not identify the Town ' $N$ Country area, the selected general subarea location for this study, as having high pedestrian demand, based upon the presence of pedestrian attractors. However, Hanley Road between Hillsborough Avenue and Waters Avenue was identified as an Unfunded Priority Pedestrian Corridor. Hillsborough Avenue between Memorial 
Highway and Dale Mabry Highway was identified as a Cost Affordable Pedestrian Priority Corridor. Some pedestrian counts were conducted at selected intersections. Pedestrian facility connectivity to transit focused upon sidewalks and not trails.

While Pinellas MPO has considered transit stations as one of 14 different destination types in the identification of proposed locations for on-road and off-road nonmotorized facilities, and both Hillsborough and Pinellas MPOs recognize the development of multimodal systems as long range transportation planning goals, the explicit connectivity planning of trails with public transit has not yet been systematically studied. This was found to be the case of most urban areas in the United States, based upon the literature review and case study development. Likewise for the Tampa Bay area, the "2010 Regional Multi-Use Trails Map of the West Central Florida MPO Chairs Coordinating Committee" (2011) shows a list of Regional Bicycle and Pedestrian Attractors. These are largely beaches, parks, piers, memorials and other cultural facilities. Transit centers or services are not listed. The "Hillsborough Greenways System Greenway Recreational Corridors Map" (Hillsborough County 2011) does not show transit facilities or services, nor does the "Multi-Use Trails, West Central Florida Regional Priorities" map (Hillsborough County MPO 2014a) indicate transit facilities.

The Hillsborough MPO "Interactive Bicycle Suitability Map" (2015) does not show bicycle facilities relative to transit services. The "Hillsborough County Trails and Bike Facilities, Existing, Planned Conceptual" map (Tindale Oliver and Associates, Inc. 2015) for the Tampa-Hillsborough Greenways and Trails Plan Update does not include transit services. The Tampa Bay Area Regional Transportation Authority (TBARTA) has identified multimodal transportation priorities for horizon year 2040. These include multi-use trails; however, the maps do not illustrate connectivity of trails with other modes. (TBARTA 2015)

Most recently, the Imagine 2040: Hillsborough Long Range Transportation Plan was adopted November 14, 2014, with most recent revisions, dated December 9, 2015. The planning process for this new Plan included the development of multiple investment scenarios for a multimodal system, including "Real Choices When Not Driving." These included low, medium and high investment-level scenarios for enhanced transit service and for trails and side paths. Mapping for planned and potential trails and side paths included transit transfer centers in the map legend. (Hillsborough County MPO 2014b, Figure 3-23) The update cycle for MPO long range transportation planning also coincided with the update process for the Hillsborough County comprehensive plan. Goal \#1 of the update for the Transportation Section of the Hillsborough County Comprehensive Plan is to develop an integrated multimodal transportation system. (Hillsborough County 2015) Final adoption of the comprehensive plan is anticipated in 2017. In addition, HART began a promotion for the month of October 2015, offering a free month of Coast Bike Share with the purchase of a 31-day HART fare card. This is to serve the first milelast mile connectivity to HART bus stops.

\section{Discussions with Agency Representatives}

The research team contacted agency representatives for bicycle and pedestrian planning, transit planning, parks and recreation, greenway and livable roadways planning, and the GIS departments for Pinellas and Hillsborough MPOs. One 
comment made by the staff for the Hillsborough Bicycle and Pedestrian Advisory Committee is that by virtue of the composition of members of the BPAC, discussions are uncommon about the needs of transit patrons and their ability to access public transit by walking and bicycling.

The research team met with both BPACs for the Hillsborough and Pinellas County MPOs and queried them regarding what should be the priority reasons for connecting public transit with public trails. They were also asked to provide ideas on particular transit/trail locations, general areas, and communities or neighborhoods they thought should serve as a focus for transit trail planning. They were also asked to forward any other contacts, such as community activists or leaders, trail users or transit riders who might be willing to speak with the research team about transit/trail connectivity.

A technical support staff member from the Pinellas County Parks and Conservation Resources Department who also serves on the Pinellas BPAC said that the key challenges in Pinellas County include not only a lack of adequate bicycle and pedestrian accommodations on several bridges to the beaches, but also the general lack of trails that run east to west. He said that the main priorities for connecting public transit with trails should be to increase access and connectivity in areas where infrastructure and transit service is poor. Another top priority is to reduce dependency on car/bus transportation by establishing safe connections for bicyclists and pedestrians. Members of the Pinellas BPAC emphasized the need for bicycle parking as a means to enable more people to bicycle for transportation.

A PSTA planner said that staff had wanted to produce an analysis to identify the number of trail connections within $1 / 4$ mile and $1 / 2$ mile of both the PSTA core routes and the supporting local routes. However, a lack of resources had prevented them from further considering transit connections to trails.

The Hillsborough BPAC technical support planner said that the concept of trails connectivity with public transportation has been discussed by Hillsborough County planning staff, in concept, but no studies have been conducted. There also were discussions with the Chair of the Hillsborough BPAC, a representative of the GreenARTery in Tampa, and the City of Tampa Bicycle and Pedestrian Planner. The Chair of the Hillsborough BPAC emphasized that a priority for transit/trail connectivity should be to increase access to jobs, education, retail, etc. by underserved communities. She also suggested that the Keystone Recreation Center and the Austin Davis Library at Gunn Highway and Wayne Road in Hillsborough County, adjacent to the new Upper Tampa Bay Trail north could be a good future park and ride connection from Pasco County to Hillsborough County.

\section{Description of Methodological Approach}

With an overall goal of improving community livability, the methodological approach developed in this study has focused upon improving transit connections with public trails. This is to improve access and connectivity to destinations desired by travel markets of interest to transit planners. Figure 4 illustrates the steps of the process.

The counties constituting the study area were selected for illustrative purposes. The selection of analysis tools is somewhat influenced by the characteristics of the study area. For example, a hierarchical functional class system of bicycle and 
pedestrian facilities, as was used by Oregon Metro might be premature in areas without a vision for such well-developed bicycle and pedestrian networks. It also may depend upon the existing available data or the level of funding allocated to the planning effort. For example, the development of a bicycle travel demand model, like that used by Oregon Metro, but which also would include the added modeling of bicycle-to-transit trips, would be ideal but would also require funding an ongoing program of bicycle trip counting. For this study, it was assumed that most planning areas in Florida will not yet be ready to undertake the development of a bicycle travel demand model.

The use of a prioritization matrix or scoring system with weighted criteria, as discussed previously, appears handy in cases where there are a large number of locations to evaluate and rank as most important for improvements. It also is handy where there are many factors that should be considered in the decision making. Use of a scoring system would produce best results in conjunction with a carefully moderated public involvement process to identify factors that are important to the community and in the determination of the factors' importance relative to each other. Use of such a scoring system also depends upon an investment in the collection of similar data for all the potential locations evaluated. The prioritization matrix or scoring system using weighted criteria would be a good approach to consider for use in the future when the public trail systems and public transit systems are further along in their development.

The recommended methodological approach presented in this study includes borrowing several elements from the case studies. These include the search for best practices from other localities, use of a GIS spatial analysis, engaging public participation, the application of a typology to help with organizing and prioritization, and the use of site visits and observation. The main steps in the recommended method for linking greenways and trails with public transportation is listed in chronological order below, with the aim of creating a consistent, uniform and repeatable approach.

The study methodology is different from the case study methodologies in that it assesses the value of the connection made between transit and the trail, based upon its location within a subarea that defines a desired travel area connecting origin to destination. 
Select a community goal as defined by travel market and trip purpose.

Map trail network.

Map transit routes and location of transit stops near trails.

Identify data sources to describe location of travel market(s) and trip destination(s).

Map origins of selected travel market(s) and destination(s) by trip purpose to identify areas of greater concentration of both.

Define the subarea within which travel is likely to take place between origiin and destination.

Develop a typology that organizes identified trail/transit intersections into sets having similar characteristics.

Conduct site observations and inventories, with recommendations for strengthening transit/trail connections at selected sites.

Figure 4: Steps in the method for linking greenways and trails with public transportation

\section{Seek Community Input}

One difference of the recommended approach from the case studies is that it starts with the selection of a transportation goal of importance to the community as defined by a particular travel market and trip purpose. There are many different possible goals to improve access and connectivity for improving livability. Such a goal can be found in the community's local government comprehensive plan transportation element, as well as in the development of the MPO long range transportation plan where regional facilities are considered. The goal also might be more specifically articulated by public input, for example, through public workshops, surveys or a community's bicycle and pedestrian advisory committee (BPAC). For purposes of expediency in this study, public input was received from the MPO BPAC technical support staff and BPAC committee members, transit agency planners, and parks and conservation staff. Other public participation 
strategies used in the case studies include the maintenance of Web sites developed for the purpose of informing the public and receiving feedback, surveys, stakeholder meetings, the transit advisory committee, input from related interest groups, such as bicycle clubs, and engaging volunteers from the public to help in data collection efforts. With the use of some combination of these tools, the collection and use of community input should guide the course of the study in an ongoing manner, from start to finish.

\section{Select a Community Goal as Defined by Travel Market and Trip Purpose}

Reflecting community preferences, planners can choose to define the traveler market of interest as narrowly or as broadly as they wish. Transit/trail connections can serve the gamut of travel markets as well as different trip purposes. For example, planners could select certain characteristics of individuals that might define them as more likely candidates for bicycling and riding public transit, such as those who already bicycle or ride transit, those in zero car households, those in low-income households, and college students.

Areas with large concentrations of low-income households may use transit/trail connections to access more job opportunities. Another example of a traveler market is senior citizens. Seniors today are more physically active than previous generations. They desire better access to recreational facilities for which purpose better transit/trail connections may serve. If the senior population is a targeted travel market of interest, assisted living communities could potentially be identified as locations where large concentrations of elderly live and from where their trips begin. Another example might be populations residing in suburban areas just beyond where public transit serves. These areas are automobile dependent. Trail locations that extend outward from urban areas can provide a link connecting these suburban neighborhoods to public transit service. Depending on the context, there may be specific trip origins of interest, such as the location of community redevelopment areas or in the case of student populations, the locations of colleges and universities.

For purposes of illustrating the analysis approach based upon accomplishing a community goal, the researchers decided to select three target markets and their associated trip purposes. One example goal, selected for illustrative purposes in this study, is to help people of lower incomes connect with job opportunities. The selection of lower income persons as a travel market and the work travel purpose to define key destinations aligns well with comprehensive planning goals of both Hillsborough County and Pinellas County. This also is a travel market of interest to both the Hillsborough BPAC and the Pinellas BPAC, based upon their input. A second example goal, illustrated below with GIS spatial analysis, is to help senior citizens access recreational opportunities. A third example goal, also illustrated below, is to help adult studentsto access school campuses.

If the travel market of interest is defined broadly, then the location of trip origin of these markets will also likely be more dispersed. As a result, the travel area of interest between trip origins and destinations might be quite large. A broader definition of travel market and trip purpose to analyze will likely result in the identified number of candidate trail/transit connections to be much larger. This is not a problem if planners have sufficient time and staff resources to examine a 
larger number of candidate locations. An alternative is to iteratively analyze trip origins and destinations of multiple travel markets, as is demonstrated in this study.

\section{Map the Trail Network}

In unincorporated Hillsborough County, there are several existing trails, including the Upper Tampa Bay Trail, the Suncoast Trail, the Brandon Parkway Trail, the Bruce B. Downs Trail, the Old Fort King Trail, and the Town 'N Country Greenway Trail. The City of Tampa has 64 miles of trails that include hiking trails, on-road bike lane, and off-road multi-use trails. In Pinellas County, the most well-known trails include the Fred Marquis Pinellas Trail, the Pinellas Trail Loop that includes the Duke Energy Florida Trail, and numerous smaller community trails maintained by municipalities. The trail systems of Pinellas and Hillsborough Counties, including the existing trails and plans for expansion of the trail systems are described in depth in the Task 3 Memorandum. In Hillsborough and Pinellas Counties, county government and the MPOs play a prominent role in coordinating trail development. Data for existing and future programmed trails were acquired from the municipalities, counties and MPOs and evaluated to ensure up-to-date status. Using a GIS spatial analysis, the data were mapped. Figures 5 and 6 illustrate existing and programmed trails for Hillsborough and Pinellas Counties, respectively.

The analysis relied upon GIS spatial analysis, spreadsheet software and the availability of geographic data. The GIS analysis was used for identifying the patterns and spatial relationship between transit service, bike trails, sidewalks and demographic conditions surrounding these connections. The spreadsheet was used to rank order the observations using a built-in percentile rank function. The availability of geographic data is crucial for conducting the analysis.

The project team used Esri ${ }^{4}$ ArcMap for the mapping and analysis and Microsoft's Excel to perform the percentile ranking. These are both leading software applications in the industry. Similar GIS and spreadsheet software can replace the applications used by the project team. Computer, hardware specifications and purchase options can be found at the Esri and Microsoft websites, Esri.com and Microsoft.com. It is important to note that in general, GIS software requires more powerful computing power, including graphics capabilities. Groups looking to undertake this approach should first ensure their computing capacity is suited for the analysis.

Much of the data acquired from the municipal agencies were provided by the county GIS departments. Each of the counties has mature GIS departments with significant sources dedicated towards GIS inventories. Both counties utilize the Esri server platform for distribution of GIS assets. In many instances, the data for the two counties were acquired via GIS Web interface or a file transfer protocol (FTP)

\footnotetext{
${ }^{4}$ Environmental Systems Research Institute is known as Esri.
} 
site. For communities with less advanced GIS, the process of data collection may be more arduous requiring direct contact with the agencies.

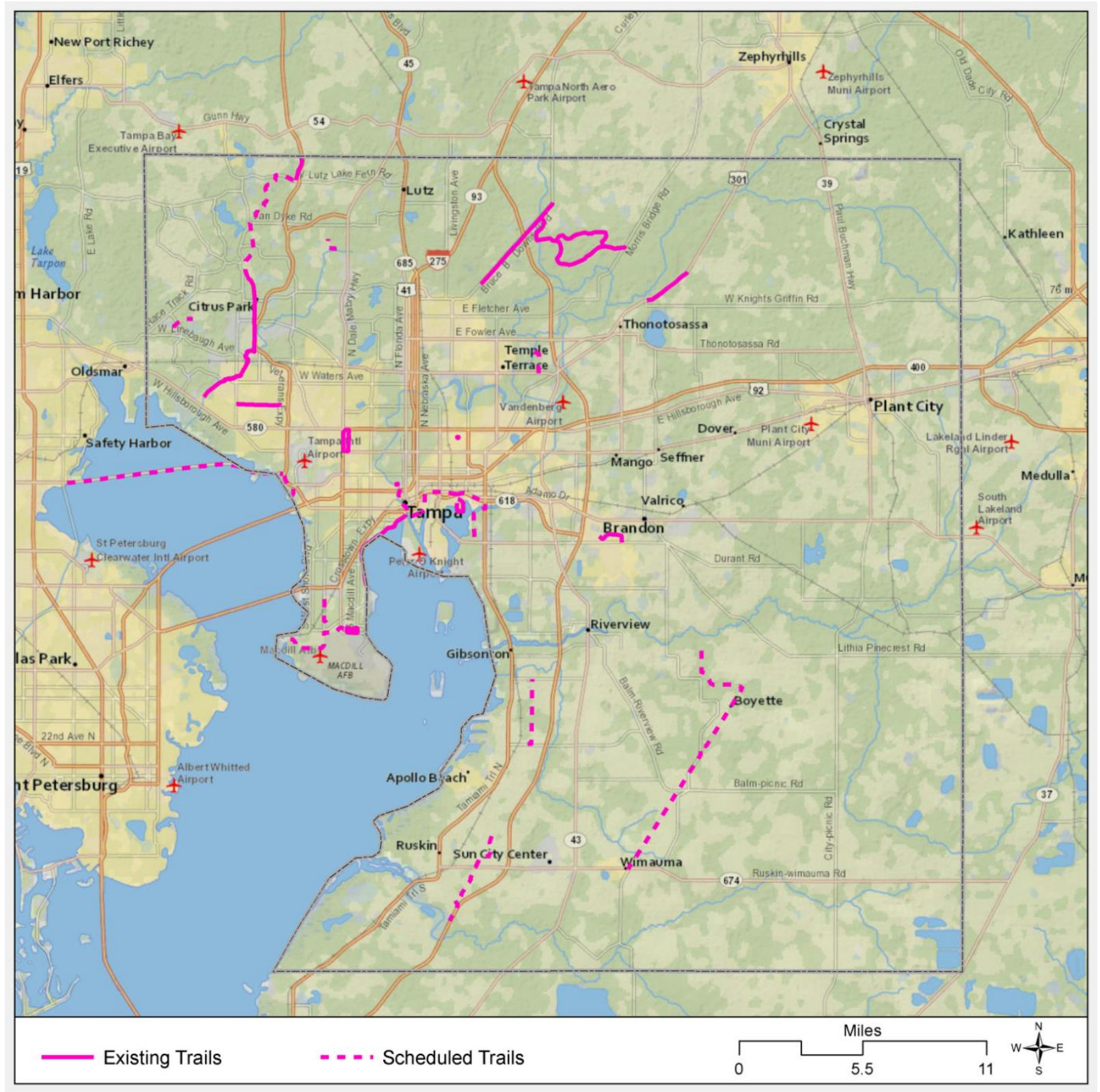

Figure 5: Hillsborough County trails 


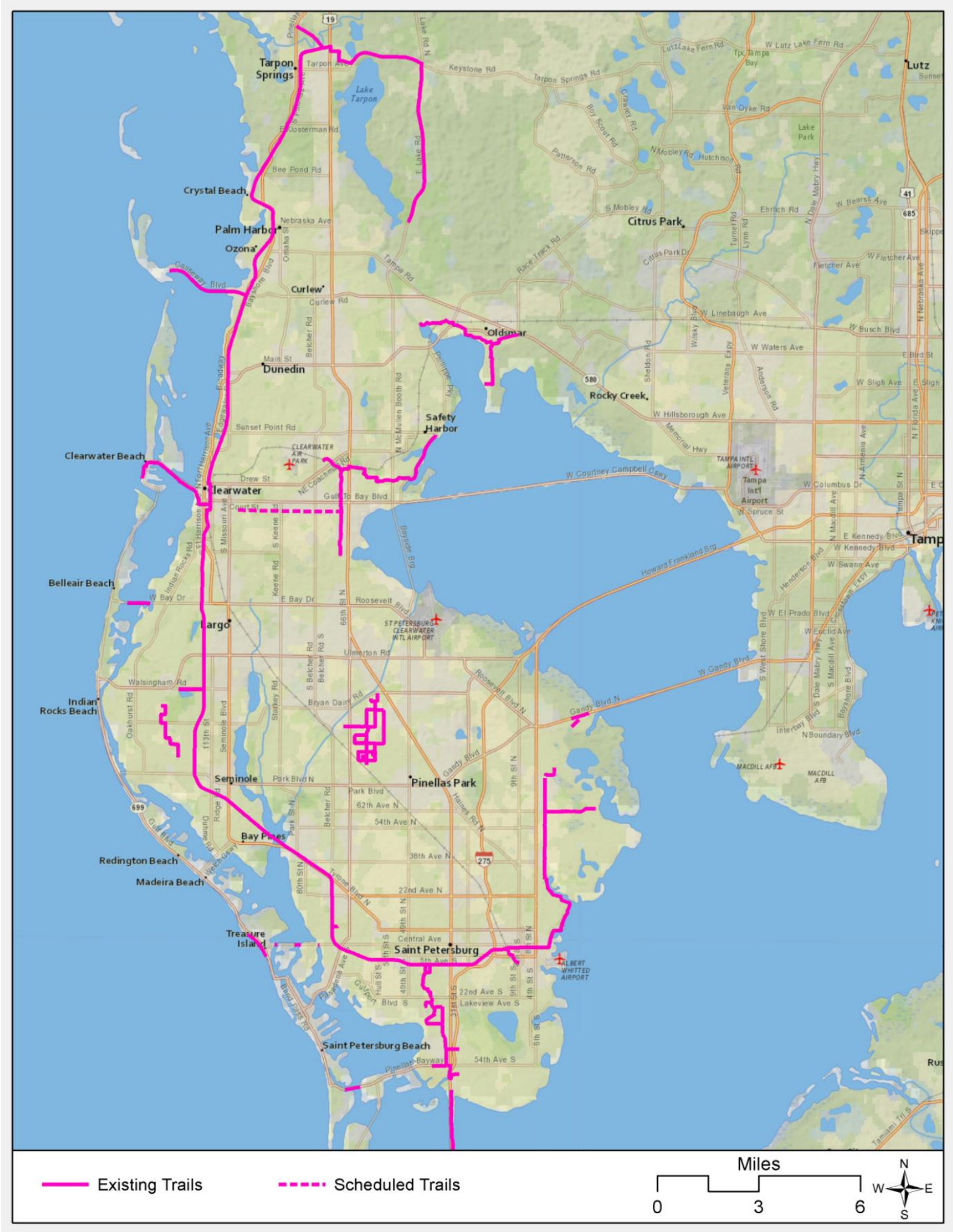

Figure 6: Pinellas County trails 


\section{Map Transit Routes and Locations of Transit Stops near Trails}

The Hillsborough Area Regional Transit Authority (HART) provides 365-day per year bus service to an area within Hillsborough County that is approximately 1,000 square miles. HART operates a fleet of 175 buses. HART serves 28 local routes, 12 express routes, five flex routes, three in-town trolleys, one MetroRapid bus rapid transit route, and 21 park-and-ride lots. All HART buses are equipped with bicycle racks. HART entered into joint participation agreements to operate regional express transit service to Pinellas and Pasco Counties. HART received funding to extend bus service along SR 60 in Brandon to Valrico. HART conducted a study of pedestrian/bicycle connectivity around several proposed Metro-Rapid East-West stations based on a history of pedestrian and bicycle-related crashes. Implementation of recommendations is currently unfunded. HART installed bicycle accommodations at the Downtown Marion Transit Center, in coordination with the City of Tampa, and the Tampa Downtown Partnership. These facilities include a bicycle self-repair station and a site for a station of the Coast Bike Share program. The HART TDP does not address connectivity with public trails. (HART 2015)

PSTA serves 21 of the 24 incorporated communities in Pinellas County plus some unincorporated areas. PSTA operates 40 bus routes and 5,735 bus stops with 195 buses. These include 28 fixed routes, two circulators, three connector routes, three commuter routes, two express routes and two trolley services. Eleven of PSTA's fixed routes have peak hour frequencies greater than 30 minutes, four routes have 30-minute frequencies and the remaining fixed routes have 60-minute frequencies. Between FY 2012/13 and FY 2013/14, bicycle user ridership increased 2.63 percent. PSTA provides free bikes-on-bus service on all buses. PSTA staff is looking at route performance data to streamline the network to maximize service efficiencies, cut costs, allow for needed bus replacements, and support PSTA's primary mission to serve low income households, zero car households, provide access to major destinations, and support tourism. (PSTA 2015) PSTA staff coordinates with FDOT for projects along state roads to coordinate bus stop locations, bus bay locations, roadway modifications and "...bicycle/pedestrian access infrastructure could be considered as part of these projects." (PSTA 2014, 3-8) PSTA's five-year constrained capital improvement program includes $\$ 31,850$ for bike access facilities and equipment. (PSTA 2014, Appendix B-1)

Using a GIS spatial analysis, the transit route data were mapped to develop Figure 7 showing bus routes provided by HART and PSTA. 


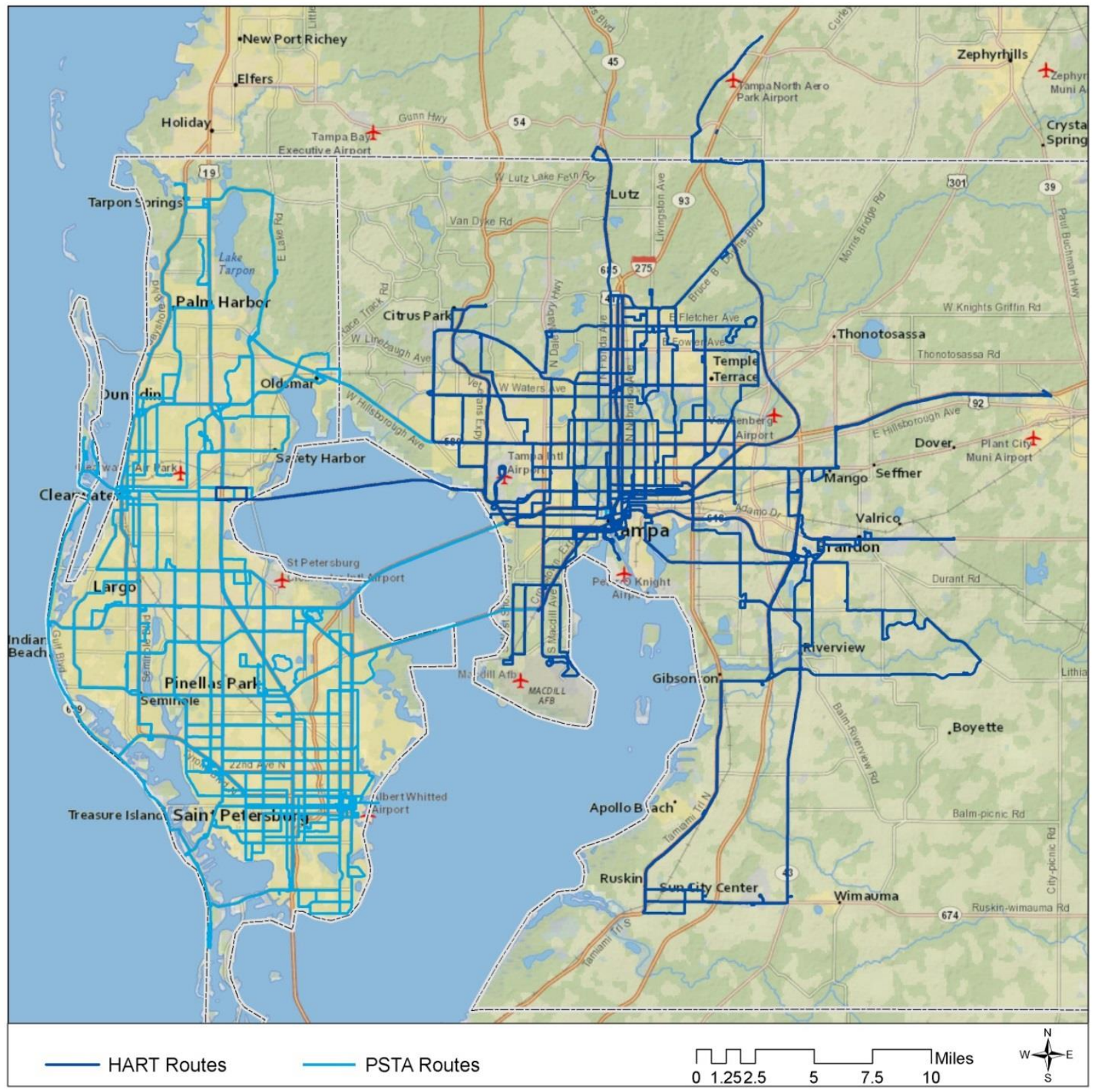

Figure 7: Bus routes illustrate service areas for HART and PSTA.

The location of transit bus stops is needed to provide the link between trail users and the transit system. These data were acquired from the transit agencies. HART and PSTA have bus stop inventory and route alignments in GIS format. The stop and route information were evaluated for accuracy and timeliness by comparing schedule data and Google maps data. Both agencies share their General Transit Feed Specification (GTFS) data with Google and the GTFS files were used to compare with the GIS files. Consistency revealed the GIS data were accurate and up-to-date. In Hillsborough County, the trail system, including trails that are programmed for construction, was overlaid with the HART bus stop inventory. 
To capture existing and potential connections, bus stops within 2,000 feet of a trail were initially considered. There were 18 existing or future trail locations served within 2,000 feet (approximately an 11-minute walk) of 365 HART bus stops, as illustrated in Figure 8 and listed in Table 2. In Pinellas County, there were 23 trail locations within 2,000 feet of over 1,400 PSTA bus stops, as illustrated in Figure 9 and listed in Table 3. Many stops in downtown St. Petersburg represent areas most supportive of non-motorized travel and public transit. However, the goal is to identify areas that would benefit more from new transit and trail connections.

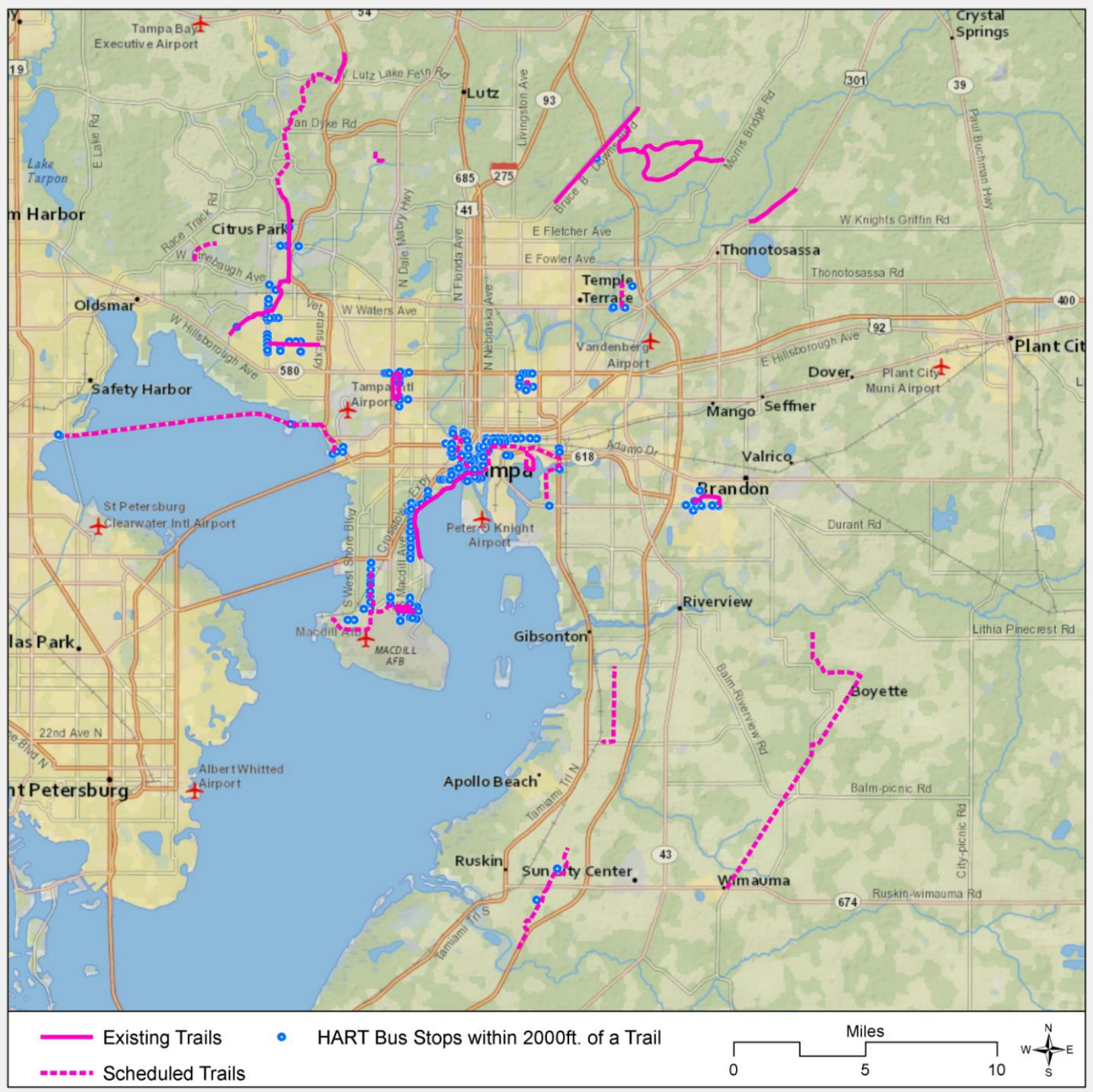

Figure 8: Intersection of HART bus stops and trails 
Table 2: Hillsborough Trail Locations within 2000 Feet of HART Bus Stops

\begin{tabular}{|c|c|c|c|c|}
\hline TRAIL NAME & DESCRIPTION / LIMITS & JURISDICTION & STATUS & $\begin{array}{l}\text { LENGTH IN } \\
\text { MILES }\end{array}$ \\
\hline $\begin{array}{l}\text { Upper Tampa Bay Trail } \\
\text { Phases I, II, III }\end{array}$ & $\begin{array}{l}\text { Memorial Highway/Montague } \\
\text { St to Peterson Road }\end{array}$ & Hillsborough & Existing & 7.0 \\
\hline $\begin{array}{l}\text { Town 'N Country } \\
\text { Greenway Trail }\end{array}$ & $\begin{array}{l}\text { Sheldon Road to south of } \\
\text { George Road }\end{array}$ & Hillsborough & Existing & 2.0 \\
\hline South Tampa Greenway & MacDill Trail at Gadsden Park & Tampa & Existing & 1.5 \\
\hline Bruce B. Downs Trail & $\begin{array}{l}\text { Amberly Drive to Hunters } \\
\text { Green Blvd, parallels Bruce B. } \\
\text { Downs Road }\end{array}$ & Tampa & Existing & 4.4 \\
\hline $\begin{array}{l}\text { Bayshore Boulevard } \\
\text { Greenway (BBG) }\end{array}$ & $\begin{array}{l}\text { Columbus Statue Park at Platt } \\
\text { St. to Gandy Blvd. }\end{array}$ & Tampa & Existing & 4.3 \\
\hline West Tampa Greenway & Al Lopez Park Loop & Tampa & Existing & 2.2 \\
\hline East Tampa Greenway & $\begin{array}{l}\text { Fair Oaks Park/Pond } \\
\text { Enhancement }\end{array}$ & Tampa & Existing & 0.2 \\
\hline Brandon Parkway & $\begin{array}{l}\text { Lumsden Road to Town Center } \\
\text { Blvd. }\end{array}$ & $\begin{array}{l}\text { Expressway } \\
\text { Authority }\end{array}$ & Existing & 1.4 \\
\hline $\begin{array}{l}\text { Upper Tampa Bay Trail } \\
\text { Phase IV }\end{array}$ & $\begin{array}{l}\text { Lutz Lake Fern Road to Van } \\
\text { Dyke Road }\end{array}$ & Hillsborough & Programmed & 4.4 \\
\hline $\begin{array}{l}\text { South Tampa } \\
\text { Greenway/Friendship } \\
\text { Trail }\end{array}$ & Tyson South to Interbay Blvd. & Tampa & Programmed & 1.5 \\
\hline South Tampa Greenway & $\begin{array}{l}\text { Friendship Trail to Picnic } \\
\text { Island, MacDill AFB and } \\
\text { Bayshore }\end{array}$ & Tampa & Programmed & 4.4 \\
\hline $\begin{array}{l}\text { South Coast Greenway } \\
\text { Phase I }\end{array}$ & $\begin{array}{l}\text { College Ave E. to 19th Ave., } \\
\text { west of Wolf Branch in the } \\
\text { Ruskin area }\end{array}$ & Hillsborough & Programmed & 1.9 \\
\hline $\begin{array}{l}\text { Bayshore Boulevard } \\
\text { Greenway }\end{array}$ & $\begin{array}{l}\text { Platt Street to Gandy Blvd. } \\
\text { (west side) }\end{array}$ & Tampa & Programmed & 4.3 \\
\hline $\begin{array}{l}\text { Hillsborough River } \\
\text { Greenway }\end{array}$ & $\begin{array}{l}\text { Beneficial Drive Bridge to } \\
\text { Heights Residential } \\
\text { Development }\end{array}$ & Tampa & Programmed & 2.5 \\
\hline West Tampa Greenway & $\begin{array}{l}\text { Courtney Campbell Causeway } \\
\text { - McMullen Booth Road to } \\
\text { Veterans Expy. }\end{array}$ & Tampa/State & Programmed & 9.9 \\
\hline McKay Bay Greenway & $\begin{array}{l}\text { 11-mile trail loop around } \\
\text { McKay Bay }\end{array}$ & Tampa & Programmed & 6.1 \\
\hline $\begin{array}{l}\text { Temple Terrace Multi- } \\
\text { Use Trail }\end{array}$ & $\begin{array}{l}\text { Temple Terrace Highway to } \\
\text { Whiteway Drive and Riverhills } \\
\text { Drive }\end{array}$ & Temple Terrace & Programmed & 1.1 \\
\hline $\begin{array}{l}\text { South Coast Greenway } \\
\text { Phase IV }\end{array}$ & $\begin{array}{l}\text { College Ave. E. to the Little } \\
\text { Manatee River }\end{array}$ & Hillsborough & Programmed & 2.9 \\
\hline $\begin{array}{l}\text { SR60/Memorial Highway } \\
\text { Trail }\end{array}$ & $\begin{array}{l}\text { Cypress Point Park to } \\
\text { Courtney Campbell Causeway }\end{array}$ & FDOT & Programmed & 1.4 \\
\hline
\end{tabular}




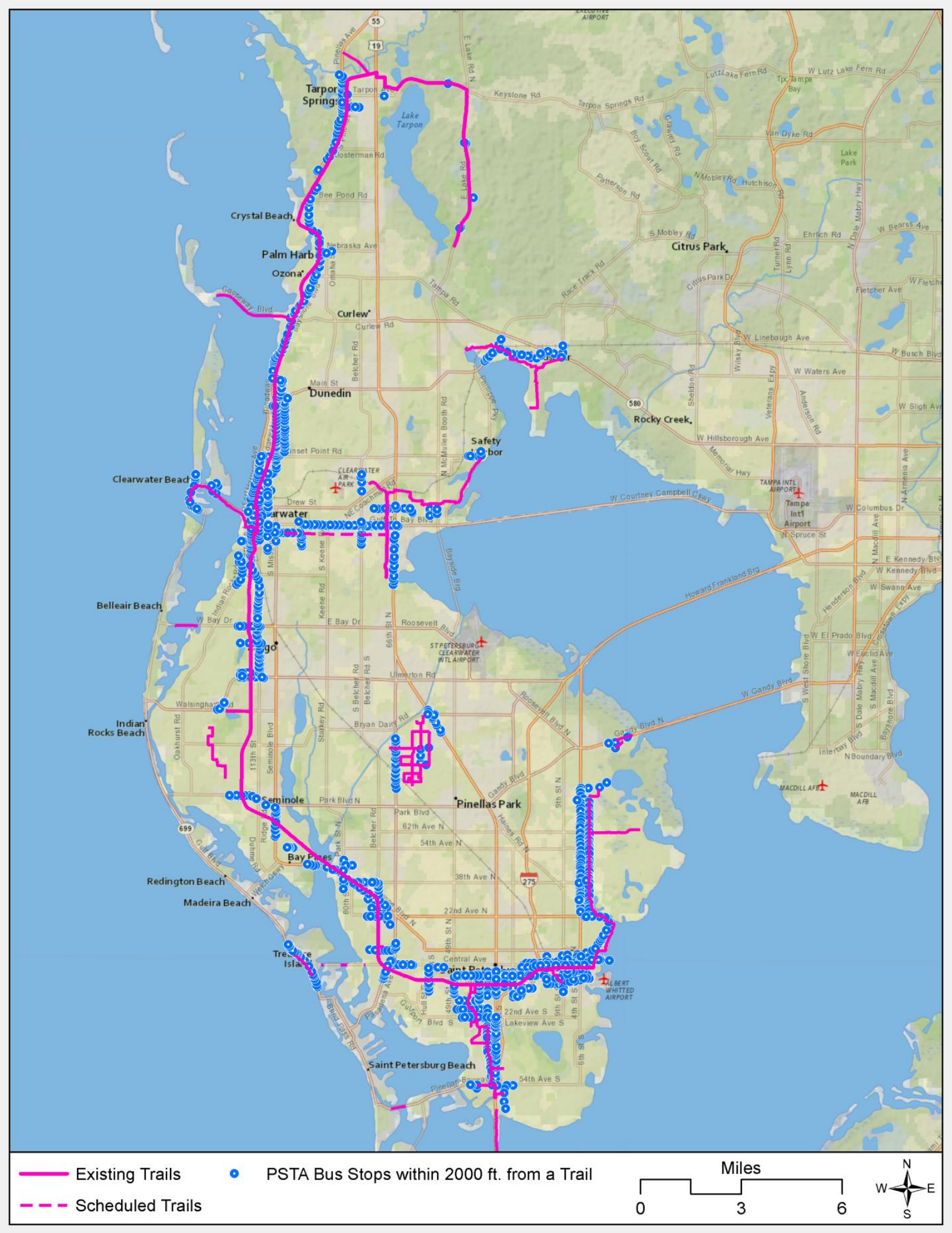

Figure 9: Intersection of PSTA bus stops and trails 
Table 3: Pinellas Trail Locations within 2000 Feet of PSTA Bus Stops

\begin{tabular}{|c|c|c|}
\hline TRAIL NAME & STATUS & JURISDICTION \\
\hline 37th Street Trail & Existing & St Petersburg \\
\hline 62 Ave NE Trail & Existing & St Petersburg \\
\hline Bayshore Trail (Clearwater) & Existing & Clearwater \\
\hline Bayway Trail North & Existing & County - St Petersburg \\
\hline Booker Creek Trail & Existing & St Petersburg \\
\hline Childs Park Trail (Clam Bayou) & Existing & St Petersburg \\
\hline Childs Park Trail (Clam Bayou) & Existing & St Petersburg \\
\hline Clearwater Beach Connector Trail & Existing & Clearwater \\
\hline Clearwater Beach Trail & Existing & Clearwater \\
\hline Clearwater Beach Trail Spur - Mandalay Channel & Existing & Clearwater \\
\hline Clearwater Beach/Memorial Causeway Path & Existing & Clearwater \\
\hline Druid Trail & Scheduled & County - Clearwater \\
\hline East Avenue Connector & Existing & Clearwater \\
\hline Friendship Trail & Existing & County \\
\hline Honeymoon Island Trail & Existing & Dunedin \\
\hline North Bay Trail & Existing & St Petersburg \\
\hline North Bay Trail (Rio Vista Trail Connection) & Existing & St Petersburg \\
\hline Oldsmar Trail & Existing & Oldsmar \\
\hline Pinellas Community Trail - Downtown Connection Trail & Existing & County - St Petersburg \\
\hline Pinellas Trail & Existing & County \\
\hline Pinellas Trail - East Lake Rd & Existing & County \\
\hline Pinellas Trail Northeast Extension-Jasmine Section & Existing & County - Tarpon Springs \\
\hline Pinellas Trail Northeast Extension-Keystone Section & Existing & County -Tarpon Springs \\
\hline Pinellas Trail Progress Energy Ext- Segment B & Existing & Determined By City Limits \\
\hline Ream Wilson Clearwater Trail & Existing & Clearwater \\
\hline Skyway Trail & Existing & St Petersburg \\
\hline South Beaches Trail & Existing & St Petersburg \\
\hline SPC Trail & Existing & St Petersburg \\
\hline St Petersburg Trail & Existing & St Petersburg \\
\hline Treasure Island Causeway Trail & Existing & Treasure Island \\
\hline Walsingham Spur & Existing & County \\
\hline
\end{tabular}




\section{Identify Data Sources to Describe Location of Travel Market and Trip Destination}

Perhaps the most accurate method to know the travel patterns of populations of interest is to count them. This can be expensive and time consuming; however, more local governments are investing in hardware and software that can be permanently placed at various sites of interest. Pinellas County recently invested in five counters. Other methods include observations at selected locations by staff who can record details that loop counters or infrared sensors cannot, such as gender, general age, and other traveler attributes. Surveys of a sample of travelers can capture their responses regarding their travel origins and destinations.

In the absence of resources to conduct more detailed studies like these about the travel characteristics of the selected markets of interest, the following method is suggested:

The trip origins, or home locations, of travelers of selected demographic characteristics can be identified, as well as potential desired destinations based upon selected trip purposes, using the EPA SLD. The target markets and trip purposes selected for illustrative purposes include low income workers accessing employment destinations, senior citizens accessing recreational destinations, and adult students accessing post-secondary education campuses. Using local sources provides a robust and up-to-date resource for planners to evaluate transit and trails connection potential. However, many smaller local governments may have inconsistent data formats and a lack of data. Furthermore, national data resources have evolved to offer reasonable alternatives to local data.

For example, the Environmental Protection Agency (EPA) offers robust national datasets that are a consistent alternative to local data. The EPA Smart Location Database (SLD) delivers research backed metrics and data to help support livability and sustainability efforts. Many of the data produced in the SLD address built environment, quality transit service and socio economic measures that impact public transportation usage and support non-motorized travel.

This approach leverages local transit and trail data withGIS software by overlaying the built environment and socio-demographic data and evaluating the intersection of the transit-supportive areas and the trail data. The following section describes the data used and illustrates the screening process used to help guide the selection of the study areas. Table 4 provides examples of available data sets.

Table 4: Examples of Alternative Data Sources

\begin{tabular}{|l|l|l|l|}
\hline CATEGORY & MARKET & DESCRIPTION & DATA \\
\hline Density & $\begin{array}{l}\text { Population } \\
\text { Density }\end{array}$ & $\begin{array}{l}\text { Areas with higher density are supportive } \\
\text { of pedestrian travel due to the close } \\
\text { proximity of services and destinations in } \\
\text { dense areas. }\end{array}$ & $\begin{array}{l}\text { U.S. Census Table: } \\
\text { B01001 - SEX BY AGE } \\
\text { Universe: Total } \\
\text { population }\end{array}$ \\
\hline Demographic & $\begin{array}{l}\text { Zero Vehicle } \\
\text { Population }\end{array}$ & $\begin{array}{l}\text { Those without access to personal vehicles } \\
\text { would benefit from the improvements to } \\
\text { transit and trail connections. }\end{array}$ & $\begin{array}{l}\text { B25044 - TENURE BY } \\
\text { VEHCLES } \\
\text { AVAILABLE:Universe: } \\
\text { Occupied housing units, } \\
\text { EPA data }\end{array}$ \\
\hline
\end{tabular}




\begin{tabular}{|c|c|c|c|}
\hline CATEGORY & MARKET & DESCRIPTION & DATA \\
\hline Demographic & $\begin{array}{l}\text { Millennials } \\
\text { (born between } \\
1982 \text { and } \\
1998 \text { ) }\end{array}$ & $\begin{array}{l}\text { Millennials are a large submarket to have } \\
\text { shown trends towards lower automobile } \\
\text { ownership and greater proclivity towards } \\
\text { non-motorized transportation and public } \\
\text { transportation usage. }\end{array}$ & $\begin{array}{l}\text { B01001 - SEX BY AGE } \\
\text { Universe: Total } \\
\text { population }\end{array}$ \\
\hline Demographic & Active Seniors & $\begin{array}{l}\text { In the state of Florida the senior } \\
\text { population can take advantage of the } \\
\text { opportunities to connect to recreational } \\
\text { and shopping opportunities through the } \\
\text { transit and trail connections. }\end{array}$ & $\begin{array}{l}\text { B01001 - SEX BY AGE } \\
\text { Universe: Total } \\
\text { population }\end{array}$ \\
\hline Demographic & Adult Students & $\begin{array}{l}\text { College age students are a growing } \\
\text { segment of bicycling travelers. } \\
\text { Connecting these riders to more } \\
\text { opportunities via public transit offers } \\
\text { communities an opportunity to increase } \\
\text { transit usage as well as help those } \\
\text { without access to a private automobile. }\end{array}$ & $\begin{array}{l}\text { B14007 - SCHOOL } \\
\text { ENROLLMENT BY } \\
\text { DETAILED LEVEL OF } \\
\text { SCHOOL FOR THE } \\
\text { POPULATION } 3 \text { YEARS } \\
\text { AND OVER: Universe: } \\
\text { POpulation Over age } 3\end{array}$ \\
\hline Demographic & Poverty Status & $\begin{array}{l}\text { Those suffering from poverty may have } \\
\text { more opportunities to find better } \\
\text { employment using a combination of } \\
\text { transit service and trails. }\end{array}$ & $\begin{array}{l}\text { S1701 - POVERTY } \\
\text { STATUS IN THE PAST } \\
12 \text { MONTHS }\end{array}$ \\
\hline Design & $\begin{array}{l}\text { Walkable } \\
\text { Neighborhoods }\end{array}$ & $\begin{array}{l}\text { Communities with greater intersection } \\
\text { density are more supportive of non- } \\
\text { motorized and public transit modes. By } \\
\text { identifying walkable areas, investments } \\
\text { in these areas may suppot increase use } \\
\text { of public transit and nonmotorized } \\
\text { modes. }\end{array}$ & $\begin{array}{l}\text { Environmental } \\
\text { Protection Agency } \\
\text { Smart Location } \\
\text { Database }\end{array}$ \\
\hline Density & $\begin{array}{l}\text { Transit } \\
\text { Supportive } \\
\text { Areas }\end{array}$ & $\begin{array}{l}\text { Enhancing bicycle and transit connections } \\
\text { in areas with transit supportive } \\
\text { population and employment densities are } \\
\text { more likely to improve the rider and } \\
\text { bicyclist access to goods, services and } \\
\text { employment opportunities. }\end{array}$ & $\begin{array}{l}\text { Smart Location } \\
\text { Database Residential } \\
\text { and Employment } \\
\text { Density Calculations }\end{array}$ \\
\hline $\begin{array}{l}\text { Transit } \\
\text { Service }\end{array}$ & $\begin{array}{l}\text { Transit Service } \\
\text { Areas }\end{array}$ & $\begin{array}{l}\text { Locations with better transit service offer } \\
\text { greater transit accessibility to } \\
\text { employment and other destinations. } \\
\text { Areas with greater service frequency and } \\
\text { access to transit stops would enhance } \\
\text { bicyclist access to more destinations }\end{array}$ & $\begin{array}{l}\text { Smart Location } \\
\text { Database Jobs Transit } \\
\text { Accessibility } \\
\text { Calculation }\end{array}$ \\
\hline
\end{tabular}

\section{Map Origins of Selected Travel Market and Destinations by Trip Purpose to Identify Areas of Greater Concentrations of Both}

To illustrate the method, low wage workers with limited access to personal vehicles are one of the selected travel markets, demonstrated first below. These individuals would benefit from improvements to connections between trails and transit service to increase access to a selected trip purpose, in this case, employment 
opportunities. Each county has areas that have higher concentrations of lowincome populations and areas with higher concentrations of jobs.

Planners also may choose other traveler markets and destination types. The purpose of these selections is to use them to identify major travel desire lines from origin to destination. The general area between the origin and destination becomes the basis for defining a subarea within which to look closer. The subareas will be discussed further below. Selection of these markets and destination types would be derived from the transportation goals and priorities articulated in the community's comprehensive plan, the transit development plan, bicycle/pedestrian and/or greenways/trails plans and from public input. These sources might identify other priority populations, such as the elderly, students and bicyclists, and to serve other priority trip purposes, such as recreation.

To map the home locations of the low income workers, demographics from the EPA SLD were used and ranked according to the areas with higher numbers of low income workers. The SLD data contain the work and home locations of the workers earning less than $\$ 1,250$ per month. The low wage employment category is defined as jobs earning $\$ 1,250$ or less per month. The SLD uses this category directly from a separate Census database known as the Longitudinal Employer Household Dynamics (LEHD) database. To help differentiate the distribution of low wage workers and low wage jobs, each block group is assigned a number representing the percentile rank. For example, Census block groups in the percentile rated a " 5 " contain higher numbers of low wage workers than those block groups rated "4" or lower but contain lower numbers of low wage workers than those block groups rated "6" or higher. Scores for the corresponding percentile ranking can be found in Table 5. A map of the distribution of low income worker home locations and job locations for Pinellas County can be seen in Figures 10 and 11 , respectively. The distributions for Hillsborough County can be found in Figures 12 and 13 . There are larger numbers of low wage workers and low wage jobs indicated on the maps by moving toward the blue end of the color scale.

Table 5: Percentile Ranking Scores

\begin{tabular}{|l|l|}
\hline PERCENTILE & SCORE \\
\hline $100-90$ & 10 \\
\hline $89-80$ & 9 \\
\hline $79-70$ & 8 \\
\hline $69-60$ & 7 \\
\hline $59-50$ & 6 \\
\hline $49-40$ & 5 \\
\hline $39-30$ & 4 \\
\hline $29-20$ & 3 \\
\hline $19-10$ & 2 \\
\hline $9-0$ & 1 \\
\hline
\end{tabular}




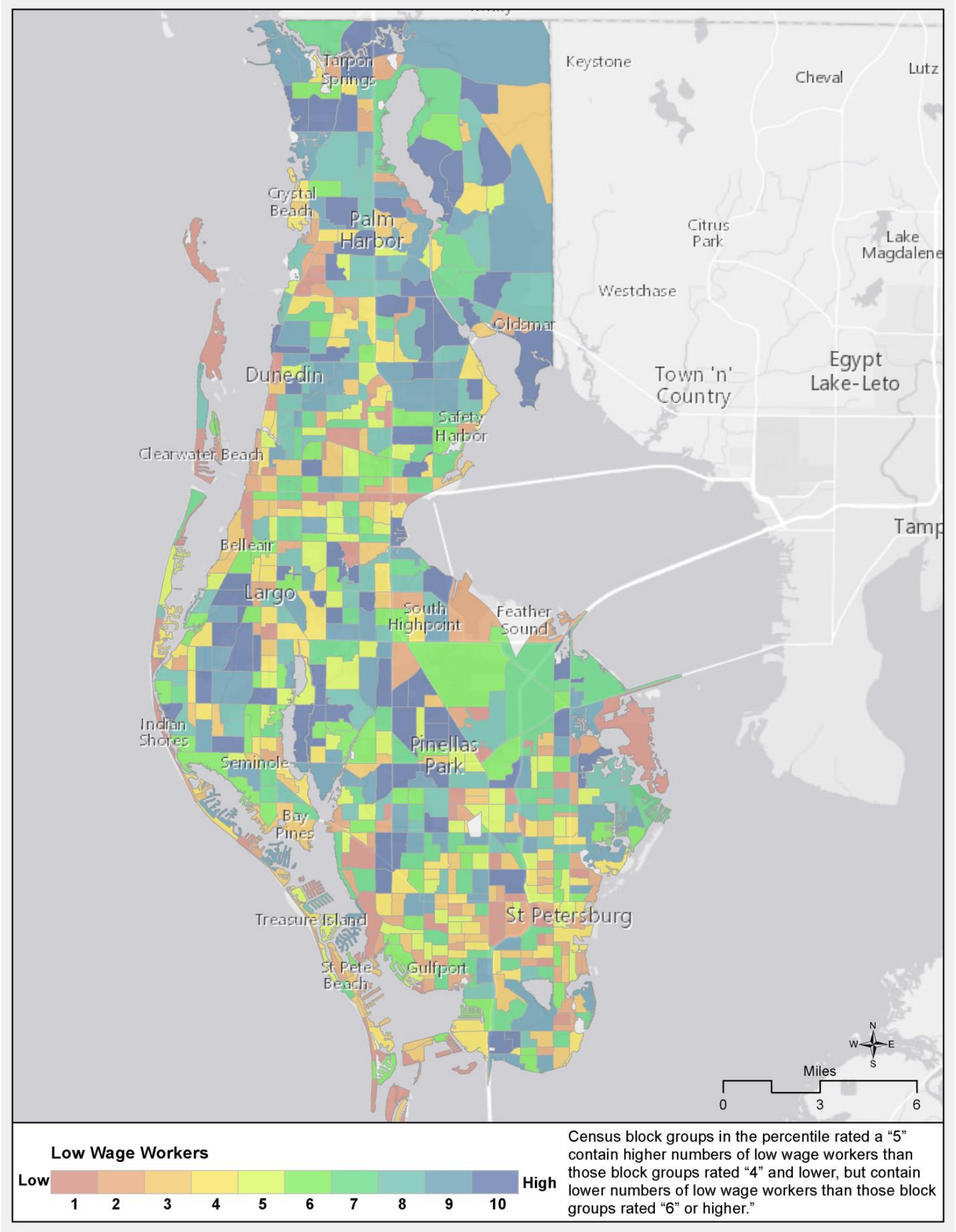

Figure 10: Low wage worker home location concentration with blue having the highest concentration, Pinellas County 


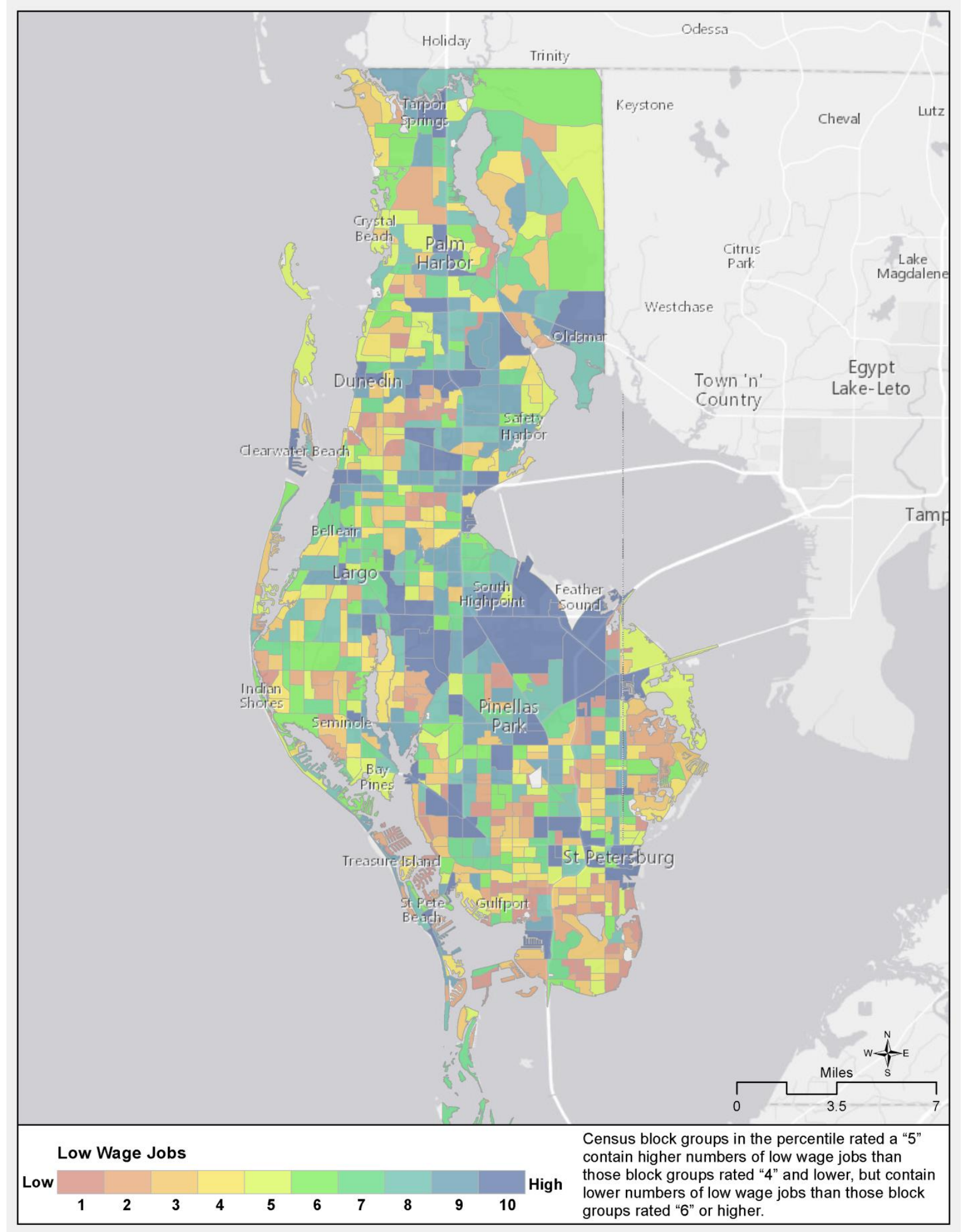

Figure 11: Low wage job location concentration, Pinellas County 


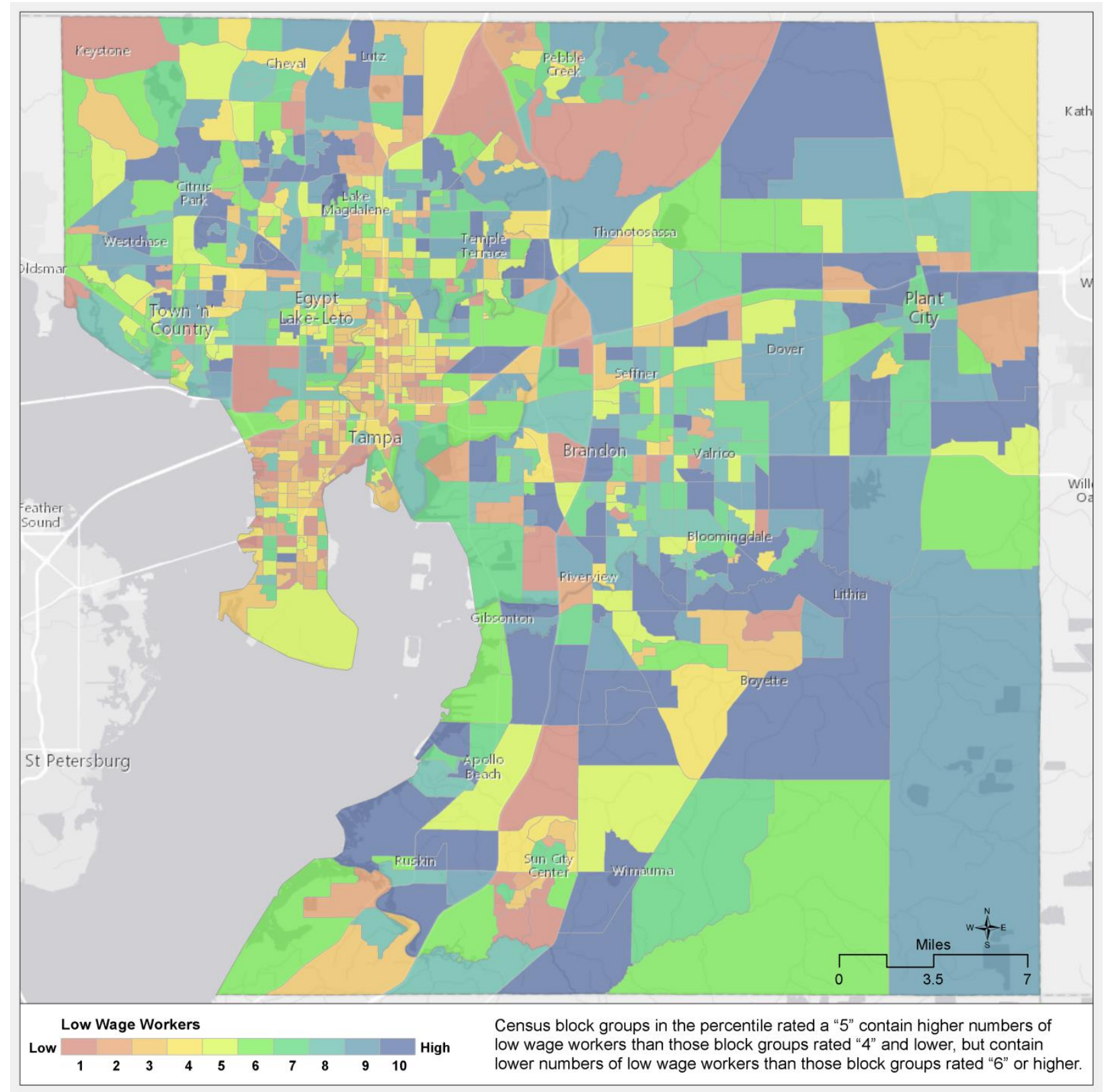

Figure 12: Low wage worker home location concentration with blue having the highest concentration, Hillsborough County 


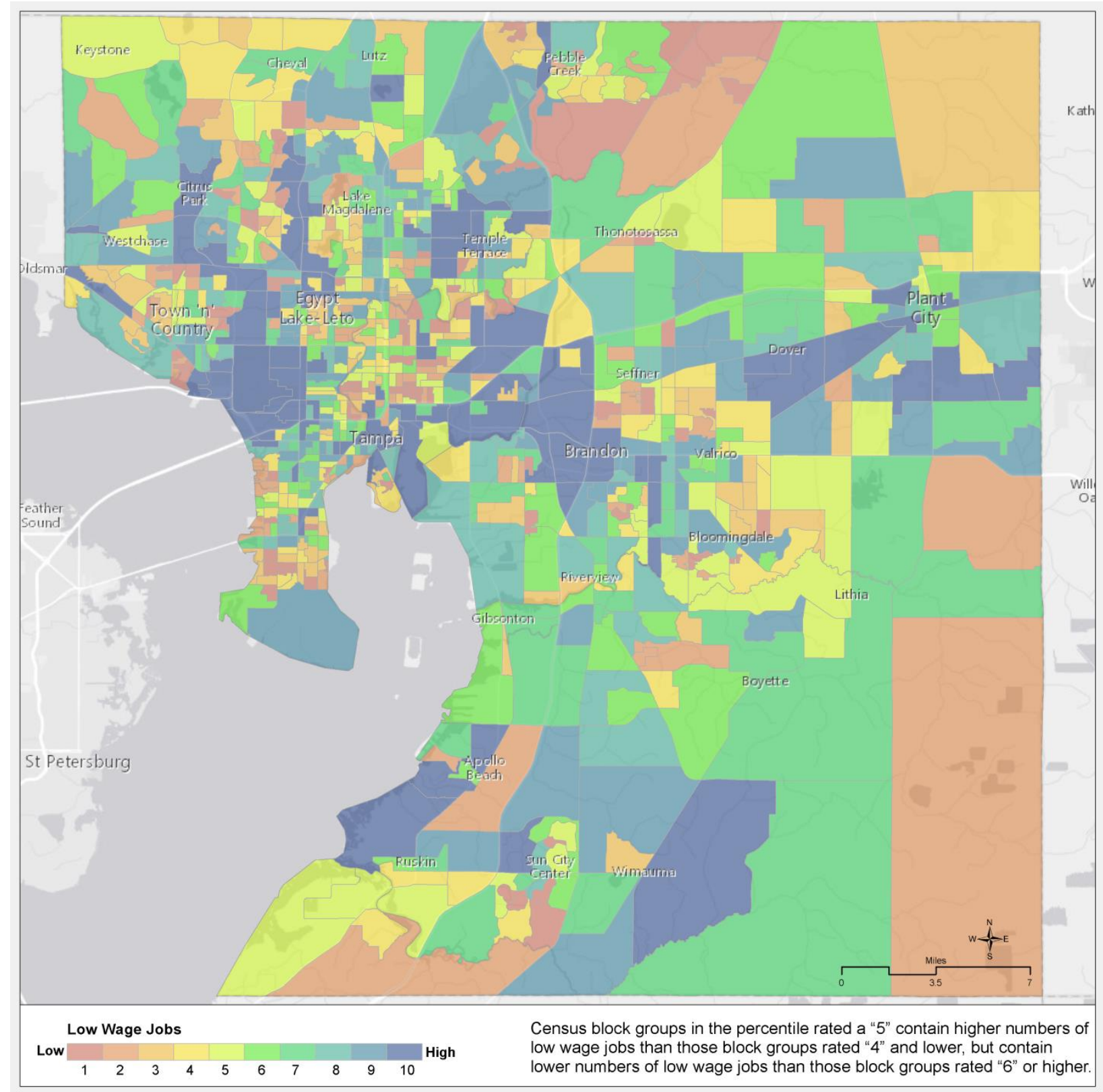

Figure 13: Low wage job location concentration, Hillsborough County

By mapping the home and work locations of low income workers, the opportunities to connect these two areas become apparent. The general areas that lay between the home and job locations of higher concentrations of low income workers become 
the ideal candidate subareas for closer evaluation, especially if these areas contain transit service that overlaps with trails.

Figures 14 and 15 show Census block groups that have more lower wage workers and more jobs, respectively, than 80 percent of the block groups in the county. These block groups include those with scores of 8, 9, and 10 .

When the block groups with the highest percentiles $\left(80^{\text {th }}\right)$ of low wage jobs and workers are mapped together, opportunities to connect workers to jobs are more apparent.

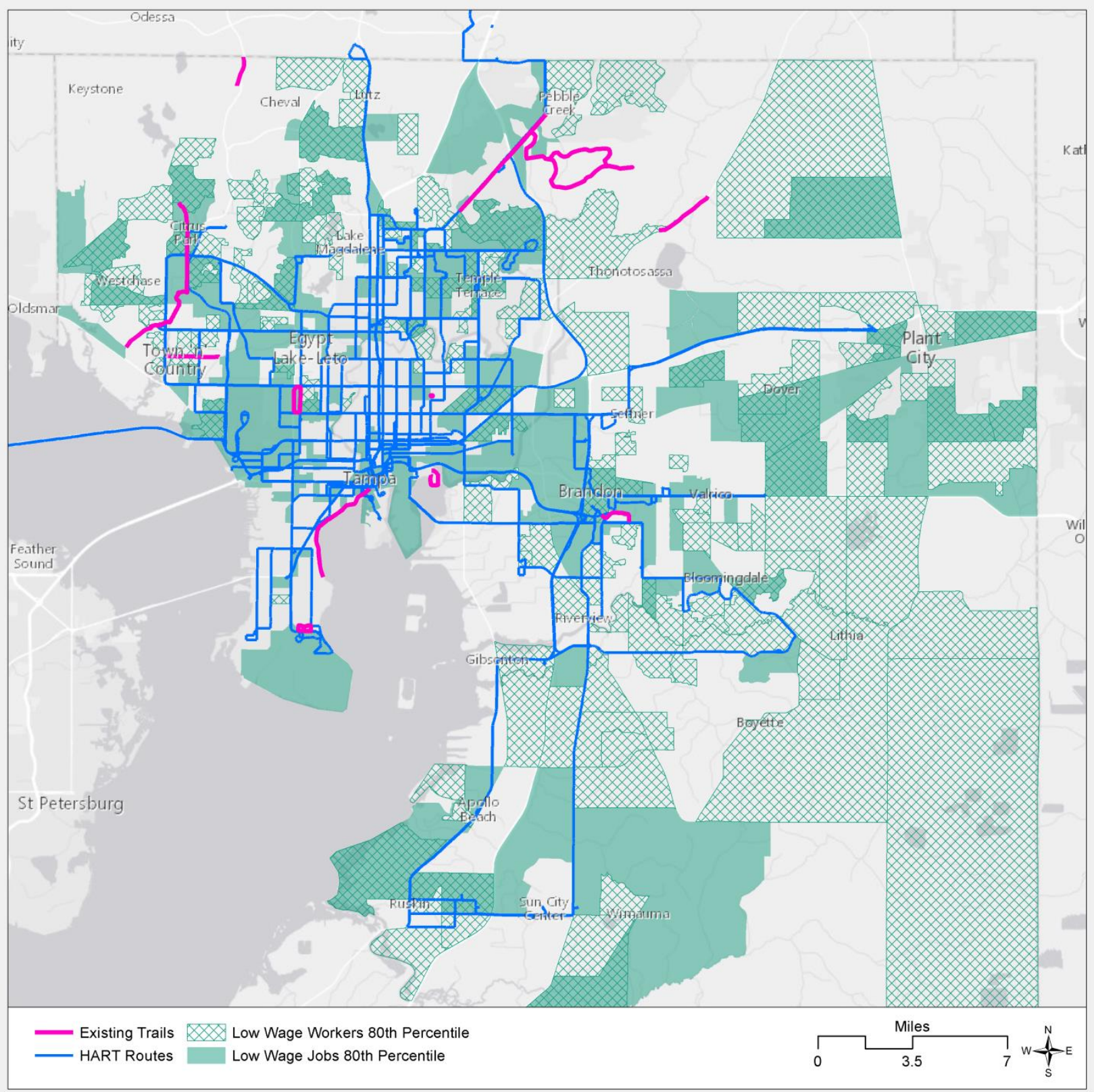

Figure 14: 80th percentile of low wage jobs and low wage workers in Hillsborough County 


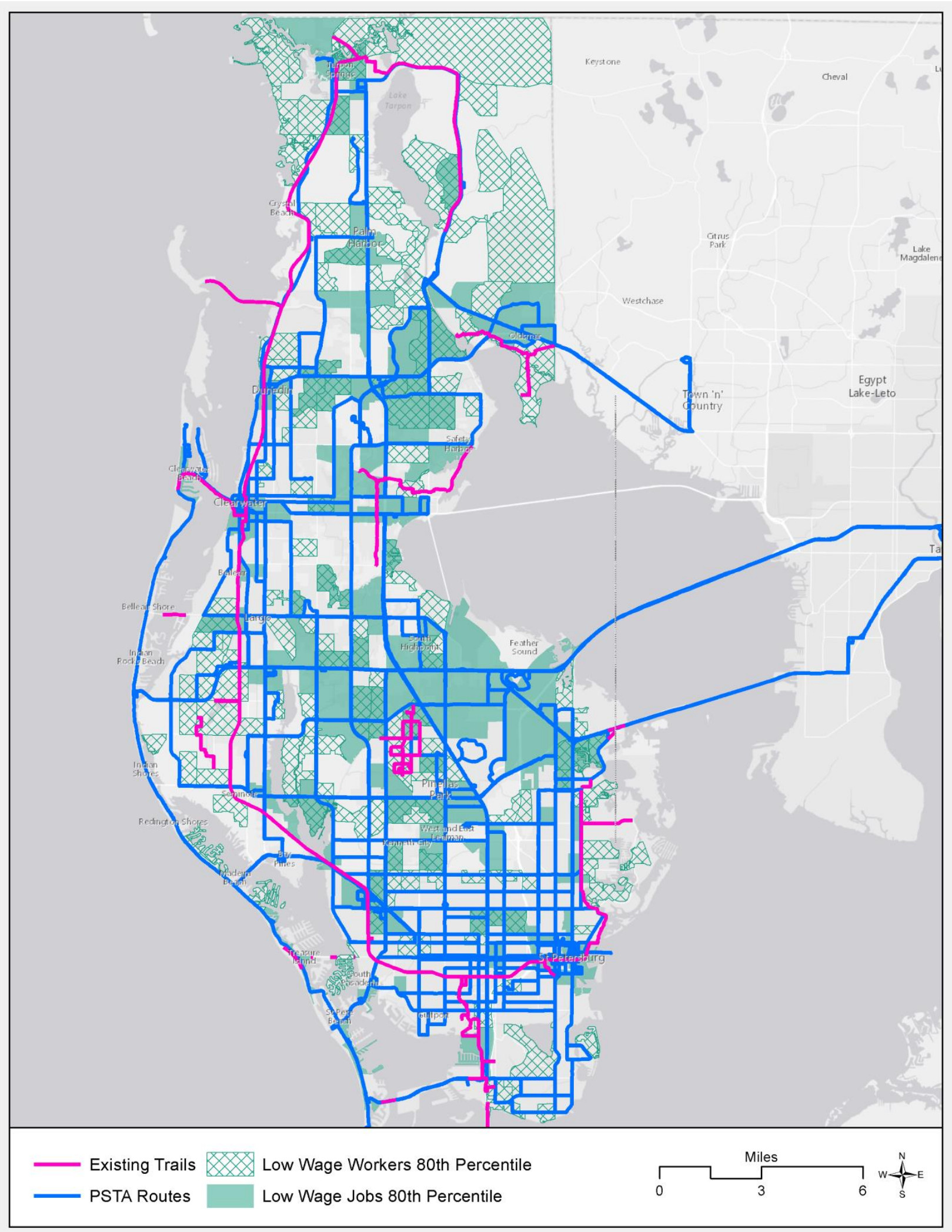

Figure 15: 80th percentile of low wage jobs and low wage workers in Pinellas County 
It is recommended that the definition of the subareas be developed for narrowly defined travel markets and trip purposes, because a narrow focus will result in a subarea within which greater opportunities to identify priority transit/trail locations will exist for the selected market and trip purpose. While different travel markets can be analyzed separately in successive iterations of the method, it is not recommended to define a traveler market broadly, such as including low income workers, elderly, students and bicyclists all into one market for analysis purposes, because it will likely result in a subarea that is too large and dispersed to provide any useful guidance for prioritizing transit/trail connections. Given the large number of existing transit/trail connections, the development of the subarea is 
intended to help planners prioritize transit/trail connections that would provide better potential for accomplishing the selected community transportation goal.

Planners also can repeat the process for each travel market of interest. For example Figures 16 and 17 for Hillsborough County and for Pinellas County, respectively, below illustrate the mapping of data describing Census block groups with the relative concentrations of adult student home locations and the dots show the locations of post-secondary education campuses. These include colleges, universities, and trade schools.

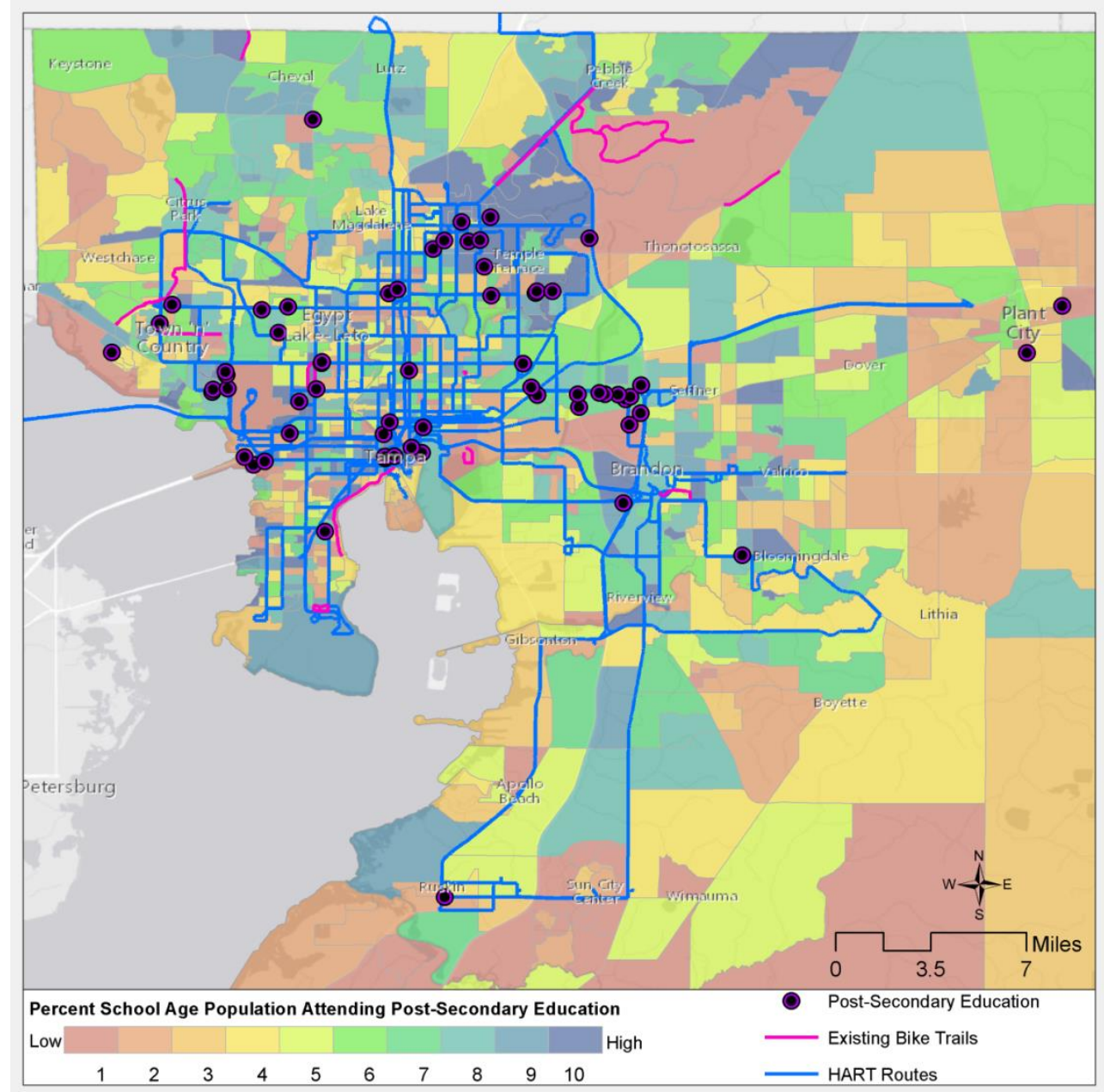

Figure 16: Locations of school age population in Hillsborough County attending postsecondary education 


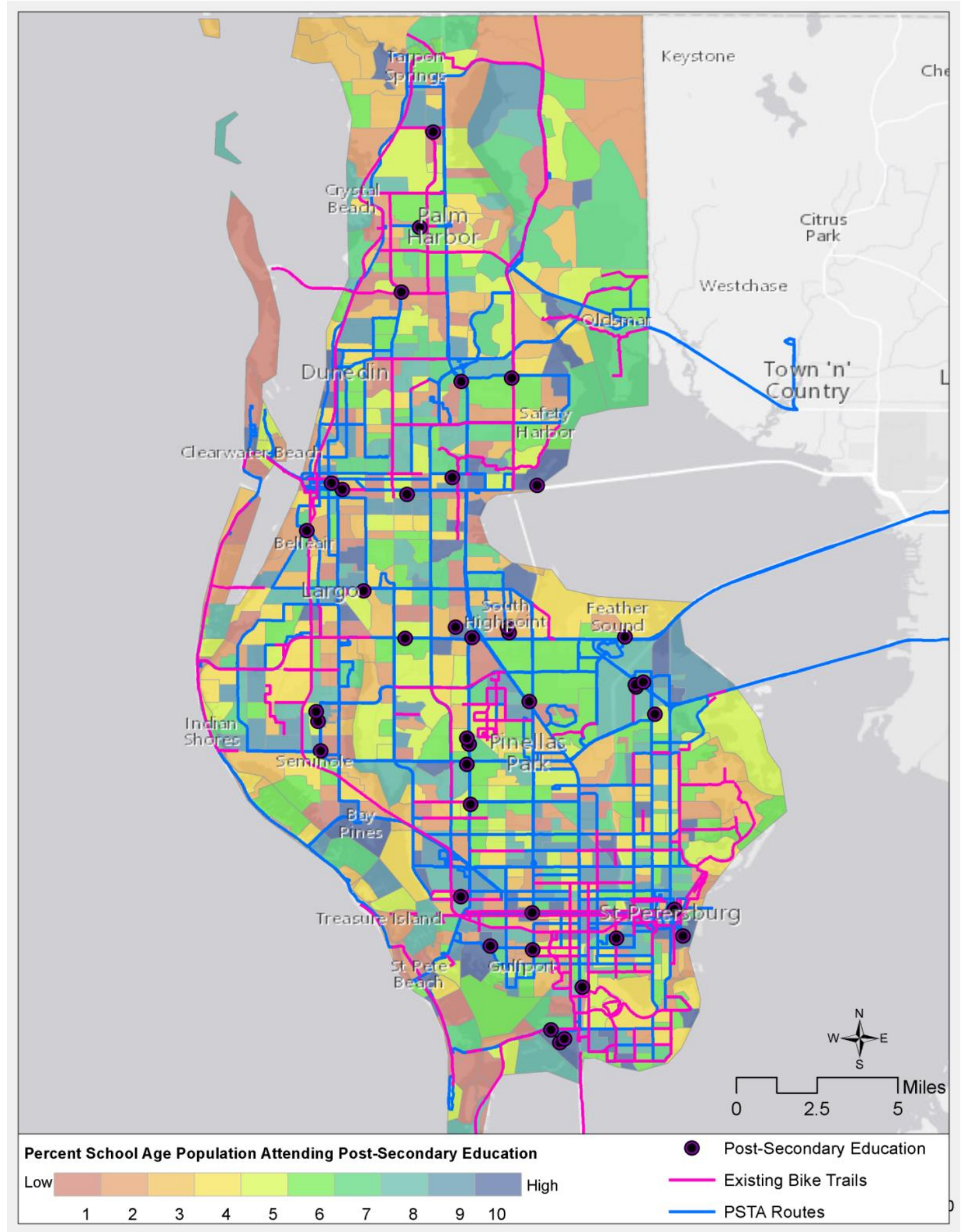

Figure 17: Locations of school age population in Pinellas County attending post-secondary education 
Figures 18 and 19 for Hillsborough and Pinellas Counties highlight those Census block groups having post-secondary education populations at the 80th percentile. This same analysis process and map generation also can be conducted for the senior population that desires to access recreational centers. Illustrative maps showing higher concentrations of the senior population relative to recreation centers are provided in Figures 26 and 27.

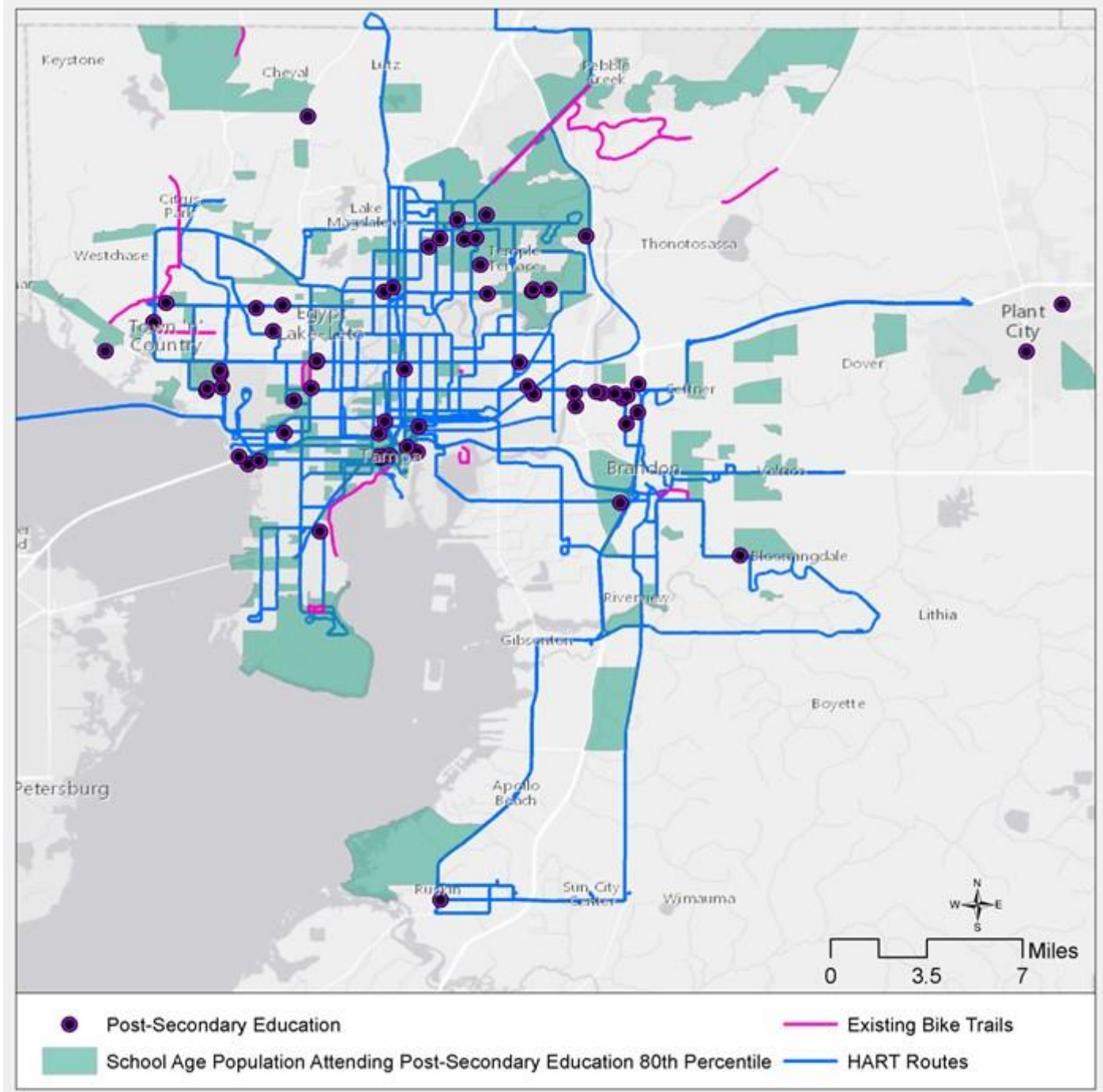

Figure 18: Locations in Hillsborough County having the highest concentrations of school age population 


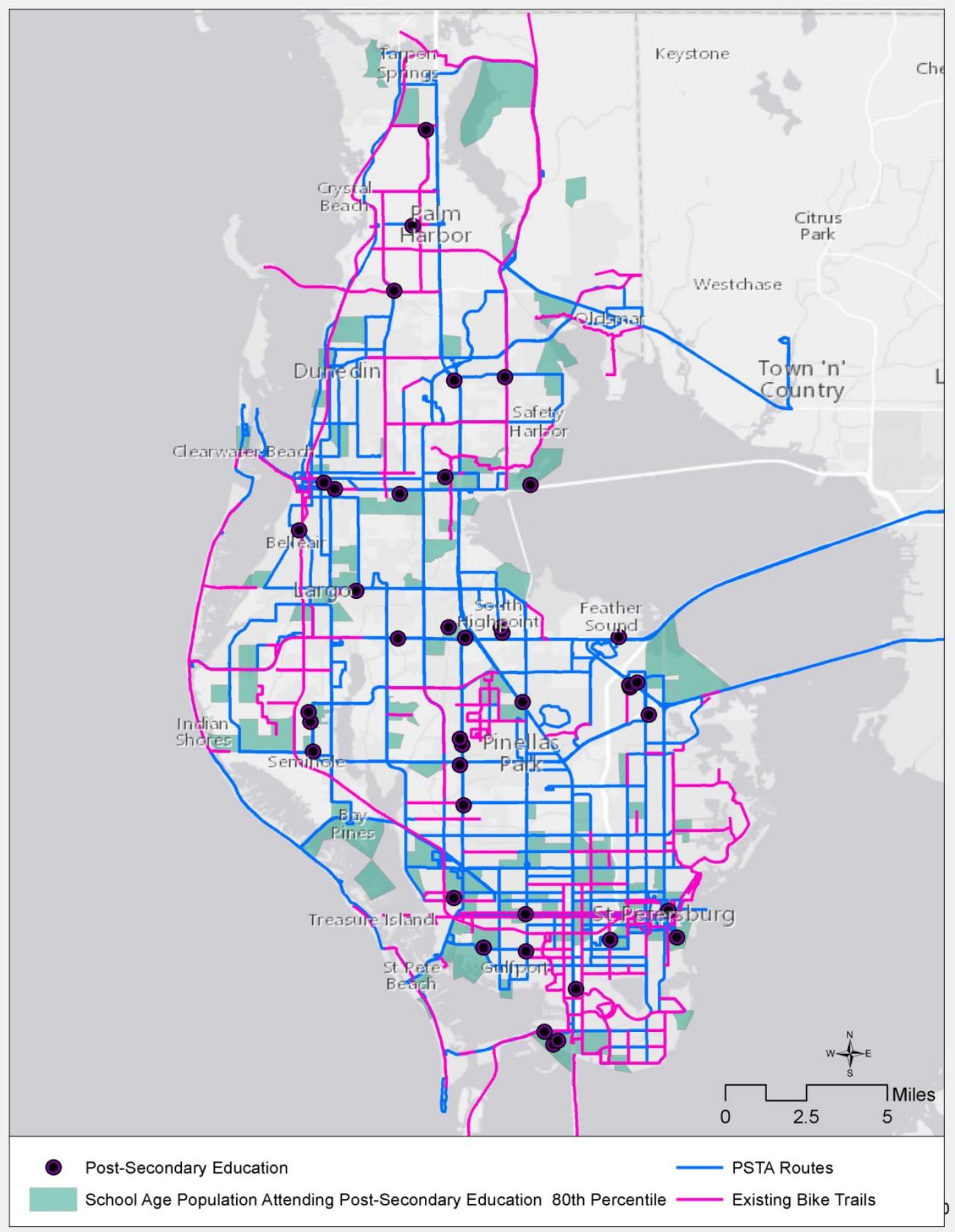

Figure 19: Locations in Pinellas County having the highest concentrations of post-secondary school age population

\section{Define the Sub-Area within which Travel is Likely to Take Place between} Origin and Destination

By applying a buffer of 2,000 feet (approximately an 11-minute walk) around the trails, over 1,750 transit/trail intersections were identified by mapping bus stops in proximity to trails in the bi-county region. Planners may choose a different buffer 
size, based upon data they may have indicating the distance their selected travel market is willing to walk or bicycle between the trail and transit stop.

Many staff hours would be required to survey all 1,750 of these locations.

Therefore, a subarea selection process was used. A subarea is a smaller portion of the county upon which to focus greater planning attention. The selection of subareas is intended to enable planners to drill down to locations where prioritizing improvements has the greater potential to serve a selected travel market to use a trail/transit multimodal combination to complete their trips. Sub-areas with greater potential will contain transit and trails between locations with higher concentrations of the selected travel market and the selected desired destination types.

One sub-area in Hillsborough County and one subarea in Pinellas County were selected based on observations of the built environment and socio-demographic characteristics.

Subarea selection was conducted by using widely available demographic data, local transit data and trail data. Using these data with GIS, Census block groups were evaluated based on the availability of transit service, proximity to trails, and larger concentrations of the example travel market-low income workers-and employment opportunities. The general area between large numbers of low income worker households and large numbers of jobs becomes the subarea, within which there may be transit service and trails. For the senior travel market, the selected trip purpose of interest is access to recreational opportunities. For the college student market, the trip purpose of interest is the school campus location.

The more rural sections of Hillsborough County (eastern and southern county) have large areas of lower income households that might benefit from these trail/transit connections. However, as illustrated in Figure 20, there are fewer existing bicycle trails and less transit service in the southern and eastern parts of the county, so 
opportunities to connect the lower income workers with jobs via improved transit and trail connections are low.

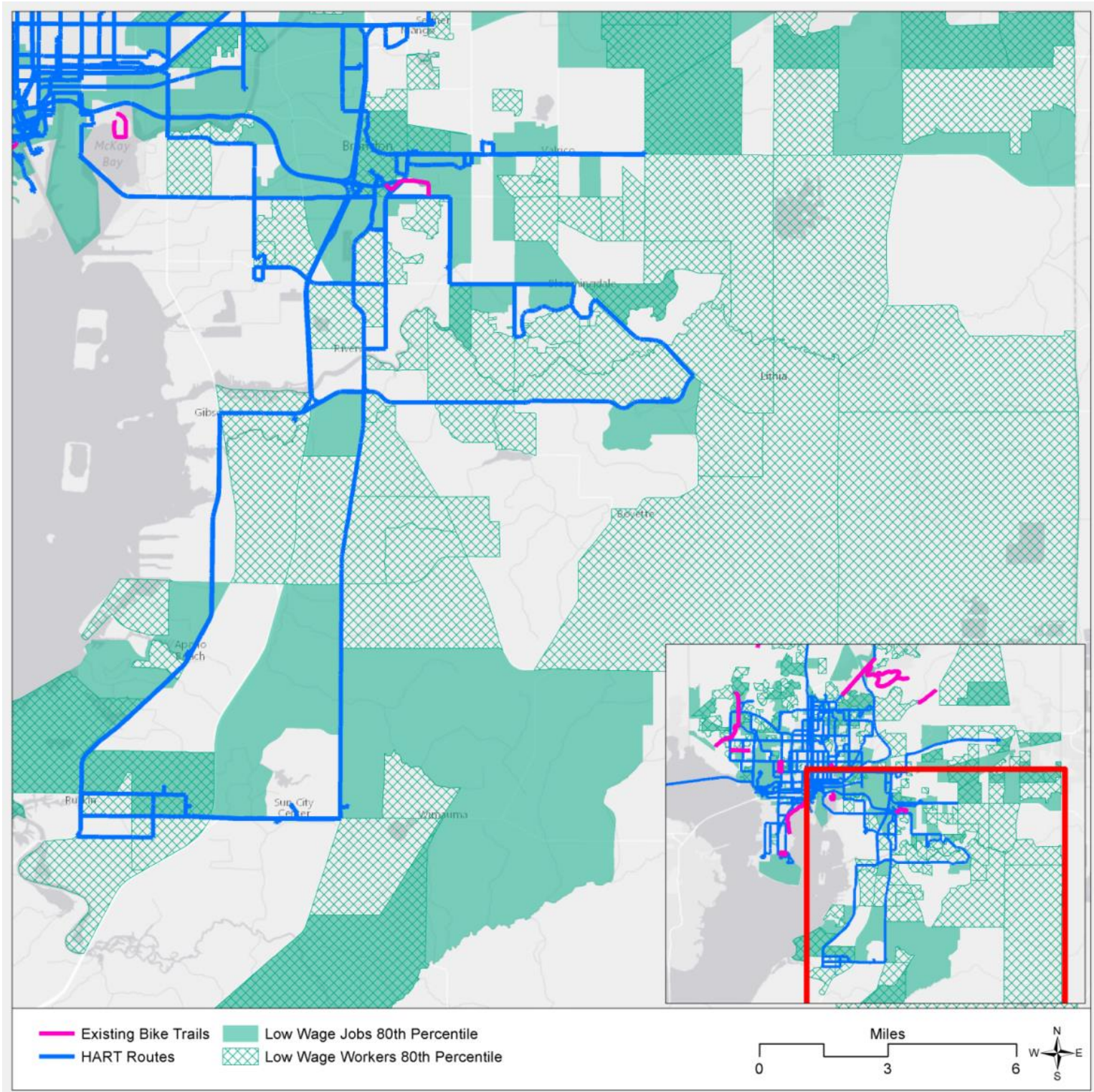

Figure 20: Jobs and lower income workers in southern Hillsborough County

The northern section of Hillsborough County has more transit service and bicycle trails, containing two areas that are more potentially suited as a subarea to select for further evaluation. The two areas in the northern (Bruce B. Downs Trail area) and northwestern (Upper Tampa Bay Trail area) parts of Hillsborough County both have transit service and trails between the home and work locations of low wage workers, making these more suitable potential sub-areas. These conditions 
illustrate suitability for further evaluation. Figure 21 illustrates the higher distributions of the employment opportunities and low wage workers.

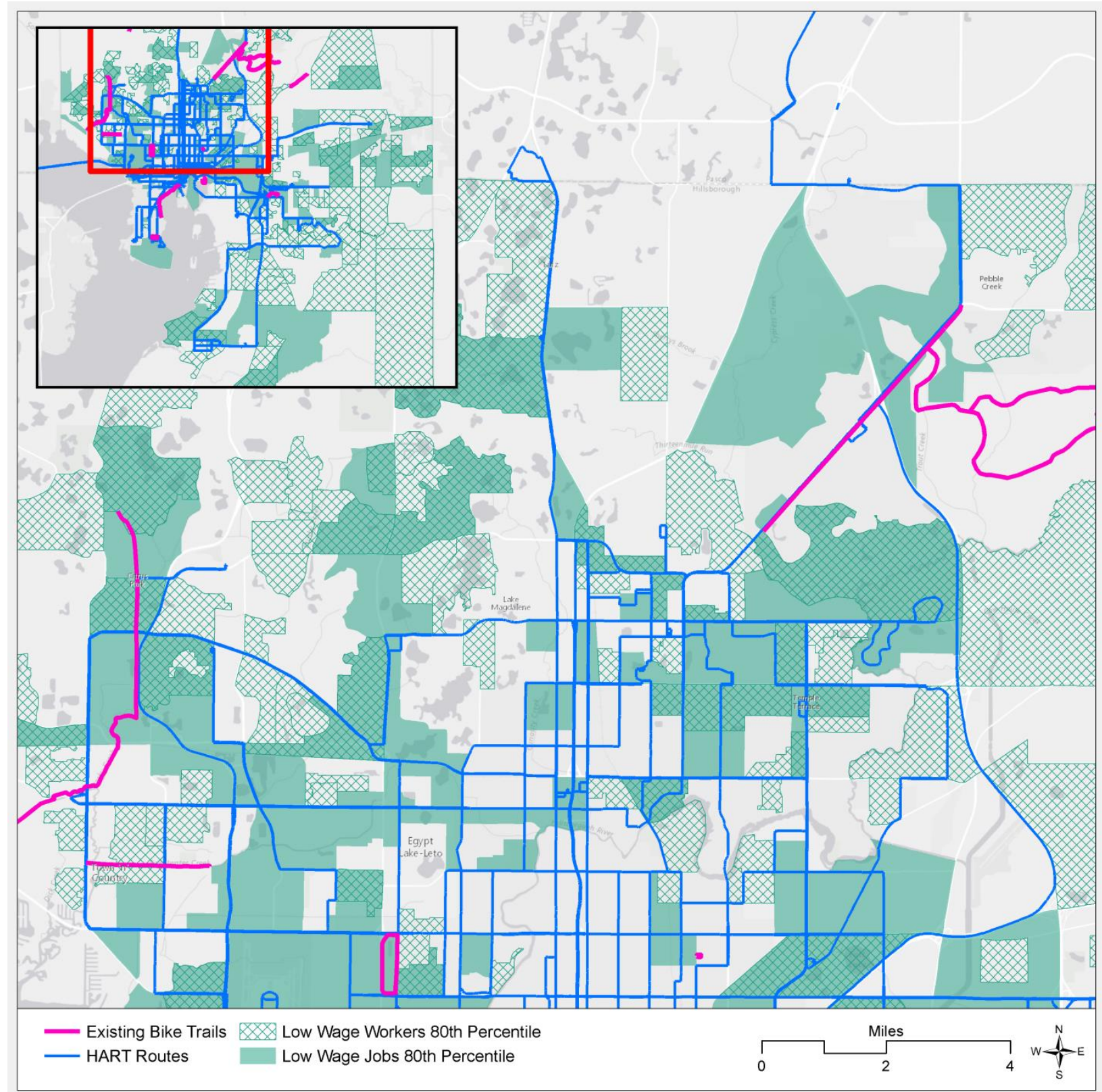

Figure 21: Jobs and lower income workers in northern Hillsborough County

An evaluation of the employment accessibility helps differentiate the two areas. The area with greater employment accessibility by transit will be better suited as a subarea because transit/trail connectivity improvements that connect to employment opportunities may have a greater likelihood of serving the work trip. Using the SLD, the number of jobs accessible by transit can be mapped and used to 
evaluate the area. Figure 22 illustrates the employment accessibility via public transit routes in northern Hillsborough County.

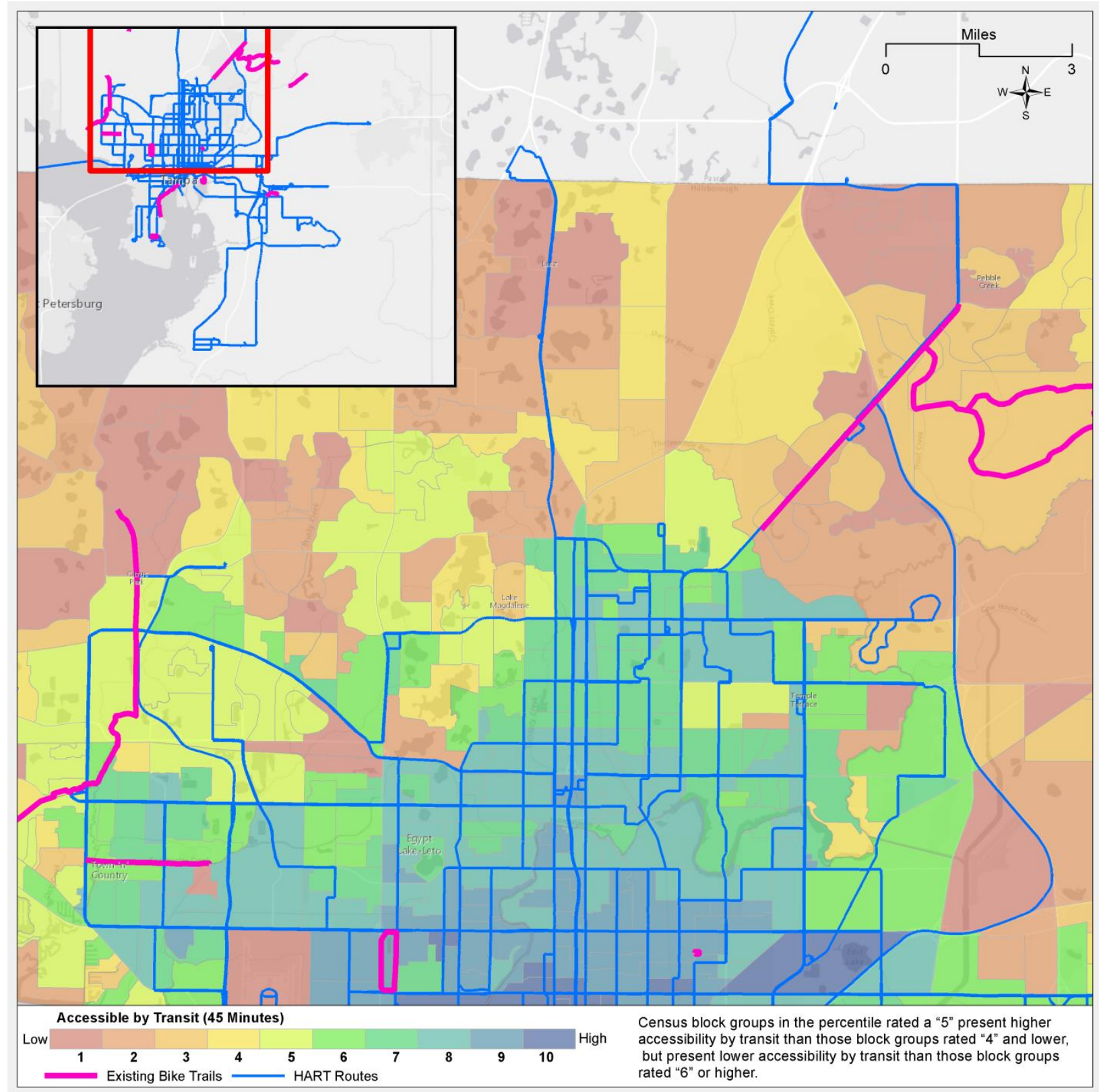

Figure 22: 45-minute transit accessibility to employment

To interpret this, for example, those Census block groups in the percentile rated a " 5 " represent block groups with a larger number of jobs that are within a 45 -minute transit trip within the HART service area than those block groups rated "4" or lower. Those Census block groups in the percentile rated a " 5 " also represent a lesser 
number of jobs that are within a 45-minute transit trip within the HART service area than those block groups rated a "6" or higher.

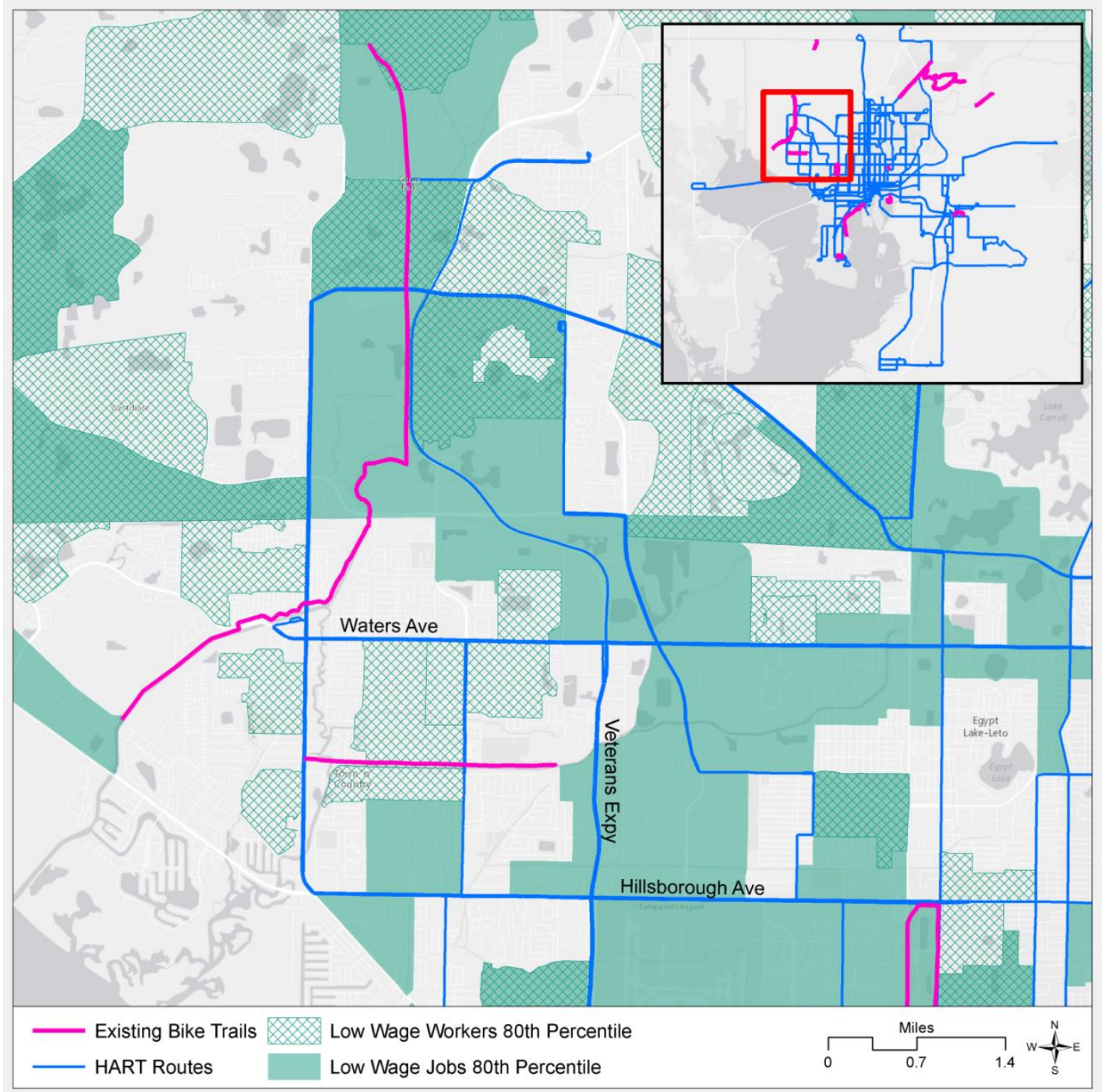

Figure 23: Selected Hillsborough County subarea

The Upper Tampa Bay Trail in northwestern Hillsborough County is located in an area with somewhat greater transit accessibility to employment than the area in the vicinity of the Bruce B. Downs Trail, as indicated by more green areas nearer to the Upper Tampa Bay Trail in Figure 22. There also are a greater number of transit/trail intersections. In contrast, the Bruce B. Downs Trail is more redundant as it parallels transit service. The longer length of the Upper Tampa Bay Trail provides greater opportunity to serve travel purposes and more transit connections. Consequently, the transit and trail conditions as well as the distribution of lower income workers and jobs makes the northwestern part of Hillsborough County better suited for further evaluation. Figure 23 contains the transit routes, trails and 
the low income household and work locations and the boundaries of the selected subarea in Hillsborough County.

In localities with extensive trail systems and/or public transit routes, the number of existing and potential trail/transit connections could be large, making investigations difficult if there is no way to prioritize the connections for evaluation. Establishing a subarea is used because it provides a means to narrow down the focus to those transit/trail connections that are of most importance to accomplishing a defined planning goal of the locality.

By contrast, Pinellas County is more urbanized than Hillsborough County and has areas of lower income workers and jobs spread throughout the county in clusters located within city centers. Further, the more developed trail system covers more of the county than Hillsborough's trail system. As a result, Pinellas County contains more potential subareas than Hillsborough County. The challenge with Pinellas County is selecting among the multiple areas. Figure 24 identifies the multiple locations, circled in red, which may serve as candidate subareas. These areas have trail connections to transit service between jobs and workers. Again, planners using this method could choose, based on the availability of staff resources, to survey transit/trail connections in all these areas.

Alternatively, planners also could choose to apply additional analysis to prioritize a subarea. Two decisions guided the selection of the Pinellas subarea. First, given the long length of the county's Pinellas Trail, and the transportation potential that affords, it was decided that the subarea should include the Pinellas Trail. Secondly, the ideal subarea should be positioned between large numbers of employment opportunities and locations of larger low wage worker populations. An area in the west central portion of the county shows where the Pinellas Trail is located between a concentration of lower income households on the west side, and jobs on the east side. Furthermore, there is less transit service in the area than other potential subareas, such as south St. Petersburg, making the connections to the trail for transportation purposes potentially more valuable. This area is centrally located between the City of Clearwater to the north, large industrial parks and the airport district to the east, the City of St. Petersburg to the south, and tourism jobs to the west.

In the central part of Pinellas County, one observes that the primary development pattern is commercial development along the major east-to-west and north-tosouth highways with enclaves of residential neighborhoods within the large blocks created by the grid street system. The major streets are multi-lane divided facilities. Not all of the streets have bicycle lanes. Ulmerton Road, Ridge Road SW, and Walsingham Road have bike lanes in the vicinity of the Pinellas Trail, but the remaining east-to-west and north-to-south streets do not have bicycle lanes. Pinellas MPO maps show that several of these main streets have proposed bicycle/shared use lanes. Even with the bicycle lanes, these wide streets with heavy traffic may be intimidating to ride upon for many bicyclists. The subarea selected for study includes portions of the City of Largo and the City of Seminole, where they are traversed by the Pinellas Trail. Furthermore, portions of the selected subarea fall outside the $1 / 4$-mile buffer service area of PSTA (PSTA 2014, Map 2-2),' making a trail connection potentially more valuable for a transportation purpose. As a result, it was concluded to select the subarea, shown in red in Figure 
25 , to serve as the location within which three transit/trail connection scenarios would be identified and evaluated further.

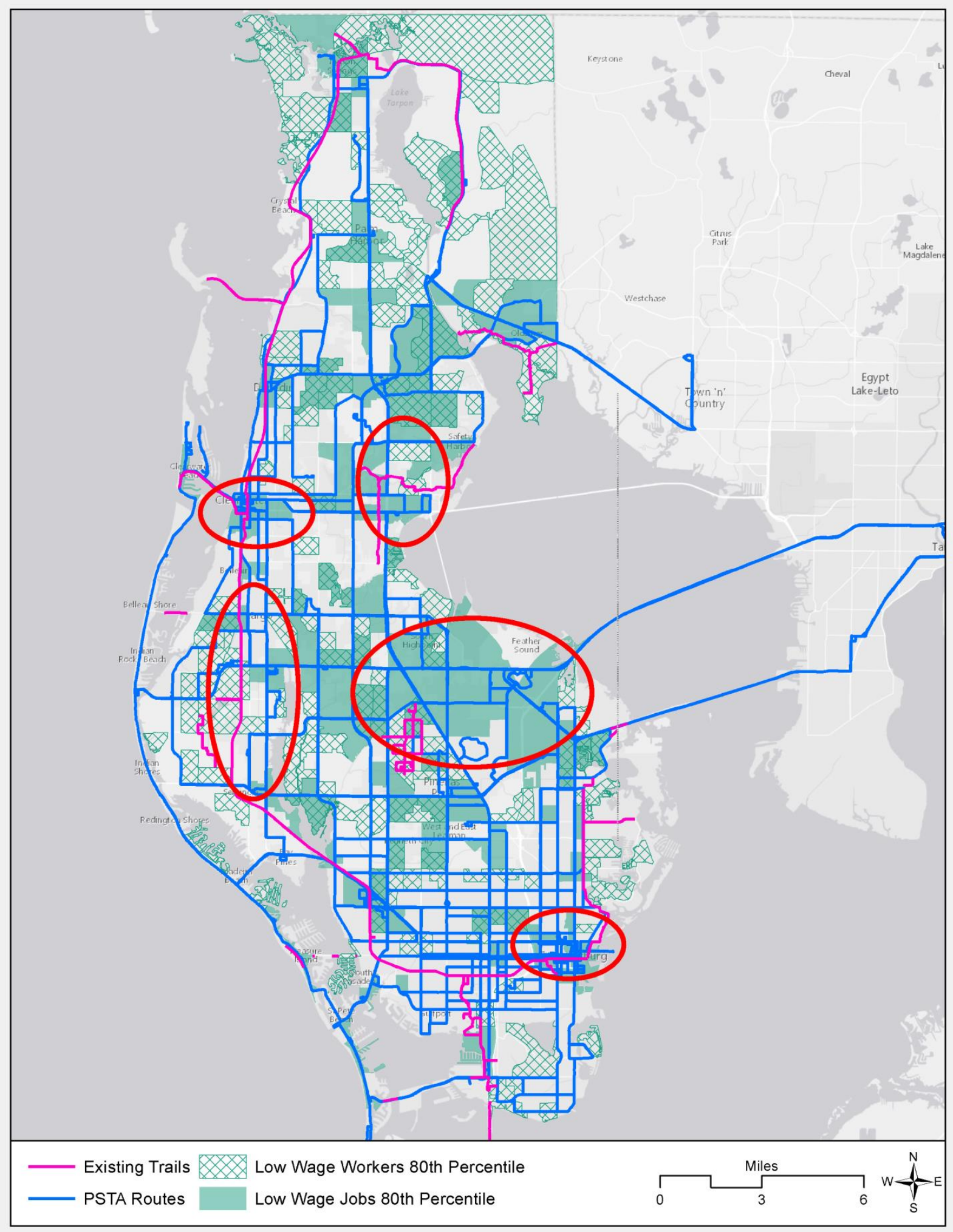

Figure 24: Pinellas County potential subareas 


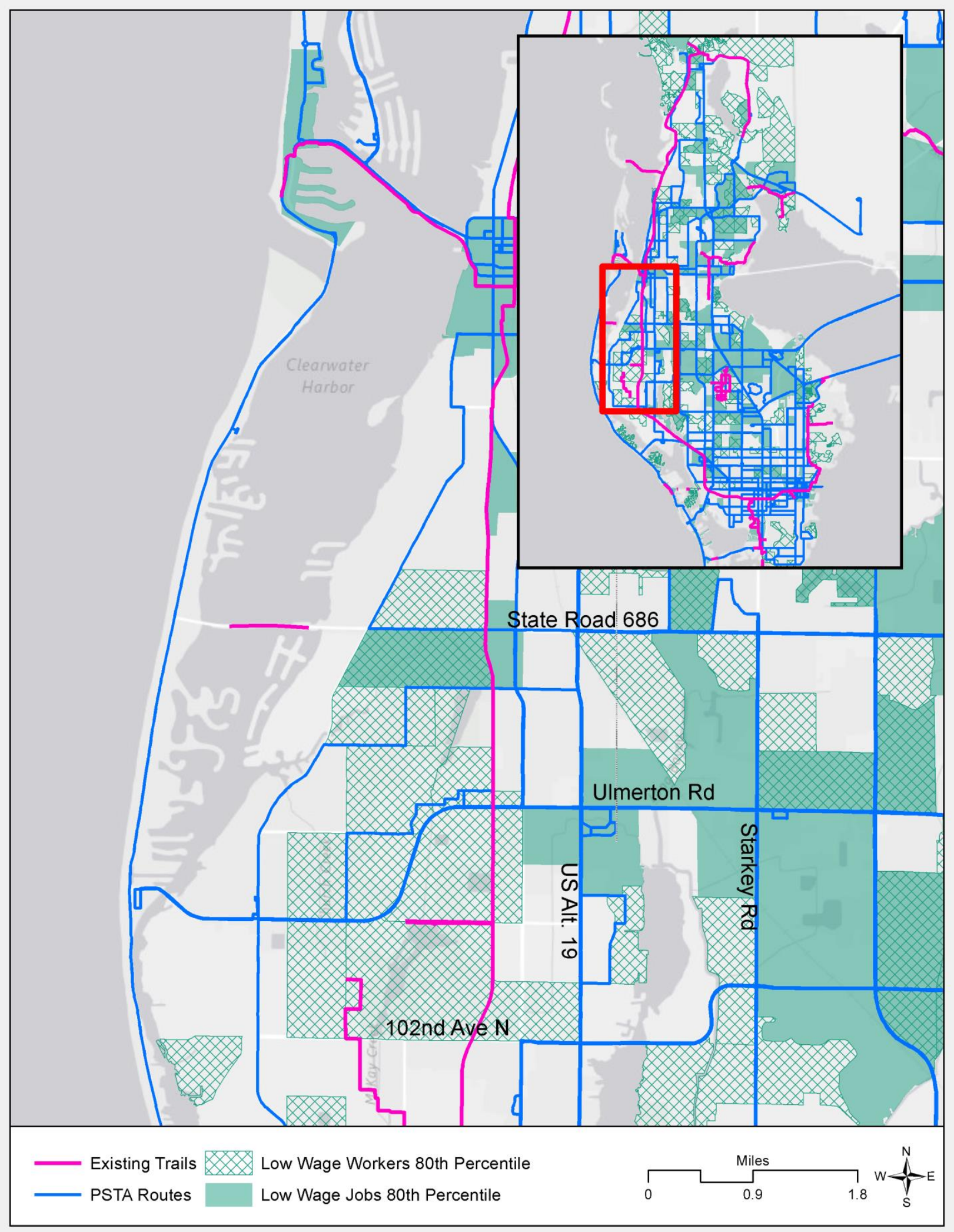

Figure 25: Selected Pinellas County subarea 


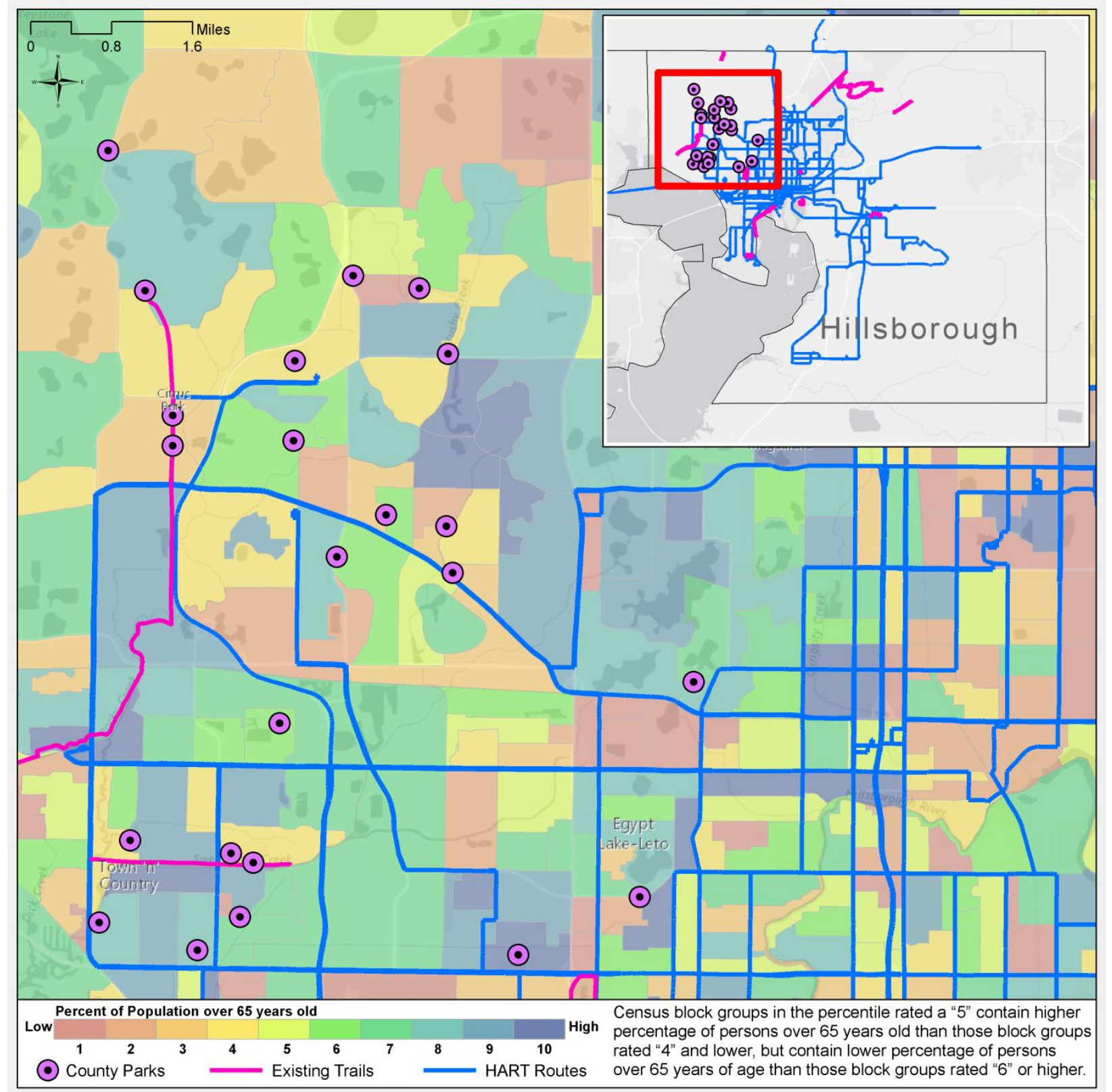

Figure 26: Location of relative numbers of Hillsborough County seniors by census block group and the locations of recreational opportunities

For the senior population, Figures 26 and 27 below demonstrate the selection of the senior travel market, defined as persons aged 65 and over, and the location of parks and recreational opportunities. The focus of Figure 26 was on the area where the Upper Tampa Bay Trail has the potential to provide transportation service and connect to HART service to enable a senior traveler to access recreational opportunities. Likewise, the focus of Figure 27 was on the Clearwater area of Pinellas County. 


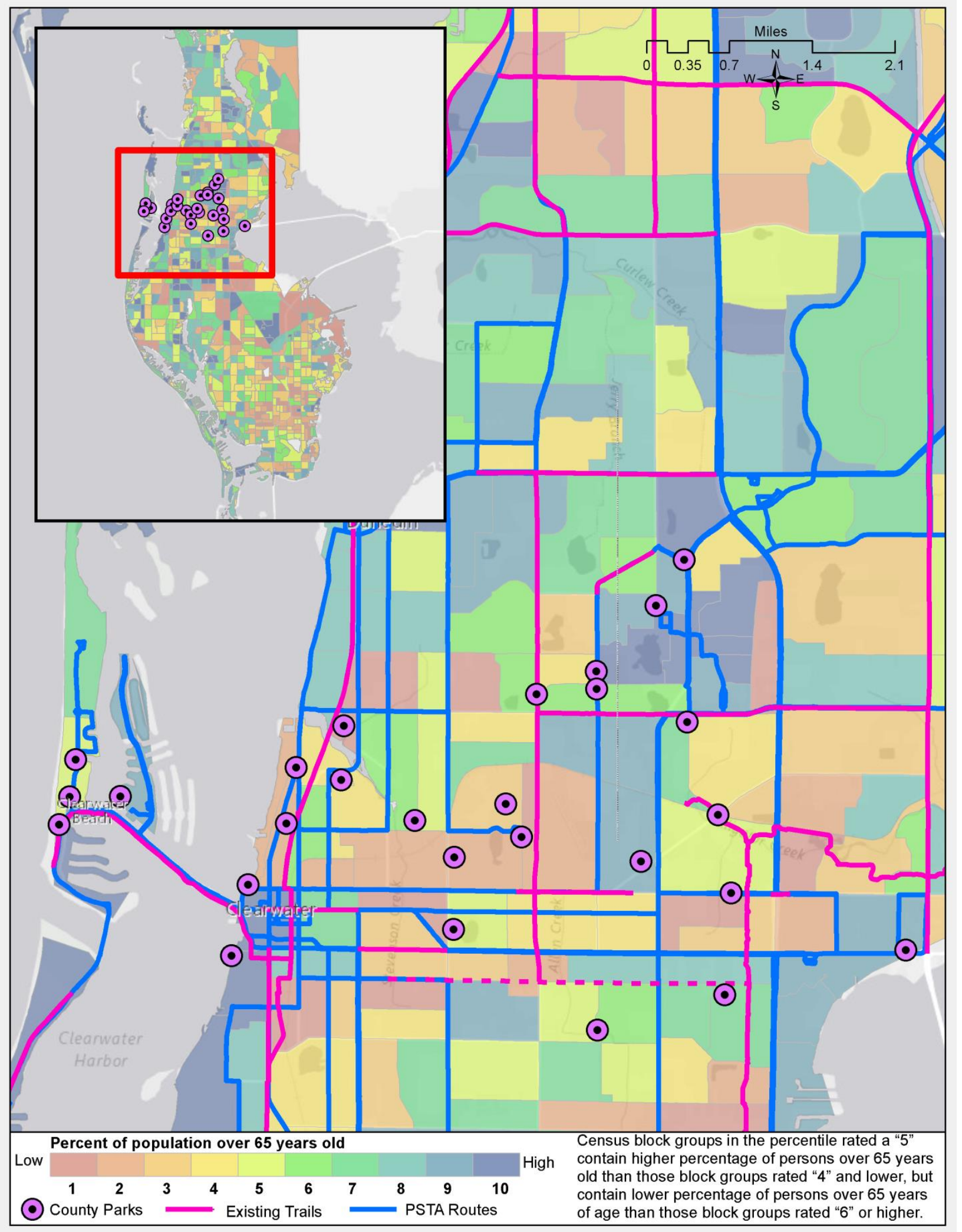

Figure 27: Location of relative numbers of Pinellas County seniors by ensus block group and locations of recreational opportunities 


\section{Develop a Typology that Organizes Trail/Transit Intersections into Sets Having Similar Characteristics}

The next step is to identify trail/transit intersections within the selected subareas of interest and apply a typology that organizes trail/transit intersections into sets having similar characteristics. The intersections of trails and transit routes are the set of potential locations where connectivity improvements can be made. Site inspections narrow the set of transit/trail connections to those that need improvements.

With regard to the earlier case study of the WMATA rail station typology, this was a way to generalize the operating conditions and attributes of the areas as they affect bicyclists and pedestrians, with general improvement concepts developed for each of the station types as a point of departure for developing specific recommendations from on-site observations. This is a concept that can be borrowed from the WMATA case study and applied to the trail locations in Hillsborough County and Pinellas County. Three types, or scenarios, were used.

1. Where a trail and a transit route intersect and connect (scenario 1 )

2. Where a trail and a transit route intersect but do not connect (scenario 2)

3. Where a trail and transit route are aligned close to each other but do not intersect (scenario 3)

These three scenarios were defined based on the level of intensity of improvements needed to make a safe and convenient transit/trail connection, with scenario 1 requiring the least investment in improvements and scenario 3 requiring the most.

Within the subareas for each county, three locations of public trail/transit connections were identified for further study, as examples of each of the scenarios. The selection of these locations was based on an attempt to find one example in each county of conditions where a public trail connects with public transit service, but for which improvements can be made to make the connection safer and more convenient. One additional example in each county was selected where there is an intersection of the public trail with transit service but for which there is the lack of a serviceable connection. Lastly, one example in each county was selected where a public trail alignment comes close to but does not intersect with public transit service. In these cases, recommendations are made for pursuing the development of a safe and convenient connection. During site visits, it was found that the connections between bus routes provided by Hillsborough Area Regional Transit (HART) and Pinellas Suncoast Transit Authority (PSTA) and the existing public trails have been designed and developed with care. Where a public trail crosses a street served by public transit, there is almost always a bus stop within sight of the crossing. Unless a location is unsafe for a bus to stop, the bus stops have been selected to serve destinations and connections, including with public trails. This may or may not be the case for other urban areas. For purposes of demonstration, Table 6 below lists the locations for the six proposed transit/trail connection scenarios in Hillsborough and Pinellas Counties. In these cases, recommendations are made for infrastructure and other program improvements to upgrade the intersection to a safer and more convenient connection. 
Table 6: Location of Proposed Trail/Transit Connection Scenarios in Hillsborough and Pinellas Counties

\begin{tabular}{|c|l|l|}
\hline $\begin{array}{l}\text { TRAIL CONNECTION } \\
\text { SCENARIO }\end{array}$ & HILLSOROUGH COUNTY & PINELLAS COUNTY \\
\hline $\begin{array}{l}\text { 1. } \\
\begin{array}{l}\text { Trail/transit } \\
\text { connection needing } \\
\text { improvements }\end{array}\end{array}$ & $\begin{array}{l}\text { HART Bus Route } 39 \text { with Upper } \\
\text { Tampa Bay Trail at Sheldon Road }\end{array}$ & $\begin{array}{l}\text { PSTA Bus Route } 66 \text { with Pinellas Trail } \\
\text { at } 8^{\text {th }} \text { Avenue SW in Largo }\end{array}$ \\
\hline 2. $\begin{array}{l}\text { Trail/transit } \\
\text { intersection but no } \\
\text { connection }\end{array}$ & $\begin{array}{l}\text { HARTFlex Town 'N Country with } \\
\text { Upper Tampa Bay Trail at Linebaugh } \\
\text { Avenue }\end{array}$ & $\begin{array}{l}\text { PSTA Bus Routes } 61 \text { and } 59 \text { with } \\
\text { Pinellas Trail at Gooden Crossing Road } \\
\text { and Ulmerton Road }\end{array}$ \\
\hline $\begin{array}{l}\text { Trail and transit } \\
\text { alignments are } \\
\text { proximate but do not } \\
\text { intersect }\end{array}$ & $\begin{array}{l}\text { HART Northwest Transfer Center } \\
\text { with Upper Tampa Bay Trail at } \\
\text { Channel Park Trailhead by W. } \\
\text { Waters Avenue Bridge }\end{array}$ & $\begin{array}{l}\text { PSTA Bus Route } 58 \text { runs proximate to } \\
\text { the Pinellas Trail at } 96^{\text {th }} \text { Place North in } \\
\text { Seminole }\end{array}$ \\
\hline
\end{tabular}

For Hillsborough County, the subarea selected for further study is characterized by suburban communities served by the Upper Tampa Bay Trail, illustrated in Figure 28. The Hillsborough County Comprehensive Plan includes a Livable Communities Element that contains 22 Community Plans. (Hillsborough County 2008a) These Community Plans represent communities that are located in the urbanizing areas of unincorporated Hillsborough County. These are areas of the county that surround the City of Tampa and touch portions of Old Tampa Bay and Hillsborough Bay, as well as Tampa Bay further to the south. Community Plans were developed to enable citizens to provide more specificity to the way their communities will grow, including a more detailed land development code associated with those plans.

Hillsborough Scenarios 1 and 3 are located within the Town 'N Country community. The Town ' $N$ Country community has supported new development in recent years, including Alonso High School that opened in 2001. The new developments of single family detached homes, condominiums, and apartment complexes are dispersed. The Town 'N Country Community plan emphasizes renewal of older commercial centers, the development of town centers and neighborhood squares, residential renovation, relief of traffic congestion, use of traffic calming, maintenance of drainage facilities, and improvements to sidewalks, bicycle lanes, and trail connectivity. (Hillsborough County 2008b, 69-73)

Hillsborough Scenario 2 is located within the Greater Carrollwood-Northdale community. The Greater Carrollwood-Northdale area features North Dale Mabry Highway that is a multilane divided highway around which commercial development has located. The Greater Carrollwood-Northdale Community Plan calls for the discouragement of strip commercial development and the encouragement of redevelopment in community activity centers. The community plan calls for the creation of walkable environments that support public transit, an interconnected system of parks, open spaces, and amenities, with special attention to pedestrian access to the Upper Tampa Bay Trail. (Hillsborough County 2008c, 197-213) 


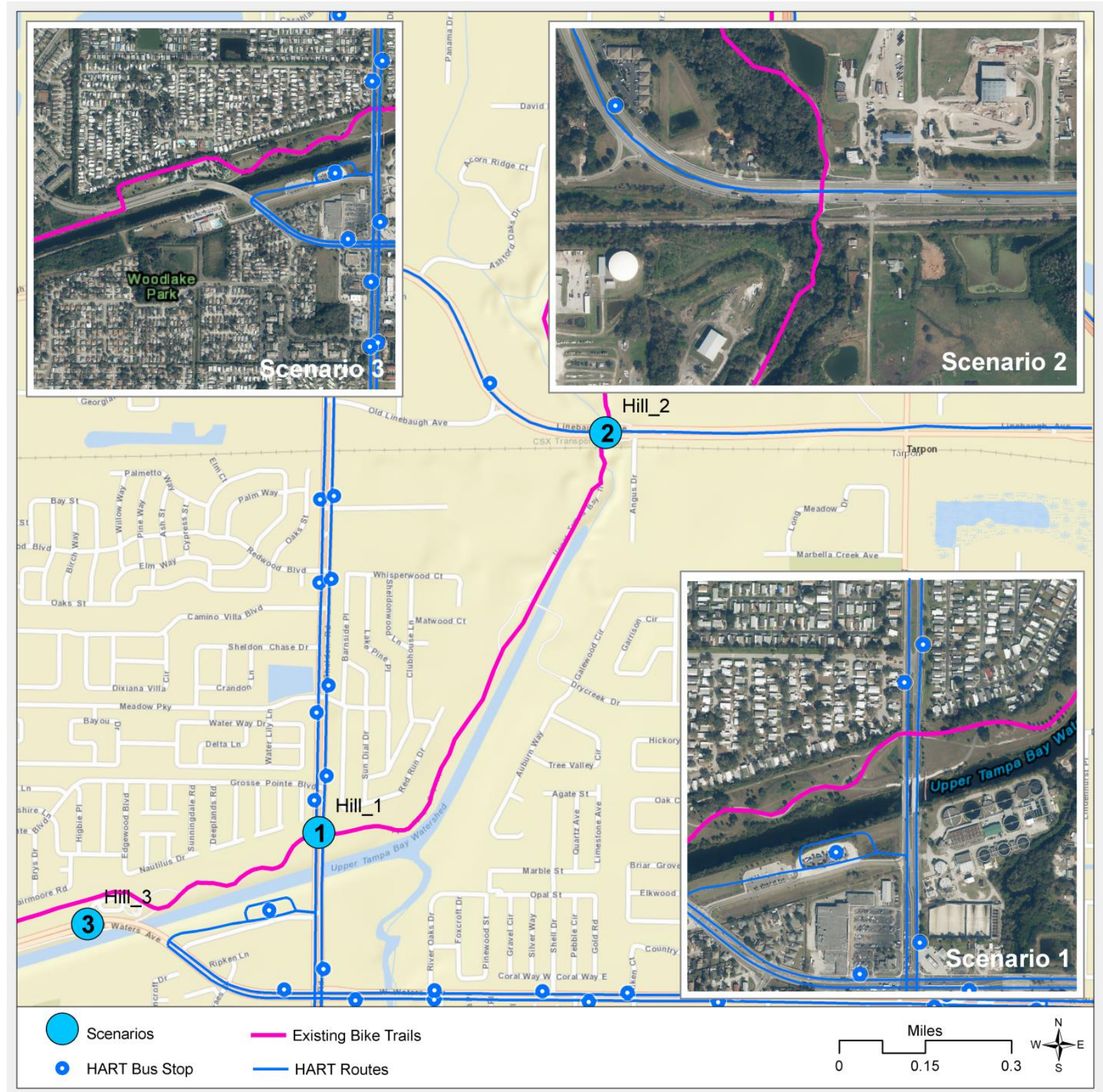

Figure 28: Hillsborough County subarea with three selected crossing locations 
In Pinellas County, the three proposed transit/trail connection scenarios within the Pinellas subarea are illustrated in Figure 29.

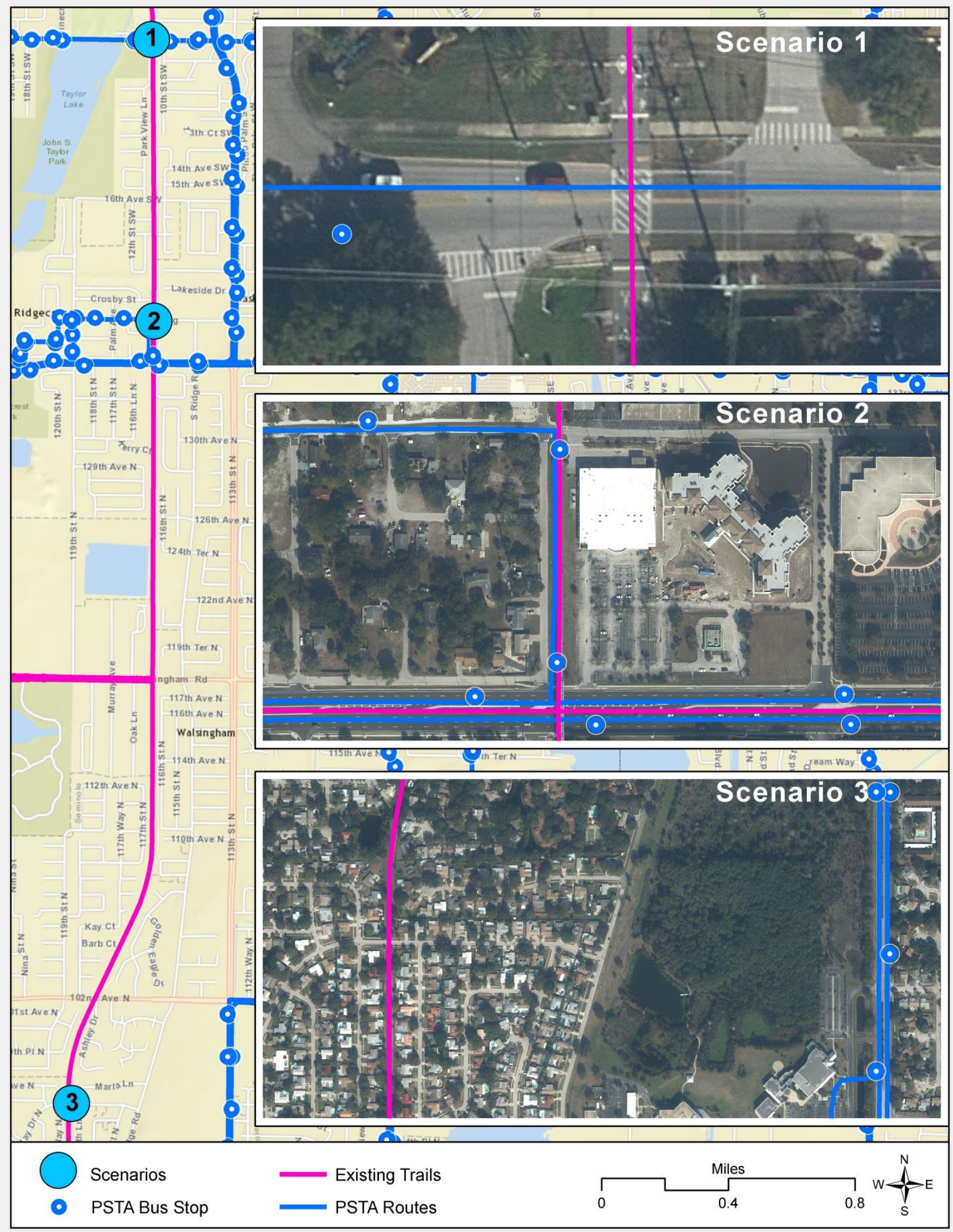

Figure 29: Pinellas County subarea with three selected crossing locations 


\section{Conduct Site Observations and Inventories, with Recommendations for Strengthening Transit/Trail Connections at Selected Sites}

Task 4 of this project represented the final step in the recommended methodology. At this stage in the analysis process, the analyst will have used community input to select a transportation goal, travel market and trip purpose. As was demonstrated in earlier sections of this report, GIS spatial analysis would have been conducted to map the locations of transit routes and stops relative to existing and programmed trails, using demographic data to map the locations of greater concentrations of the selected travel market and trip destinations of interest. In some cases, these trip destinations could be defined generally as locations, for example, in Census block groups, of greater intensities of employment. In other cases, these trip destinations could be specifically defined using points to depict the exact locations for places like recreation centers or college campuses and trade schools. Because the purpose is to make use of multimodal connections of public transit and trails, the maps will show where there are transit/trail connection opportunities that are located within the subareas of the larger study area. These subareas are where the travel market must traverse to reach the destination. The subarea narrows down the number of transit/trail connections to those that are a priority for closer consideration because it is these transit/trail connections that could be used by the travel market to complete their journey.

The next step is to go out into the field and examine these locations where it is desired to improve transit and trail connections. For purposes of this study, a typology of three different kinds of transit/trail connection scenarios was defined based upon the general level of effort or investment required to strengthen these intermodal connections. Scenario 1 represents examples where the trail and transit service connect reasonably well and just need some minor improvements to make the connection stronger. Scenario 2 represents examples where the transit service and trail intersect but do not connect well. This could be because of a lack of a bus stop at the trail crossing, or some physical barrier. In these cases, more work or investment would need to be done to make a safer and more functional connection possible. Scenario 3 represents cases where the transit service and trail are closely aligned at some point but do not intersect at all. In these cases an easement might need to be established for a trail spur to the transit stop or by on-street improvements. One example of each scenario was identified for Hillsborough County and for Pinellas County through site observations of candidate trail/transit intersections identified from the GIS spatial analysis. Six locations were identified and illustrated above. Chapter 4 discusses the results of the evaluation of the six locations of existing and potential transit/trail connections. 


\section{Chapter Four}

\section{Evaluation of Existing and Potential Transit/Trail Connections}

An inventory template was developed to guide the site observations. The guidance is intended to help identify issues relating to the transit/trail connection and point to areas where improvements could be made. These become the starting point for identifying recommendations. Each location was observed with the use of the inventory template. The completed inventory sheets are in Appendix A. A blank template is included in Appendix B and is also provided in PDF format as a separate attachment. The template can be completed using a tablet PC or iPad.

Alternatively, mobile field mapping and data collection software could be used, which can be customized to user needs.

The inventory template allows the user to collect the details about the transit/trail connection. These include basic information, such as trail and street ownership, neighborhood location and the bus routes crossing the trail. A second section in the inventory allows the user to collect information about the planning context, and this can be completed prior to going out into the field. The planning context might enable discovery of various opportunities, such as land development proposals in the vicinity of the transit/trail crossing or other characteristics that might present possibilities for trail improvement funding. The third section of the inventory template is previously collected data regarding the level of activity, including transit ridership near the transit/trail crossing, and any other characteristics of the transit riders that may have been collected by the transit agency through surveys or other means. It would also include any count data for motor vehicle traffic, pedestrian traffic and bicycle traffic.

The fourth section collects information about the transit/trail crossing location, including physical characteristics of the trail, trail operations, planning constraints and opportunities that can be identified through a perusal of relevant local plans, an inventory of transit service characteristics, and an inventory of the street characteristics. Places in the inventory template are available for notes on potential recommendations for improvements. A fifth section of the inventory template is for the Scenario 2 where trail and transit intersect but do not connect well. Lastly, there is a section for the Scenario 3 where transit and trail come close together but do not intersect. The results of the site observations for each of the selected example locations is discussed below.

The inventory template can be modified by planners to incorporate elements of physical design guidelines or specific standards for trail crossings with streets, which may have been adopted by their localities. Two such examples, referenced earlier, include Petritsch, Theodore A. and Christopher B. Fellerhoff 2014, and University of North Carolina Highway Safety Research Center 1999.

\section{Hillsborough County, Upper Tampa Bay Trail \\ Scenario 1: Trail and Public Transit Connect: Sheldon Road}

The HART Route 39 serves the Town 'N Country/Citrus Park area and goes to the Netpark Transfer Center via Busch Boulevard. From the standpoint of our selected travel market of low income workers, the Route 39 provides access to many job 
opportunities, such as various shopping centers, the North Hillsborough County Health Center, two high schools, the State of Florida and Hillsborough County One Stop Resource Center, a public library and Busch Gardens Theme Park. A trail user accessing the Route 39 via the Upper Tampa Bay Trail covers a wide area with this intermodal connection. The trail connects at-grade with the Route 39 via Sheldon Road on the west end of the route. Figures 30 and 31 illustrate the Hillsborough Scenario 1. The Route 39 is an east/west route while the Upper Tampa Bay Trail runs generally north/south. During the peak weekday hours, Sheldon Road operates at level of service (LOS) E. Bus stops are located north of the trail within easy walking or riding distance. However, there are high residential subdivision walls on both sides of the street that limit the size of the bus stops and the amenities that can be placed there. Water was observed pooling in the sidewalk on the south side of the Sheldon Road bridge that crosses over Channel A.

Recommendations include adding bus route information to Hillsborough trails maps and information on how to access bus arrival times from the OneBusAway mobile phone app. Ideally, real time information would include whether space is available on the bike rack of the next bus. It also is recommended that the trail map not only provide information about recreational opportunities, but also about other destinations accessible via the trail and via a trail/transit journey. Likewise, it is recommended that the HART bus route map for the Route 39 show the trail connection location and to list trail connections in the legend where there is information on park-and-ride lots, express pick-up stops, and car/vanpool lots. It is recommended to provide a street sign identifying the Upper Tampa Bay Trail to passing motorists. It is recommended to consider drainage improvements on the Sheldon Road bridge sidewalk on the south side of the bridge.

If a bus patron is traveling with their bike and gets off the northbound Route 39 at the bus stop, he or she may have to walk the bike southbound on the sidewalk to access the trail. Some bicyclists might be tempted to ride in the bike lane against traffic. There is another bus stop prior to the trail going north on Sheldon Road but it is located farther away, just north of Waters Avenue. HART might consider moving this bus stop closer to the trail or provide a prerecorded announcement to disembark the bus at the Waters Avenue bus stop for those wanting to access the 
trail. This way, the bicyclist is on the correct side of the road to ride in the bike lane northbound to access the trail.

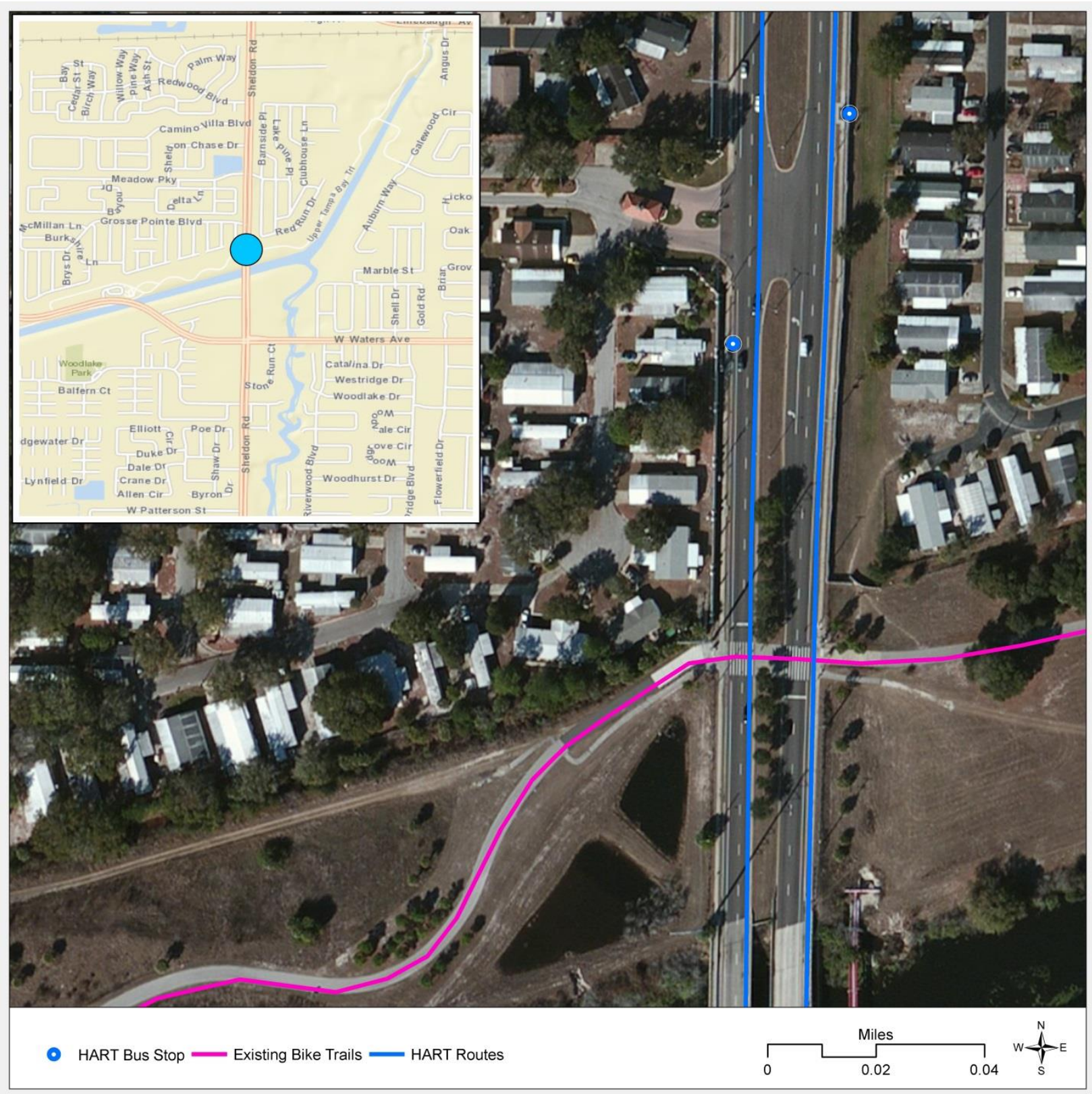

Figure 30: Hillsborough Scenario 1, HART Route 39 and Upper Tampa Bay Trail at Sheldon Road 


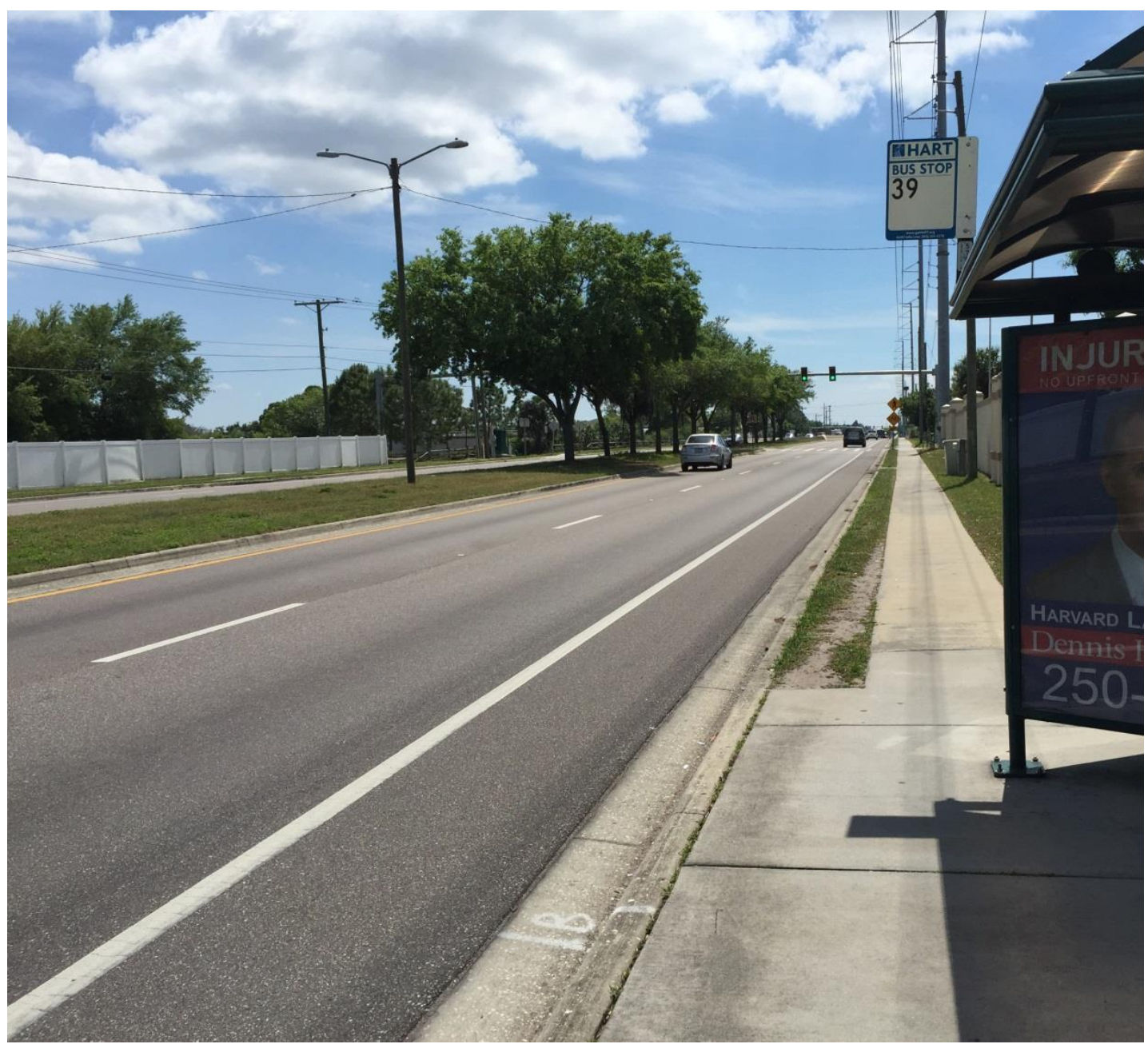

Figure 31: Hillsborough Scenario 1, Sheldon Road looking southbound at intersection with Upper Tampa Bay Trail

\section{Scenario 2: Trail and Public Transit Intersect but do not Connect: Linebaugh Avenue}

The HARTFlex Route Town ' $N$ Country is a bus trip by reservation. Service hours are weekdays from 5:15 a.m. to 7:00 p.m., with no weekend or holiday service. The HARTFlex route follows a clockwise loop eastbound along Hillsborough Avenue, then turns north via Montague Street and runs parallel to the Upper Tampa Bay Trail along Pistol Range Road. The route turns east along Waters Avenue, crosses the bridge and stops at the Northwest Transfer Center. The HARTFlex route then turns north onto Sheldon Road, then turns eastward along Linebaugh Avenue before turning south onto Wilsky Boulevard. The HARTFlex turns onto southbound Hanley Road, then passes through residential subdivisions before connecting again to Hillsborough Avenue. The driver can let a passenger off the bus at any other HART stop along the route going in the same direction. The HARTFlex route interlines with other HART routes in various locations, including Route 39 along 
Sheldon Road, Route 30 along Hanley Road, and Route 34 along Hillsborough Avenue. Figures 32, 33 and 34 illustrate the Hillsborough Scenario 2.

Travelers can access job opportunities along this HartFlex route, including several shopping centers, as well as Town 'N Country Hospital. Job seekers could also access the other HART routes that continue south and east, via the HARTFlex route where it crosses Waters Avenue. The Upper Tampa Bay Trail intersects with the HARTFlex Town ' $\mathrm{N}$ country toward the south end of the trail. This connection could provide job access opportunities to populations living north of Linebaugh Avenue, who travel southbound on the trail to the HARTFlex route along Linebaugh Avenue, which then continues south. The challenge with the HARTFlex route is the location of just a few stops along Linebaugh Avenue, none of whichare close to where the trail intersects Linebaugh Avenue. Figure 32 illustrates Scenario 2 where there are no bus stops nearby. Additionally, the HARTFlex route only goes in a clockwise direction, missing a quick connection to doctor, dentist, and law offices as well as Westchase Elementary School and several restaurants and retail establishments along Linebaugh Avenue west of the intersection with the trail. As described before, Linebaugh Avenue between Sheldon Road and Wilsky Boulevard presently is not densely developed; however, many "For Sale" signs along this segment indicate the possibility of new development of vacant parcels in the future.

Based upon the findings from the inventory, it is recommended that sun-baked and cracked signage be replaced at the trail. The signage also should include information about HART bus route connections via Linebaugh Avenue. Likewise, trail connections should be shown on the HART system map, where other intermodal information is found regarding park-and-ride lots, express pick-up stops, and car/vanpool lots. Rocky Creek floods during heavy rain, inundating the portion of the trail that goes under the Linebaugh Avenue bridge. During those times, trail users must leave the trail by taking the sidewalk that leads from the trail up to Linebaugh Avenue, and cross the street. East of the trail, there is a traffic signal at the entrance to the Northwest Solid Waste Transfer Station but no crosswalk. It is recommended to consider locating a crosswalk at this location to serve bicyclists and pedestrians. It also is recommended that HART consider providing a HARTFlex bus stop prior to the Linebaugh Avenue Bridge to serve trail users. Furthermore, it is recommended to review the direction of the HARTFlex route to see if changing it to the counterclockwise direction might add better convenience to passengers. 


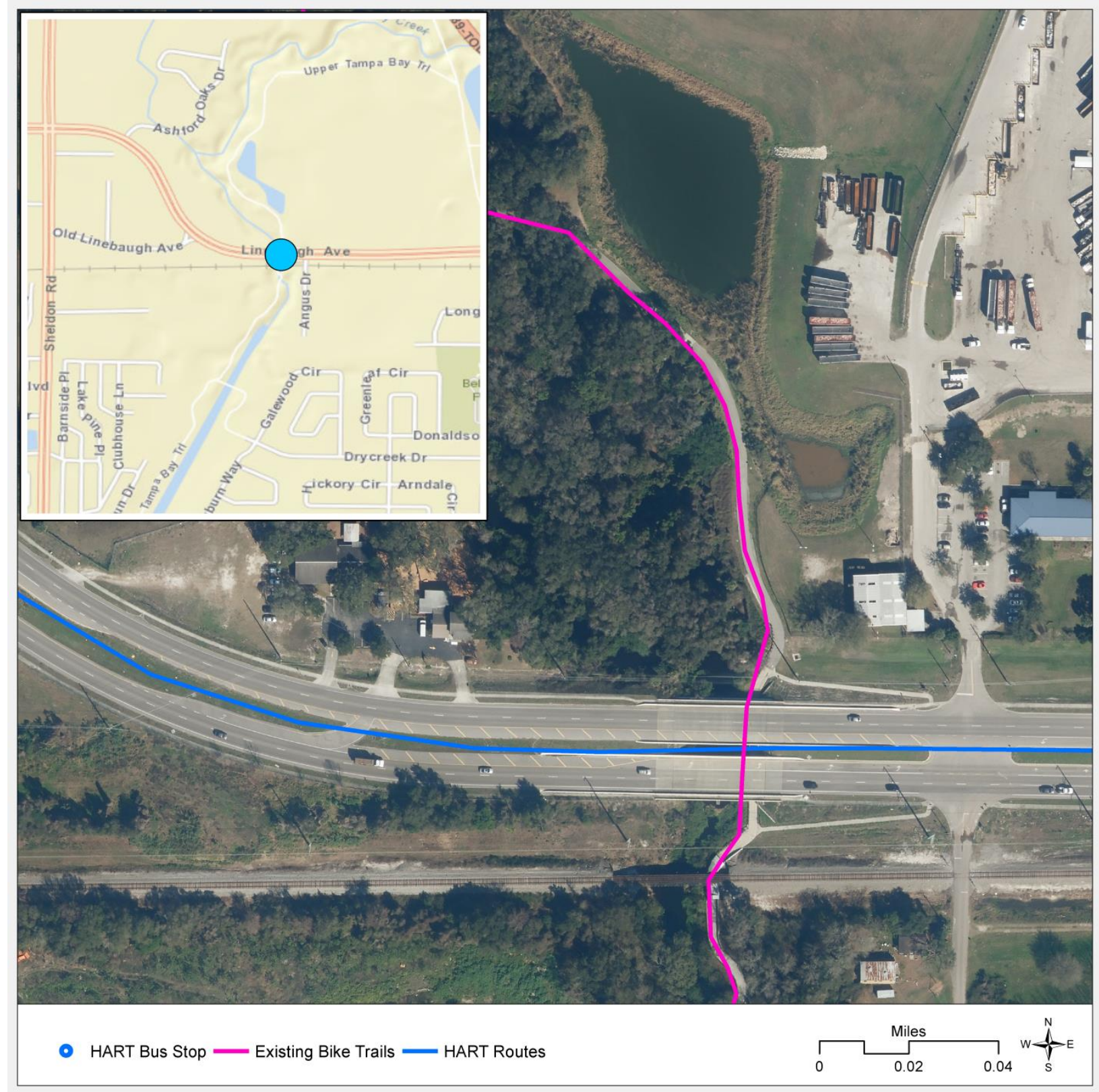

Figure 32: Hillsborough Scenario 2, HARTFlex Town 'N Country and Upper Tampa Bay Trail at Linebaugh Avenue 


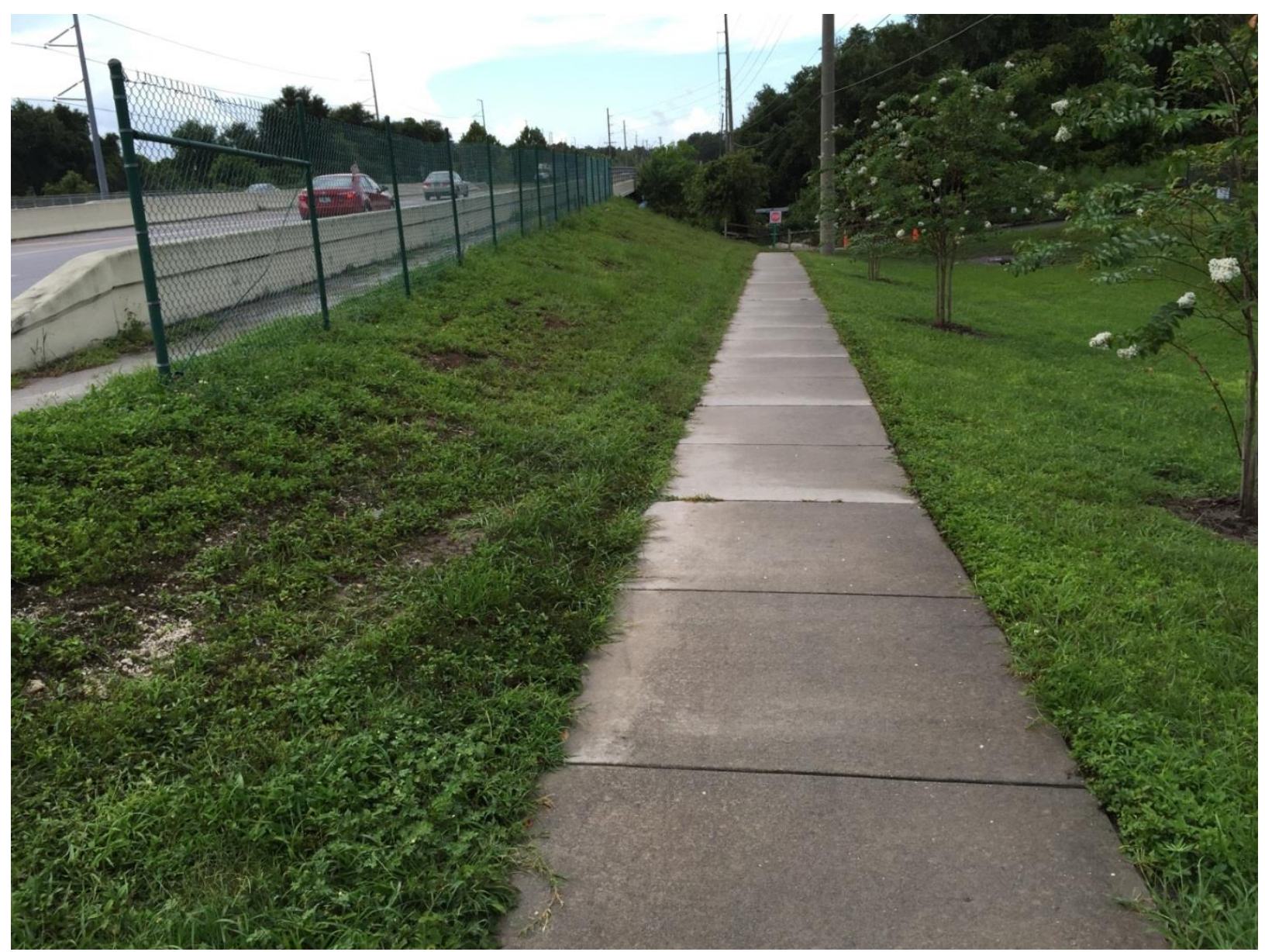

Figure 33: Hillsborough Scenario 2, sidewalk leading from Linebaugh Avenue to the Upper Tampa Bay Trail 


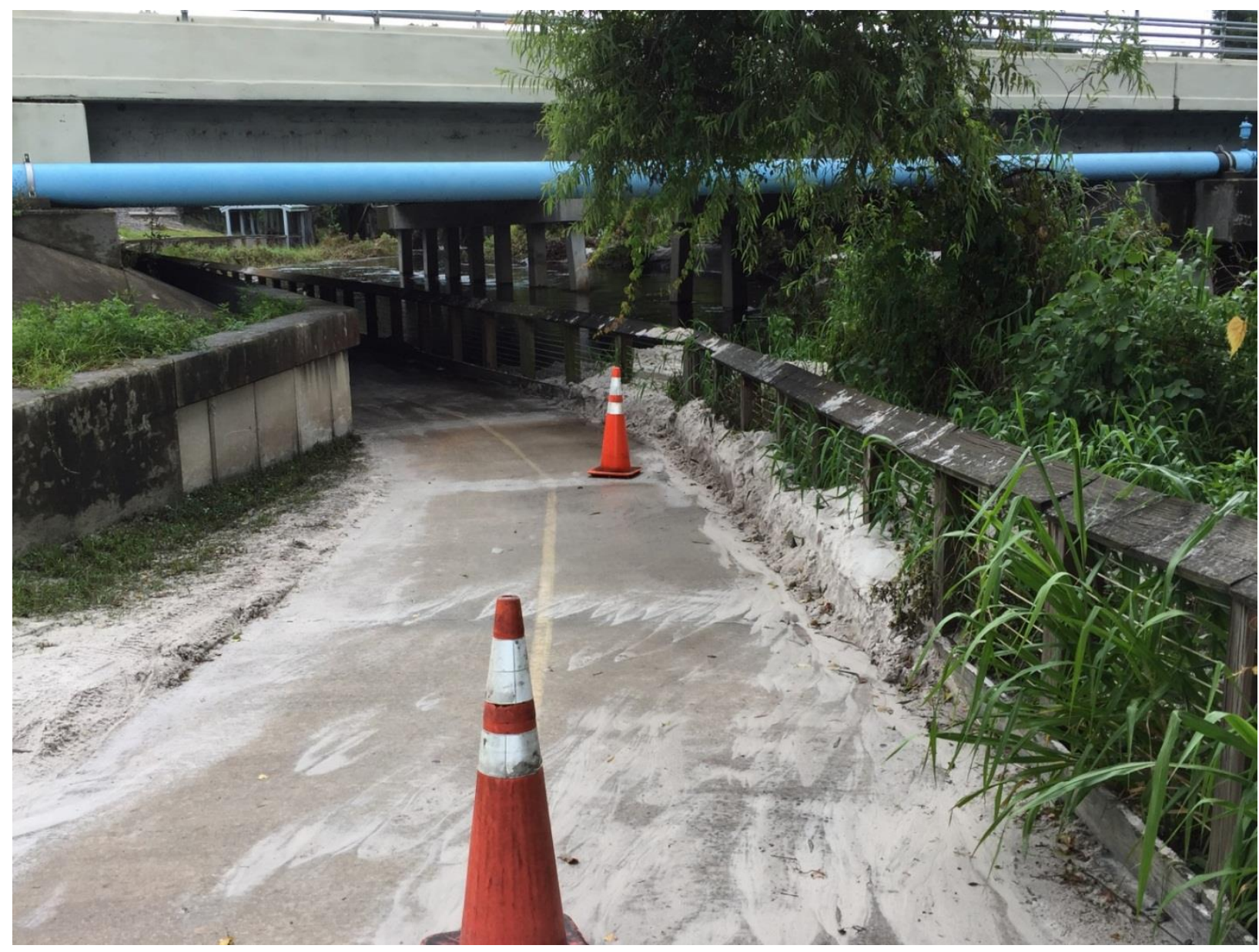

Figure 34: Hillsborough Scenario 2, Upper Tampa Bay Trail underpass at Linebaugh Avenue, after heavy rain

\section{Scenario 3: Trail and Public Transit do not Intersect: Waters Avenue}

The HART Northwest Transfer Center is a hub for Routes 16, 30, 34, 39, 61X, and the HARTFlex Town ' $N$ Country. The Transfer Center provides transit connection opportunities to these routes that extend to multiple destinations, including employment sites to the north, east and south. These connection opportunities may be especially helpful to Upper Tampa Bay Trail users that live to the west of Sheldon Road and to the north of Gunn Highway. Hillsborough Avenue to the south has been identified as a future Priority Trail, potentially further expanding trail access to transit service for neighborhoods to the west. The Transfer Center is accessed from W. Waters Avenue and is adjacent to but separated from the Upper Tampa Bay Trail by flood Channel A. Figures 35 and 36 illustrate the Hillsborough Scenario 3.

This is a scenario where it would likely be cost prohibitive to build a physical connection for the trail to the Transfer Center. However, bike lanes and sidewalks are presently in place over the Waters Avenue bridge, with a traffic signal at the intersection of Waters Avenue with the HART Transfer Center entrance. Pedestrians can access the Transfer Center from the Upper Tampa Bay Trail via existing sidewalk on the north side of the bridge. This provides easy access to the Transfer Center. 
From the view shown in Figure 36, HART Northwest Transfer Center is just across the bridge on the left side of W. Waters Avenue and on the east side of Channel A. Upper Tampa Bay Trail runs under the bridge on the west side of Channel A.Bicyclists will have to exit the Upper Tampa Bay Trail at Channel Park by turning left from the park entrance onto eastbound Waters Avenue. The bicyclist would enter the traffic stream, using the available bicycle lane, then take position in the left turn lane to enter the Transfer Center. Alternatively, the bicyclist could walk the bicycle along the sidewalk. Another existing connection option for the pedestrian and bicyclist is to continue north on the Upper Tampa Bay Trail, then turn right onto Sheldon Road. There is a sidewalk and a bicycle lane on the west side of Sheldon Road that provides access to the Transfer Center on its east side. In this way, a bicyclist could avoid having to cross over four lanes of traffic on Waters Avenue to ride in the bicycle lane, then avoid having to turn left again through the signalized intersection into the west entrance of the Transfer Center.

These bike lane and sidewalk connections are an effective connection between the trail and public transit service. However, it is likely not obvious to a bus rider that it is possible to access the trail from the Transfer Center, nor is it obvious to a trail user that bus service provided by several routes is just across the bridge. Similarly to the recommendations for Scenarios 1 and 2, it is recommended that the HART system map show public trails, including the Upper Tampa Bay Trail, with trail connections listed in the legend of the map where other intermodal information is found about park-and-ride lots, express pick-up stops, and car/vanpool lots. Likewise, it is recommended that the Hillsborough trails system map provide information about locations to access public transit from the trails, bikes-on-bus service, bus fare information and the OneBusAway mobile app. Information about trail access also could be posted at the kiosk at the Transfer Center. Information about HART bus service access also could be posted at Channel Park. It also is recommended that drainage improvements be made to the Sheldon Road bridge, where water pools in the sidewalk. 


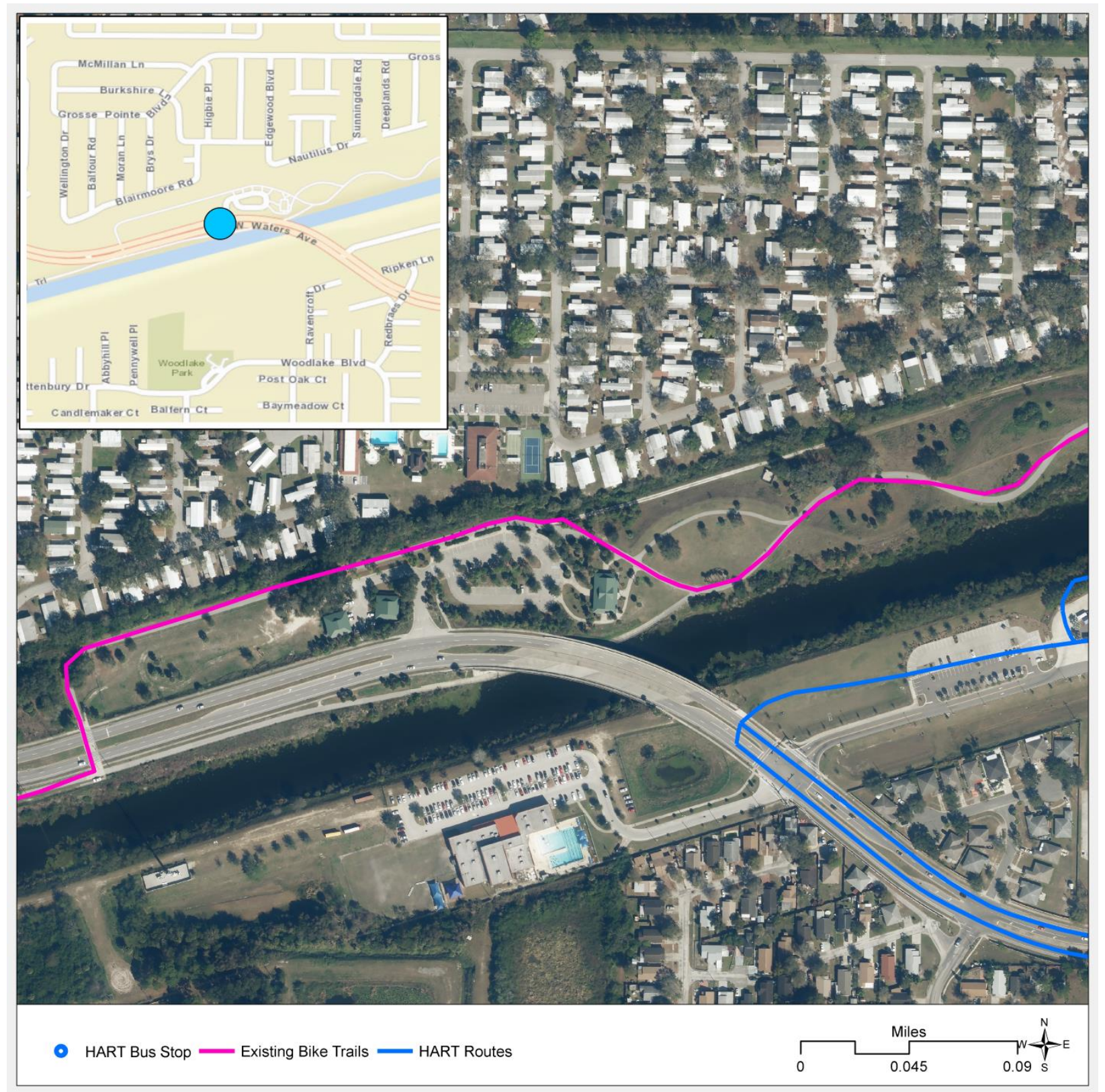

Figure 35: Hillsborough Scenario 3: HART Northwest Transfer Center and Upper Tampa Bay Trail at W. Waters Avenue Bridge 


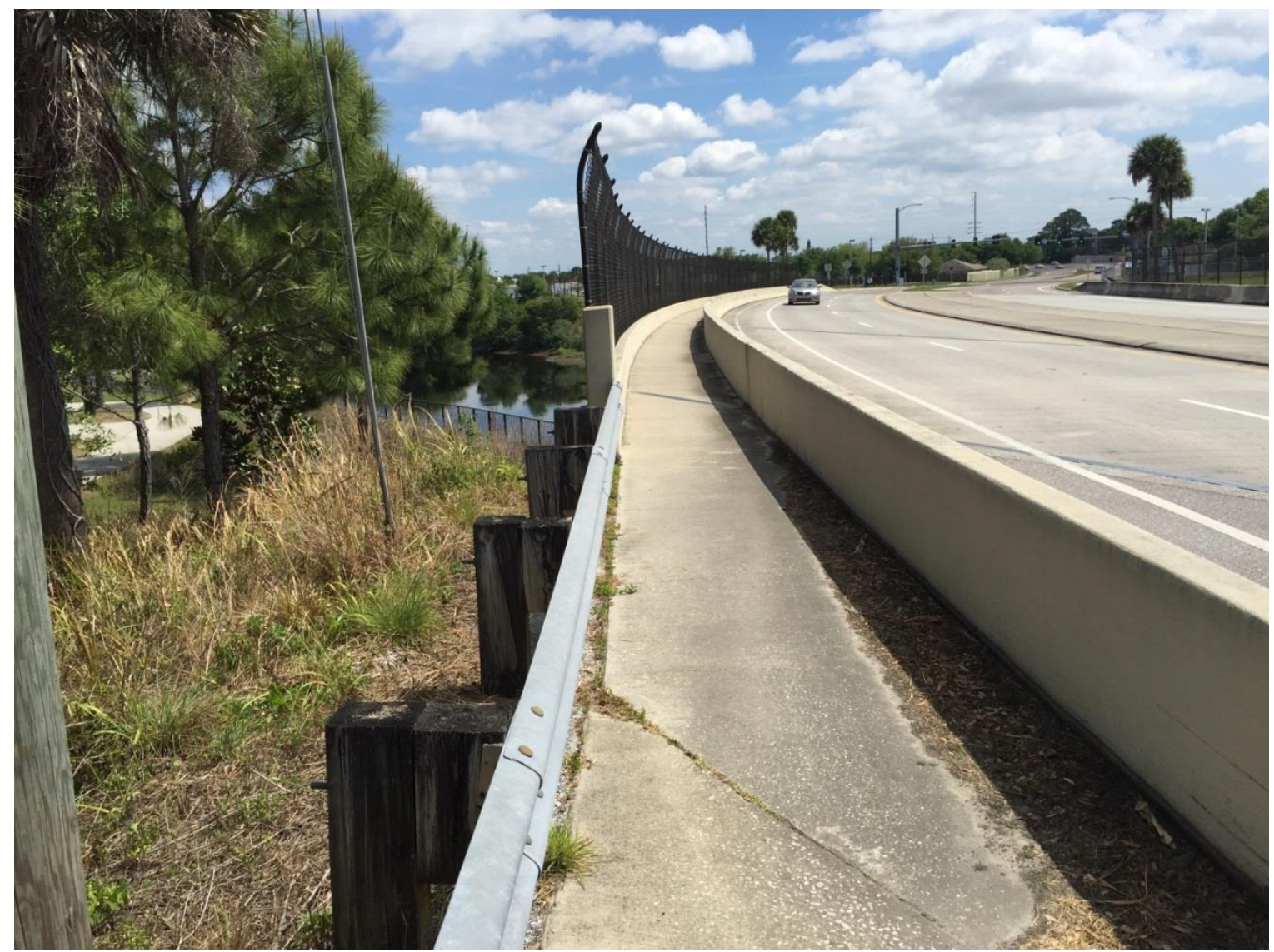

Figure 36: Hillsborough Scenario 3, W. Waters Avenue Bridge over Flood Control Channel A

\section{Pinellas County, Pinellas Trail}

\section{Scenario 1: Trail and Public Transit Connect: 8th Avenue SW}

The PSTA Route 66 starts in Tarpon Springs to the north and extends southward through the City of Largo to the Indian Rocks Shopping Center. The connection of the bus route with the Pinellas Trail is toward the south end of the bus route. While the Pinellas Trail runs north/south and this route also is generally north/south, the bus route still affords access to many destinations to the east and west of the trail. The bus route also could take many miles off a trip that begins by bus, for example, in Tarpon Springs down to 8th Avenue SW, and ending with a Pinellas Trail bike ride down to St. Petersburg College in Seminole. Figures 37 and 38 illustrate the Pinellas Scenario 1.

The inventory for this at-grade crossing of the Pinellas Trail with 8th Avenue SW shows an easy connection to the bus stop in both directions. This crossing is located at the southwest tip of the Downtown Largo Multimodal Transportation District area boundary. 8th Avenue SW also is designated as part of the Largo Green Trail, even though there is no off-road path along $8^{\text {th }}$ Avenue SW. It is identified as a Potential Future Largo Urban Trail Route with its crossing of the Pinellas Trail as a Trail Gateway. This trail crossing also coincides with an 
elementary school speed zone, adding an extra layer of regulatory caution with reduced speed limits.

There are two recommendations for this site. Similarly to the Upper Tampa Bay Trail, cross-modal information on signage and maps would be helpful to bus riders that might not have considered combining a bus ride with a segment on the journey by trail. A trail rider might begin considering using the trail not just for recreation but also for transportation purposes if trail maps and signage included information about PSTA bus service and the destinations that could be accessed. Secondly, the sidewalks along 8th Avenue SW are in need of repair. This could be an opportunity to not only repair the sidewalks but add ADA compliant features, such as wheelchair ramps from the sidewalk to the street at bus stops. Since right-of-way is limited on 
8th Avenue SW, it is recommended to consider providing signage or sharrows to designate a shared use lane with bicycles.

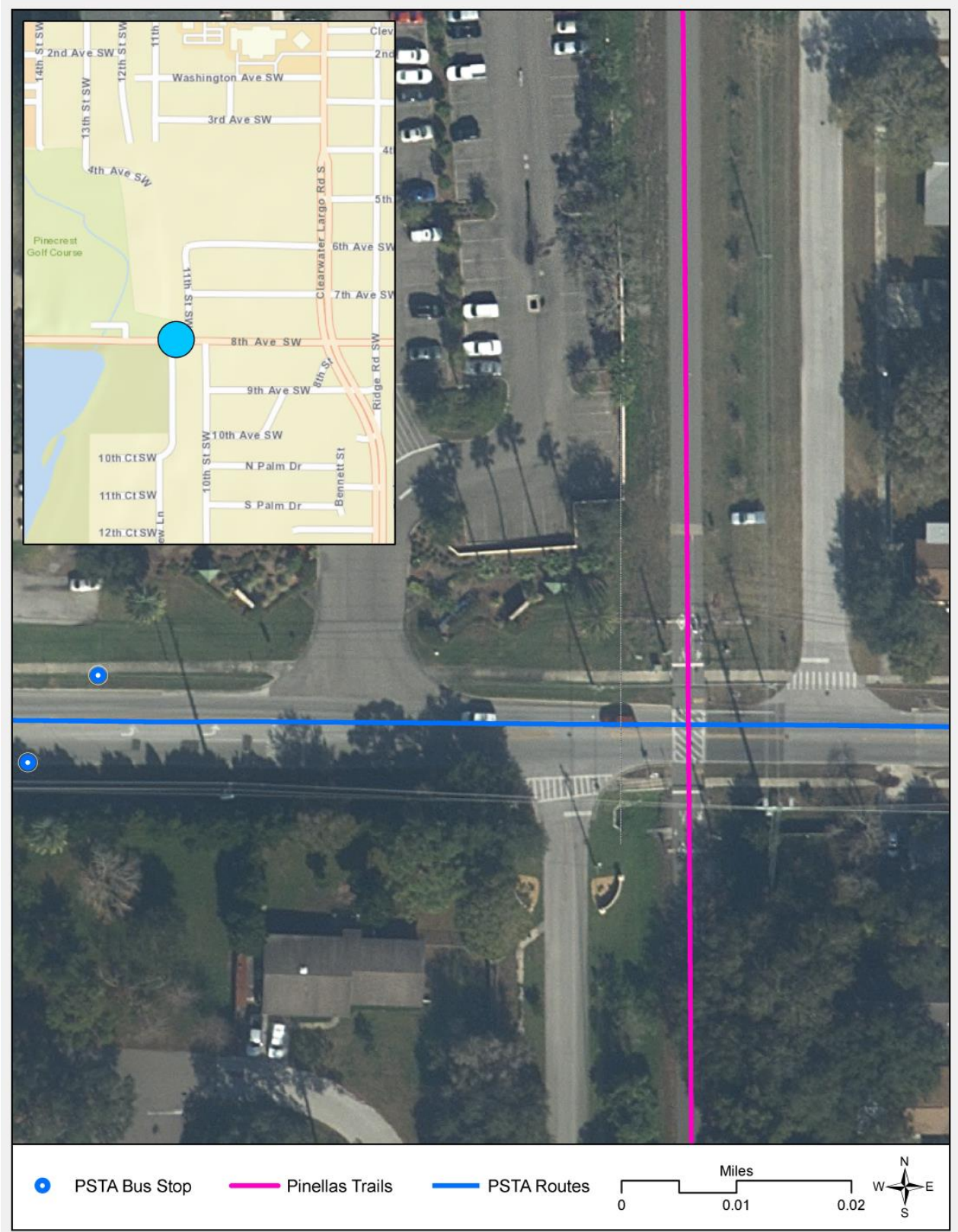

Figure 37: Pinellas Scenario 1, PSTA Route 66 and Pinellas Trail at 8th Avenue SW in Largo 


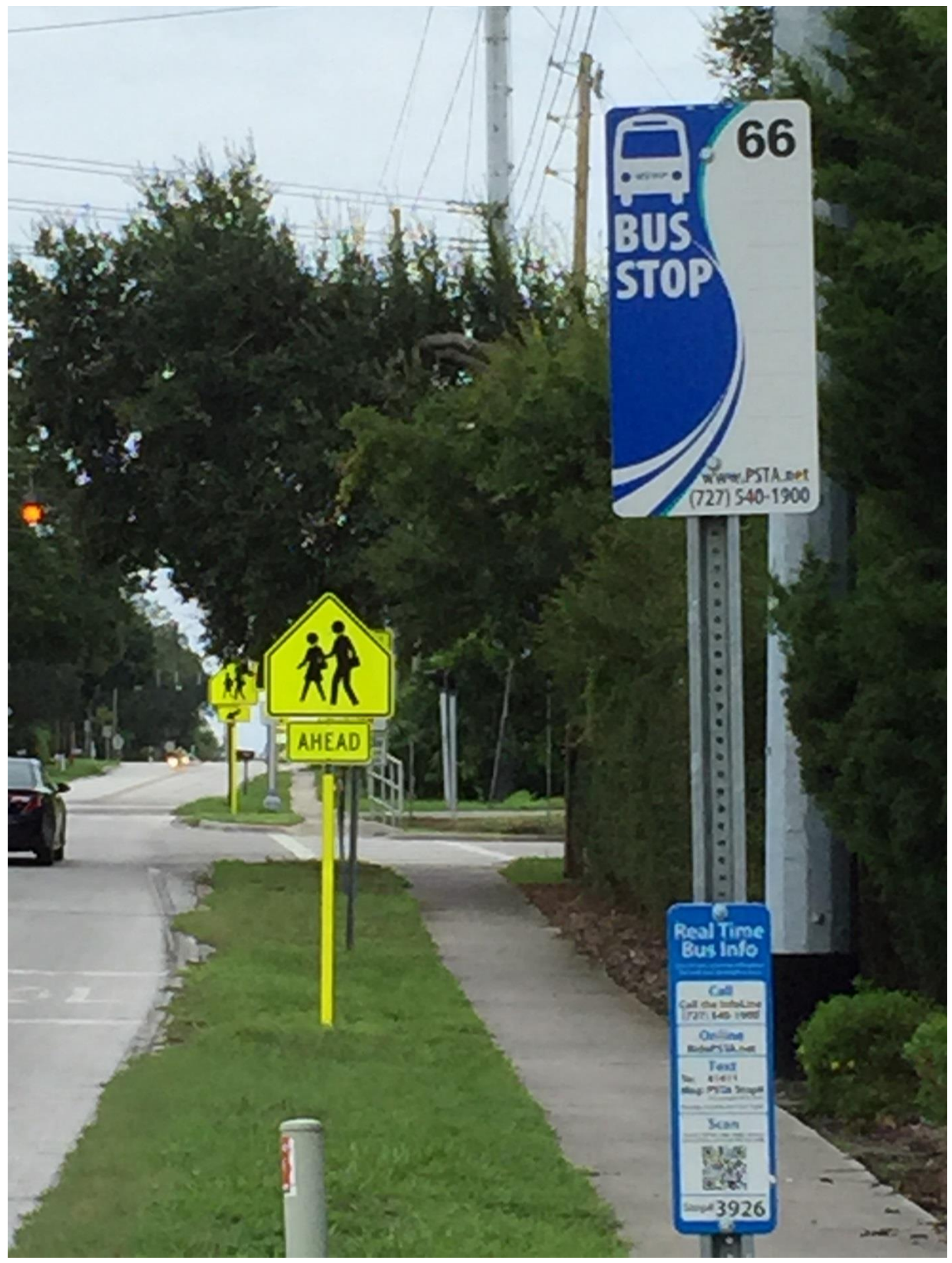

Figure 38: Pinellas Scenario 1, PSTA Route 66 looking eastbound on 8th Avenue SW at the Pinellas Trail 


\section{Scenario 2: Trail and Public Transit Intersect but do not Connect: Gooden Crossing Road}

The PSTA Routes 59 and 61 intersect but do not connect with the Pinellas Trail at Ulmerton Road and Gooden Crossing Road, respectively. The Route 61 runs from the Indian Rocks Shopping Center northward to Dunedin. Someone traveling from Seminole along the Pinellas Trail could choose to access the Route 66 to go to the Indian Rocks Shopping Center area. More likely, someone would be traveling by Route 61 from the north, to get off at Gooden Crossing Road to travel by the Pinellas Trail directly further south to the commercial area along Walsingham Road. Unlike Route 61 , the Route 59 is an east/west bus route that goes from Williams Park in Downtown St. Petersburg westward all the way to Indian Rocks Beach. Figures 39 through 42 illustrate the Pinellas Scenario 2.

The Route 61 parallels the Pinellas Trail along Railroad Avenue with a bus stop within easy walking distance of the Pinellas Trail crossing with Gooden Crossing Road. This is a quiet residential area with sparse motor vehicle traffic. While no bicycle lanes or sidewalks exist along Railroad Avenue, there are sidewalks along Gooden Crossing Road and the negligible motor vehicle traffic at this location makes it an easy connection, if not a direct one. No recommendations for improvements are offered at this location, except perhaps considering coordination with economic development agencies to encourage small businesses to this highly accessible location. There appear to be several vacant land parcels. The Neighborhood Watch group in this community might appreciate more economic activity here as there would be more eyes on the street and added security to Pinellas Trail users.

The intersection of trail with public transit service that is more troublesome at this location is the Route 59 that has stops on both sides of the highway along Ulmerton Road. The Pinellas Trail crosses over Ulmerton Road with a bridge overpass. Depending on the desired direction of travel, some users might be tempted to cross Ulmerton Road at-grade to avoid having to backtrack the distance to enter the ramps leading up to the overpass. Bus passengers were observed disembarking the Route 59 bus and crossing this six-lane divided highway. It is recommended to consider alternative treatments for street crossing that are both safe and convenient, anticipating that travelers, especially those on foot, will choose the shortest distance, even if the shortest distance is less safe. One alternative might be to use rectangular rapid flash beacons (RRFB) with a cross walk at this location. These could be activated at one direction at a time with a pedestrian refuge equipped with an activation button. Pedestrian traffic was not observed to be heavy at this location. A lower speed limit with coordination of traffic signals might smooth motor vehicle traffic and reduce delay. An alternative crossing treatment at Ulmerton Road would not defeat the utility of the Pinellas Trail bridge overpass as most of the trail traffic is already on the trail. The Route 59 provides great east/west connectivity. If the purpose is to improve public transit connections with public trails, then providing safety enhancements to cross Ulmerton Road at-grade would lend convenience to a roadway that bicyclists and pedestrians might otherwise use only if they must. 


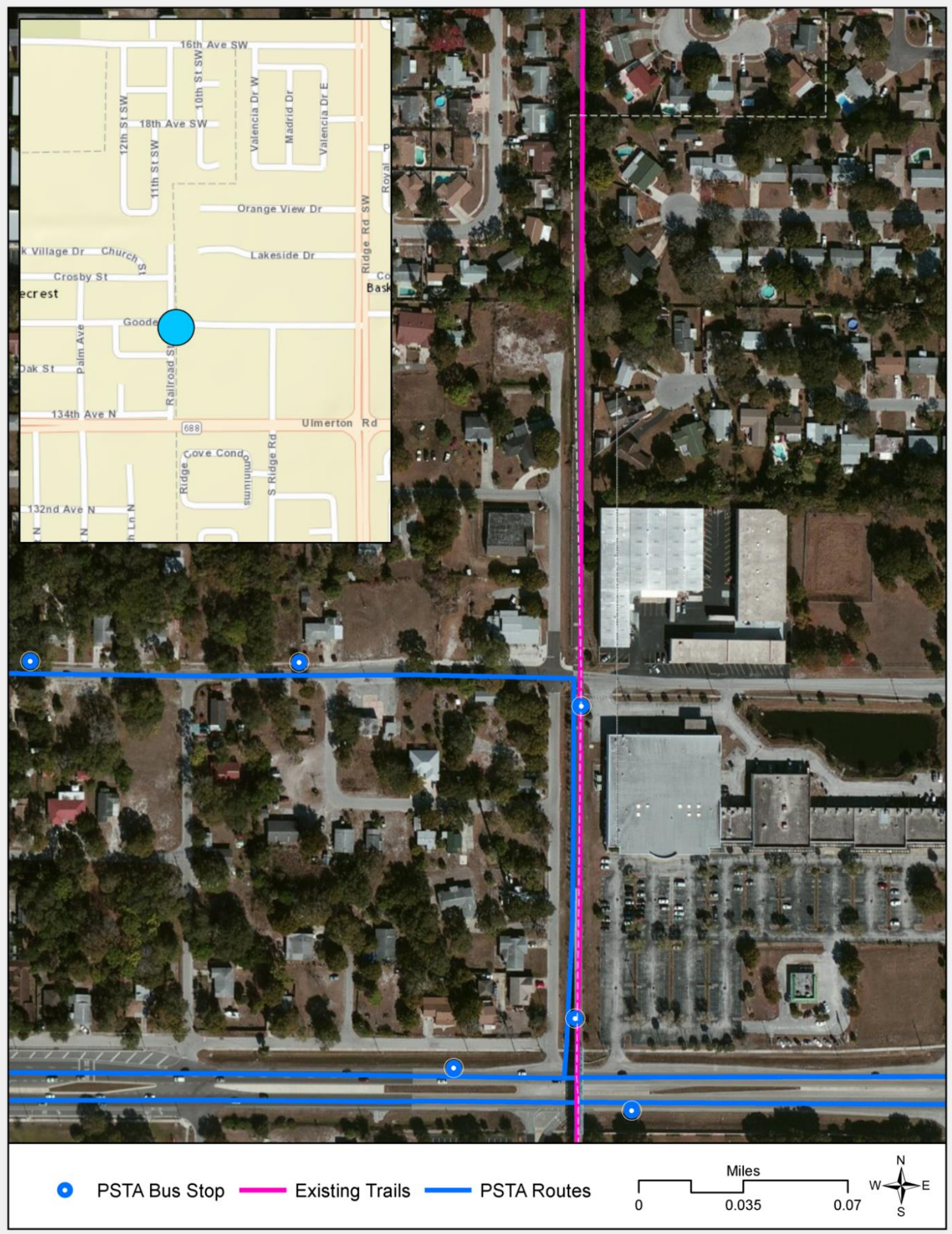

Figure 39: Pinellas Scenario 2, PSTA Routes 61 and Pinellas Trail at Gooden Crossing Road, and PSTA Route 59 at the Ulmerton Road bridge over Pinellas Trail in Largo 


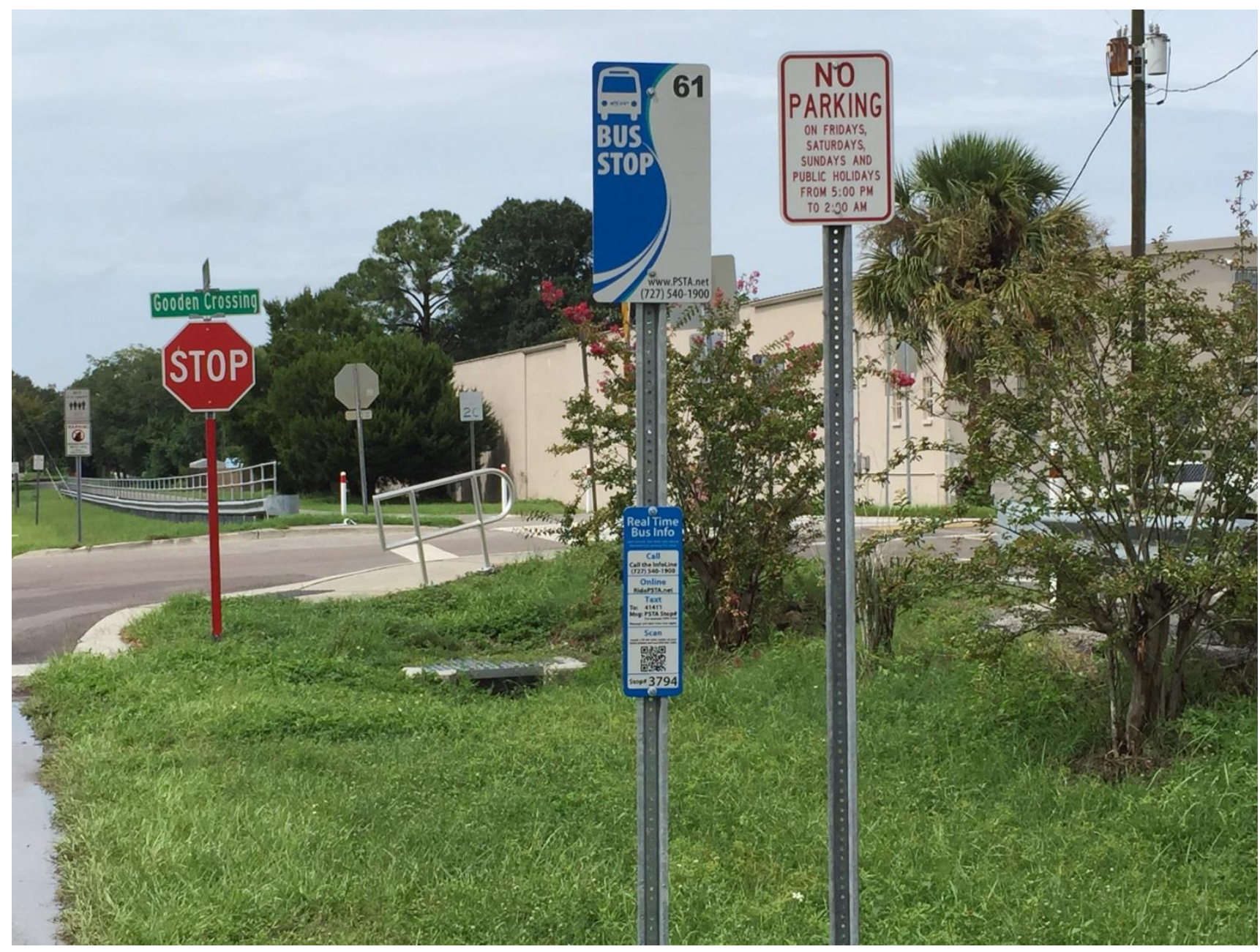

Figure 40: Pinellas Scenario 2, PSTA Route 61, looking northbound along Railroad Avenue at Gooden Crossing with Pinellas Trail 


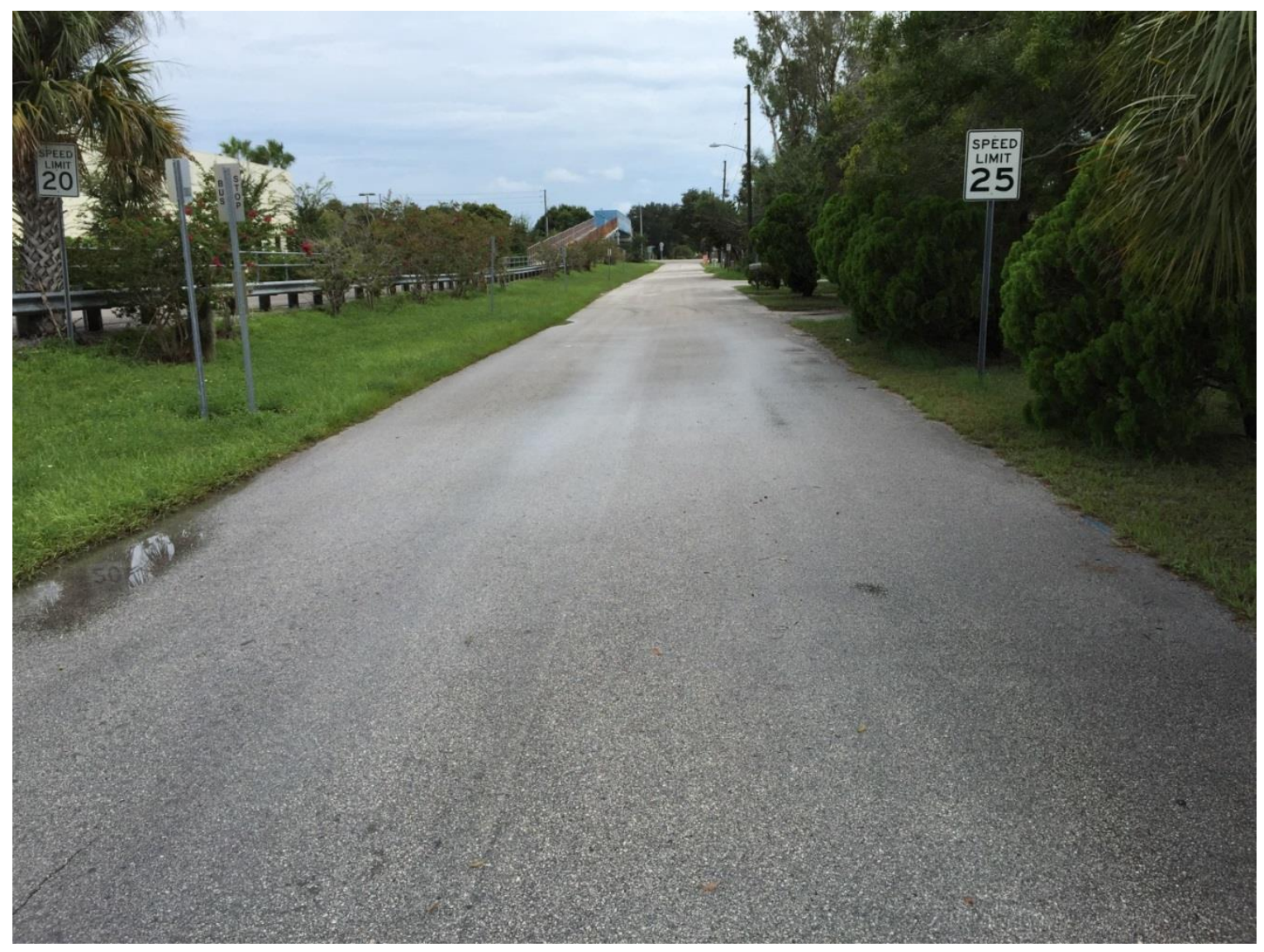

Figure 41: Pinellas Scenario 2, looking southbound along Railroad Avenue toward Ulmerton Road 


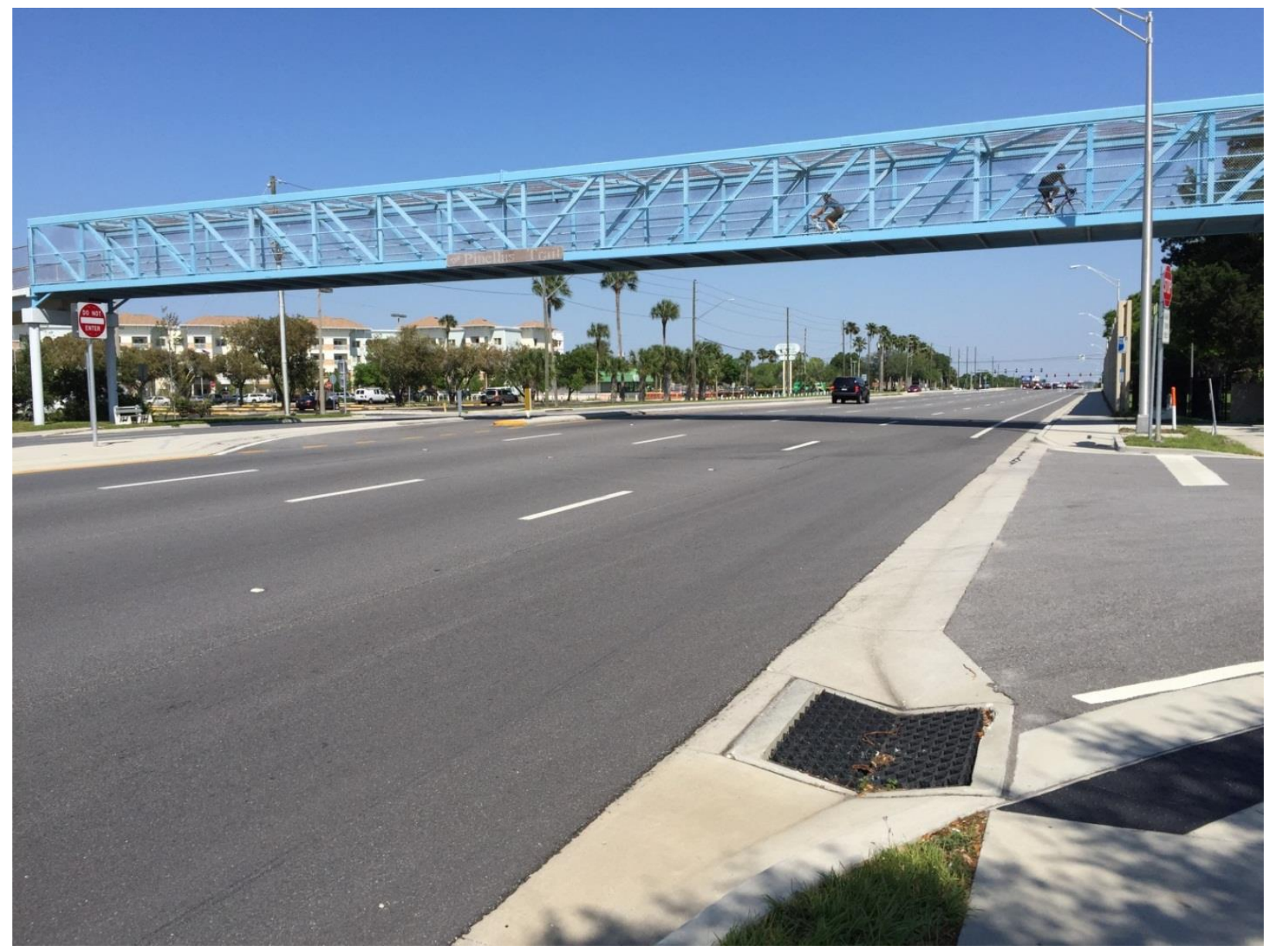

Figure 42: Pinellas Scenario 2, looking eastbound, where PSTA Route 59 passes under the Pinellas Trail bridge at Ulmerton Road

\section{Scenario 3: Trail and Public Transit do not Intersect: $96^{\text {th }}$ Place N}

The PSTA Route 58 runs east/west and serves the Seminole Mall on the west end of the route, and the Gateway Mall on the east end. Intermittent service is provided to the St. Petersburg College Seminole Campus. This route was identified as performing below standard with regard to ridership. This route provides service in an east/west corridor that otherwise has no bus service. One option to help improve ridership is to connect the route with the Pinellas Trail by way of a designated bicycle route through a largely residential area west of the college. Presently, the Route 58 does not intersect with the Pinellas Trail, which makes it an example of a Scenario 3. Figures 43 through 47 illustrate the Pinellas Scenario 3.

There are long stretches of the Pinellas Trail that run through large residential areas. The crossing of the Pinellas Trail with $96^{\text {th }} \mathrm{PI} \mathrm{N}$ in the Quail Ridge neighborhood of the City of Seminole is equipped with a water fountain, shelter and benches. It is recommended that no improvements are needed at this crossing. However, by designating a bicycle route from this trail crossing eastbound along $96^{\text {th }} \mathrm{PI} \mathrm{N}$, it would lead travelers along an easy ride to the St. Petersburg College Seminole Campus. From $96^{\text {th }} \mathrm{PI} N$, by turning south onto Ridge Road and traveling to $93^{\text {rd }}$ Avenue $\mathrm{N}$, there is a sidewalk on the college campus that abruptly terminates just short of Ridge Road. With a proposed agreement and collaboration 
with the college, this sidewalk location could potentially be enhanced as a multi-use path, leading to a large parking lot on the campus, and access ways that lead to the bus stop in front of the library. This potential connection would require a relatively 
low amount of funds for signage, and minor improvements to the campus parking area to make this connection work.

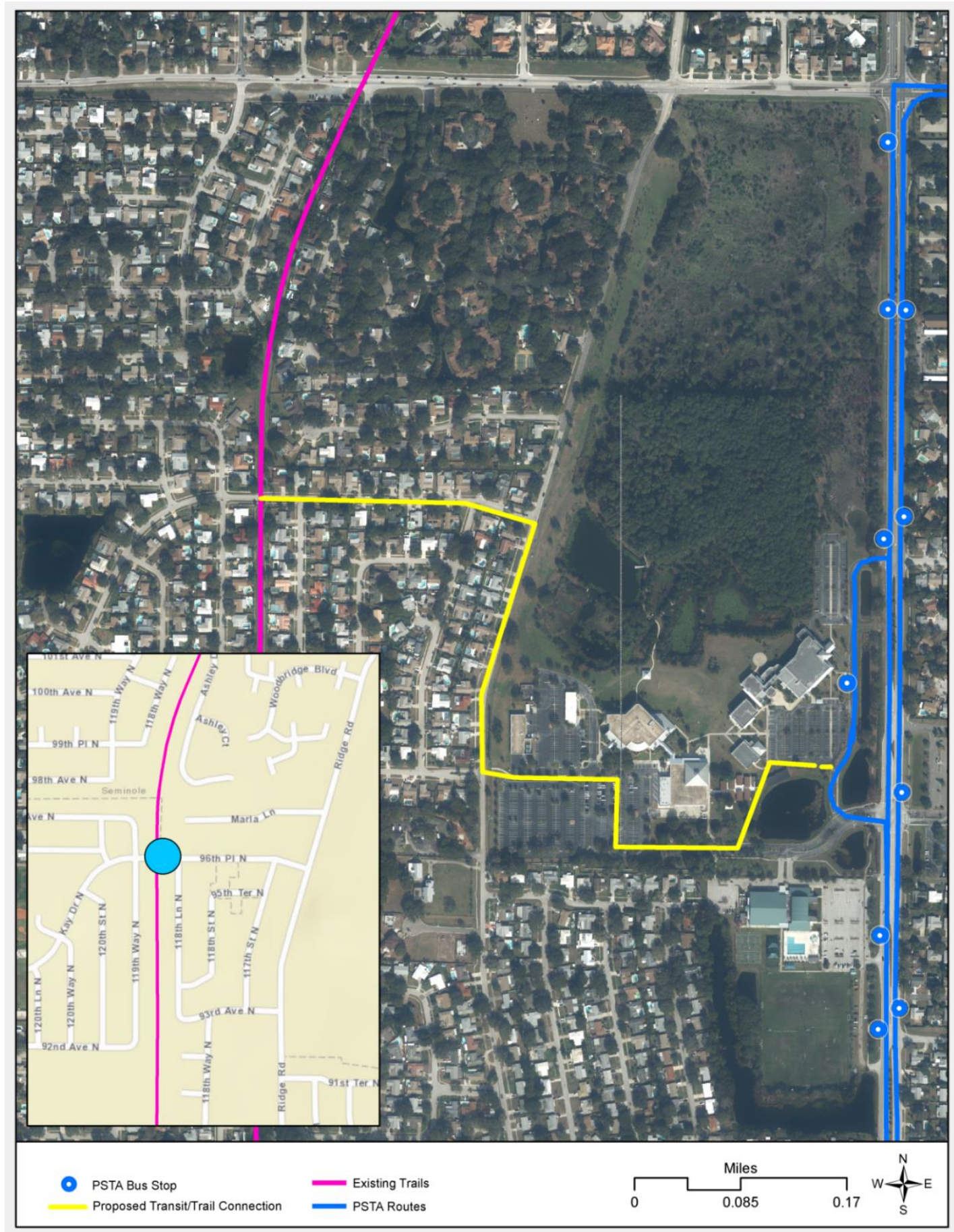

Figure 43: Pinellas Scenario 3, Pinellas Trail at 96th Place North is proximate to but does not intersect with the closest PSTA Route 58. 


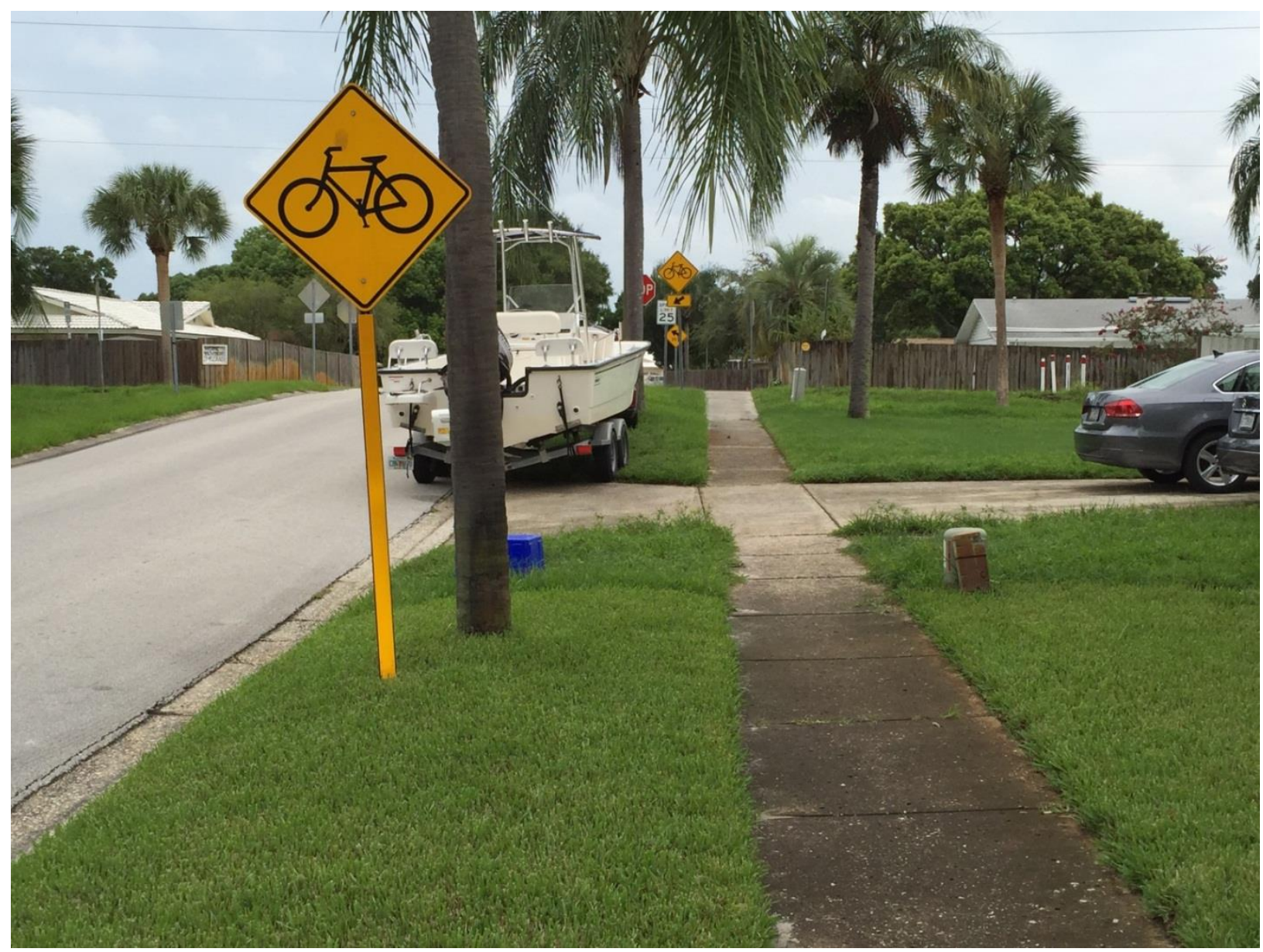

Figure 44: Pinellas Scenario 3, 96th Place N., looking westbound toward its intersection with the Pinellas Trail 


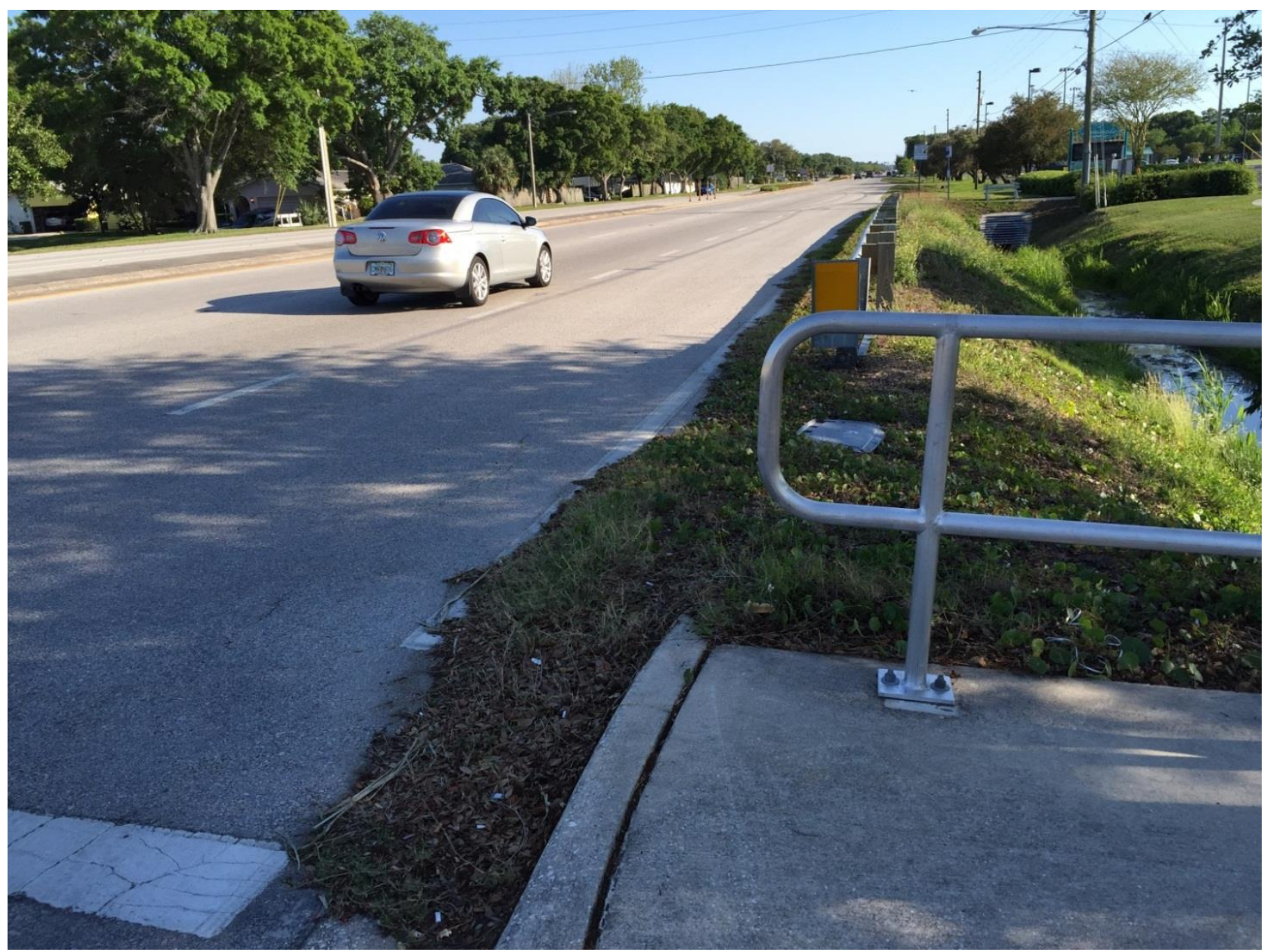

Figure 45: Pinellas Scenario 3, $113^{\text {th }}$ Street N. at St. Petersburg College where there are no bike lanes or sidewalk facilities 


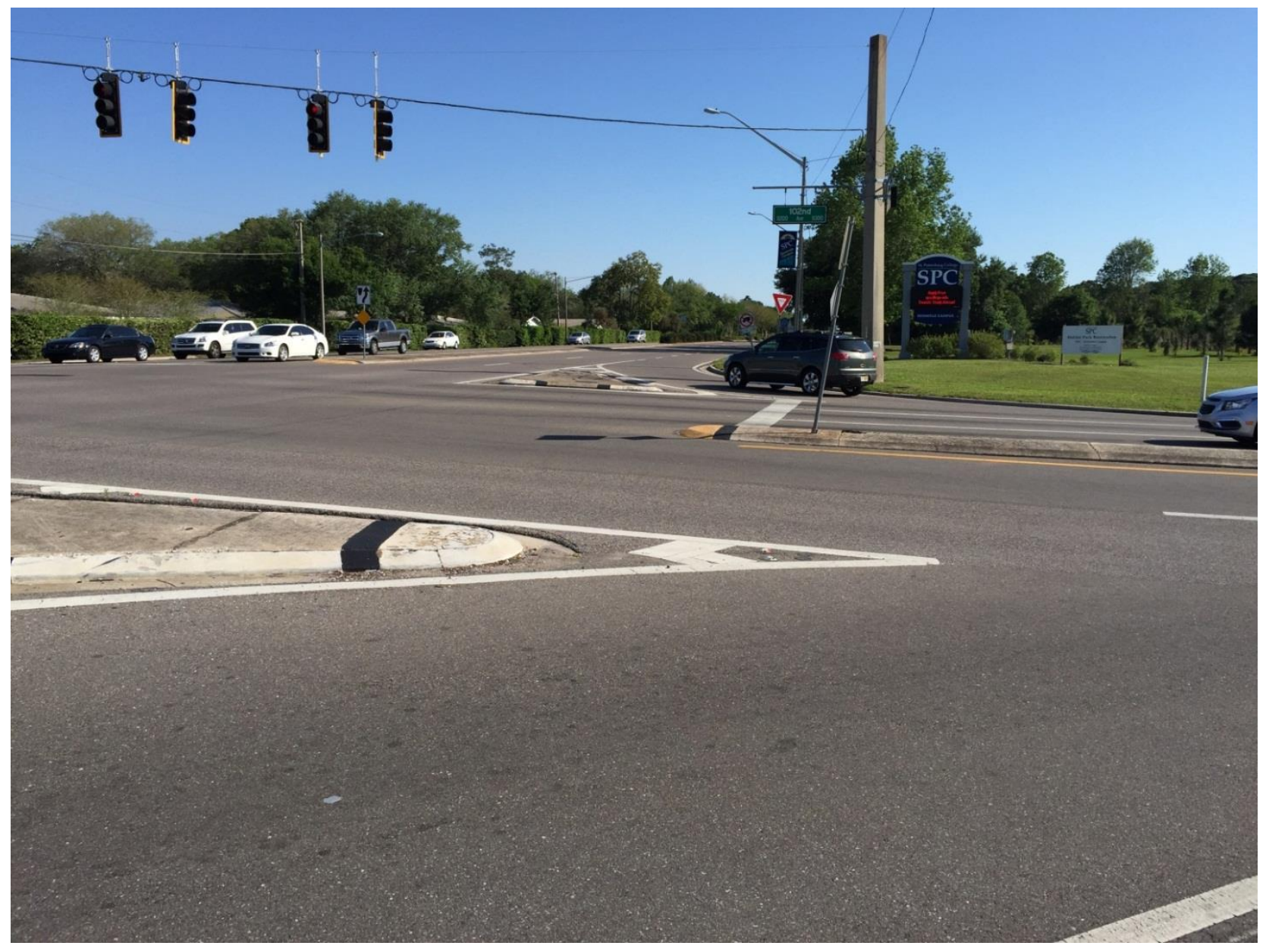

Figure 46: Pinellas Scenario 3, intersection of $102^{\text {nd }}$ Avenue $N$ with 113th St. N 


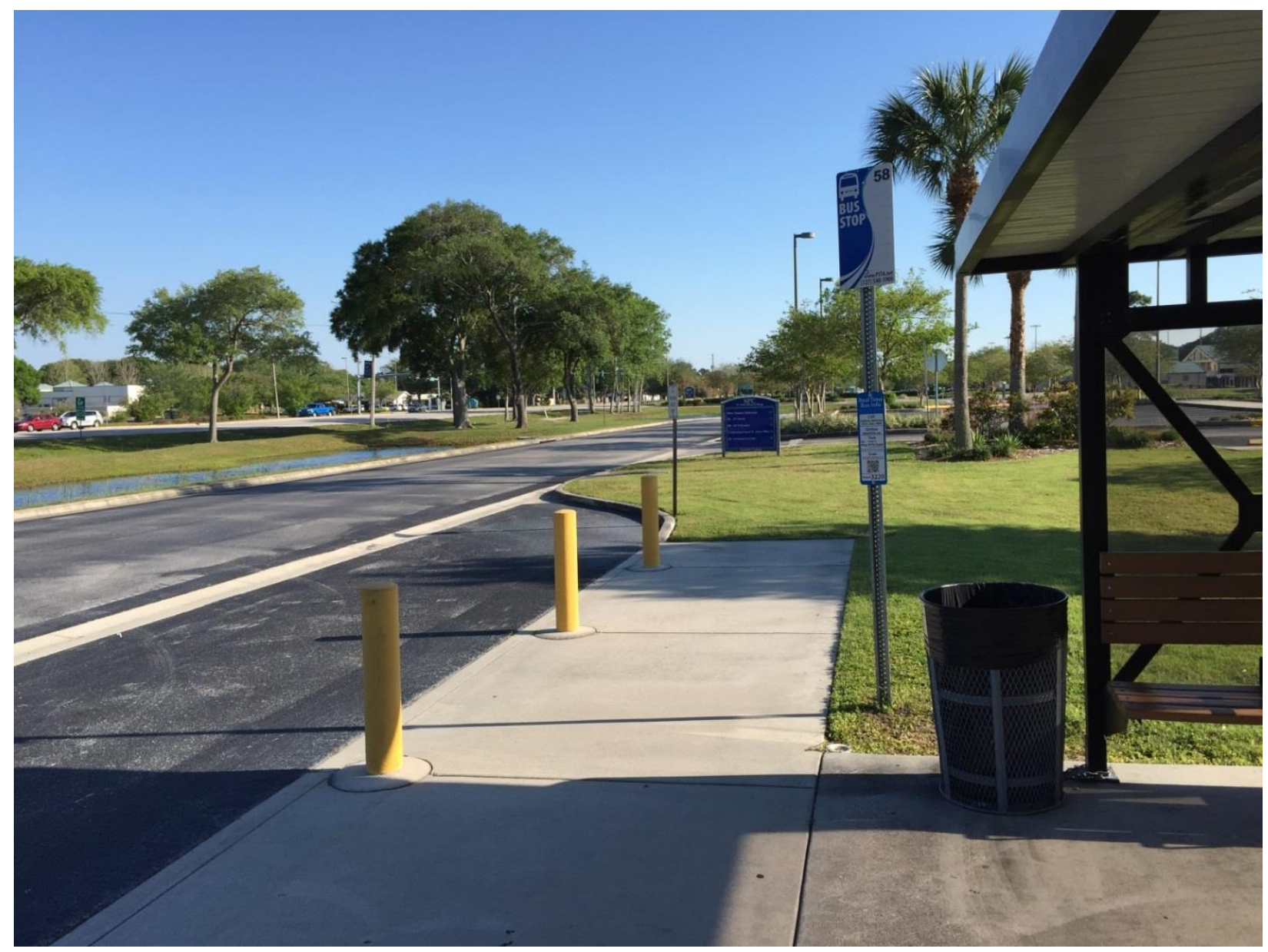

Figure 47: Pinellas Scenario 3, PSTA Route 58 bus stop is located within the St. Petersburg College, Seminole Campus. 


\section{Chapter Five:}

\section{Conclusions and Recommendations}

The purpose of this study has been to develop a methodology for improving public trails connections with public transit service to advance the goal of improving community livability through enhanced access and connectivity. This study included a literature review, the development of case studies, the development of a proposed methodology for evaluating the linking of greenways and trails with public transportation, and its application as demonstrated in Hillsborough and Pinellas Counties. This methodology has nine basic steps.

1. Seek community input.

2. Select a community goal as defined by travel market and trip purpose.

3. Map trail network.

4. Map transit routes and locations of transit stops near trails.

5. Identify data sources to describe location of travel market and trip destination.

6. Map origins of selected travel market and destinations by trip purpose to identify areas of greater concentration of both.

7. Define the subarea within which travel is likely to take place between origin and destination.

8. Develop a typology that organizes identified trail/transit intersections into sets having similar characteristics.

9. Conduct site observations and inventories, with recommendations for strengthening transit/trail connections at selected sites.

There are many methodologies tailored to the availability of data and most of which were applied to evaluate roadway improvements for bicyclists and pedestrians. The methods describe different ways of determining where to make improvements and what improvements to make. Determining where can include simply identifying where there is a lack of facilities, improving facilities where travel activity is documented (existing higher demand), where safety hazards exist, where there are bottlenecks (such as bridges), where potential travelers live, and where there are desired destinations. In the case of this study, the question of where is focused upon the locations of trail crossings with bus routes.

\section{Trail Locations may not be Optimal for Transportation}

Public trails have typically been developed originally for recreational purposes and have been located where linear land opportunities already exist, such as along the banks of a river, on top of a dike, along a former or existing railroad track, or along a highway right-of-way or utility easement. Sometimes land is bequeathed to a community and planners propose linking parcels of land together, sometimes purchasing key properties, to develop a ribbon of right-of-way, when opportunities arise. As such, the location of the public trail may not have been originally positioned optimally for transportation. More opportunities for transit/trail intersections may exist where the trail network is denser, where well developed onroad bicycle and pedestrian facilities networks provide key connections, and where public transit routes are more extensive and spaced closer together. The Oregon Metro case study is the best example where all three of these conditions exist, and 
illustrative of perhaps an exception to the rule, where alternative alignments for a trail corridor are considered, with proximity to transit an important criterion. The Council Creek Regional Trail Master Plan is an example of this.

\section{Gains in Comfort when Bicycling and Using Public Transportation May Encourage Linking the Modes}

On the Pinellas Trail, based upon limited observations of bicyclists and pedestrians, the majority of trail users were dressed in sports attire and were walking/jogging and bicycling for recreation. Those who appeared to be using the trail for transportation were wearing backpacks or carrying bags on handlebars. They tended to be walking rather than jogging. As bicyclists, they also tended not to be wearing athletic cycling clothes and helmets. These observations indicate that some people may be using the trail for transportation purposes. However, no observations were made of someone using the trail to access public transit. It is suggested that before more people consider linking public transit and trails together in one trip, the general level of convenience experienced by walking or bicycling to and from the bus will need to improve first. As more travelers gain greater comfort and experience riding transit, as well as bicycling or walking, they may begin considering combining these modes in one trip.

\section{Transit/Trail Connections Can Serve a Variety of Goals}

Each community may want to apply the development of transit/trail connections to support a goal that is different from other communities. The case studies demonstrated not only different kinds of goals but also the application of different methodologies. Their methodologies were tailored to their goals. It is suggested that there is no one correct or better methodology, but that a community should first consider what they want to accomplish, then tailor their methodology for that goal. Communities can learn from the experience of these case studies as well as the method proposed here. Many elements of the case studies could be borrowed by Florida communities.

\section{Transit/Trail Linkages Should be Considered at the Transportation Planning Stage}

Plans for public transit should illustrate existing trail links and consider new opportunities to link to trails. Highway planning should incorporate not only onstreet bicycle facilities and sidewalks but also include data layers for public transit routes and trails. Likewise, trail plans should address use of trails for transportation purposes and consider streets linkages where trail users can access public transit.

\section{Data Collection for Planning}

The ability to collect data that characterizes one's particular community also might better characterize the travel needs of the population. Communities have extensive datasets on the location of infrastructure and car counts. They have less information on pedestrian and bicycle activity. However, less activity does not necessarily mean less demand but might be reflective of the degree to which existing infrastructure and services supports bicycling, walking, and public transit.

Perhaps the most accurate method to determine where populations of interest travel is to count them. This can be expensive and time consuming; however, more 
local governments are investing in hardware and software that can be permanently placed at various sites of interest. Pinellas County recently invested in five counters. Other methods include actual staff observations that can record details that loop counters or infrared sensors cannot, such as gender, general age, and other traveler attributes. Surveys of a sample of travelers can capture their responses regarding their travel origins and destinations. Oregon Metro used results from a Portland State University study that equipped volunteer commuter and utilitarian bicyclists to carry a GPS device to track their preferred travel routes. This would be great information to have in planning and prioritizing transit/trail connections for improvements. In the absence of these kinds of resources to conduct more detailed studies about the travel characteristics of the selected markets of interest, an alternative method was described in this report using the EPA Smart Location Database. This is a sufficient and economical way to identify and prioritize transit/trail connections for improvements, particularly in communities that may have a smaller number of developed trails.

As a community further develops its pedestrian and bicycle on-road networks as well as its trail network and public transit system, there will be many more transit/trail crossings to consider. The Portland-Salem metropolitan area is known for its bicycle and transit friendly environment with an extensive system of bicycle and pedestrian facilities. The completion of their bicycle and pedestrian networks is based upon adopting a hybrid "spider web/grid" network that maximizes connectivity.

At this stage, it is recommended that a community consider investing in permanent counting systems to collect more complete data about trail usage. The metropolitan planning organization may also consider beginning a program of periodic on-street bicycle and pedestrian traffic counting throughout the on-street system. Populating such a database could potentially prepare an urban area to develop bicycle travel models that could calculate preferred bicycle-to-transit travel paths on a travel network that includes both on-street and trail systems. Oregon Metro's bicycle travel model stops short of modeling multimodal trips.

There also is limited data available on the size of bicycle access sheds. How far is one willing to bicycle to access public transportation? According to the Transit Capacity and Quality of Service Manual (TCQSM), as referenced earlier, approximately 75-80 percent of bus passengers walked 0.25 mile or less to a bus stop, although there are variations by city, vertical grade, income group, and transit type (bus versus rail). It also varies by the quality of the pedestrian environment, such as the presence of sidewalks, street width and pattern, intersection density, and perception of security. The bicycle access shed could be four or more times larger than the pedestrian access shed based upon average bicycle travel speed compared to average walking speed. It is possible that for those planning to access public transit by use of public trails, they may be willing to walk or bicycle longer distances than the average. It is recommended, as communities are able, to conduct further studies characterizing these travel attributes, like the distance the local population is willing to walk or bicycle. This information could aid in planning public transit routing in addition to transit/trail connections. 


\section{Redundancy is Important}

The Upper Tampa Bay Trail and the Pinellas Trail are remarkable for their lengths and continuity, and they both follow an alignment that is separate from an existing street. These qualities give the two trails potential to provide more connectivity and transportation access opportunities via public transit than a shorter trail or one that runs alongside an existing street. Numerous street crossings provide trail connection opportunities wherever a transit route follows a cross street. These crossings also generate challenges regarding safely enabling trail users to cross busy streets, as well as maintaining adequate level of service on the streets for motorists. Both trails are served by either bridges or underpasses that cross heavily travelled streets. Bridges or underpasses from the trail to street level are served by sidewalks and ramps.

Redundancy is important in the transportation system to support nonmotorized transportation connections with public transportation. Trails that provide high transportation value will connect trip origins to desired destinations. Particularly in urban areas, trails that are particularly well-placed to serve trip origins and destinations will inevitably cross over busy streets. Where trails cross over or under wide highways with the placement of an overpass, there are times when pedestrians and bicyclists nonetheless must cross at street level. When Rocky Creek in Hillsborough County floods and the Upper Tampa Bay Trail is under water, bicyclists and pedestrians need another safe option to cross and continue on their way. Providing this reliability for travel is important to anyone considering using the trail for transportation purposes. A protected cross walk at the signalized intersection just east of the bridge could serve this purpose.

At the Ulmerton Road bus stops adjacent to the Pinellas Trail bridge overpass, a transit patron was observed disembarking a westbound Route 59 bus that stopped at the trail crossing. She was carrying bags of groceries and wanted to cross Ulmerton Road. She could have used the Pinellas Trail Bridge to cross Ulmerton Road but instead she crossed Ulmerton Road at street level where there is no street crosswalk and no traffic signal.

At this location, there are three general purpose lanes in each direction, in addition to an eastbound right turn lane approaching Railroad Avenue. While there is a median separating opposing traffic, motor vehicles are moving at high speed at this location. Using the Pinellas Trail bridge would have required her to walk out of her way to access the ramp, then again going down the ramp on the other side would have taken her far beyond where she wanted to turn. While the bridge overpass greatly improves motor vehicle traffic flow by removing trail traffic, a second alternative for pedestrians is needed.

In general, pedestrians will tend to choose to walk the shortest distance between two points, even if they may be putting themselves at higher risk. To serve transit patrons like this woman carrying groceries, a midblock crosswalk and/or pedestrian signal would have made her crossing much safer. It is important, as a matter of policy, to prioritize the safety and convenience of pedestrians over the convenience of motorists who are already comfortably seated in their air conditioned vehicles.

A protected cross walk at street level at the bridge would not defeat the purpose of the bridge overpass since most trail users will opt to take the bridge. However, a 
cross walk will improve pedestrian and bicyclist safety as well as greatly improve the travel experience of those who ride public transit and must walk and bicycle from the stop to their destination. While this convenience to bus riders might not always translate into traveling on a segment of the trail to complete their journey, it matters that all travel experiences by bus patrons, pedestrians and bicyclists are safe, convenient, and comfortable. This positive experience will increase the choice to travel by bus, bicycle, and by walking. As a matter of course, habitual traveling by transit, walking and bicycling will increase the chances of more multimodal trip making, including pairing bus travel with public trails.

\section{Closed at Sunset}

It was observed that both the Pinellas Trail and the Upper Tampa Bay Trail are not open after sunset. For individuals who plan to use the trail for part of their commute trip, this may be a serious hindrance if the traveler's work schedule includes evening hours. In the above example of someone disembarking the Route 59 bus at Ulmerton Road, if it is after sunset, the Pinellas Trail bridge overpass would not be available, even if the traveler were willing to backtrack to the ramp entrances of the bridge. This is a second reason to consider providing protected crosswalks at trail overpasses or underpasses, in the event that the trail cannot be used to cross the highway.

\section{On-Street Roadway Improvements Link Trails to Transit}

Where public trails and public transit do not connect, on-street roadway improvements may be able to provide a safe connection. For state roads, the Plans Preparation Manual of the Florida Department of Transportation contains a revision of the standard width for the Urban Arterial Travel Lane Width, effective January 1 , 2015. It was decreased from 12 feet to 11 feet for roadways with a divided typical section in or within one mile of an urban area and with a Design Speed of 45 miles per hour or less. This creates additional space for bicycle facilities. In addition, the new standard for marked bicycle lanes is seven-foot Buffered Bike Lanes. (FDOT 2015) These changes create the opportunity for additional roadway space for the bicyclist, providing a more comfortable on-street riding environment. Combined with pedestrian crosswalks, signal improvements and other facilities for nonmotorized users, where needed, the "complete street" environment may provide the final segment in a journey to safely deliver the bicyclist and pedestrian to their destination.

\section{Signs, Maps, Brochures, Websites, and Mobile Phone Apps Should Cross-Promote Transit and Trails}

Hillsborough County MPO and the Pinellas County MPO, HART and PSTA, the Hillsborough County Parks and Recreation Department and the Pinellas County Parks \& Conservation Resources Department have done a great job with equipping transit/trail connections where they occur, with design serving safety and the comfort of transit and trail users in mind. Both counties have their own design standards and guidelines for transit stop facilities and for trail facility interface with the street. Another example that could be considered by other communities is the Miami Dade County Trail Design Guidelines and Standards and the best practice principles for accessible street crossings as described in its Ludlam Trail Case Study, described in the Task 1 literature review. However, one observation noted for all six 
locations in Hillsborough and Pinellas Counties, which were evaluated in this research is the lack of signage informing motorists and other roadway users that they are passing across not just any crosswalk, but a high quality public trail. Likewise, the fact that public transportation opportunities exist at most urban trail crossings with roadways is not promoted to trail users. In their plans, the City of Largo refers to these street/trail crossings as Trail Gateways. It is suggested that to promote more use of the combination of public transit with trails, more wayfinding and even celebratory signage should be considered to raise public awareness. The signage at these crossings, as well as maps and other information on transit agency and government websites and mobile phone apps should provide enough information to enable a trail user to switch modes to public transit and vice versa. It is recommended to add transit access information to bicycle and pedestrian wayfinding signs and bicycle and pedestrian facilities and trails maps. Conversely, it is recommended to provide information about bicycle and pedestrian facilities, including on-street and public trails information and locations, on public transit maps and on other informational media developed for passengers.

\section{Adopt Policies for Planning and Promotion}

It is recommended that public transit agencies adopt policies to consider and develop transit stops where transit service crosses a public trail or is aligned near a trail. An example provided in this report was the Hillsborough County Scenario \#1 where the Upper Tampa Bay Trail crosses Sheldon Road. Placing a bus stop closer to the south side of the trail crossing for northbound Route 39 bus travelers will let bicyclists disembarking the bus off onto the correct side of the roadway for bicycling in the bike lane in the direction of traffic flow for approaching the trail. As it exists now, the closest bus stop for northbound Route 39 is beyond the trail. This places a bicyclist getting off the bus in a position of either walking the bicycle on the sidewalk to the trail, or crossing over four lanes and the median to bicycle a short distance in the bike lane to the trail. Alternatively, the bicyclist might betempted to ride the bike on the sidewalk or worse, in the bike lane against traffic.

Similarly, transit agencies and local government parks and recreation departments could consider developing policies and programs that support or incentivize multimodal travel. HART's recent joint promotional campaign with Coast BikeShare is a specific example.

\section{Develop and Promote a Multimodal Route Finding System}

To encourage transit/trail trip making, it is recommended to develop a multimodal route finding system that includes trails, like Cyclopath, described earlier in the Literature Review. A similar project, a multi-modal travel options app, found at https://www.locationaware.usf.edu/ongoing-research/projects/usf-travel-optionsapp $/$, is being developed at the University of South Florida. It provides students, staff, and visitors information for how to navigate the pedestrian paths on campus. This includescombining links to other modes such as the new bike sharing system Share-A-Bull as well as the USF Bull Runner campus shuttle and Hillsborough Area Regional Transit system. The multi-modal travel options app at USF is based on OpenTripPlanner (http://www.opentripplanner.org/), an open-source multimodal trip planning software system that links biking and walking data from OpenStreetMap and General Transit Feed Specification data from transit agencies. 
Such data include transit schedules, routes and bus stops, and it can be used to develop multimodal routing. The walking and biking data also can be obtained from other locally available public-domain data sources. OpenTripPlanner, as well as the USF travel options app, can be deployed to any community that provides multimodal data in these standardized formats. (NCTR 2011)

\section{Use Crowd Sourcing for Continual Transit and Trail User Feedback}

As more travelers begin to combine the use of public trails with public transit to complete a trip, their experiences and ideas will be valuable to capture for continual improvement of the multimodal network and its intermodal connections. It is recommended that a crowd sourcing approach be used for ongoing surveying of the community regarding identifying issues and needs related to the use of the trails and transit service. Feedback could potentially be gathered via HART's OneBusAway Tampa mobile app (http://tampa.onebusaway.org), which is currently heavily used by transit riders,. Another useful app is the Pinellas County/City of St. Petersburg's SeeClickFix.com system at http://seeclickfix.com/pinellas county. Both are currently under development with the transit agencies and FDOT District 7. Additional research in the area of improving crowd-sourcing of user feedback is being conducted in the study "BDV26 TWO 977-05 Improving Access to Transit Through Crowdsourced Information," funded by FDOT and NCTR. Research support for all these tools is ongoing at the University of South Florida.

\section{Use Local Knowledge to Identify Needed Amenities}

There are supportive organizations, such as Pinellas Trail, Inc. which assist the Pinellas County Parks \& Conservation Resources Department in the development of amenities for the trail. Members of such organizations likely have a strong local knowledge of what amenities are needed in various places along the trail. For applying the methodology described in this report to different travel markets, such as the senior population, knowing where more seniors use the trail is important to selecting amenities that may be more important for them. For example, where a larger percentage of seniors use certain portions of the trail, one might consider placing a priority on providing benches more frequently spaced along those areas.

\section{Bikes on Buses}

Based upon the information from the case studies, especially the H-GAC case study, when travelers use their bicycles to access public transit, they prefer to take their bicycles with them. While it may be useful to provide bicycle parking at transit stops where ever possible, it may be even more important to provide greater capacity for carrying bicycles within buses. It is recommended that transit agencies provide the capability in their automated vehicle locator mobile phone app to let bicyclists know if the next bus has bicycle rack space available. This allows the bicyclists extra time to change travel plans if necessary. Alternatively, it is recommended to allow bicyclists to bring bicycles on board the bus when the frontmounted bicycle rack on the outside of the bus is full. This is an important consideration to encouraging and enabling a trails/transit multimodal trip. This is 
especially important because the properties on which many bus stops are located are too small to accommodate secure, covered bicycle parking.

There may be different considerations for urban areas served by passenger rail. The amenities at a rail station may differ from those provided at bus stops, for example, bike parking might be better accommodated within the footprint of a rail station than at a bus stop. Cervero, Caldwell, and Cuellar (2013) studied the effect of rail station bicycle facilities upon bike-to-rail travel. They found evidence that better facilities do increase bike mode share accessing the rail station. Bicycle facilities also result in greater willingness to bicycle farther distances to the station.

\section{Provide Additional Trail Access Points}

It was observed for both the Pinellas Trail and for the Upper Tampa Bay Trail that there are some long stretches of trail segments with no public access but instead with residential properties and continuous fencing on both sides of the trail. It is recommended that host communities consider providing additional points of access to existing trails, such as easements along selected property lines that allow nonmotorized access. This concept would be informed by the Neighborhood Greenway concept described in the Draft Multi-Modal Transportation Plan of the City of Birmingham, MI. (The Greenway Collaborative, Inc. 2013, 64) Another example is the Miami-Dade County Ludlam Trail case study (AECOM 2011) that recommended that trail access should be primarily through sidewalk connections and access from private property.

\section{Economic Activity at Trail/Transit Crossings}

For trails to have optimum value for transportation, they provide access to many destinations. The Pinellas Scenario \#2 at Gooden Crossing Road was characterized by many vacant land parcels at the Pinellas Trail crossing. It also was observed that in some areas along the trail, some business properties have provided retail, such as bicycle shops or cafes positioned for trail users to access directly from the trail. Such business opportunities would increase the value of the trail to serve a transportation purpose. In the future, as the Pinellas Trail becomes connected to the regional trail system, businesses serving tourists could locate at these trail/transit access nodes.

\section{Transit Perspective on the BPAC}

The staff for the Hillsborough BPAC commented that due to the composition of BPAC membership, discussions about the needs of transit patrons and their ability to access public transit by walking and bicycling are uncommon. The Hillsborough BPAC staff suggested to alter the composition of the BPAC to incorporate representatives who ride the bus as their primary source of transportation. This would likely lend a whole different perspective to the discussions, and would also bolster discussion about the needs of pedestrians. It is relatively easy to find bicycling advocates to serve on the BPAC but less so for "pedestrian advocates." Transit patrons directly experience issues relating to accessing transit stops from the perspective of a pedestrian. Incorporating a citizen transit representative to the BPAC would encourage discussion about multimodal connections between walking, bicycling and public transit. This person could be someone already serving on the 
transit advisory committee. Likewise, a BPAC representative could attend transit advisory committee meetings. 


\section{References}

AASHTO (American Association of State Highway and Transportation Officials). 1999. Guide for the Development of Bicycle Facilities. $3^{\text {rd }}$ ed. Washington, D.C.: AASHTO.

AECOM. 2011. Miami-Dade County Trail Design Guidelines and Standards, Ludlam Trail Case Study, Section One: Research \& Analysis. Miami-Dade County, FL: Miami-Dade County Park and Recreation Department. Accessed December 19, 2015.

http://www.miamidade.gov/parksmasterplan/library/trail-design-report-section-1.pdf.

Alta Planning + Design. 2013. "Pedestrian Network Analysis." Metro Regional Active Transportation Plan. Final Report. Portland-Salem Metropolitan Area, OR: Oregon Metro. June. Accessed December 19, 2015. http://rim.metro-

region.org/webdrawer/webdrawer.dll/webdrawer/rec/296174/view/Planning\%20and\%20De velopment\%20-\%20Regional\%20Tran dices\%20-

$\% 20$ Regional\%20Active\%20Transportation\%20Plan\%20(ATP)\%20-

$\% 20$ Pedestrian\%20Network\%20Analysis.PDF.

Asakura Robinson Company LLC, Traffic Engineers, Inc., and Nancy R. Edmonson Transportation Consulting. 2014. "METRO Bike \& Ride Access \& Implementation Plan." Houston: Houston-Galveston Area Council and METRO. January. Accessed December 20, 2015. http://www.h-gac.com/taq/sub regional/docs/METRO-Bike-Ride-study.pdf.

Broach, Joseph, Jennifer Dill, and John Gliebe. 2012. "Where do cyclists ride? A route choice model developed with revealed preference GPS data." Transportation Research Part A - Policy and Practice 46: 1730-1740. Accessed December 21, 2015. http://ac.elscdn.com/S0965856412001164/1-s2.0-S0965856412001164-main.pdf? tid=a7c9ed48-a7fb11e5-96ce-00000aab0f01\&acdnat=1450713679 db86501d6d445505755751fa1f238f09.

Cervero, R., B. Caldwell, and J. Cuellar. 2013. "Bike-and-Ride: Build it and They Will Come." Journal of Public Transportation. 16 (4): 83-105. Accessed December 19, 2015. http://scholarcommons.usf.edu/jpt/vol16/iss4/5/.

"CNT Housing + Transportation Index" webpage. The Center for Neighborhood Technology. Chicago, IL. Accessed December 19, 2015. http://www.cnt.org/tools/housing-andtransportation-affordability-index.

East Coast Greenway website, "2,900 Miles from Maine to Florida," East Coast Greenway Alliance. Accessed December 18, 2015. http://greenway.org/.

FDEP (Florida Department of Environmental Protection) website. "Designation Program" for the Florida Greenways and Trails System. Tallahassee: FDEP. Last modified July 16, 2015, http://www.dep.state.fl.us/gwt/designation/.

FDOT (Florida Department of Transportation). 2015. "Pedestrian, Bicycle, and Public Transit Facilities" In Plans Preparation Manual. Volume 1, Section 8.6 Shared Use Paths. Topic \# 525-000-007. Tallahassee: FDOT. Last modified January 1, 2015. http://www.dot.state.fl.us/rddesign/PPMManual/2015/Volume1/Chap08.pdf.

FDOT (Florida Department of Transportation). 2015. "Roadway Design Bulletin 15-01. Revisions to Volume 1, Chapters 2, 8, 21, and 25: Volume 2 Chapter 6 Exhibits-Typical Sections Urban Arterial Lane Width and Bicycle Lane Options." Tallahassee, FL: FDOT. January 1. Accessed December 21, 2015. http://www.dot.state.fl.us/rddesign/Bulletin/RDB15-01.pdf. 
FHWA (Federal Highway Administration). 2001. "Trail Development," in Designing Sidewalks and Trails for Access, PART II of II: Best Practices Design Guide. Section 12.3 Types of trails. Washington, D.C.: FHWA. Last modified February 10, 2014.

http://www.fhwa.dot.gov/environment/bicycle pedestrian/publications/sidewalk2/sidewalks 212.cfm\#typ.

Florida Office of Greenways and Trails (OGT). 2013. Florida Greenways \& Trails System Plan 2013-2017. Tallahassee, FL: Department of Environmental Protection, Division of Recreation \& Parks. Accessed December 21, 2015.

http://www.dep.state.fl.us/gwt/FGTS Plan/PDF/FGTS Plan 2013-17 publication.pdf.

Florida Office of Greenways and Trails (OGT). 2012. 2012 Land Trails Opportunity. Florida Greenways \& Trails System Plan. Map book. Tallahassee, FL: Department of Environmental Protection, Division of Recreation \& Parks. Accessed December 21, 2015.

http://www.dep.state.fl.us/gwt/FGTS Plan/PDF/LANDTRAILS MapBook.pdf.

FTA (Federal Transit Administration). 2013. Transit Capacity and Quality of Service Manual. 3rd ed. Transit Cooperative Highway Research Program (TCRP) Report 165. Washington, D.C.: Transportation Research Board of the National Academies.

The Greenway Collaborative, Inc. 2013. "Draft Multi-Modal Transportation Plan for Consideration by the City of Birmingham, Michigan." Birmingham, MI. Accessed December $19,2015$.

http://greenwaycollab.com/Projects/Birmingham/BMMTP Report 1125 2013.pdf.

Hillsborough Area Regional Transit Authority. 2015. Transit Development Plan Annual Update. FY 2015-FY 2025. Tampa, FL. September. Accessed December 30, 2015. http://www.gohart.org/Style\%20Library/goHART/pdfs/board/TDP final draft 092515.pdf.

Hillsborough County. 2015. "Hillsborough County. CPA 14-09-B. Comprehensive Plan Update-Transportation Section." Proposed text amendment. January 15. Accessed December 19, 2015. http://www.planhillsborough.org/wp-content/uploads/2014/09/CPA14-09-B-Transportation-Section-Proposed-Plan-Update-Amendment3.pdf.

Hillsborough County. 2011. "Hillsborough Greenways System Greenway Recreational Corridors." Map. Real Estate Department Geomatics Division, GIS Section. Tampa, FL. April 6.

Hillsborough County. 2008a. Future of Hillsborough: Comprehensive Plan for Unincorporated Hillsborough County, Florida, Livable Communities Element. Tampa, FL: Hillsborough County Board of County Commissioners. August 26. Accessed December 21, 2015. http://www.planhillsborough.org/wp-content/uploads/2012/10/LIVABLECOMMUNITIES 06 13b.pdf.

Hillsborough County. 2008b. "Town 'N Country Community Plan." Comprehensive Plan Amendments. As contained within the Future of Hillsborough: Comprehensive Plan for Unincorporated Hillsborough County, Florida, Livable Communities Element. Tampa, FL: Hillsborough County Board of County Commissioners. Effective January 7. pp.69-73. . Accessed December 21, 2015. http://www.planhillsborough.org/wpcontent/uploads/2012/10/LIVABLE-COMMUNITIES 06 15.pdf.

Hillsborough County. 2008c. "Greater Carrollwood-Northdale Communities Plan." $1^{\text {st }}$ Cycle 2010 Comprehensive Plan Amendments. As contained within the Future of Hillsborough: Comprehensive Plan for Unincorporated Hillsborough County, Florida, Livable Communities Element. Tampa, FL: Hillsborough County Board of County Commissioners. August 26. pp. 197-213. Accessed December 21, 2015. http://www.planhillsborough.org/wpcontent/uploads/2012/10/LIVABLE-COMMUNITIES 06 13b.pdf.. 
Hillsborough County. 1995. Hillsborough Greenways Master Plan. Hillsborough County, FL: Planning and Development Management Department. Tampa, FL. May 9. Accessed

December 21, 2015. http://www.planhillsborough.org/wpcontent/uploads/2013/09/Greenway-Master-Plan-.pdf.

Hillsborough County MPO. 2014a. "Multi-Use Trails, West Central Florida Regional Priorities." Map. Tampa, FL. January. . Accessed December 19, 2015.

http://www.pinellascounty.org/mpo/bikeped/MUTMap0114.pdf.

Hillsborough County MPO. 2014b. Imagine 2040: Hillsborough Long Range Transportation Plan, Summary Report. Tampa, FL. Accessed December 19, 2015. http://www.planhillsborough.org/wp-content/uploads/2014/10/2040-LRTP-Final-FullReport-revised-12-9-151.pdf.

Hillsborough County MPO. 2004. 2025 Comprehensive Pedestrian Plan. Final Report. Tampa, FL. November 1. Accessed December 19, 2015. http://www.planhillsborough.org/wpcontent/uploads/2015/04/2025CompPedestrian Plan with maps2004.pdf.

Hillsborough County MPO. 2015. "Interactive Bicycle Suitability." Map. Tampa, FL. Accessed December 19, 2015. http://www.planhillsborough.org/interactive-bicycle-suitability-map/.

H.R. Green Company. 2009. "Metropolitan Transit Bicycle and Pedestrian Connections to Transit Infrastructure Study." Metropolitan Transit-Metropolitan Council Contract Number 07P138. St. Paul, MN. February 12. Accessed December 19, 2015.

http://www.metrocouncil.org/Transportation/Publications-And-Resources/Bicycle-and-

Pedestrian-Connections-to-Transit-Infr.aspx.

Little, Charles E. 1990. Greenways for America. Baltimore: The Johns Hopkins University Press.

City of Maple Valley. 2013. Non-Motorized Transportation Plan, Maple Valley, WA. March. Accessed December 19, 2015. http://www.ci.maple-

valley.wa.us/home/showdocument?id=1653.

MetroPlan Orlando. 2015. "Technical Report 6: Bicycle and Pedestrian Plan." Final Plan for Adoption. 2040 Long Range Transportation Plan. Final Adopted Plan. Orlando, FL:

MetroPlan. Accessed December 19, 2015. http://metroplanorlando.com/files/view/2040Irtp-bicycle-pedestrian.pdf.

NCTR (National Center for Transit Research). 2011. "Enabling Cost-Effective Multimodal Trip Planners through Open Transit Data, Final Report." Florida Department of Transportation. May. Accessed December 19, 2015. http://www.nctr.usf.edu/wpcontent/uploads/2011/06/77926.pdf.

Oregon Metro. 2012. "Existing Conditions, Findings and Opportunities Report." for the Regional Active Transportation Plan. Draft 2-Advisory Committees and Metro Council Review Copy. Portland-Salem Metropolitan Area, OR: Oregon Metro. August 28. Accessed December 20, 2015. http://rim.metroregion.org/webdrawer/webdrawer.dll/webdrawer/rec/296173/view/Planning\%20and\%20De velopment\%20-\%20Regional\%20Tran ortunities\%20Report\%20-\%20draft\%202\%20$\% 20$ Advisory\%20Committees $\% 20$ and $\% 20$ Metro\%20Council\%20review\%20copy.PDF. 
Oregon Metro. 2013. "Regional Bicycle Network Evaluation: Technical Report for the Regional Active Transportation Plan." Portland-Salem Metropolitan Area, OR: Oregon Metro. April. Accessed December 19, 2015. http://rim.metro-

region.org/webdrawer/webdrawer.dll/webdrawer/rec/296175/view/Planning\%20and\%20De velopment\%20-\%20Regional\%20Tran ion\%20-

\%20Technical\%20report\%20for\%20the\%20Regional\%20Active\%20Transportation\%20Plan \%20-\%20April\%202013.PDF

Oregon Metro. 2014a. 2014 Regional Transportation Plan, Portland-Salem Metropolitan Area, OR: Oregon Metro. Accessed December 19, 2015.

http://www.oregonmetro.gov/sites/default/files/RTP-2014-final.PDF.

Oregon Metro. 2014b. 2014 Regional Active Transportation Plan, Portland-Salem Metropolitan Area, OR: Oregon Metro. July. Accessed December 19, 2015.

http://www.oregonmetro.gov/sites/default/files/2014 regional active transportation plan $\underline{0 . p d f}$.

Oregon Metro. 2014c. Bicycle Network Map Book, Regional Active Transportation Plan. Portland-Salem Metropolitan Area, OR: Oregon Metro. Accessed December 19, 2015. http://www.oregonmetro.gov/sites/default/files/atp 2 bikemapbook.pdf

Parametrix. 2015. Council Creek Regional Trail Master Plan. Portland-Salem Metropolitan Area, OR: Oregon Metro. May. Accessed December 19, 2015.

http://www.oregonmetro.gov/sites/default/files/Council\%20Creek\%20Regional\%20Trail\%2 0Master\%20Plan.pdf.

Parsons Brinckerhoff and Toole Design Group. 2010. "Metrorail Bicycle \& Pedestrian Access Improvements Study." Washington, D.C.: Washington Metropolitan Area Transit Authority. Accessed December 19, 2015. http://planitmetro.com/wp-

content/uploads/2010/12/Metrorail-Bicycle-Pedestrian-Access-Improvements-StudyFinal.pdf.

Petritsch, Theodore A. and Christopher B. Fellerhoff. 2014. "Shared Use Path-Roadway Intersections; Guidelines for Assigning Priority and Determining Traffic Control at Shared Use Path/Roadway Intersections, Pinellas County, FL." Lutz, FL: Sprinkle Consulting.

August. Accessed December 19, 2015.

http://www.pinellascounty.org/mpo/Traffic\%20Studies/10 A Trail\%20Guidelines\%20Repor $\underline{\text { t.pdf. }}$

Pinellas County. 2012. Pinellas County Comprehensive Plan. Transportation Element, Chapter 4, Bicycle and Pedestrian Travel. Amended March 27. Accessed December 19, 2015. http://www.pinellascounty.org/Plan/comp plan/03trans/1-intro.pdf.

Pinellas County MPO. 2013a. Bicycle Pedestrian Master Plan, Facilities Element. Adopted December 11. Accessed December 19, 2015.

http://www.pinellascounty.org/MPO/bikeped/BikePedFacElement.pdf.

Pinellas County MPO. 2013b. 2035 Long Range Transportation Plan. Originally adopted December 9, 2009. Accessed December 19, 2015.

https://www.pinellascounty.org/mpo/LRTP/LRTP.pdf.

Pinellas County MPO. 2015a. "2014 State of the System (SOS) Report." June 10. Accessed December 19, 2015. https://www.pinellascounty.org/mpo/SOS/SOS2014.pdf.

Pinellas County MPO. 2015b. "Partnerships to Improve Community Health (PICH) Grant." May 13. PowerPoint presentation. Accessed December 19, 2015..

https://www.pinellascounty.org/mpo/agendas/MPO Meeting/May\%202015/Partnership $\% 20$ to\%20Improve\%20Community\%20Health\%20(PICH).pdf. 
PSTA (Pinellas Suncoast Transit Authority). 2015. "FY2016 Budget Process and Key Assumptions." Finance and Performance Management and Planning Committees. PowerPoint presentation. St. Petersburg, FL: PSTA. March 20. Accessed December 21, 2015. http://www.psta.net/PDF/PSTA\%20-\%20FY\%202016\%20Budget.pdf.

PSTA (Pinellas Suncoast Transit Authority). 2014. Transit Development Plan Progress Report. FY 2015-2024. St. Petersburg, FL: PSTA. November. Accessed December 21, 2015. http://www.psta.net/PDF/TDP\%20Progress\%20Report\%202015.pdf.

TBARTA (Tampa Bay Area Regional Transportation Authority). 2015. "Regional Multi-Use Trail Projects; West Central Florida Regional Priorities." July. Accessed December 19, 2015. http://www.tbarta.com/images/ccc/2015 0710\%20Adopted\%20MUT\%20Priority\%20List\%20Map.pdf.

Terveen, L. 2013. "Bike, Bus, and Beyond: Extending Cyclopath to Enable Multi-Modal Routing." University of Minnesota, Minneapolis and Minnesota Department of Transportation, Office of Policy Analysis, Research \& Innovation. Research Project Final Report 2013-19. July. Accessed December 19, 2015. http://conservancy.umn.edu/bitstream/handle/11299/155992/MnDOT201319. pdf? sequence $=1$ \&isAllowed $=y$.

Tindale Oliver and Associates, Inc. 2015. "Hillsborough County Trails and Bike Facilities, Existing, Planned Conceptual." Map. Draft. Prepared for the Tampa-Hillsborough Greenways and Trails Plan Update slide presentation Committee Briefings. Hillsborough County, FL. May 21. Accessed December 19, 2015. http://www.planhillsborough.org/wpcontent/uploads/2015/04/Tampa-Hillsborough-Greenways-and-Trails-Plan-Update-v3.pdf.

Tindale Oliver and Associates, Inc. 2005. "Hillsborough County Bicycle \& Pedestrian Counts, 2000 \& 2005." Tampa, FL: Hillsborough County MPO. March. Accessed December 19, 2015. http://www.planhillsborough.org/wp-content/uploads/2015/04/Bike-Ped-Counts-Report2005.pdf.

TriMet (Tri-County Metropolitan Transportation District of Oregon). 2011. "Pedestrian Network Analysis, A safer, easier, more comfortable walk to transit." Portland, OR: TriMet. September. Accessed December 20, 2015. http://trimet.org/pdfs/pednetwork/trimetpedestrian-network-analysis-report.pdf.

TriMet (Tri-County Metropolitan Transportation District of Oregon). 2012. "Pedestrian Network Analysis, Better Walking Access to Transit in the Portland Metro Region. Draft Technical Memo \#3: Existing Conditions and Needs Analysis for Ten Focus Areas." Portland, OR: TriMet. September. Accessed December 20, 2015.

http://trimet.org/pdfs/pednetwork/trimet-ped-network-technical-memo-3.pdf.

University of North Carolina Highway Safety Research Center. 1999. "Trail Intersection Design Guidelines." Tallahassee, FL: Florida Department of Transportation. Revised. Accessed December 19, 2015. http://atfiles.org/files/pdf/trailintersect.pdf.

"Walk Score ${ }^{\circledR}$ Professional" webpage. Redfin. Seattle, WA. Accessed December 19, 2015. https://www.walkscore.com/professional/research.php.

West Central Florida MPO Chairs Coordinating Committee. 2011. "2010 Regional Mulit-Use Trails. Map. Updated January 11. 


\section{Appendix A: Inventories of Six Selected Transit/Trail Crossings Trail/Transit Connection Audit}

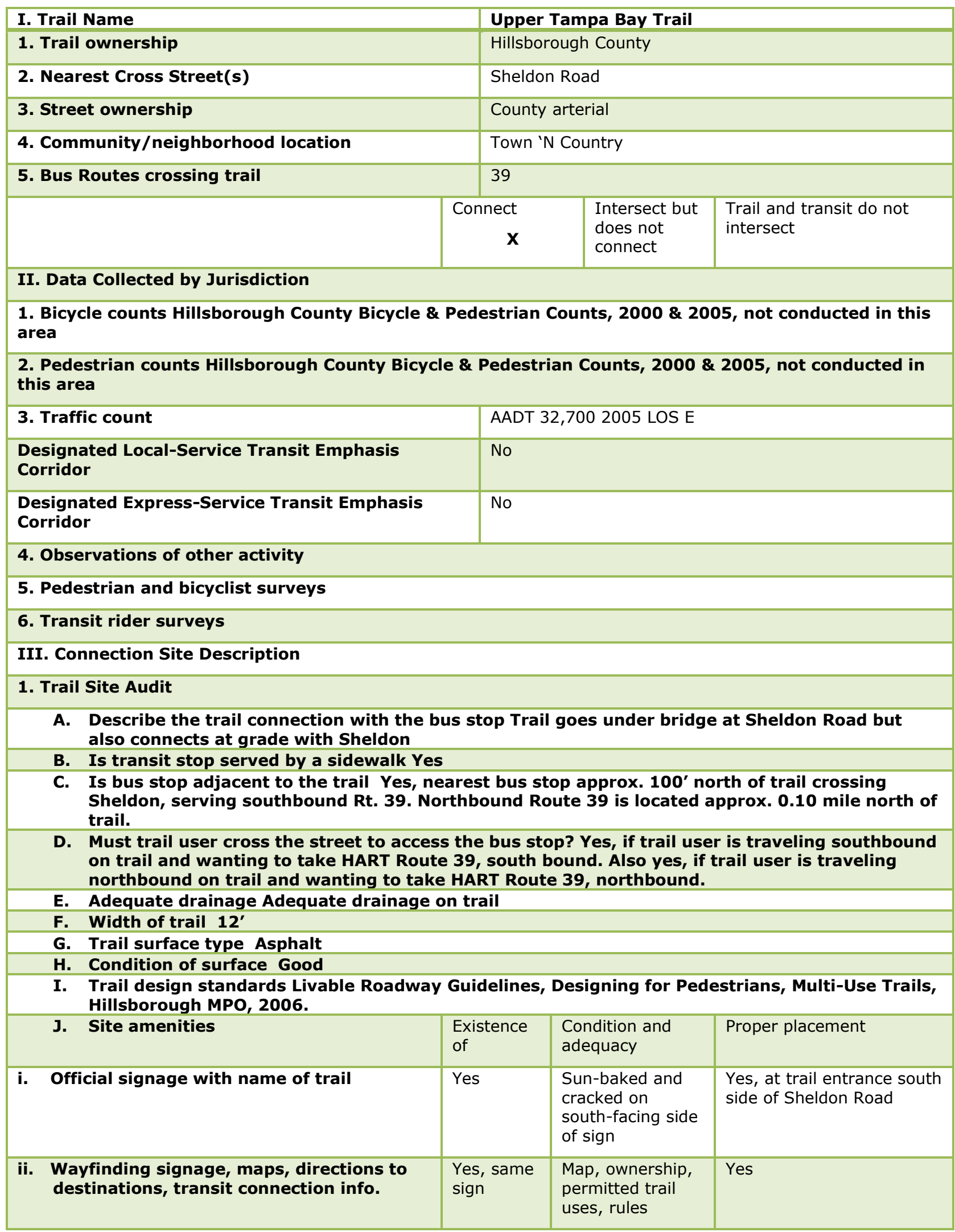




\begin{tabular}{|c|c|c|c|}
\hline $\begin{array}{l}\text { iii. Interpretative signage, natural and } \\
\text { cultural history }\end{array}$ & No & & \\
\hline iv. Shelter structure & No & & \\
\hline v. Shade trees & No & & \\
\hline vi. Aesthetic landscaping & No & & \\
\hline vii. Bench & No & & \\
\hline viii. Trash can & Yes & Good & $\begin{array}{l}\text { Trail entrance, south side } \\
\text { of Sheldon }\end{array}$ \\
\hline ix. Water fountain & No & & \\
\hline x. $\quad$ Rest rooms & No & & \\
\hline xi. Lighting & No & & \\
\hline xii. Motor vehicle parking & No & & \\
\hline xiii. Other observ & 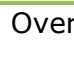 & & with good \\
\hline
\end{tabular}

xiv. Recommendations for improvements Interpretive signage would add interest value.

\section{Trail Operations}

A. Hours of operation Dawn until dusk. Temporary signage posts actual time of sunset at trailheads.

B. Cost of admission Free

C. Security service Parks personnel were seen riding utility cart along trail in afternoon. There is a 911 Station Number System with yellow decals affixed to trail every 200'

D. Availability of trail map Yes, "Hillsborough Trails, Paths and Bicycle Guide"

E. Trail map identifies transit stop locations and routes No. There are bus symbols located at HART transfer stations but the map legend does not identify what the bus symbol means. No bus routes shown.

F. Trail map provides information about destinations Recreational destinations, skate parks, dog parks only.

G. Web site http://www.planhillsborough.org/wp-content/uploads/2013/09/Trail-map.pdf See also map that illustrates Upper Tampa Bay Trail http://www.hillsboroughcounty.org/DocumentCenter/View/13127

H. Information dissemination-Advertising, incentives, promotion Found on Web site of Hillsborough Parka and Recreation Department at http://www.hillsboroughcounty.org/utbtrail

I. "Adopt-A-Trail" sponsorships/volunteer groups Hillsborough Bicycle and Pedestrian Advisory Committee of the Hillsborough MPO

J. Recommendations for improvements Replace faded signage. Add bus routes on trail maps.

3. Planning Constraints and Opportunities

\section{A. Local Government Comprehensive Plan}

B. Bicycle and/or Pedestrian Plan

C. Parks, Recreation, Greenways Plan
Transportation Element Goal 3: Provide a county-wide bikeway and pedestrian system that is integrated with other transportation modes. p. 143

Goals 6: Maximize connection b/w transportation modes.

Sheldon Rd., b/w Hillsborough and Linebaugh Avenues, identified as a study corridor in the Pedestrian \& Bicycle High Crash Areas Strategic Plan for Unincorporated Hillsborough County Roads, 2012

Town 'N Country Community Plan, with goals to improve sidewalk, bike lane and trail connectivity, to improve traffic calming methods, and pedestrian-friendly urban design that supports creation of town centers. Trail/transit crossing is within the County Urban Service Area, and adjacent to the Coastal High Hazard Area where the channel is located.

Town 'N Country Community Plan, with goals to improve sidewalk, bike lane and trail connectivity, to improve traffic calming methods, and pedestrian-friendly urban design that supports creation of town centers. Trail/transit crossing is 


\begin{tabular}{|c|c|c|}
\hline & \multicolumn{2}{|c|}{$\begin{array}{l}\text { within the County Urban Service Area, and adjacent to the } \\
\text { Coastal High Hazard Area where the channel is located. }\end{array}$} \\
\hline E. MPO LRTP & \multicolumn{2}{|c|}{$\begin{array}{l}2035 \text { LRTP Needs Assessment and County ROW Corridor Plan } \\
\text { indicates future widening from 4D to 6D }\end{array}$} \\
\hline \multicolumn{3}{|l|}{ 4. Transit Service Site Audit } \\
\hline \multicolumn{3}{|c|}{$\begin{array}{l}\text { Transit stop location Approx. 200' north of trail going south bound and approx. } 0.10 \text { mile north of trail } \\
\text { going northbound. }\end{array}$} \\
\hline $\begin{array}{l}\text { A. Type of transit stop (bus bay, on- } \\
\text { street, park and ride) }\end{array}$ & On-street & \\
\hline B. Bicycle parking & No & \\
\hline C. Covered bicycle parking & No & \\
\hline D. Sufficient bicycle parking & No & \\
\hline E. Shelter & Yes & \\
\hline F. Bench & Yes & \\
\hline $\begin{array}{l}\text { G. Adequate room for bicyclists to wait } \\
\text { at bus stops }\end{array}$ & No & $\begin{array}{l}\text { High residential walls on both sides of } \\
\text { street limit size of transit stops and } \\
\text { amenities that can be placed there. }\end{array}$ \\
\hline H. Clear areas for pedestrians to wait & \multicolumn{2}{|l|}{ Yes } \\
\hline I. Service hours & \multicolumn{2}{|c|}{$\begin{array}{l}\text { Weekdays every } 30 \text { minutes, } 5: 30 \text { am to } 10 \mathrm{pm} \text {; } \\
\text { Saturday, every } 30 \text { minutes, } 8 \text { am to } 9: 30 \mathrm{pm} \\
\text { Sunday, every hour, } 8 \text { a.m. to } 8 \mathrm{pm}\end{array}$} \\
\hline $\begin{array}{l}\text { J. Transit customer map shows trail } \\
\text { connection locations }\end{array}$ & No & \\
\hline K. Transit stop design standards & \multicolumn{2}{|c|}{$\begin{array}{l}\text { Transit Friendly Planning and Design Handbook and } \\
\text { Technical Manual, HART, and Livable Roadway Guidelines, } \\
\text { Designing for Transit Facilities, General Guidelines, } \\
\text { Hillsborough MPO, 2006. }\end{array}$} \\
\hline L. Transit Development Plan & \multicolumn{2}{|c|}{$\begin{array}{l}\text { Transit Development Plan Update, Fiscal Year 2016-2025. } \\
\text { No proposed improvements per GO Hillsborough Component. } \\
\text { Shows bus stop improvements for bicycle, FY 2017-2026, } \\
\text { Infrastructure for Town 'N Country Flex, FY } 2022 .\end{array}$} \\
\hline \multicolumn{3}{|c|}{$\begin{array}{l}\text { Recommendations for improvements Provide one bicycle rack at northbound and southbound transit } \\
\text { stops. Show public trails on HART system map. List trail connections in legend where information is } \\
\text { found on park-and-ride lots, express pick-up stops, and Car/Vanpool lots. }\end{array}$} \\
\hline \multicolumn{3}{|l|}{ 5. Street Site Audit } \\
\hline A. Street width & \multicolumn{2}{|c|}{$12^{\prime}$ for each general purpose lane } \\
\hline B. Surface condition & \multicolumn{2}{|c|}{ Asphalt, good } \\
\hline C. Curb and gutter & Yes & \\
\hline D. Storm water collects in the road & No & \\
\hline $\begin{array}{l}\text { E. Drainage grates, manhole covers, } \\
\text { longitudinal joints that could trap a } \\
\text { bicycle wheel }\end{array}$ & No & \\
\hline $\begin{array}{l}\text { F. Number of lanes each direction } \\
\text { general purpose }\end{array}$ & 1 & \\
\hline G. Number of right turn lanes & None & \\
\hline H. Number of left turn lanes & None & \\
\hline I. Median refuges & Yes & \\
\hline J. Posted speed limit & \multicolumn{2}{|c|}{ Not seen from trail crossing } \\
\hline
\end{tabular}




\begin{tabular}{|c|c|c|}
\hline $\begin{array}{l}\text { K. Crosswalks available to help trail user } \\
\text { access the transit stop }\end{array}$ & Yes & \\
\hline i. $\quad$ Mid-block & \multicolumn{2}{|c|}{ Yes, the trail crosses Sheldon mid-block } \\
\hline Intersection & $\mathrm{N} / \mathrm{A}$ & \\
\hline Raised crosswalk & no & \\
\hline $\begin{array}{l}\text { Curb cut at crosswalk intersection } \\
\text { with road }\end{array}$ & Yes & \\
\hline Line of sight, adequate & Yes & \\
\hline Stop sign & No & \\
\hline Signalization for motorists & Yes & \\
\hline Pedestrian signal & Yes & \\
\hline Pedestrian activated & Yes & \\
\hline ii. Count-down signals & Yes & \\
\hline iii. Audible signal & No & \\
\hline Q. Rectangular Rapid Flashing Beacons & No & \\
\hline R. Sidewalks & Yes & \\
\hline S. Bicycle lanes, one side or both sides & Both sides & \\
\hline T. Shoulders, one side or both sides & No & \\
\hline U. Sharrows & No & \\
\hline V. Street signage identifying trail & $\begin{array}{l}\text { No street s } \\
\text { yellow caut } \\
\text { crossing, at }\end{array}$ & $\begin{array}{l}\text { e identifying trail for motorists but there are } \\
\text { igns indicating pedestrian and bicycle } \\
\text { h bound and south bound approaches to trail }\end{array}$ \\
\hline $\begin{array}{l}\text { W. Planned and programmed street } \\
\text { improvements }\end{array}$ & & \\
\hline \multicolumn{3}{|c|}{$\begin{array}{l}\text { Recommendations for improvements. Some pooling of water observed on Sheldon Road bridge } \\
\text { sidewalk on south side of bridge. Recommend drainage improvement }\end{array}$} \\
\hline \multicolumn{3}{|l|}{$\begin{array}{l}\text { IV. Trail and Transit Intersect } \quad \text { N/A } \\
\text { But Do Not Connect }\end{array}$} \\
\hline \multicolumn{3}{|l|}{$\begin{array}{l}\text { 1. Description of the intersection and why the } \\
\text { trail and transit service do not connect }\end{array}$} \\
\hline \multicolumn{3}{|l|}{ 2. Should there be a connection? } \\
\hline \multicolumn{3}{|l|}{ 3. Existing number of trail users at location } \\
\hline \multicolumn{3}{|l|}{ 4. Existing transit ridership at location } \\
\hline \multicolumn{3}{|l|}{ 5. Is this a good connection location? } \\
\hline \multicolumn{3}{|l|}{$\begin{array}{l}\text { 6. Presence of attractive destinations within } \\
\text { sight }\end{array}$} \\
\hline \multicolumn{3}{|l|}{ 7. Safety considerations } \\
\hline \multicolumn{3}{|l|}{$\begin{array}{l}\text { 8. Presence of bike lanes, shoulders, } \\
\text { sidewalks, ADA accessibility }\end{array}$} \\
\hline \multicolumn{3}{|l|}{ 9. Street layout (grid?) } \\
\hline \multicolumn{3}{|l|}{ 10. Presence of physical barriers } \\
\hline A. River & & \\
\hline B. Retaining wall & & \\
\hline C. Drainage structures & & \\
\hline
\end{tabular}




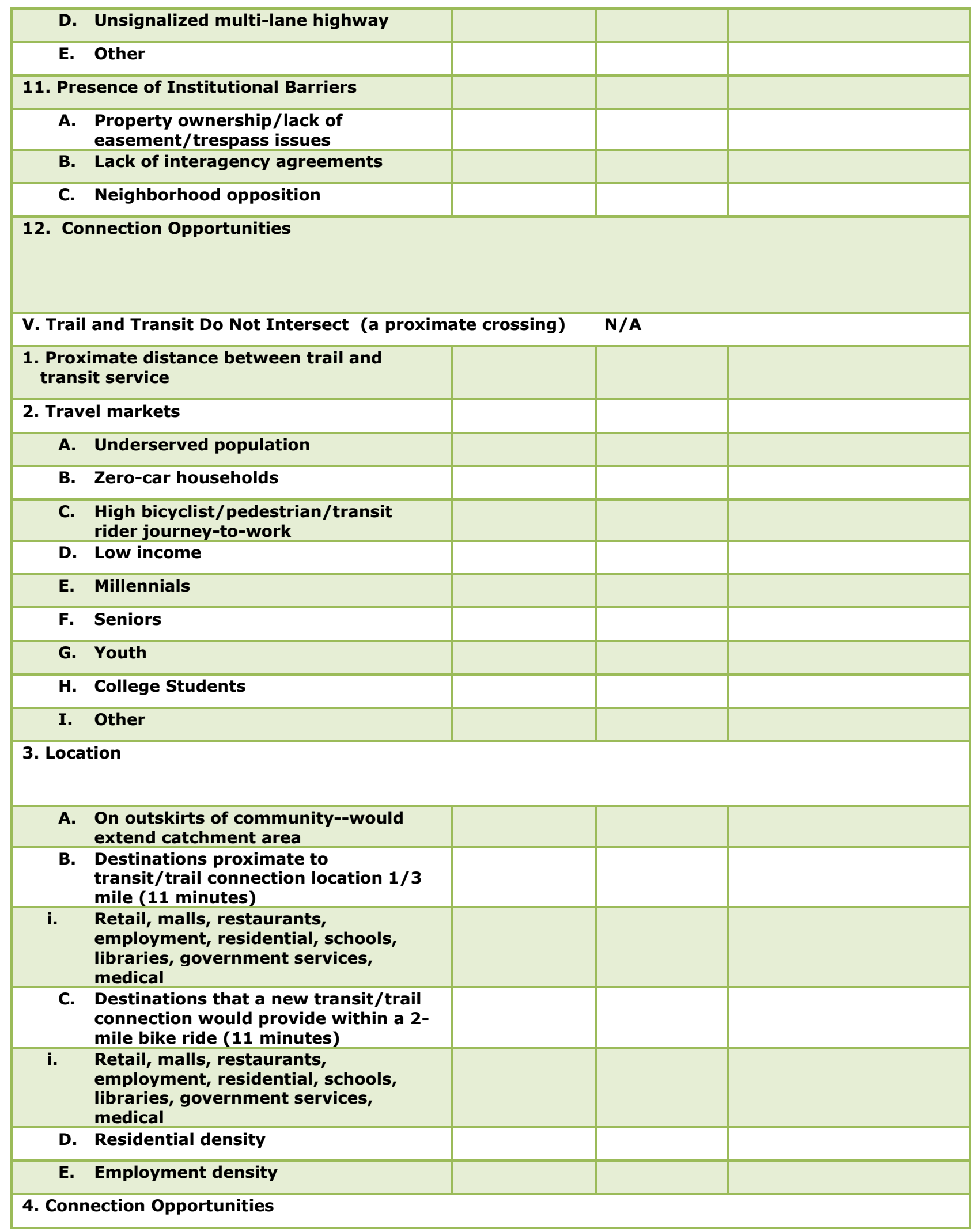




\section{Trail/Transit Connection Audit}

\begin{tabular}{|c|c|c|c|}
\hline I. Trail Name & \multicolumn{3}{|c|}{ Upper Tampa Bay Trail } \\
\hline 1. Trail ownership & \multicolumn{3}{|c|}{ Hillsborough County } \\
\hline 2. Nearest Cross Street(s) & \multicolumn{3}{|c|}{ Linebaugh Avenue } \\
\hline 3. Street ownership & \multicolumn{3}{|c|}{ Hillsborough County arterial } \\
\hline 4. Community/neighborhood location & \multicolumn{3}{|c|}{ Town 'N Country } \\
\hline 5. Bus Routes crossing trail & & \multicolumn{2}{|c|}{ HART Flex Town 'N Country } \\
\hline & Connect & $\begin{array}{l}\text { Intersect but } \\
\text { does not } \\
\text { connect } \mathbf{X}\end{array}$ & $\begin{array}{l}\text { Trail and transit do not } \\
\text { intersect }\end{array}$ \\
\hline
\end{tabular}

2. Pedestrian counts Hillsborough County Bicycle \& Pedestrian Counts, 2000 \& 2005, not conducted in this area

\begin{tabular}{|l|l|}
\hline 3. Traffic count & AADT 31,800 2005 LOS F \\
\hline $\begin{array}{l}\text { Designated Local-Service Transit Emphasis } \\
\text { Corridor }\end{array}$ & No \\
\hline $\begin{array}{l}\text { Designated Express-Service Transit Emphasis } \\
\text { Corridor }\end{array}$ & No \\
\hline 4. Observations of other activity & \\
\hline 5. Pedestrian and bicyclist surveys & \\
\hline 6. Transit rider surveys & \\
\hline III. Connection Site Description
\end{tabular}

1. Trail Site Audit

K. Describe the trail connection with the bus stop Trail goes under bridge at Linebaugh Avenue. Underpass also goes under a railroad bridge.

L. Is transit stop served by a sidewalk No. The HART Flex Town 'N Country route travels past the trail at Linebaugh but there is no designated bus stop there.

M. Is bus stop adjacent to the trail No. See explanation above.

N. Must trail user cross the street to access the bus stop? The HART Flex service stops on Linebaugh at Sheldon Road and on Wilsky Blvd. beyond Linebaugh, at Bellamy Elementary School. The trail user would have to exit the trail and ride or walk along Linebaugh a distance of at least 0.25 mile to access the nearest Flex designated stop.

O. Adequate drainage No. Heavy rains flood the banks of Rocky Creek and submerge the trail under Linebaugh Avenue.

P. Width of trail 12' prior to the Linebaugh Bridge and $10^{\prime}$ under the Linebaugh bridge

Q. Trail surface type Asphalt. Concrete under bridge.

R. Condition of surface Generally good with yellow painted dividing line. However, the segment of trail at Wilsky Blvd. was washed out due to recent flooding. When flood waters recede, thick deposits of sand and debris must be removed from the trail before it can be used again.

S. Trail design standards Livable Roadway Guidelines, Designing for Pedestrians, Multi-Use Trails, Hillsborough MPO, 2006.

\begin{tabular}{|l|l|l|l|}
\hline T. Site amenities & $\begin{array}{l}\text { Existence } \\
\text { of }\end{array}$ & $\begin{array}{l}\text { Condition and } \\
\text { adequacy }\end{array}$ & Proper placement \\
\hline Official signage with name of trail & Yes & $\begin{array}{l}\text { Sun-baked and } \\
\text { cracked on } \\
\text { south-facing side } \\
\text { of sign }\end{array}$ & $\begin{array}{l}\text { Yes, at trail entrance north } \\
\text { side of Linebaugh Avenue }\end{array}$ \\
\hline
\end{tabular}




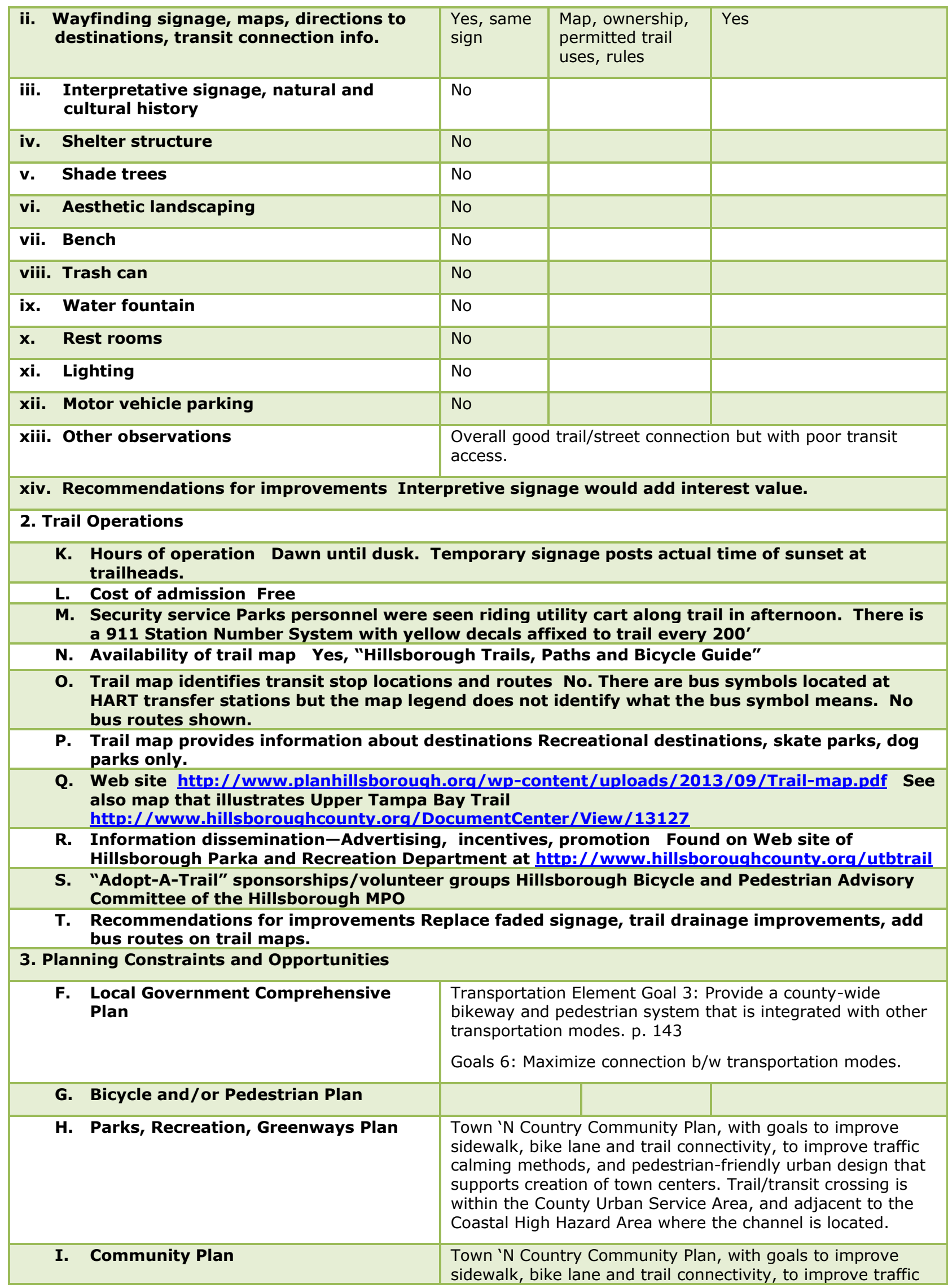




\section{J. MPO LRTP}

calming methods, and pedestrian-friendly urban design that supports creation of town centers. Trail/transit crossing is within the County Urban Service Area, and adjacent to the Coastal High Hazard Area where the channel is located.

\section{Transit Service Site Audit}

Transit stop location Approx. 0.25 mile west of trail crossing, there is a HART Flex Town ' $N$ Country designated bus stop, east of Sheldon Road. A patron must make a reservation at least 2 hours in advance for a seat on the HART Flex van, if he or she would like to be picked up or dropped off at a location in the Flex zone that is not a HARTFlex stop.

\begin{tabular}{|c|c|c|}
\hline $\begin{array}{l}\text { M. Type of transit stop (bus bay, on- } \\
\text { street, park and ride) }\end{array}$ & On-street & \\
\hline N. Bicycle parking & No & \\
\hline O. Covered bicycle parking & No & \\
\hline P. Sufficient bicycle parking & No & \\
\hline Q. Shelter & No & \\
\hline R. Bench & Yes & \\
\hline $\begin{array}{l}\text { S. Adequate room for bicyclists to wait } \\
\text { at bus stops }\end{array}$ & Yes & \\
\hline T. Clear areas for pedestrians to wait & \multicolumn{2}{|c|}{$\begin{array}{l}\text { No. There is no concrete pad for a waiting area. Transit } \\
\text { patrons must wait standing on the sidewalk or in the grass. }\end{array}$} \\
\hline U. Service hours & \multicolumn{2}{|c|}{$\begin{array}{l}\text { Weekday service only, between, } 5: 15 \text { a.m. to } 7 \text { p.m. No } \\
\text { holiday service. HARTFlex departures are hourly. }\end{array}$} \\
\hline $\begin{array}{l}\text { V. Transit customer map shows trail } \\
\text { connection locations }\end{array}$ & No & \\
\hline W. Transit stop design standards & \multicolumn{2}{|c|}{$\begin{array}{l}\text { Transit Friendly Planning and Design Handbook and } \\
\text { Technical Manual, HART, and Livable Roadway Guidelines, } \\
\text { Designing for Transit Facilities, General Guidelines, } \\
\text { Hillsborough MPO, } 2006 .\end{array}$} \\
\hline X. Transit Development Plan & \multicolumn{2}{|c|}{$\begin{array}{l}\text { Transit Development Plan Update, Fiscal Year 2016-2025. } \\
\text { No proposed improvements per GO Hillsborough Component. } \\
\text { Shows bus stop improvements for bicycle, FY 2017-2026, } \\
\text { Infrastructure for Town 'N Country Flex, FY } 2022 .\end{array}$} \\
\hline \multicolumn{3}{|c|}{$\begin{array}{l}\text { Recommendations for improvements Provide concrete pad on which patrons can wait. As funding } \\
\text { permits, consider providing a HART Flex stop prior to the Linebaugh Avenue bridge, closer to the trail. } \\
\text { Show public trails on HART system map. List trail connections in legend where information is found on } \\
\text { park-and-ride lots, express pick-up stops, and Car/Vanpool lots. }\end{array}$} \\
\hline \multicolumn{3}{|l|}{ 5. Street Site Audit } \\
\hline A. Street width & \multicolumn{2}{|c|}{$12^{\prime}$ for each general purpose lane } \\
\hline B. Surface condition & \multicolumn{2}{|c|}{ Asphalt, good } \\
\hline C. Curb and gutter & Yes & \\
\hline D. Storm water collects in the road & No & \\
\hline $\begin{array}{l}\text { E. Drainage grates, manhole covers, } \\
\text { longitudinal joints that could trap a } \\
\text { bicycle wheel }\end{array}$ & No & \\
\hline $\begin{array}{l}\text { F. Number of lanes each direction } \\
\text { general purpose }\end{array}$ & 2 & \\
\hline G. Number of right turn lanes & 1 & \\
\hline H. Number of left turn lanes & 1 & \\
\hline I. Median refuges & Yes & \\
\hline
\end{tabular}




\begin{tabular}{|c|c|c|}
\hline J. Posted speed limit & \multicolumn{2}{|l|}{45} \\
\hline $\begin{array}{l}\text { K. Crosswalks available to help trail user } \\
\text { access the transit stop }\end{array}$ & No & \\
\hline iv. Mid-block & \multicolumn{2}{|l|}{ No } \\
\hline v. Intersection & N/A & \\
\hline vi. $\quad$ Raised crosswalk & No & \\
\hline $\begin{array}{l}\text { Curb cut at crosswalk intersection } \\
\text { with road }\end{array}$ & No & \\
\hline Line of sight, adequate & Yes & \\
\hline Stop sign & No & \\
\hline Signalization for motorists & No & \\
\hline Pedestrian signal & No & \\
\hline Pedestrian activated & No & \\
\hline v. Count-down signals & No & \\
\hline vi. Audible signal & No & \\
\hline Q. Rectangular Rapid Flashing Beacons & No & \\
\hline R. Sidewalks & Yes & \\
\hline S. Bicycle lanes, one side or both sides & Both sides & \\
\hline T. Shoulders, one side or both sides & No & \\
\hline U. Sharrows & No & \\
\hline V. Street signage identifying trail & \multicolumn{2}{|l|}{ No } \\
\hline \multicolumn{3}{|l|}{$\begin{array}{l}\text { W. Planned and programmed street } \\
\text { improvements }\end{array}$} \\
\hline \multicolumn{3}{|l|}{ Recommendations for improvements None } \\
\hline \multicolumn{3}{|l|}{$\begin{array}{l}\text { IV. Trail and Transit Intersect } \\
\text { But Do Not Connect }\end{array}$} \\
\hline $\begin{array}{l}\text { 1. Description of the intersection and why the } \\
\text { trail and transit service do not connect }\end{array}$ & \multicolumn{2}{|c|}{$\begin{array}{l}\text { There is no HARTFlex designated stop where the trail passes } \\
\text { under Linebaugh Avenue }\end{array}$} \\
\hline \multicolumn{3}{|l|}{ 2. Should there be a connection? } \\
\hline 3. Existing number of trail users at location & \multicolumn{2}{|c|}{$\begin{array}{l}\text { During a } 2 \text { - hour observation period on a Friday, there were } \\
\text { less than ten trail users; however, there also had been } \\
\text { scattered showers that day. }\end{array}$} \\
\hline 4. Existing transit ridership at location & \multicolumn{2}{|l|}{ Not known } \\
\hline 5. Is this a good connection location? & \multicolumn{2}{|c|}{$\begin{array}{l}\text { Presently, land use intensity is low in the vicinity of the trail } \\
\text { crossing. Along Linebaugh, on the west side of the trail, } \\
\text { there is Westwood Professional Park, containing doctor } \\
\text { offices, and a day care center. On the east side, there is } \\
\text { the Northwest Solid Waste Transfer Station. This location } \\
\text { could remain a lower priority for strengthening the } \\
\text { transit/trail connection until the area is redeveloped. }\end{array}$} \\
\hline $\begin{array}{l}\text { 6. Presence of attractive destinations within } \\
\text { sight }\end{array}$ & Few & \\
\hline 7. Safety considerations & \multicolumn{2}{|c|}{$\begin{array}{l}\text { Linebaugh Avenue has heavy traffic flowing at high speeds } \\
\text { because the traffic signals are spaced far apart and land } \\
\text { development along Linebaugh at this time is not dense }\end{array}$} \\
\hline
\end{tabular}




\begin{tabular}{|c|c|}
\hline $\begin{array}{l}\text { 8. Presence of bike lanes, shoulders, } \\
\text { sidewalks, ADA accessibility }\end{array}$ & $\begin{array}{l}\text { There are bike lanes and sidewalks along Linebaugh, } \\
\text { however, the sidewalk to the trail underpass is on an incline. }\end{array}$ \\
\hline 9. Street layout (grid?) & No grid \\
\hline 10. Presence of physical barriers & $\begin{array}{l}\text { The low density development and high speed traffic makes } \\
\text { Linebaugh Avenue unwelcoming for pedestrians and } \\
\text { bicyclists despite the presence of sidewalks and bicycle } \\
\text { lanes. }\end{array}$ \\
\hline F. River & $\begin{array}{l}\text { Because Rocky Creek is crossed by Linebaugh Avenue, the } \\
\text { creek is not a barrier. }\end{array}$ \\
\hline G. Retaining wall & No \\
\hline H. Drainage structures & No \\
\hline I. Unsignalized multi-lane highway & No \\
\hline J. Other & \\
\hline 11. Presence of Institutional Barriers & \\
\hline $\begin{array}{l}\text { D. Property ownership/lack of } \\
\text { easement/trespass issues }\end{array}$ & \\
\hline E. Lack of interagency agreements & \\
\hline F. Neighborhood opposition & \\
\hline
\end{tabular}

VI. Trail and Transit Do Not Intersect (a proximate crossing) N/A

1. Proximate distance between trail and transit service

2. Travel markets

Underserved population

Zero-car households

High bicyclist/pedestrian/transit rider journey-to-work
A. Low income
B. Millennials
C. Seniors
D. Youth
E. College Students
F. Other

\section{Location}

On outskirts of community--would extend catchment area

Destinations proximate to transit/trail connection location 1/3 mile (11 minutes)

Retail, malls, restaurants, employment, residential, schools, libraries, government services, medical Destinations that a new transit/trail connection would provide within a 2-mile bike ride (11 minutes) Retail, malls, restaurants, employment, residential, schools, libraries, government services, medical
A. Residential density
B. Employment density 


\section{Connection Opportunities}

\section{Trail/Transit Connection Audit}

\begin{tabular}{|l|}
\hline I. Trail Name \\
\hline 1. Trail ownership \\
\hline 2. Nearest Cross Street(s) \\
\hline 3. Street ownership \\
\hline 4. Community/neighborhood location \\
\hline $\begin{array}{l}\text { 5. Bus Routes crossing trail HART } \\
\text { Northwest Transfer Center serves the } \\
\text { HARTFlex Town 'N country, and Routes } \\
\text { 16, 30, 34, 39, and 61LX. }\end{array}$ \\
\hline
\end{tabular}

$16,30,34,39$, and $61 \mathrm{LX}$.

Upper Tampa Bay Trail

Hillsborough County

Waters Avenue

Hillsborough County arterial

Town 'N Country

HARTFlex Town 'N Country passes by the Channel Park Trailhead but does not have a designated stop there. The HART Northwest Transfer Center is on Waters Avenue but separated from the trail by a flood control channel. Trail users can access the Transfer Center but only by leaving the trail, and going to the Channel Park entrance off Waters Avenue, and crossing the bridge via sidewalk and bike lane.

Connect

Intersect but does $\quad$ Trail and not connect transit do not intersect $\mathbf{X}$

\section{Data Collected by Jurisdiction}

1. Bicycle counts Hillsborough County Bicycle \& Pedestrian Counts, 2000 \& 2005, not conducted in this area

2. Pedestrian counts Hillsborough County Bicycle \& Pedestrian Counts, 2000 \& 2005, not conducted in this area

\begin{tabular}{|l|l|}
\hline 3. Traffic count & AADT 38,100 2005 LOS F \\
\hline $\begin{array}{l}\text { Designated Local-Service Transit } \\
\text { Emphasis Corridor }\end{array}$ & No \\
\hline $\begin{array}{l}\text { Designated Express-Service Transit } \\
\text { Emphasis Corridor }\end{array}$ & No \\
\hline 4. Observations of other activity & \\
\hline 5. Pedestrian and bicyclist surveys & \\
\hline 6. Transit rider surveys \\
\hline III. Connection Site Description
\end{tabular}

1. Trail Site Audit

A. Describe the trail connection with the bus stop Trail goes under bridge at Waters Avenue and also connects at grade with Waters Avenue approx. 0.25 miles to the south of Channel Park where there is a pedestrian traffic signal but there is no HARTFlex designated stop.

B. Is transit stop served by a sidewalk N/A

C. Is bus stop adjacent to the trail No, however, east of the trail and across the flood control channel, the HART Northwest Transfer Center entrance is on Waters Avenue just east of the bridge.

D. Must trail user cross the street to access the bus stop? Yes, see above explanation

E. Adequate drainage Sometimes trail floods under the bridge

F. Width of trail 12'

G. Trail surface type Asphalt

H. Condition of surface Good

I. Trail design standards Livable Roadway Guidelines, Designing for Pedestrians, Multi-Use Trails, Hillsborough MPO, 2006.
J. Site amenities
Existence of
Condition and adequacy




\begin{tabular}{|c|c|c|c|}
\hline i. Official signage with name of trail & Yes & Good & $\begin{array}{l}\text { Yes, at entrance to } \\
\text { Channel Park } \\
\text { trailhead }\end{array}$ \\
\hline $\begin{array}{l}\text { ii. Wayfinding signage, maps, } \\
\text { directions to destinations, transit } \\
\text { connection info. }\end{array}$ & Yes, same sign & $\begin{array}{l}\text { Map, ownership, } \\
\text { permitted trail uses, } \\
\text { rule }\end{array}$ & Yes \\
\hline $\begin{array}{l}\text { iii. Interpretative signage, natural } \\
\text { and cultural history }\end{array}$ & $\begin{array}{l}\text { M } \\
\text { tr } \\
\text { th } \\
\text { e }\end{array}$ & \multicolumn{2}{|c|}{$\begin{array}{l}\text { Midway between the Channel Park Trailhead and } \\
\text { the trail crossing at Sheldon Road, there is signage } \\
\text { that explains the history of flood control and recent } \\
\text { efforts to restore local ecosystem. }\end{array}$} \\
\hline iv. Shelter structure & \multicolumn{2}{|l|}{ Yes } & \\
\hline v. Shade trees & \multicolumn{2}{|l|}{ Yes } & \\
\hline vi. Aesthetic landscaping & \multicolumn{2}{|l|}{ Yes } & \\
\hline vii. Bench & \multicolumn{3}{|c|}{ Yes and picnic tables } \\
\hline viii. Trash can & \multicolumn{3}{|c|}{ Yes, in abundance near benches and picnic tables } \\
\hline ix. Water fountain & \multicolumn{2}{|l|}{ Yes } & \\
\hline x. $\quad$ Rest rooms & \multicolumn{2}{|l|}{ Yes } & \\
\hline xi. Lighting & \multicolumn{3}{|c|}{ No, Park closes at sunset } \\
\hline xii. Motor vehicle parking & \multicolumn{2}{|l|}{ Yes } & \\
\hline xiii. Other observations & \multicolumn{3}{|c|}{$\begin{array}{l}\text { Overall good trail/street connection with poor transit access but } \\
\text { for the Waters Avenue bridge }\end{array}$} \\
\hline
\end{tabular}

xiv. Recommendations for improvements None

\section{Trail Operations}

A. Hours of operation Dawn until dusk. Temporary signage posts actual time of sunset.

B. Cost of admission Free but $\$ \mathbf{2 . 0 0 / d a y ~ f o r ~ p a r k i n g ~}$

C. Security service Parks personnel were seen riding utility cart along trail in afternoon. There is a 911 Station Number System with yellow decals affixed to trail every 200'

D. Availability of trail map Yes, "Hillsborough Trails, Paths and Bicycle Guide"

E. Trail map identifies transit stop locations and routes No. There are bus symbols located at HART transfer stations but the map legend does not identify what the bus symbol means. No bus routes shown.

F. Trail map provides information about destinations Recreational destinations, skate parks, dog parks only.

G. Web site http://www.planhillsborough.org/wp-content/uploads/2013/09/Trail-map.pdf See also map that illustrates Upper Tampa Bay Trail http://www.hillsboroughcounty.org/DocumentCenter/View/13127

H. Information dissemination-Advertising, incentives, promotion Found on Web site of Hillsborough Parka and Recreation Department at http://www.hillsboroughcounty.org/utbtrail

I. "Adopt-A-Trail" sponsorships/volunteer groups Hillsborough Bicycle and Pedestrian Advisory Committee of the Hillsborough MPO

J. Recommendations for improvements Add bus routes on trail maps.

3. Planning Constraints and Opportunities
A. Local Government Comprehensive Plan
Transportation Element Goal 3: Provide a county-wide bikeway and pedestrian system that is integrated with other transportation modes. p. 143
Goals 6: Maximize connection b/w transportation modes.
B. Bicycle and/or Pedestrian Plan
C. Parks, Recreation, Greenways
Hillsborough Greenways Master Plan 1995, currently undergoing Plan update, with project prioritization in September/October 2015. 


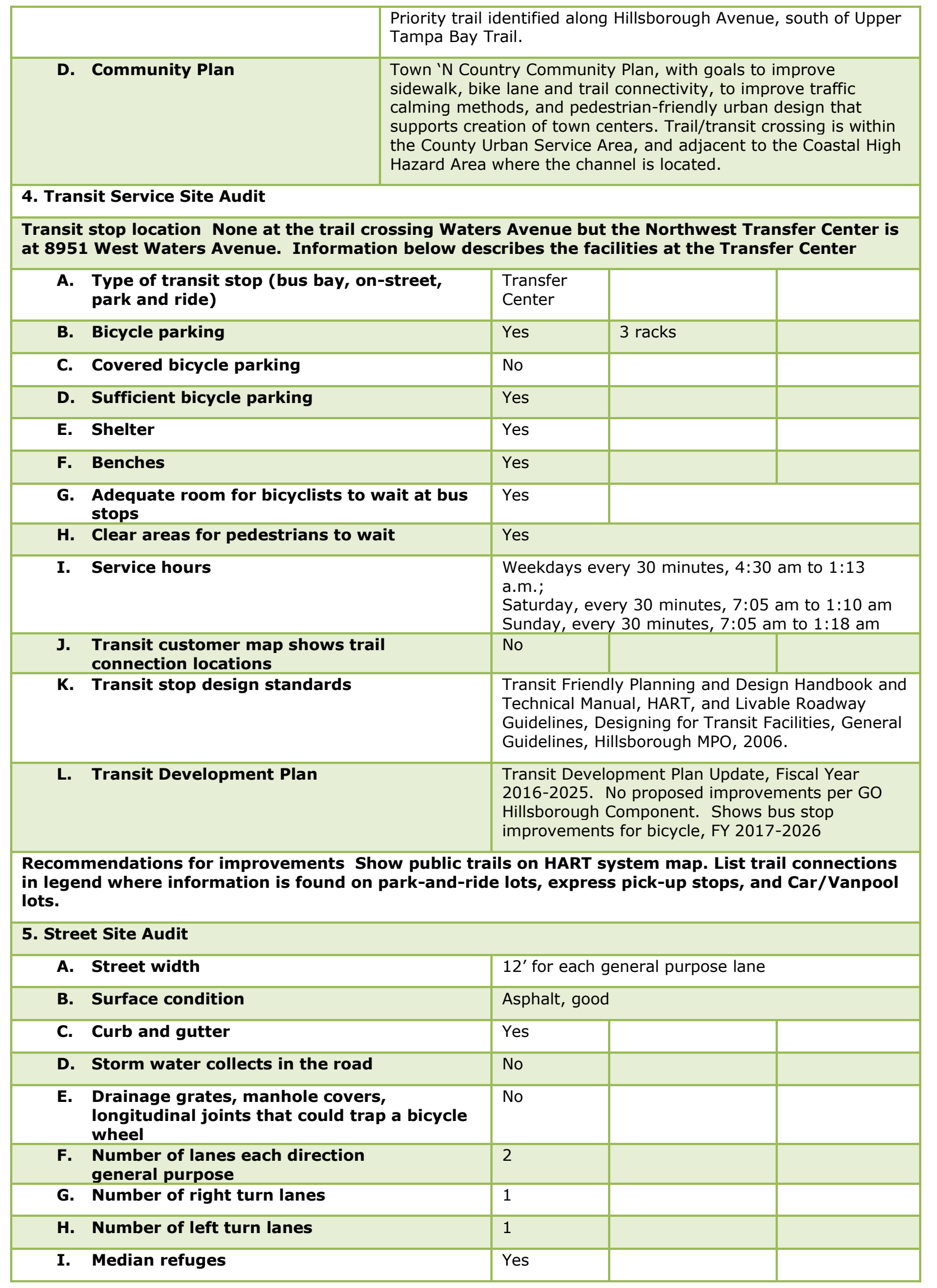




\section{J. Posted speed limit}

K. Crosswalks available to help trail user access the transit stop

No, crosswalk not needed for pedestrians since street access from Channel Park is on same side of street as the HART Northwest Transfer Center. There is a sidewalk along the bridge. Bicyclists will have to turn left upon exiting Channel Park and enter traffic stream on Waters Avenue and take position in left turn lane to enter the Transfer Center. Alternatively, walk bicycle along the sidewalk.

\begin{tabular}{|c|c|c|}
\hline vii. Mid-block & \multicolumn{2}{|l|}{$\mathrm{N} / \mathrm{A}$} \\
\hline Intersection & $\mathrm{N} / \mathrm{A}$ & \\
\hline Raised crosswalk & $\mathrm{N} / \mathrm{A}$ & \\
\hline L. Curb cut at crosswalk intersection with road & Yes & \\
\hline M. Line of sight, adequate & Yes & \\
\hline N. Stop sign & No & \\
\hline O. Signalization for motorists & Yes & \\
\hline P. Pedestrian signal & Yes & \\
\hline Pedestrian activated & Yes & \\
\hline Count-down signals & Yes & \\
\hline ix. Audible signal & No & \\
\hline Q. Rectangular Rapid Flashing Beacons & No & \\
\hline R. Sidewalks & Yes & \\
\hline S. Bicycle lanes, one side or both sides & Both sides & \\
\hline T. Shoulders, one side or both sides & No & \\
\hline U. Sharrows & No & \\
\hline V. Street signage identifying trail & Yes & \\
\hline $\begin{array}{l}\text { W. Planned and programmed street } \\
\text { improvements }\end{array}$ & & \\
\hline \multicolumn{3}{|c|}{$\begin{array}{l}\text { Recommendations for improvements Add street sign for traffic traveling southbound on Waters } \\
\text { Avenue upon entering bridge, cautioning that bicycle traffic may be entering the road from Channel } \\
\text { Park. }\end{array}$} \\
\hline \multicolumn{3}{|l|}{$\begin{array}{l}\text { IV. Trail and Transit Intersect N/A } \\
\text { But Do Not Connect }\end{array}$} \\
\hline \multicolumn{3}{|l|}{$\begin{array}{l}\text { 1. Description of the intersection and why the trail } \\
\text { and transit service do not connect }\end{array}$} \\
\hline \multicolumn{3}{|l|}{ 2. Should there be a connection? } \\
\hline \multicolumn{3}{|l|}{ 3. Existing number of trail users at location } \\
\hline \multicolumn{3}{|l|}{ 4. Existing transit ridership at location } \\
\hline \multicolumn{3}{|l|}{ 5. Is this a good connection location? } \\
\hline \multicolumn{3}{|l|}{ 6. Presence of attractive destinations within sight } \\
\hline \multicolumn{3}{|l|}{ 7. Safety considerations } \\
\hline \multicolumn{3}{|l|}{$\begin{array}{l}\text { 8. Presence of bike lanes, shoulders, sidewalks, } \\
\text { ADA accessibility }\end{array}$} \\
\hline \multicolumn{3}{|l|}{ 9. Street layout (grid?) } \\
\hline \multicolumn{3}{|l|}{ 10. Presence of physical barriers } \\
\hline A. River & & \\
\hline
\end{tabular}




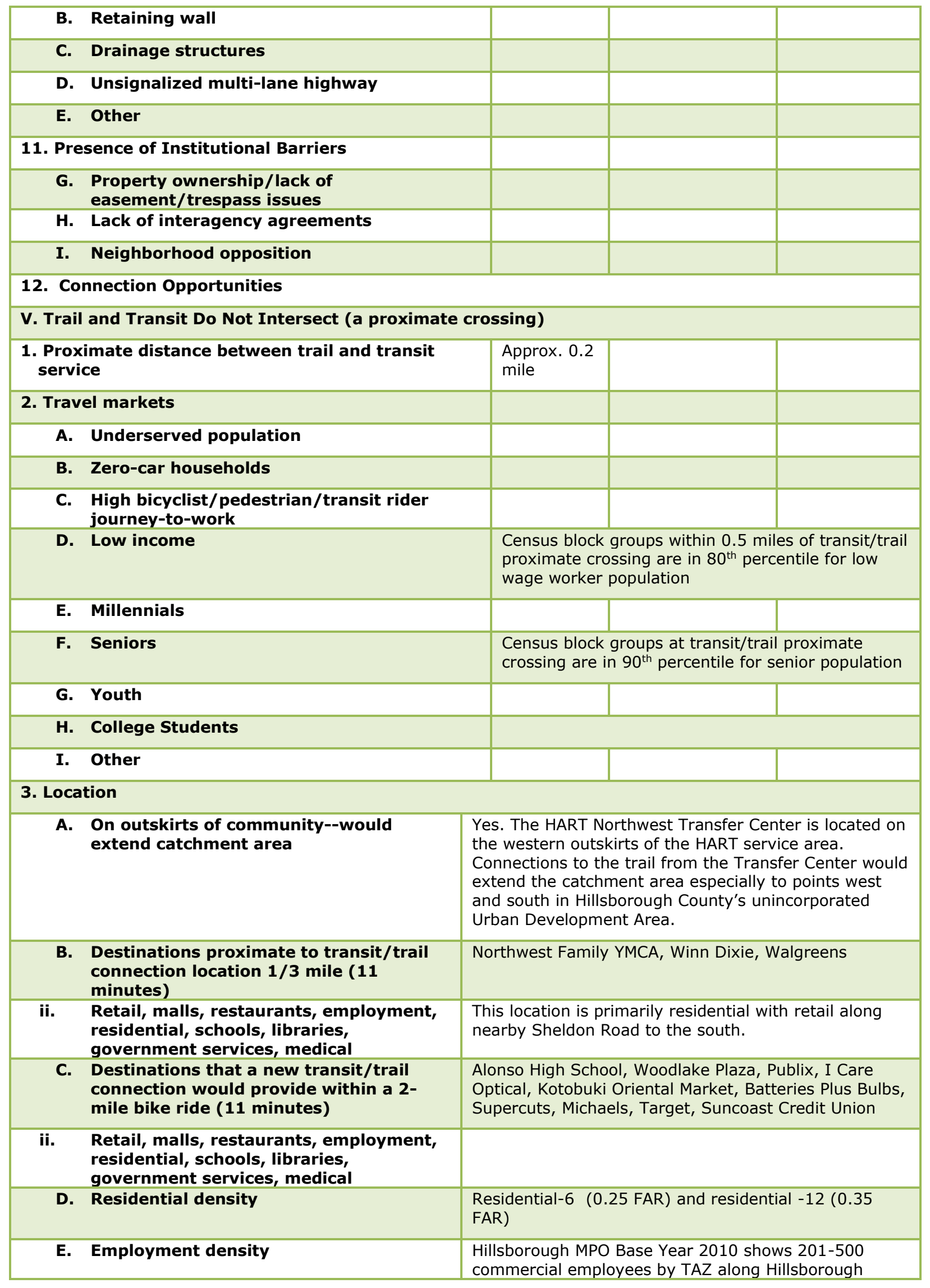


Avenue south of the trail terminus. The MPO 2040

maps show high growth in service employment in the

area south of Hillsborough Avenue,

4. Connection Opportunities: Transit and trail do not connect but are linked by the Waters Avenue Bridge. The bridge has a protected pedestrian sidewalk and bicycle lanes. Riding along the trail, it is not obvious that the HART Northwest Transit Transfer Center is located directly on the other side of the channel. Likewise, at the HART Transfer Center, it is not obvious that the Upper Tampa Bay Trail is on the other side of the channel. While providing a physical trail connection across the channel to the HART Transfer Center would be cost prohibitive, both transit and trail locations could be improved with wayfinding information to promote the linkage opportunity by way of the Waters Avenue Bridge.

\section{Trail/Transit Connection Audit}

I. Trail Name Pinellas Trail

1. Trail ownership: Pinellas County

2. Nearest Cross Street(s) $8^{\text {th }}$ Avenue SW

3. Street ownership: City of Largo

4. Community/neighborhood location: Park View. Residential medium density with land uses such as apartment building with 10-49 units. It is located near the John S. Taylor County Park, the Mildred Helms Elementary School, and the Largo Medical Center. This area is included in Pinellas MPO planning sector 7 .

5. Bus Routes crossing trail: PSTA Route 66

\begin{tabular}{|l|c|l|l}
\hline $\mathbf{X}$ & $\begin{array}{l}\text { Connect } \\
\begin{array}{l}\text { Intersect but } \\
\text { does not } \\
\text { connect }\end{array}\end{array}$ & $\begin{array}{l}\text { Trail and transit do not } \\
\text { intersect }\end{array}$ \\
\hline
\end{tabular}

II. Planning Context

1. Community Redevelopment Areas: crossing is located just south of the West Bay Drive Community Redevelopment District Boundary on $4^{\text {th }}$ Avenue SW

2. Other: This location is on the southwest tip of the Downtown Largo Multimodal Transportation District study area boundary

III. Previously Collected Data

1. Bicycle counts: not available

2. Pedestrian counts: not available

3. Traffic count AADT < 11,000 (Pinellas MPO 2014 State of the System (SOS) Report)

4. Other observations of activity: dog walkers, recreational and utilitarian bicyclists, carrying bags and backpacks

5. Pedestrian and bicyclist surveys: 618,188 trails users overall in 2013, Pinellas County Parks and Conservation Resources

6. Transit rider surveys: PSTA Annual Ridership estimate 70,572 (2009)

IV. Connection Site Description

1. Trail Site Audit

A. Describe the trail connection with the bus stop Located approx. 200' from the trail, Eastbound Route 66 riders disembarking the bus just west of the trail might not recognize that a trail is located there. They would see the pedestrian crossing sign and the school speed limit sign. Likewise, from the trail, it is not apparent that a bus stop is located close by.

B. Is transit stop served by a sidewalk yes

C. Is bus stop adjacent to the trail? yes, approx. 200' west of trail crossing for those going eastbound and approx. 350' from west side of trail crossing for those going westbound. 


\begin{tabular}{|c|c|c|}
\hline \multicolumn{3}{|c|}{$\begin{array}{l}\text { Must trail user cross the street to access the bus stop? Not if going eastbound, yes if going } \\
\text { westbound }\end{array}$} \\
\hline \multicolumn{3}{|l|}{ Adequate drainage: yes } \\
\hline \multicolumn{3}{|l|}{ Width of trail: $10^{\prime}$} \\
\hline \multicolumn{3}{|l|}{ Trail surface type: asphalt } \\
\hline \\
\hline $\begin{array}{l}\text { H. Condition of surface: good } \\
\text { i. Official signage with name of trail }\end{array}$ & \multicolumn{2}{|l|}{ no } \\
\hline $\begin{array}{l}\text { Wayfinding signage, maps, directions to } \\
\text { destinations, transit connection info. }\end{array}$ & \multicolumn{2}{|c|}{$\begin{array}{l}\text { Yes, for view by trail users, identifies the Largo Green Trail, } \\
\text { which is along the } 8^{\text {th }} \text { Avenue SW alignment, and continues } \\
\text { north along } 4^{\text {th }} \text { Street SW to Ulmer Park. The sign identifies } \\
\text { the Largo Green Trail crossing with Pinellas Trail, with } \\
\text { identified major land marks, such as Largo Public Library, } \\
\text { with direction and distance }\end{array}$} \\
\hline $\begin{array}{l}\text { iii. Interpretative signage, natural and } \\
\text { cultural history }\end{array}$ & & \\
\hline iv. Shelter structure & no & \\
\hline v. Shade trees & \multicolumn{2}{|c|}{$\begin{array}{l}\text { trees are part of street scape and on adjacent private } \\
\text { property }\end{array}$} \\
\hline vi. Aesthetic landscaping & no & \\
\hline vii. Bench & yes & \\
\hline viii. Trash can & yes & \\
\hline ix. Water fountain & yes & \\
\hline x. $\quad$ Rest rooms & no & \\
\hline xi. Lighting & yes & \\
\hline xii. Motor vehicle parking & no & \\
\hline \multicolumn{3}{|l|}{ xiii. Other observations } \\
\hline \multicolumn{3}{|c|}{ xiv. Recommendations for improvements: Sidewalk joints are raising up } \\
\hline \multicolumn{3}{|l|}{ 2. Trail Operations } \\
\hline \multicolumn{3}{|c|}{ A. Hours of operation: 7 days a week, 7 a.m. until sunset } \\
\hline \multicolumn{3}{|c|}{ Cost of admission: free } \\
\hline \multicolumn{3}{|c|}{$\begin{array}{l}\text { Security service: There is a Pinellas Trail Security Task Force. The Pinellas County Parks and } \\
\text { Conservation also organizes volunteer Auxiliary Rangers who patrol by bike and on foot, } \\
\text { provide information to visitors and assist with light maintenance and special events. Yellow } \\
\text { markers affixed to the asphalt every 200' display a location number to provide to the } 911 \\
\text { dispatcher. }\end{array}$} \\
\hline \multicolumn{3}{|c|}{$\begin{array}{l}\text { Availability of trail map: Many maps are available at } \\
\text { http://www.pinellascounty.org/trailgd/default.htm }\end{array}$} \\
\hline \multicolumn{3}{|c|}{ Trail map identifies transit stop locations and routes: no } \\
\hline \multicolumn{3}{|c|}{ Trail map provides information about destinations: no } \\
\hline \multicolumn{3}{|c|}{ Web site: http://www.pinellastrails.org/ } \\
\hline \multicolumn{3}{|c|}{ Information dissemination-Advertising, incentives, promotion: active website } \\
\hline \multicolumn{3}{|c|}{ "Adopt-A-Trail" sponsorships/volunteer groups: Pinellas Trail, Inc. } \\
\hline $\begin{array}{l}\text { J. Recommendations for improvements } \\
\text { this site provides information about } \\
\text { transit, as well as information about } \\
\text { message that the trail can be used n }\end{array}$ & $\begin{array}{l}\text { http: } \\
\text { arkin } \\
\text { ccess } \\
\text { t just }\end{array}$ & $\begin{array}{l}\text { ellascounty.org/park/amenities.htm } \\
\text { should list access to the trail by public } \\
\text { on-park destinations to convey the } \\
\text { tion but also for travel purposes. }\end{array}$ \\
\hline 3. Planning Constraints and Opportunities & & \\
\hline $\begin{array}{l}\text { A. Local Government Comprehensive } \\
\text { Plan: Transportation Element } 2011\end{array}$ & $\begin{array}{l}\text { Objec } \\
\text { for co }\end{array}$ & $\begin{array}{l}\text { courage bicycle use and pedestrian activity } \\
\text { d recreational purposes through increased }\end{array}$ \\
\hline
\end{tabular}




\begin{tabular}{|c|c|c|}
\hline & \multicolumn{2}{|c|}{$\begin{array}{l}\text { availability, improved design, and interconnectivity of } \\
\text { different transportation modes. }\end{array}$} \\
\hline B. Bicycle and/or Pedestrian Plan & \multicolumn{2}{|c|}{$\begin{array}{l}\text { Identifies } 8^{\text {th }} \text { Avenue SW as having substandard sidewalks. } \\
\text { Identifies the Pinellas Trail crossing with } 8^{\text {th }} \text { Avenue SW as a } \\
\text { Trail Gateway. 8th Avenue SW also is identified as a } \\
\text { Potential Future Largo Urban Trail Route }\end{array}$} \\
\hline C. Community Plan & \multicolumn{2}{|c|}{$\begin{array}{l}\text { The Citywide Sidewalk Master Plan } 2009 \text { identifies } 8^{\text {th }} \text { Avenue } \\
\text { SW as a Community Street and bus route. It is not top } \\
\text { ranked for improvements. }\end{array}$} \\
\hline \multicolumn{3}{|l|}{ 4. Transit Service Site Audit } \\
\hline A. Transit stop location & \multicolumn{2}{|c|}{$200^{\prime}$ from trail on west side for both directions } \\
\hline $\begin{array}{l}\text { B. Type of transit stop (bus bay, on- } \\
\text { street, park and ride) }\end{array}$ & \multicolumn{2}{|c|}{ On-street } \\
\hline C. Transit stop amenities & \multicolumn{2}{|c|}{ Sign only } \\
\hline D. Bicycle parking & \multicolumn{2}{|l|}{ no } \\
\hline E. Covered bicycle parking & no & \\
\hline F. Sufficient bicycle parking & \multicolumn{2}{|c|}{$\begin{array}{l}\text { No, bicycle lock was seen attached to a drainage ditch } \\
\text { railing next to the trail, indicating that someone wanted to } \\
\text { park their bike there }\end{array}$} \\
\hline G. Shelter & no & \\
\hline H. Benches & no & \\
\hline $\begin{array}{l}\text { I. Adequate room for bicyclists to wait } \\
\text { at bus stops }\end{array}$ & yes & \\
\hline $\begin{array}{l}\text { J. Clear paths for pedestrians and } \\
\text { bicyclists to access stop }\end{array}$ & yes & \\
\hline K. Service hours & \multicolumn{2}{|c|}{$\begin{array}{l}\text { Monday through Saturday, 6:45 a.m. to } 7: 35 \text { p.m. Sunday } \\
\text { and holidays, 9:32 a.m. to 5:40 p.m. }\end{array}$} \\
\hline $\begin{array}{l}\text { L. Transit customer map shows trail } \\
\text { connection locations }\end{array}$ & \multicolumn{2}{|c|}{$\begin{array}{l}\text { PSTA map shows the Pinellas Trail alignment and it is listed } \\
\text { in the map legend }\end{array}$} \\
\hline M. Transit stop design standards & \multicolumn{2}{|c|}{$\begin{array}{l}\text { PSTA Transit Facilities Guidelines, 2012, contains a Bus } \\
\text { Stop Checklist in Appendix A, for assessing condition of } \\
\text { existing bus stop }\end{array}$} \\
\hline N. Transit Development Plan & \multicolumn{2}{|c|}{$\begin{array}{l}\text { 2016-2025 Transit Development Plan Major Update, } 2015 \text {, } \\
\text { identified leveraging partnerships and engaging the broader } \\
\text { community with communication and outreach. }\end{array}$} \\
\hline \multicolumn{3}{|c|}{$\begin{array}{l}\text { Recommendations for improvements: A transit rider should serve on the bicycle pedestrian } \\
\text { committee. The transit advisory committee should seek individuals who bicycle and walk fo } \\
\text { transportation or a board member of Pinellas Trails, Inc. } \\
\text { The PSTA Transit Facilities Guidelines bus Stop Checklist could be amended to include trail } \\
\text { connections considerations. }\end{array}$} \\
\hline \multicolumn{3}{|l|}{ 5. Street Site Audit } \\
\hline A. Street width & \multicolumn{2}{|c|}{$15^{\prime}$ eastbound approach } \\
\hline B. Surface condition & \multicolumn{2}{|c|}{ Asphalt--good } \\
\hline C. Curb and gutter & no & \\
\hline D. Storm water collects in the road & no & \\
\hline $\begin{array}{l}\text { E. Drainage grates, manhole covers, } \\
\text { longitudinal joints that could trap a } \\
\text { bicycle wheel }\end{array}$ & no & \\
\hline $\begin{array}{l}\text { F. Number of lanes each direction } \\
\text { G. general purpose }\end{array}$ & \multicolumn{2}{|c|}{ One lane each direction, separate left turn lane } \\
\hline
\end{tabular}




\begin{tabular}{|c|c|c|}
\hline H. Number of right turn lanes & none & \\
\hline I. Number of left turn lanes & one & \\
\hline J. Median refuges & no & \\
\hline K. Posted speed limit & \multicolumn{2}{|c|}{$\begin{array}{l}35 \mathrm{mph} \text { but there is a flashing speed sign that displays } \\
\text { speed of oncoming cars. There is also a school crossing } \\
\text { sign with posted speed limit } 15 \mathrm{mph} \text { during weekdays, } \\
7: 55-9: 00 \text { a.m. and } 2: 10-3: 15 \mathrm{p} . \mathrm{m} \text {. The area of the trail } \\
\text { crossing over the street is within the school zone. }\end{array}$} \\
\hline $\begin{array}{l}\text { L. Crosswalks available to help trail } \\
\text { user access the transit stop }\end{array}$ & \multicolumn{2}{|l|}{ No } \\
\hline Mid-block & no & \\
\hline xi. Intersection & \multicolumn{2}{|c|}{$\begin{array}{l}\text { Yes, with crosswalks at the intersection of } 12^{\text {th }} \text { St SW with } \\
8^{\text {th }} \text { Avenue SW and at the intersection of Parkview Drive } \\
\text { with } 8^{\text {th }} \text { Avenue SW }\end{array}$} \\
\hline xii. $\quad$ Raised crosswalk & no & \\
\hline $\begin{array}{l}\text { M. Curb cuts at crosswalk intersection } \\
\text { with road }\end{array}$ & \multicolumn{2}{|l|}{ yes } \\
\hline N. Line of sight, adequate & yes & \\
\hline O. Stop sign for motorists & \multicolumn{2}{|l|}{ no } \\
\hline P. Signalization for motorists & \multicolumn{2}{|c|}{ yes, continuous flashing yellow overhead signal } \\
\hline Q. Pedestrian signal & \multicolumn{2}{|c|}{ yes, continuous flashing red overhead signal } \\
\hline x. $\quad$ Pedestrian activated & No & \\
\hline Count-down signals & No & \\
\hline xii. Audible signal & No & \\
\hline R. Rectangular Rapid Flashing Beacons & No & \\
\hline S. Sidewalks & Yes, $3^{\prime}$ wide & \\
\hline T. Bicycle lanes, one side or both sides & No & \\
\hline U. Shoulders, one side or both sides & No & \\
\hline V. Sharrows & No & \\
\hline W. Street signage identifying trail & \multicolumn{2}{|c|}{$\begin{array}{l}\text { There is a pedestrian crossing sign oriented to be seen by } \\
\text { motorists. The Largo Green Trail sign is located at trail } \\
\text { crossing, oriented to be seen by trail users. }\end{array}$} \\
\hline $\begin{array}{l}\text { X. Planned and programmed street } \\
\text { improvements }\end{array}$ & \multicolumn{2}{|c|}{$\begin{array}{l}\text { Downtown Largo Multimodal Transportation District study } \\
\text { calls for a "bike lane shared with roadway" along } 8^{\text {th }} \text { Avenue } \\
\text { SW. Identifies } 8^{\text {th }} \text { Avenue SW as a Neighborhood } \\
\text { Multimodal Corridor and is part of the plan's Phase III: } \\
2026-2035 \text { for improvements. }\end{array}$} \\
\hline \multicolumn{3}{|c|}{$\begin{array}{l}\text { Recommendations for improvements: The Pinellas MPO Bicycle Pedestrian Master Plan-Facilities } \\
\text { Element, 2013, provides that where roads with pavement or right-of-way widths are not sufficient to } \\
\text { install bike lanes, these roadways should be identified as share use, marked with sharrows or road } \\
\text { signs. Page TBL-A9 of the Master Plan shows } 8^{\text {th }} \text { Avenue SW with proposed bike lane/shared use } \\
\text { lane. } \\
\text { It is recommended to place street signage oriented to motorists identify the crossing with the } \\
\text { Pinellas Trail }\end{array}$} \\
\hline \multicolumn{3}{|l|}{ V. Trail and Transit Intersect } \\
\hline But Do Not Connect & N/A & \\
\hline
\end{tabular}


1. Description of the intersection and why the trail and transit service do not connect

2. Should there be a connection?

3. Existing number of trail users at location

4. Existing transit ridership at location

5. Is this a good connection location?

6. Presence of attractive destinations within sight

7. Safety considerations

8. Presence of bike lanes, shoulders, sidewalks, ADA accessibility

9. Street layout (grid?)

10. Presence of physical barriers
A. River
B. Retaining wall
C. Drainage structures
D. Unsignalized multi-lane highway
E. Other

11. Presence of Institutional Barriers
A. Property ownership/lack of easement/trespass issues
B. Lack of interagency agreements
C. Neighborhood opposition

12. Connection Opportunities

VI. Trail and Transit Do Not Intersect

N/A

1. Proximate distance between trail and transit service

2. Travel markets

A. Underserved population

B. Zero-car households

C. High bicyclist/pedestrian/transit rider journey-to-work

D. Low income

E. Millennials

F. Seniors

G. Youth

H. College Students

I. Other

3. Location 


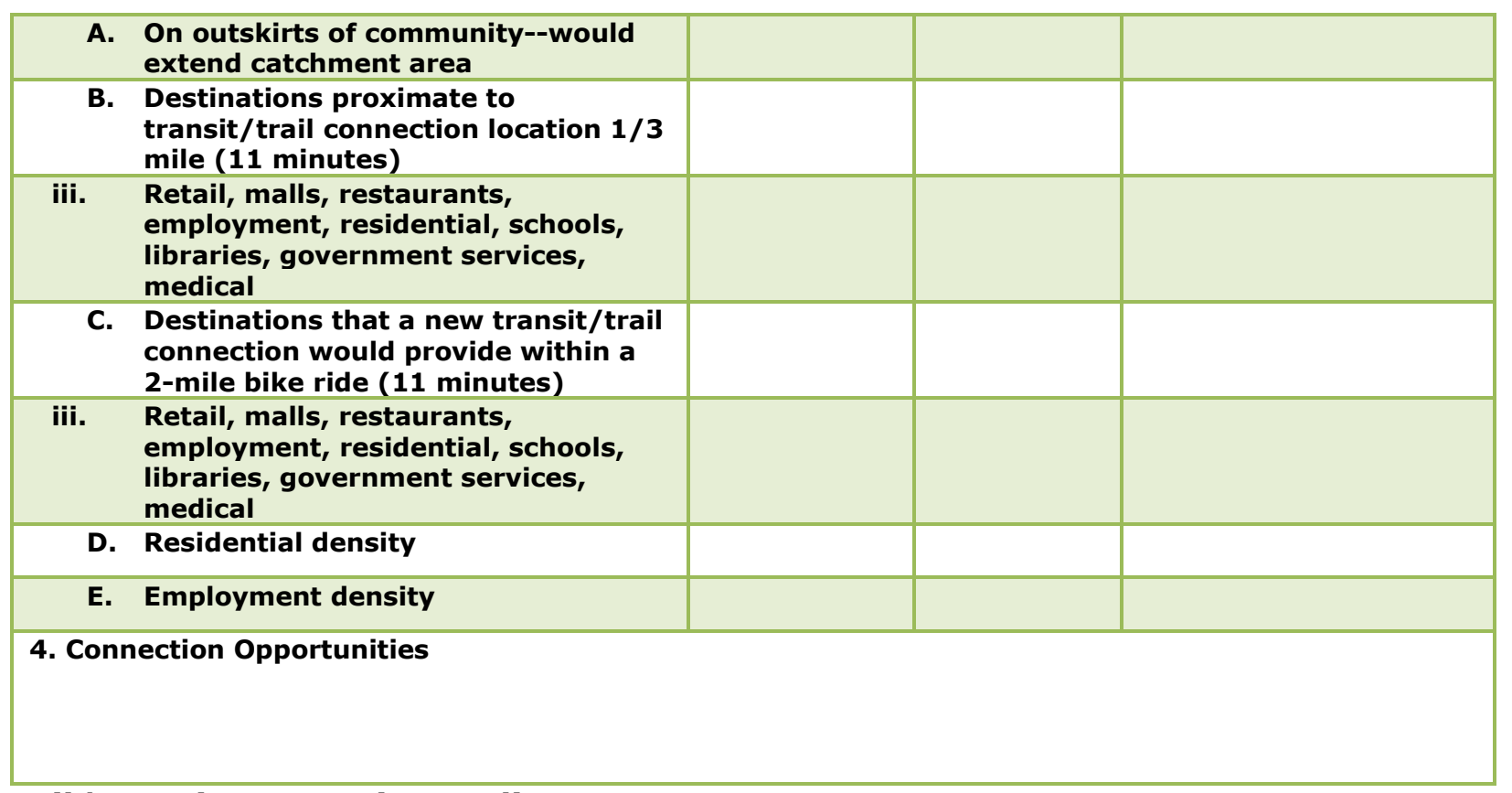

\section{Trail/Transit Connection Audit}

I. Trail Name Pinellas Trail

1. Trail ownership: Pinellas County

2. Nearest Cross Street(s): Gooden Crossing Road and Ulmerton Road (SR 688)

\section{Street ownership: City of Largo}

4. Community/neighborhood location: not named. It is near the Ridgecrest Elementary School, the YMCA and a major employment site

5. Bus Routes crossing trail: PSTA bus routes 61 and 59

\begin{tabular}{|l|l|l|} 
Connect & $\begin{array}{l}\text { Intersect but } \\
\text { does not } \\
\text { connect } \mathbf{x}\end{array}$ & $\begin{array}{l}\text { Trail and transit do not } \\
\text { intersect }\end{array}$ \\
\hline
\end{tabular}

II. Planning Context: The location is identified as adjacent to a major activity center and the ICOT Center, a major employment center, according to the Citywide Sidewalk Program 2009. The City uses the Largo Activity Center Urban Design Guidelines, 2009. This area is included in Pinellas MPo planning sector 7 .

\section{History}

III. Previously Collected Data

1. Bicycle counts: not available

2. Pedestrian counts not available

3. Traffic count: AADT on Ulmerton Road and also on $113^{\text {th }}$ Street $S$ are $b / w 30,001-60,000$ Pinellas MPO State of the System (SOS) Report 4. Other observations of activity: 618,188 trails users overall in 2013, Pinellas County Parks and
Conservation Resources

\section{Pedestrian and bicyclist surveys not available}

6. Transit rider surveys not available

IV. Connection Site Description

1. Trail Site Audit 
I. Describe the trail connection with the bus stop: The PSTA Route 61 stops along Railroad Avenue that runs parallel with the Pinellas Trail. The bus stop is approximately 50' from the intersection of Railroad Avenue and Gooden Crossing Road that crosses over the Pinellas Trail. In addition, the PSTA Route 59 runs along Ulmerton Road that is a 6-lane divided highway. There are bus stops on both sides of Ulmerton Road at the Pinellas Trail bridge overpass. Ulmerton Road also has bike lanes and sidewalks on both sides. The connection from PSTA Route 59 to the Pinellas Trail involves traveling alongside the length of the ramps to their bases where they connect to the bridge.

J. Is transit stop served by a sidewalk? The Route $\mathbf{5 9}$ is served by a sidewalk. The Route 61 is not served by a sidewalk. Railroad Avenue is a low-volume residential street.

K. Is bus stop adjacent to the trail: yes

L. Must trail user cross the street to access the bus stop? Technically, the trail user would not have to cross the street to access the bus stop in either direction. Practically speaking, those seeking to access the trail from Ulmerton Road may be tempted to cross Ulmerton Road at grade, instead of backtracking to get onto the trail via the ramp. Pedestrians were observed crossing Ulmerton Road at grade, under the bridge instead of using the bridge to cross.

M. Adequate drainage: yes. Some pooling of water in access street after rain storm.

N. Width of trail: $14^{\prime}$

O. Trail surface type: asphalt

P. Condition of surface: good i. Official signage with name of trail $\quad$ Yes, and the sign is visible to motorists

ii. Wayfinding signage, maps, directions to destinations, transit connection info.

iii. Interpretative signage, natural and cultural history

\begin{tabular}{ll|l} 
iv. & Shelter structure & no \\
\hline v. $\quad$ Shade trees & no
\end{tabular}

$\begin{array}{lll}\text { v. Shade trees } & \text { no }\end{array}$

vi. Aesthetic landscaping

vii. Bench

viii. Trash can

ix. Water fountain

x. Rest rooms

xi. Lighting

xii. Motor vehicle parking

xiii. Other observations

no no

Yes, but appears to be provided by adjacent land owner

No

Yes

No

No

Yes

No motor vehicle parking and there are signs prohibiting parking along Railroad Avenue

Motorists crossing the Pinellas Trail at Gooden Crossing Road appeared very cautious upon their approach to the Pinellas Trail crossing.

xiv. Recommendations for improvements: The trail appears very well designed and maintained. Only other observation is that many buildings along the street accessing the trail appear vacant. Economic development efforts to bring in small businesses would lend eyes on the street and trail, as well as attract more trail riders and transit patrons.

2. Trail Operations

A. Hours of operation: 7 a.m. until sunset

B. Cost of admission: free

C. Security service: "Unity in the Community" Neighborhood Watch signs were posted. There is a Pinellas Trail Security Task Force. The Pinellas County Parks and Conservation also organizes volunteer Auxiliary Rangers who patrol by bike and on foot, provide information to visitors and assist with light maintenance and special events. Yellow markers affixed to the asphalt every 200' display a location number to provide to the 911 dispatcher.

D. Availability of trail map: Many maps are available at http://www.pinellascounty.org/trailgd/default.htm

E. Trail map identifies transit stop locations and Routes: no

F. Trail map provides information about destinations: no 
G. Web site: http://www.pinellastrails.org/

H. Information dissemination-Advertising, incentives, promotion: active website

I. "Adopt-A-Trail" sponsorships/volunteer groups: Pinellas Trail, Inc.

J. Recommendations for improvements: Same as for improvements recommended for $8^{\text {th }}$ Street sw

3. Planning Constraints and Opportunities

D. Local Government Comprehensive Plan: Transportation Element 2011

Objective 1.6: Encourage bicycle use and pedestrian activity for commuting and recreational purposes through increased availability, improved design, and interconnectivity of different transportation modes.

E. Bicycle and/or Pedestrian Plan The Ulmerton Road and Gooden Crossing Road crossings with the Pinellas Trail are not addressed

F. Community Plan

In the Citywide Sidewalk Program, Ulmerton Road and Gooden Crossing Road are not identified for improvements. But it is identified as having core network sidewalk gaps. It is identified as having a bus route.

\section{Transit Service Site Audit}
A. Transit stop location

PSTA Route 61 stops along Railroad Avenue approx. 50" from the entrance to the trail at Gooden Crossing Road. PSTA Route 59 stops along Ulmerton Road under the Pinellas Trail bridge overpass.

B. Type of transit stop (bus bay, onstreet, park and ride)

C. Transit stop amenities

On-street

D. Bicycle parking

E. Covered bicycle parking

F. Sufficient bicycle parking

G. Shelter

H. Benches Sign only No

I. Adequate room for bicyclists to wait at bus stops

\begin{tabular}{l|l|l} 
No & & \\
No & & \\
No & & \\
No \\
Yes, along both westbound and eastbound Ulmerton Road. \\
No bench at Railroad Avenue.
\end{tabular}

Yes, at Railroad Avenue, there is very little traffic on this residential street to conflict with waiting transit riders.

At Ulmerton Road, there is sufficient waiting area, especially under the bridge.
J. Clear paths for pedestrians and bicyclists

K. Service hours

\section{Yes}

Route 59 Monday-Friday, 5:20 a.m. to 8:30 p.m.

Saturday, 6:29 a.m. to 8:58 p.m.

Sunday and holidays, 6:17 a.m. to 8:17 p.m.

Route 61 Monday-Saturday, 7:05 a.m. to 7:20 p.m.

Sunday and holidays, 7:20 a.m. to 5:30 p.m.

L. Transit customer map shows trail connection locations

M. Transit stop design standards

N. Transit Development Plan
PSTA map shows the Pinellas Trail alignment and it is listed in the map legend.

PSTA Transit Facilities Guidelines, 2012, contains a Bus Stop Checklist in Appendix A, for assessing condition of existing bus stop

2016-2025 Transit Development Plan Major Update, 2015, identified leveraging partnerships and engaging the broader community with communication and outreach.

Recommendations for improvements: See recommended improvements for $8^{\text {th }}$ Avenue SW 


\section{Street Site Audit}

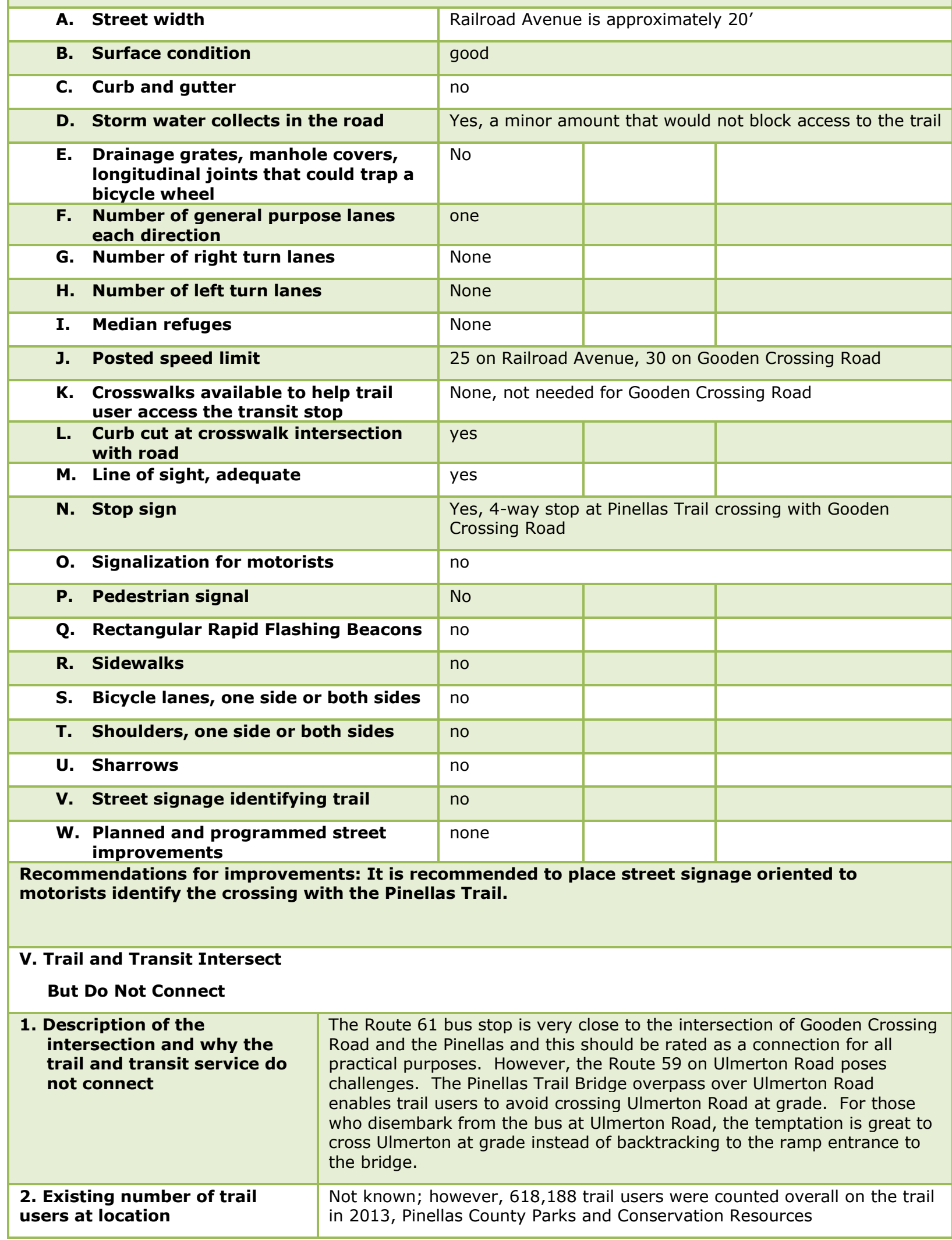




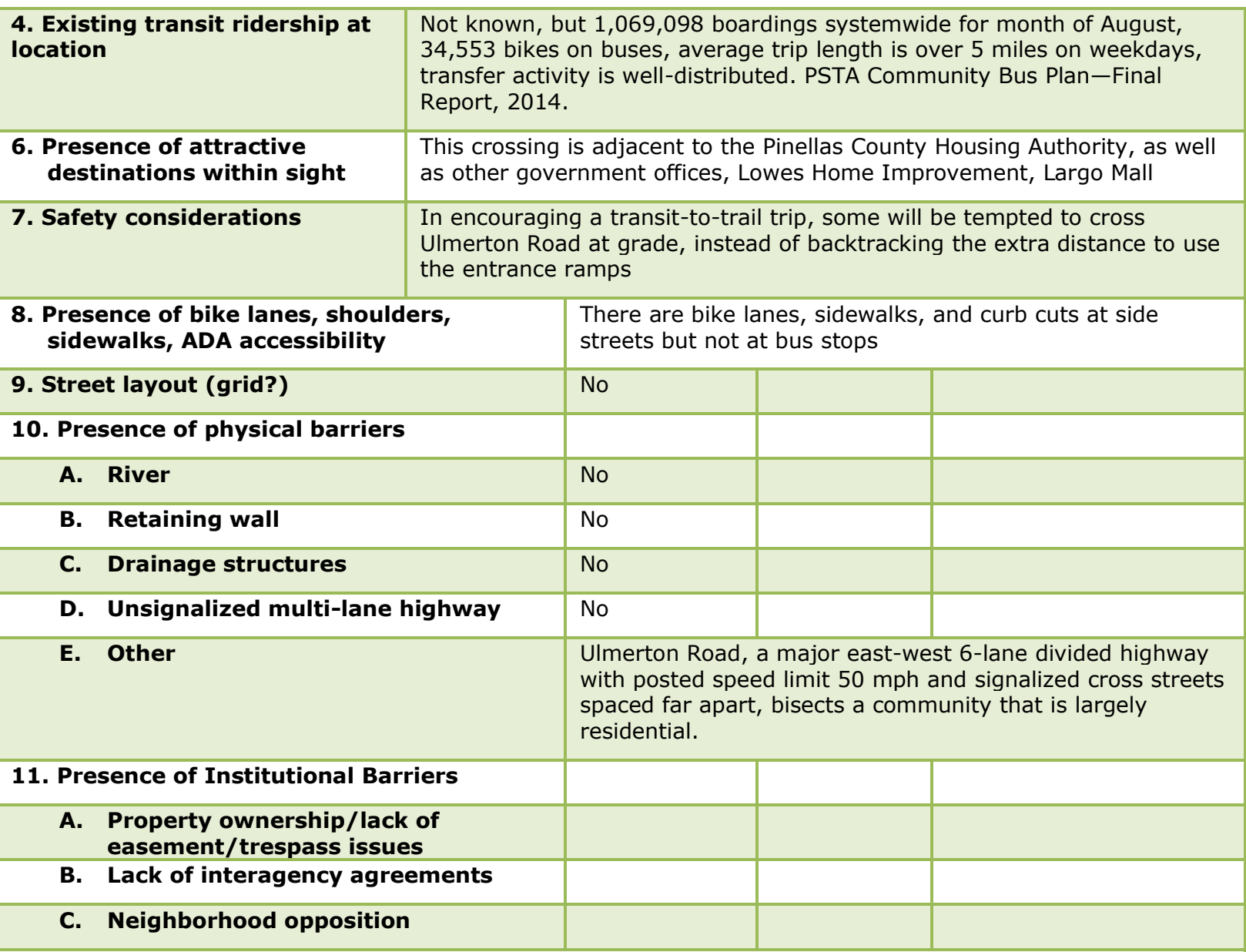

12. Connection Opportunities: While there is a the Pinellas Trail bridge overpass that makes it safe and easy to cross Ulmerton Road for trail users, there is some question what transit users do to cross the street after they disembark the bus. It is recommended to consider alternative treatments for street crossing that are both safe and convenient.

VI. Trail and Transit Do Not Intersect N/A

\section{Proximate distance between trail and} transit service

2. Travel markets

A. Underserved population

B. Zero-car households

C. High bicyclist/pedestrian/transit rider journey-to-work

D. Low income

E. Millennials

F. Seniors

G. Youth

H. College Students

I. Other

\section{Location}
A. On outskirts of community--would extend catchment area 


\begin{tabular}{|c|l|l|}
\hline B. $\begin{array}{l}\text { Destinations proximate to } \\
\text { transit/trail connection location 1/3 } \\
\text { mile (11 minutes) }\end{array}$ & & \\
\hline iv. $\begin{array}{l}\text { Retail, malls, restaurants, } \\
\text { employment, residential, schools, } \\
\text { libraries, government services, } \\
\text { medical }\end{array}$ & & \\
\hline C. $\begin{array}{l}\text { Destinations that a new transit/trail } \\
\text { connection would provide within a } \\
\text { 2-mile bike ride (11 minutes) }\end{array}$ & & \\
\hline iv. $\begin{array}{l}\text { Retail, malls, restaurants, } \\
\text { employment, residential, schools, } \\
\text { libraries, government services, } \\
\text { medical }\end{array}$ & & \\
\hline D. Residential density & & \\
\hline E. Employment density & & \\
\hline 4. Connection Opportunities & & \\
\hline
\end{tabular}

\section{Trail/Transit Connection Audit}

I. Trail Name Pinellas Trail

1. Trail ownership : Pinellas County

2. Nearest Cross Street(s) $96^{\text {th }}$ Place $\mathbf{N}$

3. Street ownership: City of Seminole

4. Community/neighborhood location: Quail Ridge

5. Bus Routes crossing trail: None; however, the PSTA Route 58 provides intermittent service to St. Petersburg College Seminole Campus, which is in the vicinity of the Pinellas Trail. Route 58 has been identified by PSTA as falling below performance standards for passengers per revenue hours and passengers per revenue mile.

\begin{tabular}{l|l} 
Connect & Intersect but does not
\end{tabular}
connect

Trail and transit do not intersect $\mathbf{x}$

II. Planning Context: The City of Seminole is one of the youngest municipalities in Pinellas County. It incorporated in 1970 and now has a population of over 17,750. It is a largely residential community. This area is included in Pinellas MPO planning sector $9.102^{\text {nd }}$ Avenue $\mathrm{N}$ in the vicinity of the study area has been identified as having $\mathbf{1 0}$ or more hours of congestion and has ranked in the top 25 congested non-SIS facilities/segments.

III. Previously Collected Data

1. Bicycle counts: not available

2. Pedestrian counts: not available

3. Traffic count: counts for $96^{\text {th }}$ PI $\mathbf{N}$ are unavailable but the nearest major streets, $102^{\text {nd }}$ Avenue $\mathbf{N}$ and $113^{\text {th }}$ Street $\mathrm{N}$ are identified as having AADTs $\mathrm{b} / \mathrm{w} 11,001-30,000$

4. Other observations of activity: 618,188 trails users overall in 2013, Pinellas County Parks and Conservation Resources

\section{Connection Site Description}

\section{Trail Site Audit}
A. Describe the trail connection with the bus stop: none at present
B. Is transit stop served by a sidewalk: yes
C. Is bus stop adjacent to the trail: no
D. Must trail user cross the street to access the bus stop? N/A
E. Adequate drainage: yes
F. Width of trail: 15'
G. Trail surface type: asphalt
H. Condition of surface: good 


\section{Site amenities}

\section{i. Official signage with name of trail \\ ii. Wayfinding signage, maps, directions to destinations, transit connection info.}

\section{iii. Interpretative signage, natural and}

cultural history

\begin{tabular}{|cl|}
\hline iv. & Shelter structure \\
\hline v. & Shade trees \\
\hline vi. & Aesthetic landscaping \\
\hline
\end{tabular}

vii. Bench

viii. Trash can

ix. Water fountain

x. Rest rooms

xi. Lighting

xii. Motor vehicle parking

xiii. Other observations

xiv. Recommendations for improvements

\section{Trail Operations}

A. Hours of operation: 7 a.m. to sunset

B. Cost of admission: free

C. Security service: Neighborhood Watch signs are posted along $96^{\text {th }} \mathrm{PI} \mathbf{N}$. There is a Pinellas Trail Security Task Force. The Pinellas County Parks and Conservation also organizes volunteer Auxiliary Rangers who patrol by bike and on foot, provide information to visitors and assist with light maintenance and special events. Yellow markers affixed to the asphalt every 200' display a location number to provide to the 911 dispatcher.

D. Availability of trail map: Many maps are available at http://www.pinellascounty.org/trailgd/default.htm

E. Trail map identifies transit stop locations and Routes: no

F. Trail map provides information about destinations: no

G. Web site: http://www.pinellastrails.org/

H. Information dissemination-Advertising, incentives, promotion: active website

I. "Adopt-A-Trail" sponsorships/volunteer groups: Pinellas Trail, Inc.

J. Recommendations for improvements: Same as for improvements recommended for $8^{\text {th }}$ Street SW

3. Planning Constraints and Opportunities
A. Local Government Comprehensive Plan: Transportation Element 2011

\section{B. Bicycle and/or Pedestrian Plan}

\section{Community Plan}

4. Transit Service Site Audit
A. Transit stop location

B. Type of transit stop (bus bay, onstreet, park and ride)
Objective 1.6: Encourage bicycle use and pedestrian activity for commuting and recreational purposes through increased availability, improved design, and interconnectivity of different transportation modes.

A potential new connection between the Pinellas Trail and PSTA Route 58 via St. Petersburg College Seminole Campus was not addressed.

Not addressed

PSTA Route 58 is in front of the Seminole Community Library at St Petersburg College Seminole Campus, accessed from $113^{\text {th }}$ St. N.

Bus bay along internal campus access road 


\begin{tabular}{|c|c|c|}
\hline \multirow{2}{*}{$\begin{array}{l}\text { C. Transit stop amenities } \\
\text { D. Bicycle parking }\end{array}$} & \multicolumn{2}{|c|}{$\begin{array}{l}\text { Bus shelter provided informational maps about PSTA and } \\
\text { the campus layout }\end{array}$} \\
\hline & no & \\
\hline E. Covered bicycle parking & no & \\
\hline F. Sufficient bicycle parking & no & \\
\hline G. Shelter & yes & \\
\hline H. Benches & yes & \\
\hline $\begin{array}{l}\text { I. Adequate room for bicyclists to wait } \\
\text { at bus stops }\end{array}$ & yes & \\
\hline $\begin{array}{l}\text { J. Clear paths for pedestrians and } \\
\text { bicyclists }\end{array}$ & yes & \\
\hline K. Service hours & $\begin{array}{l}\text { Monday-Frida } \\
\text { No Saturday, }\end{array}$ & $\begin{array}{l}5: 35 \text { a.m. to } 7: 00 \text { p.m. } \\
\text { unday or holiday service }\end{array}$ \\
\hline $\begin{array}{l}\text { L. Transit customer map shows trail } \\
\text { connection locations }\end{array}$ & $\begin{array}{l}\text { PSTA map sho } \\
\text { listed in the } n\end{array}$ & $\begin{array}{l}\text { s the Pinellas Trail alignment and it is } \\
\text { legend. }\end{array}$ \\
\hline M. Transit stop design standards & $\begin{array}{l}\text { PSTA Transit } \\
\text { Stop Checklis } \\
\text { existing bus s }\end{array}$ & $\begin{array}{l}\text { ilities Guidelines, 2012, contains a Bus } \\
\text { Appendix A, for assessing condition of }\end{array}$ \\
\hline N. Transit Development Plan & $\begin{array}{l}2016-2025 \mathrm{Tr} \\
\text { identified leve } \\
\text { broader comn }\end{array}$ & $\begin{array}{l}\text { sit Development Plan Major Update, 2015, } \\
\text { ging partnerships and engaging the } \\
\text { ity with communication and outreach. }\end{array}$ \\
\hline \multicolumn{3}{|l|}{ Recommendations for improvements: } \\
\hline \multicolumn{3}{|l|}{ 5. Street Site Audit: } \\
\hline A. Street width & $20^{\prime}$ & \\
\hline B. Surface condition & Asphalt good & \\
\hline C. Curb and gutter & No & \\
\hline D. Storm water collects in the road & No & \\
\hline $\begin{array}{l}\text { E. Drainage grates, manhole covers, } \\
\text { longitudinal joints that could trap a } \\
\text { bicycle wheel }\end{array}$ & no & \\
\hline $\begin{array}{l}\text { F. Number of general purpose lanes } \\
\text { each direction }\end{array}$ & one & \\
\hline G. Number of right turn lanes & \multicolumn{2}{|c|}{ One at intersection of $96^{\text {th }} \mathrm{PI} N$ with Ridge Road } \\
\hline H. Number of left turn lanes & \multicolumn{2}{|c|}{ One at intersection of $96^{\text {th }} \mathrm{PI} N$ with Ridge Road } \\
\hline I. Median refuges & \multicolumn{2}{|c|}{ Yes, at intersection of $96^{\text {th }} \mathrm{PI} N$ with Ridge Road } \\
\hline J. Posted speed limit & 25 & \\
\hline $\begin{array}{l}\text { K. Crosswalks available to help trail } \\
\text { user access the transit stop }\end{array}$ & \multicolumn{2}{|c|}{$\begin{array}{l}\text { Bus stop is internal to the college campus on same side of } \\
\text { access road as the library and other campus buildings }\end{array}$} \\
\hline Mid-block & $\mathrm{n} / \mathrm{a}$ & \\
\hline xiv. Intersection & $\mathrm{n} / \mathrm{a}$ & \\
\hline xv. Raised crosswalk & $\mathrm{n} / \mathrm{a}$ & \\
\hline $\begin{array}{l}\text { L. Curb cut at crosswalk intersection } \\
\text { with road }\end{array}$ & \multicolumn{2}{|c|}{ Bus bay landing pad is flush with side walk at bus stop } \\
\hline M. Line of sight, adequate & yes & \\
\hline N. Stop sign & \multicolumn{2}{|c|}{ Yes, at intersection of Ridge Road and $96^{\text {th }} \mathrm{PI} \mathrm{N}$} \\
\hline
\end{tabular}




\begin{tabular}{|c|c|c|}
\hline \multirow[b]{2}{*}{ O. Signalization for motorists } & \multicolumn{2}{|c|}{$\begin{array}{l}\text { Yes, 4-way stop along } 96^{\text {th }} \mathrm{PI} N \text { at its crossing with the } \\
\text { Pinellas Trail }\end{array}$} \\
\hline & no & \\
\hline P. Pedestrian signal & no & \\
\hline xiii. Pedestrian activated & no & \\
\hline xiv. Count-down signals & no & \\
\hline Audible signal & no & \\
\hline Q. Rectangular Rapid Flashing Beacons & no & \\
\hline R. Sidewalks & yes & \\
\hline S. Bicycle lanes, one side or both sides & no & \\
\hline T. Shoulders, one side or both sides & no & \\
\hline U. Sharrows & no & \\
\hline V. Street signage identifying trail & \multicolumn{2}{|c|}{$\begin{array}{l}\text { No but there is a pedestrian crossing sign along } 96^{\text {th }} \mathrm{PI} \mathrm{N} \\
\text { at both approaches to the Pinellas Trail }\end{array}$} \\
\hline $\begin{array}{l}\text { W. Planned and programmed street } \\
\text { improvements }\end{array}$ & \multicolumn{2}{|c|}{$\begin{array}{l}\text { During site visits to this location, there were neighborhood } \\
\text { detours in this neighborhood due to street resurfacing }\end{array}$} \\
\hline \multicolumn{3}{|l|}{ Recommendations for improvements } \\
\hline \multicolumn{3}{|l|}{ V. Trail and Transit Intersect } \\
\hline But Do Not Connect & \multicolumn{2}{|c|}{$\mathbf{N} / \mathbf{A}$} \\
\hline \multicolumn{3}{|l|}{$\begin{array}{l}\text { 1. Description of the intersection and why } \\
\text { the trail and transit service do not } \\
\text { connect }\end{array}$} \\
\hline \multicolumn{3}{|l|}{ 2. Should there be a connection? } \\
\hline \multicolumn{3}{|l|}{ 3. Existing number of trail users at location } \\
\hline \multicolumn{3}{|l|}{ 4. Existing transit ridership at location } \\
\hline \multicolumn{3}{|l|}{ 5. Is this a good connection location? } \\
\hline $\begin{array}{l}\text { 6. Presence of attractive destinations within } \\
\text { sight }\end{array}$ & & \\
\hline \multicolumn{3}{|l|}{ 7. Safety considerations } \\
\hline \multicolumn{3}{|l|}{$\begin{array}{l}\text { 8. Presence of bike lanes, shoulders, } \\
\text { sidewalks, ADA accessibility }\end{array}$} \\
\hline \multicolumn{3}{|l|}{ 9. Street layout (grid?) } \\
\hline \multicolumn{3}{|l|}{ 10. Presence of physical barriers } \\
\hline \multicolumn{3}{|l|}{ A. River } \\
\hline \multicolumn{3}{|l|}{ B. Retaining wall } \\
\hline \multicolumn{3}{|l|}{ C. Drainage structures } \\
\hline \multicolumn{3}{|l|}{ D. Unsignalized multi-lane highway } \\
\hline \multicolumn{3}{|l|}{ E. Other } \\
\hline \multicolumn{3}{|l|}{ 11. Presence of Institutional Barriers } \\
\hline $\begin{array}{l}\text { D. Property ownership/lack of } \\
\text { easement/trespass issues }\end{array}$ & & \\
\hline E. Lack of interagency agreements & & \\
\hline
\end{tabular}




\section{F. Neighborhood opposition}

12. Connection Opportunities

VI. Trail and Transit Do Not Intersect (a proximate crossing)

1. Proximate distance between trail and transit service

Approximately 0.75 miles along recommended route from Pinellas Trail at $96^{\text {th }} \mathrm{PI} \mathrm{N}$ and the St. Petersburg College bus stop

\section{Travel markets \\ A. Underserved population \\ B. Zero-car households \\ C. High bicyclist/pedestrian/transit rider journey-to-work}

D. Low income

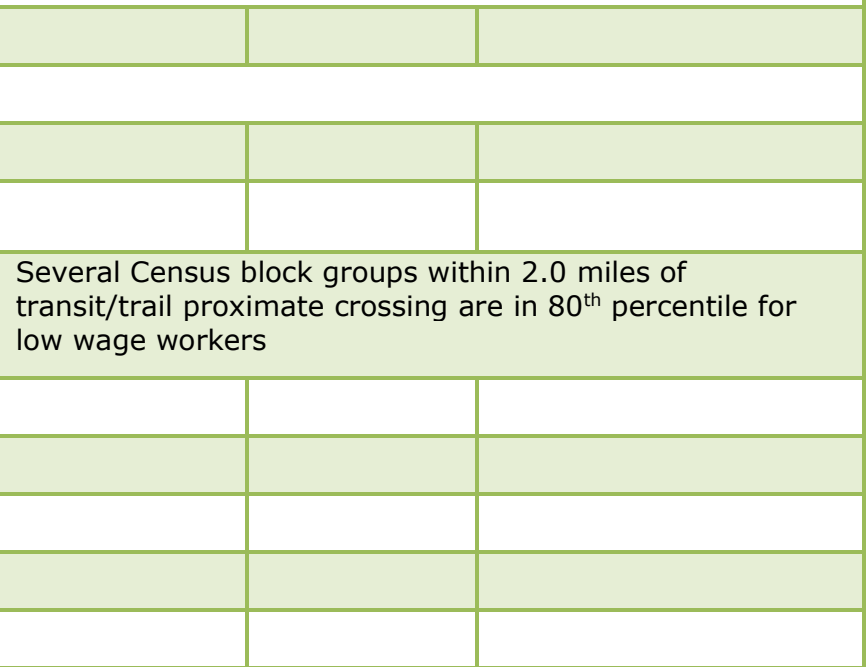

\section{Location}

E. Millennials

F. Seniors

G. Youth

H. College Students

I. Other

3. Location

A. On outskirts of community--would extend catchment area

\section{B. Destinations proximate to transit/trail connection location $1 / 3$ mile (11 minutes)}

This proposed transit/trail connection would provide additional coverage to an area in Pinellas County where there are no proximate bus routes. This is the area that is between Ulmerton Road, Oak Hurst Road, Park Blvd/78 Avenue $\mathrm{N}$, and $113^{\text {th }}$ Street $\mathrm{N}$.

Seminole Community Library, St. Petersburg College Seminole Campus, US Post Office, Seminole Recreation Center, Bus Route 58 serves Seminole Mall and Gateway Mall

4. Connection Opportunities: There are large stretches of the Pinellas Trail that run through large residential areas. Designating a bicycle route from the Pinellas Trail eastbound along $96^{\text {th }} \mathrm{PI} N$ would lead travelers to the St. Petersburg College Seminole Campus. By turning south onto Ridge Road and traveling to $93^{\text {rd }}$ Avenue $\mathbf{N}$, there is a sidewalk on the college campus that terminates just short of Ridge Road. With proposed agreement and collaboration, this sidewalk location could potentially be enhanced as a multi-use path, leading to a large parking lot on the campus, and access ways that lead to the bus stop in front of the library. This potential connection would require a relatively low amount of funds for signage, and minor improvements to the campus parking area to make this connection work. It could potentially introduce more new transit riders to the Route 58 that has been identified as performing below standard. 


\section{Appendix B: Transit/Trail Crossing Inventory Template}

Trail/Transit Connection Audit conducted by

\section{Date}

I. Trail Name

1) Trail ownership

2) Nearest Cross Street(s)

3) Street ownership

4) Community/neighborhood location

5) Bus Routes crossing trail

Connect

Intersect but does not connect

Trail and transit do not intersect

\section{Planning Context}

1) Community Redevelopment Areas

2) Brownfield Areas

3) Urban Job Tax Credit Areas

4) Reduced Transportation Impact Fee Areas

5) Municipal Services Taxing District

6) Other

7) History

\section{Previously Collected Data}

1) Bicycle counts

2) Pedestrian counts

3) Traffic count

4) Other observations of activity

5) Pedestrian and bicyclist surveys

6) Transit rider surveys 


\section{Connection Site Description}

1) Trail Site Audit

a. Describe the trail connection with the bus stop

b. Is transit stop served by a sidewalk

c. Is bus stop adjacent to the trail

d. Must trail user cross the street to access the bus stop?

e. Adequate drainage

f. Width of trail

g. Trail surface type

h. Condition of surface

i. Trail design standards

- Official signage with name of trail

-Wayfinding signage, maps, directions to destinations, transit connection info.

-Interpretative signage, natural and cultural history

○ Legible

- Visible

○ Enough info

-Site amenities

- Shelter structure

- Shade trees

- Aesthetic landscaping

○ Bench

- Trash can

- Water fountain

- Rest rooms

○ Lighting

- Motor vehicle parking

- Other observations

- Recommendations for improvements

2) Trail Operations
a. Hours of operation
b. Cost of admission
c. Security service

\begin{tabular}{l} 
Existence Condition and adequacy \\
\hline
\end{tabular}


d. Availability of trail map

e. Trail map identifies transit stop locations and Routes

f. Trail map provides information about destinations

g. Web site

h. Information dissemination-Advertising, incentives, promotion

i. "Adopt-A-Trail" sponsorships/volunteer groups

j. Recommendations for improvements

3) Planning Constraints and Opportunities
a. Local Government Comprehensive Plan
b. Bicycle and/or Pedestrian Plan
c. Parks, Recreation, Greenways Plan
d. Community Plan

4) Transit Service Site Audit
a. Transit stop location
b. Type of transit stop (bus bay, on-street, park and ride)
c. Transit stop amenities
d. Bicycle parking
e. Covered bicycle parking
f. Sufficient bicycle parking
g. Shelter
h. Benches
i. Adequate room for bicyclists to wait at bus stops
j. Clear paths for pedestrians and bicyclists
k. Service hours
I. Transit customer map shows trail connection locations
m. Transit stop design standards
n. Transit Development Plan
o. Recommendations for improvements

5) Street Site Audit

a. Street width 
b. Surface condition

c. Curb and gutter

d. Storm water collects in the road

e. Drainage grates, manhole covers, longitudinal joints that could trap a bicycle wheel

f. Number of lanes each direction

g. general purpose

h. Number of right turn lanes

i. Number of left turn lanes

j. Median refuges

k. Posted speed limit

I. Crosswalks available to help trail user access the transit stop

- Mid-block

- Intersection

- Raised crosswalk

m. Curb cut at crosswalk intersection with road

n. Line of sight, adequate

o. Stop sign

p. Signalization for motorists

q. Pedestrian signal

- Pedestrian activated

- Count-down signals

-Audible signal

r. Rectangular Rapid Flashing Beacons

s. Sidewalks

t. Bicycle lanes, one side or both sides

u. Shoulders, one side or both sides

v. Sharrows

w. Street signage identifying trail

x. Planned and programmed street improvements

y. Recommendations for improvements 


\section{Trail and Transit Intersect But Do Not Connect}

1) Description of the intersection and why the trail and transit service do not connect

2) Should there be a connection?

3) Existing number of trail users at location

4) Existing transit ridership at location

5) Is this a good connection location?

6) Presence of attractive destinations within sight

7) Safety considerations

8) Presence of bike lanes, shoulders, sidewalks, ADA accessibility

9) Street layout (grid?)

10) Presence of physical barriers
a. River
b. Retaining wall
c. Drainage structures
d. Unsignalized multi-lane highway
e. Other

11) Presence of Institutional Barriers
a. Property ownership/lack of easement/trespass issues
b. Lack of interagency agreements
c. Neighborhood opposition

12) Connection Opportunities

\section{Trail and Transit Do Not Intersect}

1) Proximate distance between trail and transit service

2) Travel markets
a. Underserved population
b. Zero-car households
c. High bicyclist/pedestrian/transit rider journey-to-work
d. Low income 
e. Millennials

f. Seniors

g. Youth

h. Adult students

i. Other

3) Location

a. On outskirts of community--would extend catchment area

b. Destinations proximate to transit/trail connection location $1 / 3$ mile (11 minutes)

- Retail, malls, restaurants, employment, residential, schools, libraries, government services, medical

c. Destinations that a new transit/trail connection would provide within a 2-mile bike ride (11 minutes)

- Retail, malls, restaurants, employment, residential, schools, libraries, government services, medical

d. Residential density

e. Employment density

4) Connection Opportunities

Site Sketch and Notes 